US Army Corps

of Engineers .

Prepared for the U.S. Army Corps of Engineers, Portland District,

under an Interagency Agreement with the U.S. Department of Energy

Contract DE-AC05-76RL01830

\title{
Migratory Behavior and Survival of Juvenile Salmonids in the Lower Columbia River, Estuary, and Plume in 2010
}

\section{FINAL Report}

GA McMichael

RA Harnish

JR Skalski

RL Townsend

KA Deters

PS Titzler

MS Hughes

KD Ham

$\mathrm{J} \mathrm{Kim}$

DM Trott

September 2011

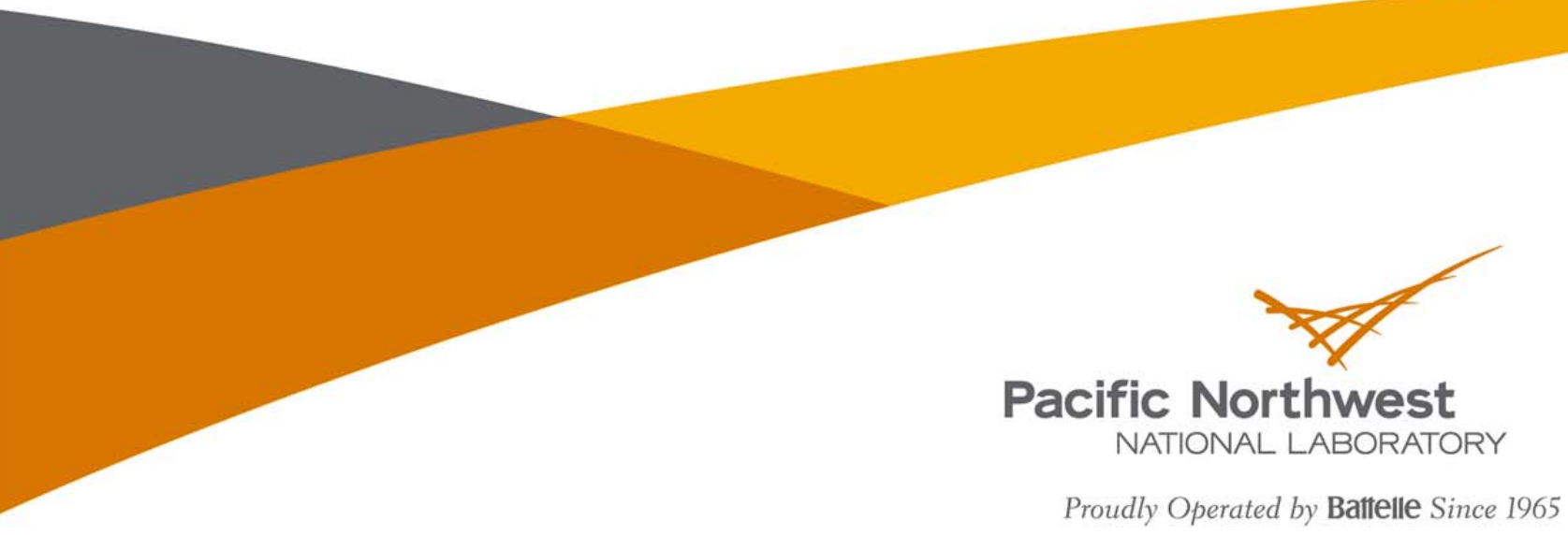




\title{
DISCLAIMER
}

This report was prepared as an account of work sponsored by an agency of the United States Government. Neither the United States Government nor any agency thereof, nor Battelle Memorial Institute, nor any of their employees, makes any warranty, express or implied, or assumes any legal liability or responsibility for the accuracy, completeness, or usefulness of any information, apparatus, produet, or process diselosed, or represents that its use would not infringe privately owned rights. Reference herein to any specific commercial product, process, or service by trade name, trademark, manufacturer, or otherwise does not necessarily constitute or imply its endorsement, recommendation, or favoring by the United States Government or any agency thereof, or Battelle Memorial Institute. The views and opinions of authors expressed herein do not necessarily state or reflect those of the United States Government or any agency thereof.

\author{
PACIFIC NORTHWEST NATIONAL LABORATORY \\ operated by \\ BA'T'TELLE \\ for the \\ INITFD STATES DFPARTMFNT OF FNERGY \\ under Contract DE-AC05-76RL01830
}

Printed in the United States of America
Available to DOE and DOE contractors from the Office of Scientific and Technical Information,
P.O. Box 62, Oak Ridge, 'IN 37831-0062; ph: (865) 576-8401
fax: (865) 576-5728
email: reports@adonis.osti.gov

\begin{abstract}
Available to the public from the National Technical Information Service, U.S. Department of Commerce, 5285 Port Royal Rd., Springfield, VA 22161 ph: (800) 553-6847 fax: $(703) 605-6900$

email: orders@ntis.fedworld.gov

online ordering: http://www.ntis.gov/ordering.htm
\end{abstract}

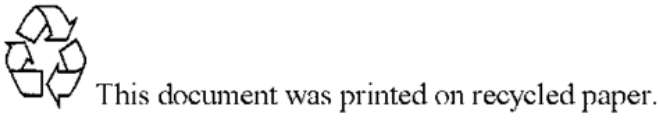

(9/2003) 


\section{Migratory Behavior and Survival of Juvenile Salmonids in the Lower Columbia River, Estuary, and Plume in $\mathbf{2 0 1 0}$}

\section{FINAL Report}

$\begin{array}{ll}\text { GA McMichael }^{1} & \text { RL Townsend } \\ \text { RA Harnish }^{1} & \text { PS Titzler } \\ \text { JR Skalski }^{2} & \text { MS Hughes }^{1} \\ \text { KA Deters }^{1} & \text { J Kim }^{1} \\ \text { KD Ham }^{1} & \text { DM Trott }\end{array}$

September 2011

Prepared for

the U.S. Army Corps of Engineers, Portland District

under an Interagency Agreement with

the U.S. Department of Energy

Contract DE-AC05-76RL01830

\footnotetext{
${ }^{1}$ Pacific Northwest National Laboratory - Richland, Washington 99352

${ }^{2}$ Columbia Basin Research, School of Aquatic and Fishery Sciences, University of Washington, Seattle, Washington 98101
} 



\section{Suggested citation:}

McMichael, G. A., R. A. Harnish, J. R. Skalski, K. A. Deters, K. D. Ham, R. L. Townsend, P. S. Titzler, M. S. Hughes, J. Kim, and D. M. Trott. 2011. Migratory behavior and survival of juvenile salmonids in the lower Columbia River, estuary, and plume in 2010. PNNL-20443, Pacific Northwest National Laboratory, Richland, Washington. 


\section{Preface}

The study reported herein was funded as part of the Anadromous Fish Evaluation Program (AFEP), which is managed by the U.S. Army Corps of Engineers (USACE). The AFEP study code was

EST-P-02-01: A Study of Salmonid Survival and Behavior through the Columbia River Estuary Using Acoustic Tags. This study was conducted by the Pacific Northwest National Laboratory (PNNL) for the USACE Portland District. The USACE technical lead was Cynthia Studebaker. The PNNL study project manager was Geoff McMichael (509-371-7162). The data are archived at PNNL offices in Richland, Washington. 


\section{Abstract}

Uncertainty regarding the migratory behavior and survival of juvenile salmonids passing through the lower Columbia River and estuary after negotiating dams in the Federal Columbia River Power System (FCRPS) prompted the development and application of the Juvenile Salmon Acoustic Telemetry System (JSATS). The JSATS has been used to investigate the survival of juvenile salmonid smolts between Bonneville Dam (river kilometer [rkm] 236) and the mouth of the Columbia River annually since 2004. In 2010, a total of 12,214 juvenile salmonids were implanted with both a passive integrated transponder (PIT) and a JSATS acoustic transmitter. Using detection information from JSATS receiver arrays deployed on dams and in the river, estuary, and plume, the survival probability of yearling Chinook salmon and steelhead smolts tagged at John Day Dam was estimated for multiple reaches between rkm 153 and 8.3 during the spring. During summer, the survival probability of subyearling Chinook salmon was estimated for the same reaches. In addition, the influence of routes of passage (e.g., surface spill, deep spill, turbine, juvenile bypass system) through the lower three dams on the Columbia River (John Day, The Dalles, and Bonneville) on juvenile salmonid smolt survival probability from the dams to rkm 153 and then between rkm 153 and 8.3 was examined to increase understanding of the immediate and latent effects of dam passage on juvenile salmon survival.

Survival probability was relatively high $(>0.95)$ for most groups of juvenile salmonids from the Bonneville Dam tailrace to about rkm 50. Downstream of rkm 50 the survival probability of all species and run types we examined decreased markedly. Steelhead smolts suffered the highest mortality in this lower portion of the Columbia River estuary, with only an estimated $60 \%$ of the tagged fish surviving to the mouth of the river. In contrast, yearling and subyearling Chinook salmon smolts survived to the mouth of the river at higher rates, with estimated survival probabilities of $84 \%$ and $86 \%$, respectively. The influence of route of passage at the lower three dams in the FCRPS on juvenile salmonid survival appeared to be relatively direct and immediate. Significant differences in estimated survival probabilities of juvenile salmonid smolts among groups with different dam passage experiences were often detected between the dams and rkm 153. In contrast, the influence of route of passage on survival to the mouth of the Columbia River was not apparent among the groups of tagged juvenile salmonids with different FCRPS passage experiences after they had already survived to a point about $80 \mathrm{~km}$ downstream of Bonneville Dam. Yearling Chinook salmon and steelhead smolts that migrated through the lower estuary in off-channel habitats took two to three times longer to travel through these lower reaches and their estimated survival probabilities were not significantly different from that of their cohorts that migrated in or near the navigation channel. A large proportion of the tagged juvenile salmonids migrating in or near the navigation channel in the lower estuary crossed from the south side of the estuary near Astoria, Oregon, and passed through relatively shallow expansive sand flats (Taylor Sands) to the North Channel along the Washington shore of the estuary. This migratory behavior may contribute to the avian predation losses ( 2 to $12 \%$ ) observed for fish in this study. The migratory behavior of juvenile salmonid smolts in the Columbia River plume revealed that large portions of the tagged fish were last detected moving out over the Continental Shelf or to the south off the coast of Oregon. This was particularly true for tagged smolts moving into the plume prior to 18 May 2010. Additional data collection or analyses of the vast JSATS database would provide valuable information to assist regional managers in identifying and assessing the effectiveness of salmonid protection and enhancement actions in the Columbia River estuary. 



\section{Executive Summary}

The U.S. Army Corps of Engineers (USACE) Portland District places a high priority on increasing the understanding of the migratory behavior and survival of juvenile salmonids emigrating through the lower $235 \mathrm{~km}$ of the Columbia River and the Columbia River estuary. This understanding is critical to determining the effects of the Federal Columbia River Power System (FCRPS) on the "posthydrosystem" performance of these populations. Increased survival rates through the FCRPS and through the estuary are necessary to meet recovery goals set forth in the 2008 Biological Opinion (BiOp) on FCRPS operations. The goal of the study reported herein is to provide information regarding the migratory behavior and survival related to juvenile salmonids passing through the lower Columbia River and estuary after they have passed Bonneville Dam as they emigrate to the Pacific Ocean. The study was conducted by the Pacific Northwest National Laboratory using the Juvenile Salmon Acoustic Telemetry System (JSATS). The Portland District of the USACE and regional fisheries managers will use the information to manage the configuration and operation of the FCRPS and to evaluate management actions such as estuary habitat restoration and avian predation management to maximize survival rates of juvenile salmonids.

\section{Objectives}

In this report we present estimates of post-hydrosystem survival for groups of acoustic-tagged juvenile yearling Chinook salmon, steelhead, and subyearling Chinook salmon downstream of Bonneville Dam as they migrated seaward through the lower Columbia River and its estuary in 2010. This study also provides estimates of survival through the lower $153 \mathrm{~km}$ of the Columbia River and estuary (posthydrosystem) for groups of fish with known passage routes at John Day, The Dalles, and Bonneville dams. The primary objective of this study was to estimate the survival of yearling and subyearling Chinook salmon and steelhead through multiple reaches of the Columbia River between the area of the Columbia River near the confluence with the Willamette River (Knapp Point, Washington, at river kilometer [rkm] 153) and the Pacific Ocean. Other objectives were to 1) compare the effects of FCRPS passage history on the survival of juvenile salmonids between release and the mouth of the Columbia River, and 2) determine the migratory behavior of juvenile salmonids within the Columbia River plume and near-shore ocean to facilitate experimental design efforts for future studies that may estimate the survival of acoustic-tagged fish into the near-shore ocean off the mouth of the Columbia River.

\section{Methods}

This study took advantage of fish collected and tagged at John Day Dam and released into the Columbia River at several locations between the reservoir upstream of John Day Dam (near Roosevelt, Washington, rkm 393) and near Hood River, Oregon (rkm 275) during the spring and summer of 2010 for other Portland District studies (the Lower Columbia River Survival Study, 2010 at John Day, The Dalles, and Bonneville dams [study codes SPE-P-08-03, SPE-P-10-2, and SPE-P-10-1, respectively]). All study fish were double tagged with a 0.43 -g JSATS acoustic transmitter and a passive integrated transponder (PIT) tag. Tagged yearling Chinook salmon $(\mathrm{N}=3,880)$ and steelhead $(\mathrm{N}=3,885)$ were released between 28 April and 1 June 2010. Subyearling Chinook salmon $(\mathrm{N}=4,449)$ were released between 13 June and 17 July 2010. An additional 1,392 tagged yearling Snake River Chinook salmon were released 
from fish transportation barges downstream of Bonneville Dam (rkm 224) between 30 April and 14 May 2010. This latter group was used in this study only to bolster sample sizes in the Columbia River plume.

The primary post-hydrosystem study area included the lower Columbia River and estuary between Knapp Point (rkm 153; $10 \mathrm{~km}$ downstream of the confluence with the Willamette River) and the Columbia River plume. Autonomous acoustic receivers were deployed in the primary study area at 125 locations between 27 April and 7 August 2010. Receivers were recovered, tested, and redeployed every 28 days to download data and replace batteries. Receivers were primarily deployed in lines, referred to as arrays, that ran perpendicular to the river shore with receivers spaced about 100 to $200 \mathrm{~m}$ apart. Receiver arrays were deployed across the river channel at Knapp Point (rkm 153), Kalama (rkm 113.0), Oak Point (rkm 86.2), East Sand Island (rkm 8.3), and on the Columbia River bar (rkm 2.8). Partial arrays were deployed across the primary channels at Three Tree Point (rkm 49.6), Harrington Point (rkm 37.3), and at the Astoria Bridge ( $\mathrm{rkm}$ 22.0). In addition to these arrays, receivers were deployed in Grays Bay and Taylor Sands (rkm 34.0 and 29.3) to provide information about the use of off-channel areas by emigrating smolts.

Detections of JSATS-tagged fish on cabled receivers on John Day, The Dalles, and Bonneville dams were used to assign passage routes to individual fish at these dams. These route assignments were then used to group fish for analyses of effects of passage route on estimated survival within the lower portion of the FCRPS and through the post-hydrosystem reaches of the Columbia River and estuary. The Cormack-Jolly-Seber (CJS) (single-release) survival model was used to estimate survival based on detection histories of the JSATS-tagged fish.

To examine migratory behavior in the estuary, detections of study fish were used to determine travel time, migration pathways through the lower $50 \mathrm{~km}$, cross-channel distribution, diel movement patterns, and tidal influence on movements. PIT tags recovered by National Oceanic and Atmospheric Administration Fisheries crews on bird colonies in the estuary were used to examine relationships between fish movement patterns and avian predation rates.

To collect the information necessary to inform the experimental design of a survival study capable of estimating survival to the near-shore ocean off of the mouth of the Columbia River, 20 additional autonomous receivers were deployed in the Columbia River plume in a "box" shape around the mouth of the river, with the outer sub-array being $17 \mathrm{~km}$ off the mouth of the river along the 100 -m depth contour. Data collected on these receivers were used to determine the travel rate and apparent direction of travel into the near-shore ocean of tagged juvenile salmonids as they exited the Columbia River.

\section{Results}

\section{JSATS Performance}

JSATS transmitters in the spring tag-life study lasted a mean of 33.1 days, but one transmitter failed after 7.8 days. In the summer, tags operated for an average of 35.5 days with the earliest tag failure occurring at 31.3 days after activation. Most of the tagged fish in this study passed out of the study area within 15 days of tag activation.

Detection probabilities of acoustic transmitters on autonomous receiver arrays were generally high $(>90 \%)$ and independent of river discharge at arrays located at rkm 113 and 86. At Three Tree Point (rkm 49.6) and Harrington Point ( $\mathrm{rkm} 37.3)$, where the estuary is very wide ( $\sim 10 \mathrm{~km})$, detection 
probabilities were lower (pooled estimates ranged from 58 to $72 \%$ ) due to the expansive area and multiple channels through which fish may migrate. Detection probabilities at the Astoria Bridge ( $\mathrm{rkm} 22)$ and East Sand Island (rkm 8.3) were between 71 and $89 \%$, with the higher probabilities occurring during summer when river discharge was lower.

\section{Survival Estimates}

\section{Seasonal and Spatial Trends}

The survival of yearling Chinook salmon smolts between Knapp Point (rkm 153) and East Sand Island (rkm 8.3) ranged from 0.803 to 0.919 during the spring season in 2010. The lowest yearling Chinook survival occurred in the weeks beginning 9 and 16 May, and the highest survival occurred the week beginning 30 May. Reach survival of yearling Chinook salmon was relatively high $(>0.98)$ between Knapp Point and Three Tree Point (rkm 49.6) and decreased substantially in the lower $50 \mathrm{~km}$ of the Columbia River estuary in 2010.

The survival of steelhead smolts in 2010 was generally low relative to yearling Chinook salmon through the lower $153 \mathrm{~km}$ of the Columbia River and estuary. The weekly probability of survival for steelhead smolts from Knapp Point (rkm 153) to the mouth of the Columbia River (rkm 8.3) in 2010 varied from 0.525 to 0.647 . The lowest estimated survival of steelhead through the lower $153 \mathrm{~km}$ of the Columbia River estuary occurred in the weeks beginning 16 and 23 May. The highest weekly estimated steelhead survival occurred the week beginning 9 May. Estimated survival probability of steelhead was greater than 0.98 between Knapp Point and Oak Point (rkm 86.2) and decreased sharply in the lower $86 \mathrm{~km}$ of the Columbia River estuary, with the lowest reach survival estimates in the reaches between Harrington Point (rkm 37.3) and East Sand Island (rkm 8.3).

Survival probability for subyearling Chinook salmon in 2010 from Knapp Point to the mouth of the river (rkm 8.3) ranged from 0.661 to 0.979 . The lowest estimated subyearling Chinook salmon survival occurred the week beginning 12 July and the highest survival occurred during the week beginning 14 June. Estimated subyearling Chinook salmon survival declined for each successive virtual-release group as the season progressed. Mortality of subyearling Chinook salmon was more evenly distributed throughout the lower Columbia River and estuary than observed for yearling Chinook salmon and steelhead. Estimated reach survival of subyearling Chinook salmon was generally in excess of 0.98 , with the exception of the week beginning 12 July, between rkm 153 and 37.3, with slightly lower survival through the reaches between rkm 37.3 and 8.3 .

\section{Survival by Dam Passage Routes}

Route assignments for juvenile salmonids at all passage routes at John Day, The Dalles, and Bonneville dams allowed us to begin to investigate the influence of FCRPS passage experience on survival through the lower Columbia River and estuary. Our analyses focused on the influence of passage routes at one, two, and three dams between the location of passage and rkm 153 and also in the posthydrosystem reach from rkm 153 to $\mathrm{rkm} 8.3$.

In general, survival impacts of passage through various routes appeared to manifest between dam passage and rkm 153 and were not apparent in the post-hydrosystem reach between rkm 153 and 8.3. For yearling Chinook salmon passing through the different routes at John Day Dam (i.e., juvenile bypass 
system [JBS], deep spill [non-top-spill weir or non-TSW], surface spill [TSW], turbine), survivals were significantly different from the route to rkm 153, but not different between rkm 153 and rkm 8.3.

Yearling Chinook salmon that passed through the JBS at John Day Dam had the lowest estimated survival to rkm 153 (0.723), while cohorts passing via deep spill and TSW routes had survival probabilities more than 0.10 higher. Between rkm 153 and rkm 8.3, individual reach survivals of yearling Chinook salmon were not significantly different for fish passing through any of the routes at John Day Dam. Passage route at The Dalles Dam had a significant effect on survival of yearling Chinook salmon from the dam to rkm 153. Survival of yearling Chinook salmon from The Dalles Dam to rkm 153 was highest for fish passing through the sluiceway (0.901) and lowest for fish passing through turbines (0.793). From rkm 153 to rkm 8.3, survival probabilities for fish that passed through the three different routes at The Dalles Dam were not significantly different. Yearling Chinook salmon passing through surface routes (corner collector and the first Bonneville powerhouse [B1] surface collectors combined) had the highest estimated survival from Bonneville Dam to rkm 153 (0.989), whereas fish passing through deep spill routes had the lowest survival (0.936). Similar to the survival estimates for the various routes at John Day and The Dalles dams, the survival of yearling Chinook salmon that passed Bonneville Dam through the different routes (JBS, non-TSW, sluiceway, and turbine) were not significantly different between rkm 153 and 8.3.

Considering the effects of route-specific passage at two and three dams reduced the number of combinations with adequate sample sizes. We focused analyses only on groups with sample sizes of 90 or more fish. There were nearly significant differences in survival from the dams to rkm 153 but no significant differences in survivals from rkm 153 to $\mathrm{rkm} 8.3$ for yearling Chinook salmon with different passage histories at John Day and The Dalles dams. The fish with a JBS/non-TSW passage history at John Day and The Dalles dams, respectively, had the lowest reach survival to rkm 153 (0.838), whereas those with a TSW/sluiceway passage history at John Day and The Dalles dams, respectively, had the highest reach survival to rkm 153 (0.939). The results indicate the greatest differences in yearling Chinook salmon survival occurred before arrival at $\mathrm{rkm} 153$. There were only five route combinations (of 48 possible) of three-dam passage histories that had virtual-release sizes at Bonneville Dam of 90 or more yearling Chinook salmon. Survival was significantly different from Bonneville Dam to rkm 153 for the various groups but was not significantly different between rkm 153 and 8.3. The lowest estimated survival of yearling Chinook salmon from Bonneville Dam to rkm 153 was for the group that passed through a TSW at John Day Dam and deep spill at both The Dalles and Bonneville dams (0.925 from Bonneville Dam to rkm 153 and 0.835 from rkm 153 to 8.3). The highest estimated survival for both reaches was for yearling Chinook salmon that passed through a TSW at John Day Dam, deep spill at The Dalles Dam, and a sluiceway (corner collector and B1 surface collectors combined) at Bonneville Dam (0.993 from Bonneville Dam to rkm 153 and 0.916 from rkm 153 to 8.3).

In contrast to yearling Chinook salmon, steelhead passing through different routes at John Day Dam did not survive at significantly different rates to rkm 153, while differences between rkm 153 and 8.3 were nearly significant. Steelhead passing John Day Dam through a TSW had the highest survival to rkm 153 (0.853). Between rkm 153 and 8.3, steelhead that passed John Day Dam through the JBS had the highest estimated survival (0.688). Steelhead passing through deep spill at The Dalles Dam had the highest survival to rkm $153(0.883)$, whereas fish that passed through turbines had the lowest survival probabilities to $\mathrm{rkm} 153(0.738)$. Survival probabilities of steelhead that passed through the three different routes at The Dalles Dam were not significantly different between rkm 153 and 8.3; however, fish that passed through turbines had the lowest survival probability through this reach $(0.501)$. Steelhead passing Bonneville Dam through different routes had significantly different survival rates to rkm 153, 
with fish passing through the JBS having the highest survival (0.987) and those passing through turbines having the lowest estimated survival (0.914) probabilities. The route of passage at Bonneville Dam did not appear to have a significant effect on the survival of steelhead between rkm 153 and 8.3.

Steelhead survival probabilities for fish passing through two route combinations at John Day and The Dalles dams did not reveal significant differences between the dams and rkm 153, nor between rkm 153 and 8.3. In contrast, the estimated survival of steelhead that passed The Dalles Dam through deep spill and Bonneville Dam through turbines (0.912) to rkm 153 was statistically different than for fish that passed via deep spill at The Dalles Dam and through a sluiceway at Bonneville Dam (0.971). Between rkm 153 and 8.3, steelhead that passed both The Dalles and Bonneville dams via deep spill had significantly lower survival probabilities (0.533) than those passing through deep spill at The Dalles Dam and through turbines at Bonneville Dam (0.650). The passage routes at all three lower Columbia River dams did not have a significant effect on the estimated survival probability of steelhead, neither from Bonneville Dam to rkm 153, nor from rkm 153 to rkm 8.3. However, only four joint passage histories (of 48 possible combinations) had sufficient sample sizes for analysis. The route combination with the highest estimated survival probability to rkm 153 was for steelhead that passed via a TSW at John Day Dam, deep spill at The Dalles Dam, and a sluiceway at Bonneville Dam (0.967), whereas the lowest estimated survival probability was for fish that passed via a TSW at John Day Dam, deep spill at The Dalles Dam, and a turbine at Bonneville Dam (0.915). Interestingly, this latter group of steelhead had the highest estimated survival probability between rkm 153 and $8.3(0.648)$ of the four groups examined.

Subyearling Chinook salmon passing via the four different routes at John Day Dam had significantly different survival rates to rkm 153. The lowest estimated survival probability was observed for fish that passed through turbines (0.703) and the highest for fish that passed through the JBS (0.816) at John Day Dam. The estimated survival of subyearling Chinook salmon that passed the Dalles Dam through the sluiceway was significantly different to rkm $153(0.889)$ than for fish passing through turbines there (0.782). The survival of subyearling Chinook salmon to rkm 153 that passed through the JBS at Bonneville Dam (0.976) was significantly higher than it was for the other routes. The survival of subyearling Chinook salmon from Bonneville Dam to rkm 153 was lowest for fish that passed through deep spill (0.931). No significant difference was observed between estimated survival from rkm 153 to rkm 8.3 for subyearling Chinook that passed through the different routes at any of the lower three Columbia River dams.

In assessing the influence of the passage routes of multiple dams on the survival of subyearling Chinook salmon, we found significant differences in survival among routes from the dams to rkm 153 , but not for the post-hydrosystem reach between rkm 153 and 8.3. Subyearling Chinook salmon that passed John Day Dam through deep spill and The Dalles Dam through the sluiceway had the highest estimated survival probability to rkm $153(0.912)$, whereas those that passed via a TSW at John Day Dam and a turbine at The Dalles Dam had the lowest estimated survival $(0.747)$ over the same distance. No significant differences were detected between estimated survivals of subyearling Chinook salmon for the various route combinations, neither from The Dalles and Bonneville dams nor for any of the three-dam combinations. 


\section{Migration Behavior}

\section{Travel Time}

Acoustic-tagged yearling Chinook salmon that were detected at Knapp Point (rkm 153) and at the mouth of the Columbia River ( $\mathrm{rkm} 8.3 ; \mathrm{N}=1,855$ ) had a median travel time of 2.36 days in 2010. Travel times decreased throughout the migration period from a median of 2.41 days for the earliest migrants to a median of 2.13 days for the later migrants. The travel rate of yearling Chinook salmon decreased as they moved between Oak Point (rkm 86.2) and the Astoria Bridge ( $\mathrm{rkm} \mathrm{22)}$ and increased and was more variable downstream of rkm 22. Travel times and travel rates of tagged steelhead followed a similar pattern to that described above for yearling Chinook salmon. Steelhead $(\mathrm{N}=1,213)$ had a median travel time of $2.17 \mathrm{~d}$. Subyearling Chinook salmon $(\mathrm{N}=2,297)$ had a median travel time of 2.38 days between rkm 153 and rkm 8.3. Median travel times increased slightly throughout the migration period from 2.21 days for the earliest migrants to 2.81 days for the later migrants. The travel rate of subyearling Chinook salmon decreased as they moved between the array at Cottonwood Island (rkm 113) and rkm 22, then increased and was more variable downstream of rkm 22.

\section{Migratory Behavior in the Estuary}

More than $80 \%$ of the acoustic-tagged juvenile Chinook salmon and steelhead migrating downstream passed in or near the navigation channel between Three Tree Point (rkm 49.6) and Harrington Point (rkm 37.3 ) in 2010. In contrast, most of the yearling Chinook salmon (79\%), steelhead (59\%), and subyearling Chinook salmon (87\%) were detected outside the navigation channel in the North Channel along the Washington shoreline at the Astoria Bridge ( $\mathrm{rkm} 22.0)$. This shift indicates that large portions of the emigrating juvenile salmonids cross the shallow expanse of the Taylor Sands area near Astoria, Oregon.

Acoustic-tagged juvenile salmonids that migrated through off-channel areas between rkm 49.6 and 37.3 in 2010 took significantly longer (two to three times) to move downstream than their cohorts moving in or near the navigation channel. Even though these fish that migrated away from the navigation channel traveled more slowly, they did not survive at significantly different rates than fish migrating in or near the navigation channel. In fact, the estimated survivals of yearling Chinook salmon and steelhead were higher for fish passing through the off-channel areas than for their cohorts in and near the navigation channel between rkm 49.6 and 37.3. In contrast, the estimated survival of subyearling Chinook salmon was higher for fish passing through this reach in the navigation channel than for fish in the off-channel areas.

\section{Migratory Behavior in the Plume}

A pilot effort in 2010 in the Columbia River plume produced the information necessary to design a robust estimate of survival of juvenile salmonids from the Columbia River into the near-shore ocean. A total of 1,680 acoustic-tagged juvenile salmonids were detected between 5 May and 7 August 2010 on the 20 autonomous receivers deployed in the plume. The median travel rate of juvenile Chinook salmon slowed upon ocean entry, whereas steelhead tended to increase speed in this transition area. The variability of travel rate was much greater in the area between the mouth of the Columbia River and the plume array than it was between rkm 153 and rkm 8.3.

Surprisingly, more yearling Chinook salmon and steelhead were last detected on the terminus and southern sub-arrays than on the northern array in the plume. This was particularly evident prior to 
18 May, when surface ocean currents were directed more southerly. Only $6 \%$ of the tagged yearling Chinook salmon were last detected on the plume sub-array to the north of the mouth of the Columbia River between 5 May and 17 May 2010. Steelhead also were rarely detected moving north (5\%) during this early portion of the emigration period, with nearly half (47\%) being last detected on the sub-array to the south of the mouth of the Columbia River. In contrast, over half (55\%) of the acoustic-tagged subyearling Chinook salmon were detected on the northern sub-array in the Columbia River plume.

\section{Cross-Channel Distribution}

Most of the yearling Chinook salmon were first detected in the Washington channel at the Astoria Bridge ( $r k m ~ 22)$ in 2010. Near East Sand Island (rkm 8.3), yearling Chinook salmon were most frequently first detected halfway between the middle of the channel and the tip of West Sand Island. At the Columbia River bar (rkm 2.8), the largest proportions of yearling Chinook salmon were first detected south of the navigation channel. The distribution of steelhead at the Astoria Bridge ( $\mathrm{rkm} 22)$ was similar to yearling Chinook salmon, with the greatest percentage of steelhead first detected in the Washington channel. However, a greater percentage of steelhead was detected in the middle of the river and in the Oregon channel (navigation channel) than was observed for yearling Chinook salmon at the Astoria Bridge. At rkm 8.3, steelhead were more often detected closer to Clatsop Spit (Oregon shore) than either yearling or subyearling Chinook salmon. At the Columbia River bar ( $\mathrm{rkm} 2.8$ ), the greatest percentage of steelhead was first detected on the Oregon side of the navigation channel. The crosschannel distribution of subyearling Chinook salmon at the Astoria Bridge (rkm 22) was highly skewed towards the North Channel on the Washington side of the estuary. The distribution of subyearling Chinook salmon at rkm 8.3 was similar to that of yearling Chinook salmon, but a greater percentage of first detections occurred near East Sand Island. The cross-channel distribution of subyearling Chinook salmon first detected at $\mathrm{rkm} 2.8$ appeared to be similar to that of yearling Chinook salmon, with large percentages detected near the navigation channel.

\section{Diel Distribution and Tidal Influence}

The timing of the arrival of tagged fish at most arrays in the lower $50 \mathrm{~km}$ of the Columbia River estuary was likely influenced more by tide than by time of day for yearling and subyearling Chinook salmon and steelhead. However, most of the acoustic-tagged juvenile salmonids were first detected on the arrays between rkm 37.3 and 8.3 during daylight hours. Most tagged fish passed the lower three arrays on ebb tides. This relationship was most evident at arrays located at the Astoria Bridge ( $\mathrm{rkm} 22$ and East Sand Island (rkm 8.3).

\section{Avian Predation}

The PIT tags from a total of 592 JSATS-tagged fish released at Roosevelt, The Dalles, and Hood River in 2010 were detected at the Caspian tern or double-crested cormorant colony on East Sand Island. Of those detected, 132 were yearling Chinook salmon, 381 were steelhead, and 79 were subyearling Chinook salmon. Of the 2,607 yearling Chinook salmon detected at rkm 153,4.1\% were detected at the colonies. The percent of yearling Chinook salmon detected at rkm 153that were later detected at the bird colonies was highest for the first three virtual-release weeks (early-mid May; 4.5-4.6\%) before declining to below $4 \%$ for the final two virtual-release weeks in late May. The percentage of steelhead detected at rkm 153that were later detected at the bird colonies was substantially higher. Of the 2,455 steelhead detected at $\mathrm{rkm} 153,11.7 \%$ were detected at the colonies. The known predation rate generally increased for steelhead as the migration season progressed, from $7.1 \%$ in early May to $14.5 \%$ in late May/early 
June. Subyearling Chinook salmon experienced the lowest known predation rate; $2.3 \%$ of the 3,022 subyearling Chinook detected at $\mathrm{rkm} 153$ were later detected at the colonies. The known predation rate increased as the season progressed for subyearling Chinook salmon, from $0.7 \%$ in mid-June to $4.1 \%$ in mid-July.

A greater percentage of the yearling Chinook salmon and steelhead tags detected at the colonies were detected at the tern colony than at the cormorant colony, with $58 \%$ and $78 \%$ of the yearling Chinook and steelhead tags, respectively, detected at the tern colony. In contrast, the percentage of subyearling Chinook salmon tags detected at the colonies was higher at the cormorant colony (53\%) than at the tern colony (47\%).

\section{Conclusions}

The estimated survival of acoustic-tagged juvenile Chinook salmon and steelhead through the lower Columbia River and estuary in 2010 was lowest in the final $50 \mathrm{~km}$ of the estuary. Probability of survival was relatively high $(>0.90)$ for yearling and subyearling Chinook salmon from Knapp Point (rkm 153) to Three Tree Point (rkm 49.6). Survival of juvenile Chinook salmon declined sharply through the lower $50 \mathrm{~km}$ of the estuary. Acoustic-tagged steelhead smolts had lower survival than juvenile Chinook salmon between Bonneville Dam and the mouth of the Columbia River. Steelhead survival began to decline farther upstream (at Oak Point [rkm 86.2]) relative to that of the Chinook salmon stocks. Subyearling Chinook salmon survival decreased markedly as the season progressed. It remains to be determined whether later migrating subyearling Chinook salmon are suffering increasing mortality as the season progresses or whether some portion of the apparent loss is due to fish extending their freshwater residence.

This study provided the first comprehensive analysis of how juvenile salmonid passage experiences through the lower three dams in the FCRPS may influence their subsequent survival after passing Bonneville Dam. It appears that most differences in mortality related to route passage history occurred prior to the time when fish reach the first downstream detection location at rkm $153(82 \mathrm{~km}$ downstream of Bonneville Dam). Because of the large number of possible combinations and because passage is not evenly distributed among routes, only the most common route history combinations had sample sizes large enough to evaluate the effects of passage histories in the lower Columbia River and estuary.

New information regarding the influence of migration pathway through the lower $50 \mathrm{~km}$ of the Columbia River estuary on travel time and probability of survival of juvenile salmonids provides an increased understanding of the interaction between travel time and survival. In addition, the detailed information about migratory patterns in the estuary should prove useful in developing or assessing management actions to reduce losses of juvenile salmonid smolts that attempt to pass through the estuary on their seaward migration.

The information about travel time to the pilot scale plume array as well as the apparent direction of travel in the plume enabled the design of an array deployment design that is expected to provide the first robust estimates of survival of acoustic-tagged juvenile salmonids to the near-shore ocean off the mouth of the Columbia River. 


\section{Acknowledgments}

We sincerely appreciate the technical, financial, and logistical support Blaine Ebberts has provided over the course of the development of the JSATS and the survival and behavior studies in the lower Columbia River and estuary. Cynthia Studebaker of the U.S. Army Corps of Engineers' Portland District became the new technical lead for the Corps on this project and has brought a fresh and invigorating perspective to this work. Brad Eppard, also of the Portland District, has provided excellent oversight in the use of JSATS as it relates to survival and dam passage and has been instrumental in the standardization of equipment and protocols related to the use of telemetry equipment for USACE-funded research in the Columbia Basin. Liz Smock of the Portland District was very helpful in coordinating receiver deployment and Corps channel maintenance activities. Dave Nichols of the Ilwaco Fuel Dock was a great host and provided support for our shore-based operations in Ilwaco and vessel operations support for work in the plume.

Advanced Telemetry Systems (ATS), Inc. manufactured the JSATS acoustic tags. Autonomous and dam-mounted hydrophones were manufactured by Sonic Concepts Inc., Bothell, Washington. Precision Acoustic Systems, also in Seattle, made the quad channel receivers and conducted node acceptance tests for PNNL. Cascade Aquatics, Inc. in Ellensburg, Washington, activated and delivered the acoustic tags.

Lynn McComas, NOAA Fisheries, has been instrumental in the development and application of JSATS in the lower Columbia River and estuary. Scott Sebring, NOAA Fisheries, provided the PIT-tag detection data for JSATS+PIT-tagged fish that were detected at the bird colonies.

We thank the North Bonneville PNNL crew who conducted the JSATS studies in the lower Columbia River in 2010. These people collected and tagged the fish at John Day Dam and provided detection data, including route of passage, for John Day, The Dalles, and Bonneville dams. They also provided detection data for JSATS-tagged fish at arrays upstream and downstream of Bonneville Dam. We sincerely appreciate the hard work and help from Mark Weiland, Gene Ploskey, Derrek Faber, James Hughes, Shon Zimmerman, Eric Fischer, and others in the North Bonneville office. Many other PNNL staff assisted in surgery training (Rich Brown and Kate Deters), JSATS development and route assignments (Eric Choi, Brian LaMarche, Daniel Deng, Tao Fu, Thomas Seim, and Thomas Carlson), and field and equipment maintenance assistance (Kate Hall and Brian Bellgraph). John Serkowski and Sara Kallio assisted with map production. Susan Ennor and Mike Parker helped to edit and format the report. Dr. David Geist was the Ecology Group Manager at PNNL, and Stephan Schlahta was the Product Line Manager during this study. 



\section{Acronyms and Abbreviations}

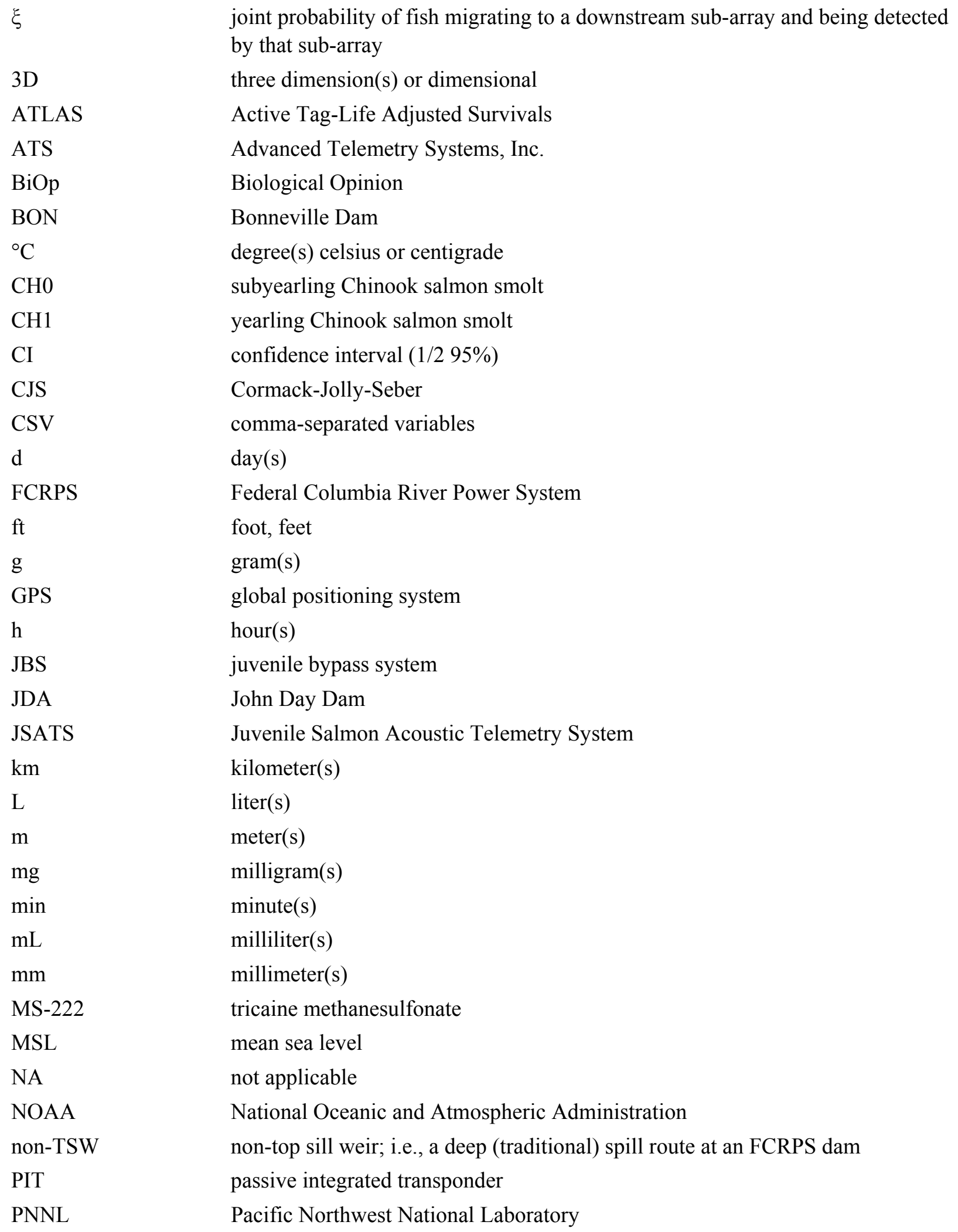


PRI

rkm

$\mathrm{S}$

SE

sluiceway

SMF

SMP

STH

TDA

TSW

USACE

UW

$\mathrm{yr}$ pulse rate interval(s)

river kilometer(s)

second(s)

standard error

a surface passage route at an FCRPS dam. This includes the ice-trash sluiceway at The Dalles Dam and the combination of the B2 corner collector and B1 sluiceway outlets at Bonneville Dam

Smolt Monitoring Facility (John Day Dam)

Smolt Monitoring Program

steelhead smolt

The Dalles Dam

top-spill weir

U.S. Army Corps of Engineers

University of Washington

year(s) 


\section{Contents}

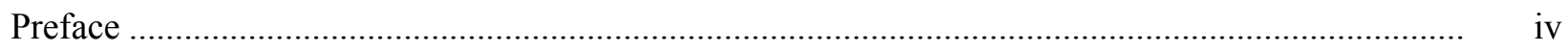

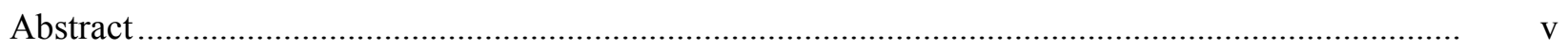

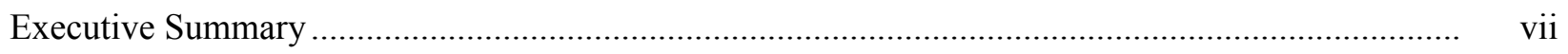

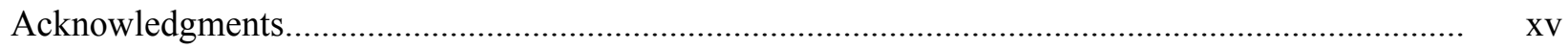

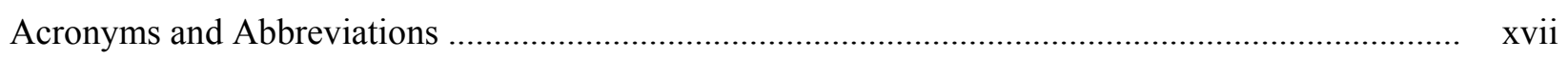

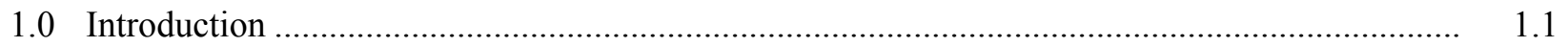

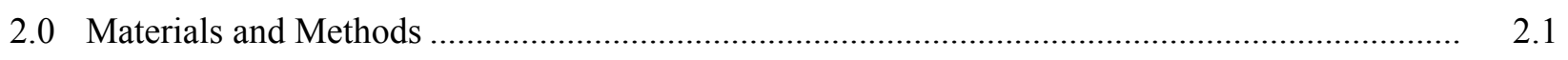

2.1 Fish Collection, Tagging, and Release ...................................................................... 2.1

2.1.1 Collection and Sampling Methods ............................................................... 2.1

2.1.2 Transmitter Specifications and Implantation...................................................... 2.2

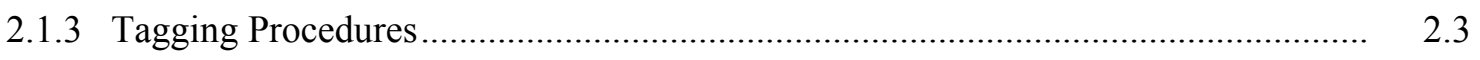

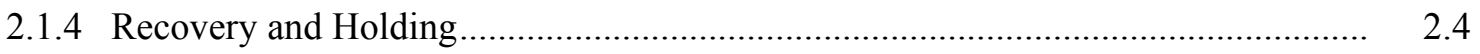

2.1.5 Fish Transportation and Release .................................................................. 2.5

2.2 Site Description and Array Locations ...................................................................... 2.6

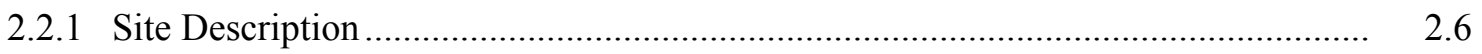

2.2.2 Autonomous Acoustic Receiver Locations ...................................................... 2.7

2.3 Autonomous Receiver Deployment, Recovery, and Servicing ..................................... 2.10

2.4 Autonomous Receiver Data Processing and Validation................................................ 2.11

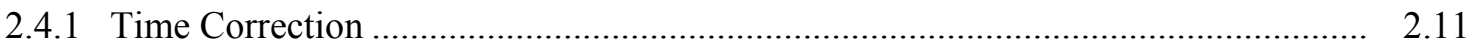

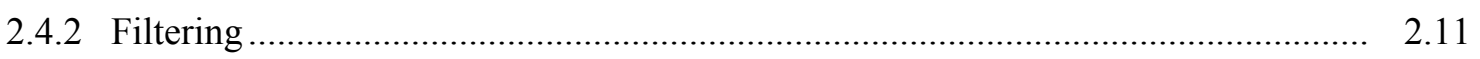

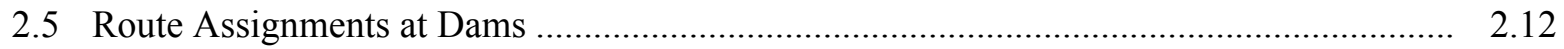

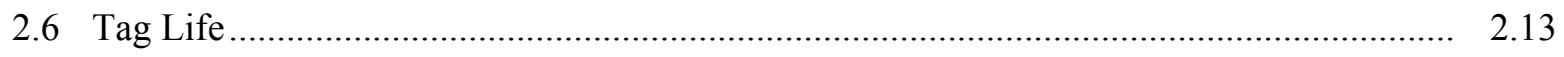

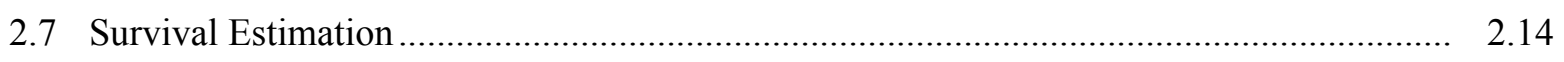

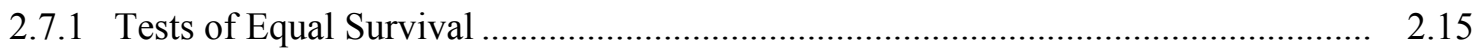

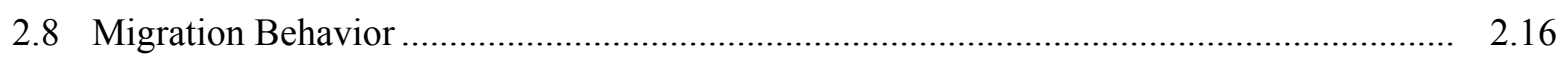

2.8.1 Travel Time and Travel Rate...................................................................... 2.16

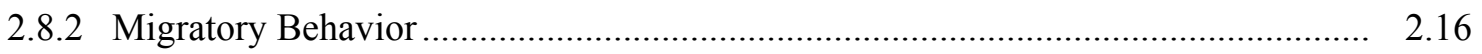

2.8.3 Cross-Channel Distribution ......................................................................... 2.19

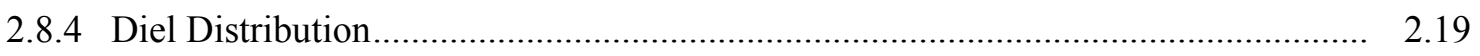

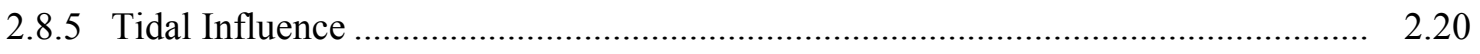

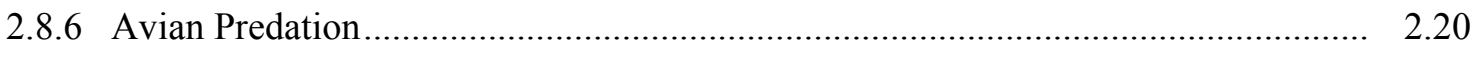

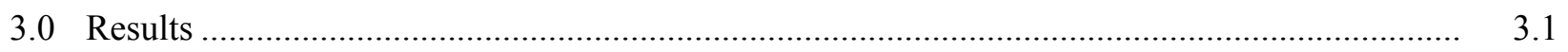

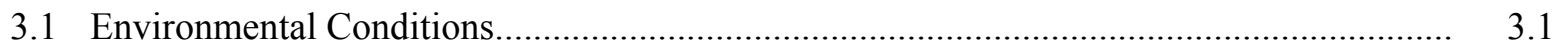

3.2 Smolt Migration Timing and Fish Size ................................................................ 3.2

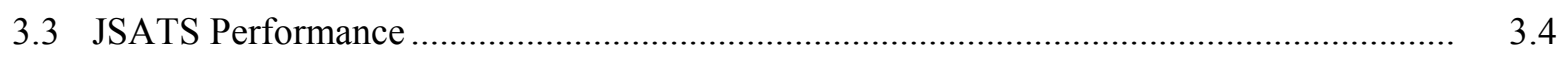

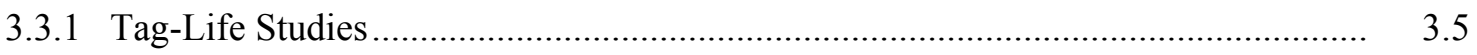




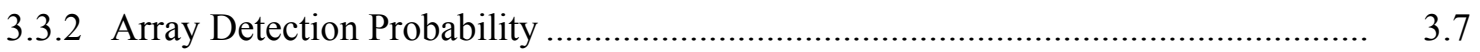

3.4 Survival Probability ............................................................................................... 3.10

3.4.1 Seasonal and Spatial Trends in Survival ........................................................... 3.10

3.4.2 Survival by Dam Passage Routes .................................................................... 3.17

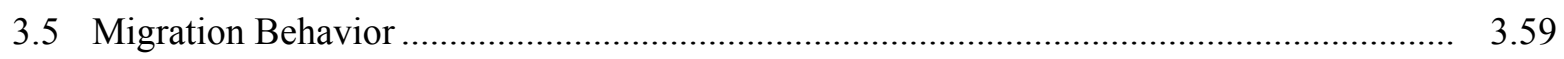

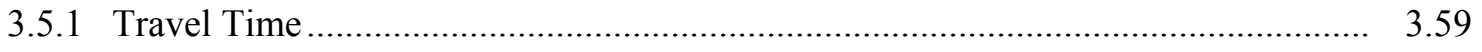

3.5.2 Migratory Behavior in the Estuary ................................................................ 3.62

3.5.3 Migratory Behavior in the Plume ................................................................. 3.68

3.5.4 Cross-Channel Distribution ......................................................................... 3.71

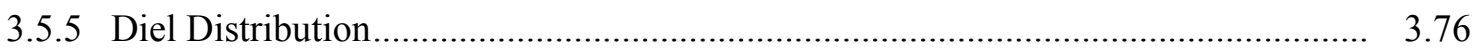

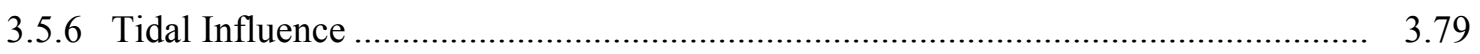

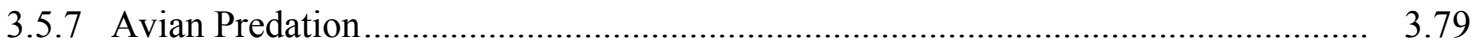

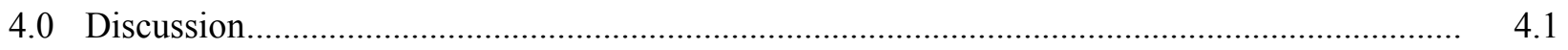

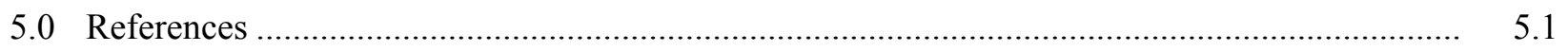

Appendix A - Acoustic-Tagged Fish Releases.......................................................................... A.1

Appendix B - Autonomous Receiver Locations....................................................................... B.1

Appendix C - Locations of CR022.0, CR008.3, and CR002.8 Receivers from Reference Points for Cross-Channel Distribution Analyses ........................................................................ C.1

Appendix D - Autonomous Receiver Data Gap Chart ............................................................ D. 


\section{Figures}

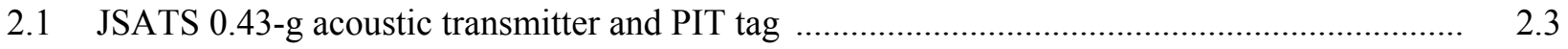

2.2 Post-surgery holding tank with recovery buckets. ............................................................. 2.4

2.3 Study site and locations of acoustic telemetry receiver arrays near Knapp Point, Cottonwood Island, Oak Point, Three Tree Point, Harrington Point, Rocky Point, Grays Point/Taylor Sands, Astoria Bridge, East Sand Island, Columbia River bar, and Columbia River Plume used to detect acoustic-tagged yearling and subyearling Chinook salmon and steelhead migrating through the Columbia River estuary in 2010.

2.4 Locations of acoustic telemetry receiver arrays at Harrington Point, in Grays Bay, Taylor Sand, at Tongue Point, and at the Astoria-Megler Bridge in relation to bathymetry................. 2.9

2.5 JSATS autonomous receivers in the Columbia River plume ............................................. 2.10

2.6 Locations of acoustic telemetry receiver sub-arrays used to determine migration pathways used by acoustic-tagged yearling and subyearling Chinook salmon and steelhead to migrate through the Columbia River estuary between river kilometer 50 and the mouth .....

3.1 Average daily water discharge of the Columbia River at the Beaver Army Terminal during the 2010 study period.

3.2 Average daily water temperature in the Bonneville Dam forebay during the 2010 study period and the preceding 10-year average for the same range of dates.

3.3 The cumulative passage percentage of yearling and subyearling Chinook salmon and steelhead smolts that emigrated past John Day Dam and the timing of tagging operations in 2010 .

3.4 Length frequency distributions for tagged and untagged yearling Chinook salmon from the Smolt Monitoring Program sampling at John Day Dam in 2010.

3.5 Length frequency distributions for tagged and untagged steelhead from the Smolt Monitoring Program sampling at John Day Dam in 2010.

3.6 Length frequency distributions for tagged and untagged subyearling Chinook salmon from the Smolt Monitoring Program sampling at John Day Dam in 2010.

3.7 Percentage of acoustic transmitters still active by days since activation and the percentage of yearling Chinook salmon first detections at the mouth of the Columbia River by days since tag activation in 2010 .

3.8 Percentage of acoustic transmitters still active by days since activation and the percentage of steelhead first detections at the mouth of the Columbia River by days since tag activation in 2010 . . .

3.9 Percentage of acoustic transmitters still active by days since activation and the percentage of subyearling Chinook salmon first detections at the mouth of the Columbia River by days since tag activation in 2010 .

3.10 Detection probability of arrays at Knapp Point, Cottonwood Island, and Oak Point for each virtual-release group of yearling Chinook salmon, steelhead, and subyearling Chinook salmon versus Columbia River discharge measured near Oak Point in 2010 .....

3.11 Detection probability of arrays at Three Tree Point, Harrington Point, the Astoria Bridge, and East Sand Island for each virtual-release group of yearling Chinook salmon, steelhead, and subyearling Chinook salmon versus Columbia River discharge measured near Oak Point in 2010 
3.12 Cumulative survival probability estimate curves for yearling Chinook salmon smolts from rkm 153 to rkm 8.3 by week over the outmigration season.

3.13 Cumulative survival probability estimate curves of steelhead smolts from rkm 153 to rkm 8.3 by week over the outmigration season.

3.14 Cumulative survival probability estimate curves of subyearling Chinook salmon smolts from $\mathrm{rkm} 153$ to $\mathrm{rkm} 8.3$ by week over the outmigration season.

3.15 Cumulative survival probability estimates for yearling Chinook salmon by passage route from dam face to rkm 153 and below to rkm 8.3 for at John Day, The Dalles, and Bonneville dams.

3.16 Cumulative survival probability estimates for yearling Chinook salmon smolts from rkm 153 to rkm 8.3 by different passage routes at John Day, The Dalles, and Bonneville dams. .....

3.17 Cumulative survival probability estimates for yearling Chinook salmon smolts for various combinations of passage routes at John Day and The Dalles dams and The Dalles and Bonneville dams, from the dam face of the downriver dam in the pair to rkm 153 and below to $\mathrm{rkm} 8.3$.

3.18 Cumulative survival probability estimates of yearling Chinook salmon smolts for various combinations of passage routes at John Day and The Dalles dams and The Dalles and Bonneville dams between rkm 153 and rkm 8.3.

3.19 Cumulative survival probability estimates for yearling Chinook salmon smolts for various combinations of passage routes at John Day, The Dalles, and Bonneville dams from Bonneville Dam to rkm 8.3.

3.20 Cumulative survival probability estimates for yearling Chinook salmon smolts for various combinations of passage routes at John Day, The Dalles, and Bonneville dams from rkm 153 to $\mathrm{rkm} 8.3$.

3.21 Cumulative survival probability estimates for steelhead smolts by passage route from dam face to rkm 153 to rkm 8.3 for at John Day, The Dalles, and Bonneville dams.

3.22 Cumulative survival probability estimates for steelhead smolts from rkm 153 to rkm 8.3 by different passage routes at John Day, The Dalles, and Bonneville dams.

3.23 Cumulative survival probability estimates for steelhead smolts for various combinations of passage routes at John Day and The Dalles dams and The Dalles and Bonneville dams, from the dam face of the downriver dam in the pair to $\mathrm{rkm} 153$ and below to $\mathrm{rkm} 8.3$.

3.24 Cumulative survival probability estimates for steelhead smolts for various combinations of passage routes at John Day and The Dalles dams and The Dalles and Bonneville dams between rkm 153 and rkm 8.3.

3.25 Cumulative survival probability estimates for steelhead smolts for various combinations of passage routes at John Day, The Dalles, and Bonneville dams from Bonneville Dam to rkm 8.3.

3.26 Cumulative survival probability estimates for steelhead smolts for various combinations of passage routes at John Day, The Dalles, and Bonneville dams from rkm 153 to rkm 8.3.

3.27 Cumulative survival probability estimates for subyearling Chinook salmon smolts by passage route from the dam face to rkm 153 and to rkm 8.3 at John Day, The Dalles, and Bonneville dams.

3.28 Cumulative survival probability estimates for subyearling Chinook salmon smolts from rkm 153 to rkm 8.3 by different passage routes at John Day, The Dalles, and Bonneville dams. 
3.29 Cumulative survival probability estimates for subyearling Chinook salmon smolts for various combinations of passage routes at John Day and The Dalles dams and The Dalles and Bonneville dams, from the dam face of the downriver dam in the pair to rkm 153 and below to rkm 8.3.

3.30 Cumulative survival probability estimates for subyearling Chinook salmon smolts for various combinations of passage routes at John Day and The Dalles dams and The Dalles and Bonneville dams between rkm 153 and rkm 8.3.

3.31 Cumulative survival probability estimates for subyearling Chinook salmon smolts for various combinations of passage routes at John Day, The Dalles, and Bonneville dams from Bonneville Dam to rkm 8.3.

3.32 Cumulative survival probability estimates for subyearling Chinook salmon smolts for various combinations of passage routes at John Day, The Dalles, and Bonneville dams from rkm 153 to rkm 8.3.

3.33 Travel time of juvenile yearling Chinook salmon by virtual-release group from detection at the Knapp Point array to detection at the Columbia River mouth, East Sand Island array.

3.34 Travel rate of yearling Chinook salmon in reaches from the Knapp Point array to detection at the Columbia River mouth, East Sand Island array

3.35 Travel time of juvenile steelhead by virtual-release group from detection at the Knapp Point array to detection at the Columbia River mouth, East Sand Island array..............................3.60

3.36 Travel rate of juvenile steelhead in reaches from the Knapp Point array to detection at the Columbia River mouth, East Sand Island array ....

3.37 Travel time of juvenile subyearling Chinook salmon by virtual-release group from detection at the Knapp Point array to detection at the Columbia River mouth, East Sand Island array

3.38 Travel rate of juvenile subyearling Chinook salmon in reaches from Knapp Point array to detection at the Columbia River mouth, East Sand Island array

3.39 Joint probability of migrating to and being detected at sub-arrays in off-channel areas and in the navigation channel at the downstream boundary of each river reach for yearling Chinook salmon, steelhead, and subyearling Chinook salmon previously detected at subarrays in the navigation channel or off-channel areas at the upstream boundary of each reach

3.40 Travel time through each reach for yearling Chinook salmon, steelhead, and subyearling Chinook salmon that migrated from each upstream sub-array.

3.41 Probability of survival through each reach for yearling Chinook salmon, steelhead, and subyearling Chinook salmon that migrated from each upstream sub-array ....

3.42 Median travel rate of acoustic-tagged yearling Chinook salmon, steelhead, and subyearling Chinook salmon in the lower Columbia River and between the mouth of the river and the JSATS plume array in 2010

3.43 Travel time of acoustic-tagged yearling Chinook salmon between the mouth of the Columbia River and last detection on the JSATS plume array in 2010.

3.44 Travel time of acoustic-tagged steelhead between the mouth of the Columbia River and last detection on the JSATS plume array in 2010 .

3.45 Travel time of acoustic-tagged subyearling Chinook salmon between the mouth of the Columbia River and last detection on the JSATS plume array in 2010 
3.46 Last detection locations of acoustic-tagged yearling Chinook salmon and steelhead on the Columbia River JSATS plume sub-arrays between 5 May and 17 May 2010.

3.47 Last detection locations of acoustic-tagged yearling Chinook salmon and steelhead on the Columbia River JSATS plume sub-arrays between 18 May and 18 June 2010.

3.48 Last detection locations of acoustic-tagged subyearling Chinook salmon on the Columbia River JSATS plume sub-arrays between 19 June and 7 August 2010.

3.49 Cross-channel distribution of the first detections of acoustic-tagged yearling Chinook salmon at the Astoria Bridge, East Sand Island, and Columbia River bar arrays.

3.50 Detail of the CR008.3 array near East Sand Island showing the proximity of receiver positions to the pile dike that extends southward from the western tip of East Sand Island. .....

3.51 Cross-channel distribution of the first detections of acoustic-tagged steelhead at the Astoria Bridge, East Sand Island, and Columbia River bar arrays.

3.52 Cross-channel distribution of the first detections of acoustic-tagged subyearling Chinook salmon at the Astoria Bridge, East Sand Island, and Columbia River bar arrays.

3.53 Hourly distributions of the first detections of yearling Chinook salmon at the Three Tree Point, Harrington Point, Astoria Bridge, East Sand Island, and Columbia River bar arrays ......

3.54 Hourly distributions of the first detections of steelhead at the Three Tree Point, Harrington Point, Astoria Bridge, East Sand Island, and Columbia River bar arrays

3.55 Hourly distributions of the first detections of subyearling Chinook salmon at the Three Tree Point, Harrington Point, Astoria Bridge, East Sand Island, and Columbia River bar arrays ......

3.56 Percentage of the first detections of yearling Chinook salmon on arrays at Three Tree Point, Harrington Point, the Astoria Bridge, East Sand Island, and the Columbia River bar versus change in tide elevation.

3.57 Percentage of the first detections of steelhead on arrays at Three Tree Point, Harrington Point, the Astoria Bridge, East Sand Island, and the Columbia River bar versus change in tide elevation

3.58 Percentage of the first detections of subyearling Chinook salmon on arrays at Three Tree Point, Harrington Point, the Astoria Bridge, East Sand Island, and the Columbia River bar versus change in tide elevation.

\section{Tables}

2.1 Criteria for accepting or rejecting smolts for implantation surgery.

2.2 Number of fish rejected during spring and summer tagging at John Day Dam according to fish selection criteria defined by the USACE

2.3 Numbers of JSATS-tagged alive and dead yearling Chinook salmon, steelhead, and subyearling Chinook salmon released at three alive-release sites and three dead-release sites on the Columbia River in 2010.

2.4 Alternative parameterization for a two-release, release-recapture model with and without adjustments for probabilities of acoustic tags being active at downstream detection sites

2.5 Reaches for travel rate calculations.

3.1 Acoustic telemetry detection probability of JSATS-tagged fish at autonomous receiver arrays in the lower Columbia River and estuary in 2010 
3.2 Weekly cumulative survival probability estimates for yearling Chinook salmon smolts from rkm 153 to rkm 8.3 with associated standard errors.

3.3 Reach-specific survival probability estimates for yearling Chinook salmon smolts from rkm 153 to rkm 8.3 on a weekly basis, 2 May to 5 June 2010

3.4 Cumulative reach survival probability estimates for yearling Chinook salmon smolts from rkm 153 to rkm 8.3 on a weekly basis, 2 May to 5 June 2010 ....

3.5 Weekly cumulative survival probability estimates for steelhead smolts from rkm $153-\mathrm{rkm}$ 8.3 with associated standard errors

3.6 Reach-specific survival probability estimates for steelhead smolts from rkm 153 to rkm 8.3 on a weekly basis, 2 May to 30 May 2010.

3.7 Cumulative reach survival probability estimates for steelhead smolts from rkm 153 to $\mathrm{rkm}$ 8.3 on a weekly basis, 2 May to 30 May 2010 ......

3.8 Weekly cumulative survivals for subyearling Chinook salmon smolts from rkm 153 to rkm 8.3 with associated standard errors

3.9 Reach-specific survival probability estimates for subyearling Chinook salmon smolts from rkm 153 to rkm 8.3 on a weekly basis, 14 June to 19 July 2010

3.10 Cumulative reach survival probability estimates for subyearling Chinook salmon smolts from rkm 153 to rkm 8.3 on a weekly basis, 14 June to 19 July 2010

3.11 Reach survival probability estimates for yearling Chinook salmon smolts passage routes at a particular dam to rkm 153 and from rkm 153 to rkm 8.3 with associated standard errors.......

3.12 Reach-specific survival probability estimates and associated standard errors for yearling Chinook salmon smolts by passage route at a particular dam to rkm 153 and six reachspecific survivals between rkm 153 and $\mathrm{rkm} 8.3$

3.13 Cumulative reach survival probability estimates and associated standard errors for yearling Chinook salmon smolts by passage route at a particular dam from rkm 153 to $\mathrm{rkm} 8.3$.....

3.14 Sample sizes of yearling Chinook salmon smolts available for survival analyses based on their joint passage history at John Day and The Dalles dams or The Dalles and Bonneville dams

3.15 Reach survival probability estimates for combinations of yearling Chinook salmon smolts by passage routes at John Day/The Dalles dams or The Dalles/Bonneville dams to rkm 153 and from rkm 153 to rkm 8.3 with associated standard errors

3.16 Reach-specific survival probability estimates and associated standard errors for yearling Chinook salmon smolts for combinations of passage routes at John Day/The Dalles dams or The Dalles/Bonneville dams to rkm 153 and six reach-specific survivals between rkm 153 and $\mathrm{rkm} 8.3$

3.17 Cumulative reach survival probability estimates and associated standard errors for yearling Chinook salmon smolts for combinations of passage routes at John Day/The Dalles dams or The Dalles/Bonneville dams from rkm 153 to rkm 8.3.

3.18 Sample sizes of yearling Chinook salmon smolts available for survival analyses based on their joint passage history starting at the John Day JBS, TSW, non-TSW, or turbine passage routes and their subsequent passage through both The Dalles and Bonneville dams

3.19 Cumulative survival probability estimates for yearling Chinook salmon smolts with known passage routes at each dam measured from Bonneville Dam to rkm 153 and from rkm 153 to $\mathrm{rkm} 8.3$ with associated standard errors. 
3.20 Reach-specific survival probability estimates and associated standard errors for yearling Chinook salmon smolts for combinations of passage routes at John Day/The Dalles/Bonneville dams to rkm 153 and six reach-specific survivals between rkm 153 and rkm 8.3

3.21 Cumulative reach survival probability estimates and associated standard errors for yearling Chinook salmon smolts for combinations of passage routes at John Day/The Dalles/Bonneville dams from rkm 153 to rkm 8.3

3.22 Reach survival probability estimates for steelhead smolts by passage routes at a particular dam to rkm 153 and from rkm 153 to rkm 8.3 with associated standard errors.

3.23 Reach-specific survival probability estimates and associated standard errors for steelhead smolts by passage route at a particular dam to rkm 153 and six reach-specific survivals between rkm 153 and rkm 8.3

3.24 Cumulative reach survival probability estimates and associated standard errors for steelhead smolts by passage route at a particular dam from rkm 153 to $\mathrm{rkm} 8.3$

3.25 Sample sizes of steelhead smolts available for survival analyses based on their joint passage history at John Day and The Dalles dams orThe Dalles and Bonneville dams.

3.26 Reach survival probability estimates for combinations of steelhead smolts by passage routes at John Day/The Dalles dams or The Dalles/Bonneville dams to rkm 153 and from rkm 153 to $\mathrm{rkm} 8.3$ with associated standard errors.

3.27 Reach-specific survival probability estimates and associated standard errors for steelhead smolts for combinations of passage routes at John Day/The Dalles dams or The Dalles/Bonneville dams to rkm 153 and six reach-specific survivals between rkm 153 and rkm 8.3

3.28 Cumulative reach survival probability estimates and associated standard errors for steelhead smolts for combinations of passage routes at John Day/The Dalles dams or The Dalles/Bonneville dams from rkm 153 to $\mathrm{rkm} 8.3$

3.29 Sample sizes of steelhead smolts available for survival analyses based on their joint passage history starting at the John Day JBS, TSW, non-TSW, or turbine passage routes and their subsequent passage through both The Dalles and Bonneville dams

3.30 Cumulative survival probability estimates for steelhead smolts with known passage routes at each dam measured from Bonneville Dam to rkm 153 and from rkm 153 to rkm 8.3 with associated standard errors

3.31 Reach-specific survival probability estimates and associated standard errors for steelhead smolts for combinations of passage routes at John Day/The Dalles/Bonneville dams to rkm 153 and six reach-specific survivals between rkm 153 and $\mathrm{rkm} 8.3$

3.32 Cumulative reach survival probability estimates and associated standard errors for steelhead smolts for combinations of passage routes at John Day/The Dalles/Bonneville dams from rkm 153 to rkm 8.3.

3.33 Reach survival probability estimates for subyearling Chinook salmon smolts by passage routes at a particular dam to $\mathrm{rkm} 153$ and from rkm 153 to $\mathrm{rkm} 8.3$ with associated standard errors

3.34 Reach-specific survival probability estimates and associated standard errors for subyearling Chinook salmon smolts by passage route at a particular dam to rkm 153 and six reachspecific survivals between rkm 153 and rkm 8.3

3.35 Cumulative reach survival probability estimates and associated standard errors for subyearling Chinook salmon smolts by passage route at a particular dam from rkm 153 to 
rkm 8.3. Results are presented for four routes at John Day Dam, three routes at The Dalles Dam, and four routes at Bonneville Dam, along with standard errors and $P$-values associated with $F$-tests of homogeneous survival.

3.36 Cumulative survival probability estimates for combinations of subyearling Chinook salmon smolts by passage routes at John Day/The Dalles dams or The Dalles/Bonneville dams to rkm 153 and from rkm 153 to rkm 8.3 with associated standard errors.

3.37 Sample sizes of subyearling Chinook salmon smolts available for survival analyses based on their joint passage history at a) John Day and The Dalles dams or b) The Dalles and Bonneville dams

3.38 Reach-specific survival probability estimates and associated standard errors for subyearling Chinook salmon smolts for various combinations of passage routes at John Day/The Dalles dams or The Dalles/Bonneville dams to rkm 153 and six reach-specific survivals between rkm 153 and $\mathrm{rkm} 8.3$

3.39 Cumulative reach survival probability estimates and associated standard errors for subyearling Chinook salmon smolts for various combinations of passage routes at John Day/The Dalles dams or The Dalles/Bonneville dams from rkm 153 to rkm 8.3

3.40 Sample sizes of subyearling Chinook salmon smolts available for survival analyses based on their joint passage history starting at the John Day JBS, TSW, non-TSW, or turbine passage routes and their subsequent passage through both The Dalles and Bonneville dams....

3.41 Cumulative survival probability estimates for subyearling Chinook salmon smolts with known passage routes at each dam measured from Bonneville Dam to rkm 153 and from rkm 153 to $\mathrm{rkm} 8.3$ with associated standard errors

3.42 Reach-specific survival probability estimates and associated standard errors for subyearling Chinook salmon smolts for various combinations of passage routes at John Day/The Dalles/Bonneville dams to rkm 153 and six reach-specific survivals between rkm 153 and rkm 8.3

3.43 Cumulative reach survival probability estimates and associated standard errors for subyearling Chinook salmon smolts for various combinations of passage routes at John Day/The Dalles/Bonneville dams from rkm 153 to rkm 8.3

3.44 Avian predator colony recoveries of PIT tags from JSATS+PIT-tagged juvenile salmonids in the lower Columbia River estuary in 2010 



\subsection{Introduction}

Since 1991, 13 Columbia River salmon stocks have been added to the list of threatened or endangered species under the Endangered Species Act, which has prompted research focused on the survival and recovery of these stocks. Much of the research has focused on survival and behavior of juvenile salmonids as they pass through reservoirs and dams within the Federal Columbia River Power System (FCRPS). Efforts by the U.S. Army Corps of Engineers (USACE) to improve passage conditions at FCRPS dams have increased survival at many of these dams over the past decade. However, until recently, little research focused on the survival and behavior of seaward migrating juvenile salmonids after they had passed Bonneville Dam (river kilometer [rkm] 235). Although some researchers have suggested that the previous passage experience through the FCRPS may influence the survival of juvenile salmonids as they transit the lower Columbia River and estuary (Budy et al. 2002; Ferguson et al. 2006; Schreck et al. 2006; Schaller and Petrosky 2007), many questions remain to be answered.

Since 2004, with the first prototype testing of Juvenile Salmon Acoustic Telemetry System (JSATS) (McMichael et al. 2010a) transmitters and receivers, researchers at the National Oceanic and Atmospheric Administration (NOAA) Fisheries and Pacific Northwest National Laboratory (PNNL) have been studying the behavior and survival of seaward migrating juvenile salmonids through the lower $235 \mathrm{~km}$ of the Columbia River and its estuary. Survival estimates from Bonneville Dam to the mouth of the river $(\mathrm{rkm} 8)$ in 2005 showed that the estimated mean survival probability was $0.67(\mathrm{SE}=0.06)$ and 0.63 $(\mathrm{SE}=0.11)$ for yearling and subyearling Chinook salmon, respectively (McComas et al. 2007). In 2006, the estimated mean survival probability was $0.75(\mathrm{SE}=0.018)$ for yearling Chinook salmon and 0.65 $(\mathrm{SE}=0.024)$ for subyearling Chinook salmon (McComas et al. 2008). The average estimated survival probability through the lower Columbia River and estuary was lower than expected in 2005 and 2006, with between 25 and 33\% of yearling Chinook salmon perishing in the $227 \mathrm{~km}$ between Bonneville Dam and East Sand Island (rkm 8). Subyearling Chinook salmon transiting the same reach suffered 35 to $37 \%$ estimated average losses.

To better understand where fish losses were occurring in the lower Columbia River and its estuary, PNNL deployed additional autonomous receiver arrays in strategic locations to separate the lower $235 \mathrm{~km}$ of the Columbia River and estuary into specific reaches in 2007, 2008, and 2009. Information from these additional arrays showed that most losses of juvenile Chinook salmon occurred in the final $50 \mathrm{~km}$ of the estuary (McMichael et al. 2010b).

This report presents the research conducted in 2010 using the JSATS to estimate survival of acoustictagged juvenile yearling Chinook salmon (CH1), subyearling Chinook salmon (CH0), and steelhead (STH) downstream of Bonneville Dam as they migrated seaward through the Columbia River and its estuary. This study also provides estimates of survival for groups of fish with known passage routes at John Day, The Dalles, and Bonneville dams. In reaches upstream of river kilometer 153, survival estimates include direct mortality from routes of passage at dams. By estimating the survival probability of fish arriving at rkm 153 as they pass through the reaches downstream, it is possible to evaluate whether the effects of passage route persist in reaches further downstream from the passage event. This report also presents the first data showing the migratory behavior of juvenile salmonids as they emigrate from the mouth of the Columbia River and into the near-shore ocean in the plume. The research presented in this report was conducted by PNNL for the USACE Portland District. 
The primary objective of this study was

- to estimate the survival of yearling and subyearling Chinook salmon and steelhead through multiple reaches of the Columbia River between Bonneville Dam and the Pacific Ocean.

Other objectives were

- to compare the effects of FCPRS passage history on the mortality of juvenile salmonids in the lower $153 \mathrm{~km}$ of the Columbia River and estuary

- to determine the migratory behavior and travel time of juvenile salmonids in the Columbia River plume to inform experimental design for survival studies.

The ensuing sections of this report present the materials and methods (Section 2), results (Section 3), and discussion (Section 4). References are listed in Section 5. Four appendices contain tagging data tables (Appendix A); information about autonomous receiver locations (Appendix B) and the locations of autonomous receivers relative to reference points for cross-channel distribution (Appendix C); and a data gap chart for autonomous receiver files (Appendix D). 


\subsection{Materials and Methods}

This section provides details on the methods used to address the project objectives. Information regarding the fish collection and tagging, acoustic receiving systems and related data processing and analyses are presented. The survival model and methods used to determine the migratory behavior and relevant influences on travel time and survival through the lower Columbia River and estuary are presented to provide the necessary background information for understanding the results and conclusions.

\subsection{Fish Collection, Tagging, and Release}

Study activities related to the careful and consistent collection, tagging, and release of fish - which are crucial to meeting the assumptions of the single release-recapture model of Skalski et al. (1998) —are described in this section.

\subsubsection{Collection and Sampling Methods}

Juvenile Chinook salmon and steelhead were collected and tagged at the John Day Dam (JDA) smolt monitoring facility (SMF) as part of the sequence of Lower Columbia River Survival Study, 2010 studies conducted at John Day. The Dalles, and Bonneville dams (study codes SPE-P-08-03, SPE-P-10-2, and SPE-P-10-1, respectively). The SMF is situated on the south side of John Day Dam at the downriver edge of the fish bypass system where bypassed juvenile salmonids and other fishes are routed through a series of flumes and dewatering structures. During collection, juvenile salmonids were diverted from the bypass system and routed into a 6800-L holding tank in the SMF. About 150 to 200 smolts and other fishes were crowded with a panel net into a $51-$ by $61-\mathrm{cm}$ pre-anesthetic chamber. Water levels in the chamber were lowered to about $20 \mathrm{~cm}(48 \mathrm{~L})$ at which point fish were anesthetized with $60 \mathrm{~mL}$ of a stock tricaine methanesulfonate (MS-222) solution prepared at a concentration of $50 \mathrm{~g} / \mathrm{L}$. Once anesthetized, fish were routed into an examination trough. Technicians added MS-222 as needed to maintain sedation, and 5 to $10 \mathrm{~mL}$ of PolyAqua to reduce fish stress. Water temperatures were monitored in the main holding tank and in the examination trough. Water in the trough was refreshed before temperatures increased more than $2^{\circ} \mathrm{C}$ above those observed in the main holding tank.

Once in the examination trough, smolts targeted for surgical procedures were evaluated in accordance with the specific criteria listed in Table 2.1. During spring and summer tagging seasons, 1,957 total fish (of 12,214 collected [16\%]) were rejected for tagging. Fish that were rejected during the tagging process were placed in a recovery tank to allow for the anesthesia to be displaced from their systems before releasing them. The total number of fish rejected and reasons for their rejection are listed below in Table 2.2.

Non-target species and fish that did not meet the criteria were released to the river through the SMF holding system after a 30-minute recovery period. Accepted fish were counted and released into transfer buckets containing fresh river water before being moved to one of six $300-\mathrm{L}$ pre-surgery holding tanks, where they were held for 18 to 30 hours before surgery. The pre-surgery holding duration depended on the time of collection and the time of tagging the following day. 
Table 2.1. Criteria for accepting or rejecting smolts for implantation surgery.

\begin{tabular}{|c|c|}
\hline Qualifying (Acceptable) Conditions & Disqualifying (Unacceptable) Conditions \\
\hline $\begin{array}{ll}\text { - } & \text { Sized }>95 \mathrm{~mm} \\
\text { - } & \text { Visible elastomer tag(s) present or absent } \\
\text { - } & \text { Adipose-fin clipped or unclipped } \\
\text { - } & \text { Trematodes, copepods, leeches } \\
\text { - } & \text { Short operculum } \\
\text { - } & \text { Healed (moderate) injuries (e.g., bird } \\
& \text { strikes) } \\
\text { - } & <3 \% \text { fungal patch } \\
\text { - } & \text { Minor fin blood } \\
\text { - } & \text { Partial descaling (3-19\%) } \\
\text { - } & \text { STH with eroded pectoral or ventral fins } \\
& \text { (likely hatchery steelhead). }\end{array}$ & $\begin{array}{l}\text { - } 20 \% \text { descaling } \\
\text { - } \quad \text { body punctures (showing blood; e.g., predator marks, } \\
\text { - } \quad \text { Obvious signs of bacterial kidney disease } \\
\text { - } \quad \text { Eye hemorrhage or popeye }>3 \% \text { coverage with fungus } \\
\text { - } \quad \text { Deformed } \\
\text { - } \text { soldovers (fish not "spring" yearling or "summer" } \\
\text { - Passive integrated transponder (PIT)- or radio-tagged or } \\
\text { - } \quad \text { Nother post-surgical fishes } \\
\text { - } \quad \text { Columnaris, furuncles } \\
\text { - Injured caudal peduncles } \\
\text { - Injured caudal fins } \\
\text { - Fin hemorrhage. }\end{array}$ \\
\hline
\end{tabular}

Table 2.2. Number of fish rejected during spring and summer tagging at John Day Dam according to fish selection criteria defined by the USACE (2011). (Yearling Chinook $=\mathrm{CH} 1$, Steelhead $=$ STH, Subyearling Chinook $=\mathrm{CH} 0$ )

\begin{tabular}{lrrr}
\hline & \multicolumn{3}{c}{ Number Rejected } \\
\cline { 2 - 4 } \multicolumn{1}{c}{ Rejection Criteria } & CH1 & STH & CH0 \\
\hline Descaling & 147 & 208 & 227 \\
Fungus & 48 & 60 & 9 \\
BKD $^{1}$ & 2 & 0 & 2 \\
Skeletal deformity & 8 & 6 & 10 \\
Parasites & 0 & 4 & 34 \\
Emaciation & 1 & 0 & 1 \\
Lacerations & 30 & 47 & 71 \\
Hemorrhage & 12 & 2 & 5 \\
Popeye & 12 & 6 & 5 \\
Fin rot & 5 & 1 & 5 \\
Head deformation & 1 & 1 & 1 \\
Lesions & 14 & 21 & 23 \\
Moribund & 0 & 0 & 2 \\
Opercle damage & 16 & 42 & 25 \\
Size & 11 & 151 & 203 \\
PIT-tagged & 156 & 149 & 119 \\
Other & 16 & 33 & 5 \\
\hline \multicolumn{1}{c}{${ }^{1}$ BKD = Bacterial Kidney } & & \\
\hline
\end{tabular}

\subsubsection{Transmitter Specifications and Implantation}

All Chinook salmon and steelhead were implanted with an acoustic transmitter and a passive integrated transponder (PIT) (Figure 2.1). The mean dimensions of the 2010 model of the JSATS acoustic transmitter (Advanced Telemetry Systems) were $12.00 \mathrm{~mm}$ long $(\mathrm{SE}=0.01), 5.21 \mathrm{~mm}(0.01)$ wide, and $3.77 \mathrm{~mm}(0.04)$ high. Transmitters had a mean weight in air of $0.43 \mathrm{~g}$, a mean weight in water 
of $0.29 \mathrm{~g}$, and a mean volume of $0.14 \mathrm{~mL}$ (all SE <0.005). The transmitters had a nominal pulse rate interval (PRI) of one complete transmission every 3 seconds. The nominal transmitter life was expected to be about 30 days. The PIT tag (Model TX1411ST, Destron Fearing) was $12.5 \mathrm{~mm}$ long, $2 \mathrm{~mm}$ wide, and weighed $0.10 \mathrm{~g}$ in air $(0.06 \mathrm{~g}$ in water; $0.04 \mathrm{~mL}$ volume). The combined weight of the tags gave each implanted fish an added burden of $0.53 \mathrm{~g}$ in air. Both acoustic transmitters and PIT are often generically referred to as 'tags'. Each day prior to the start of tagging, transmitters and PIT tags were disinfected in a bath of $70 \%$ ethanol for 10 minutes followed by a 10 -minute soak in distilled water.

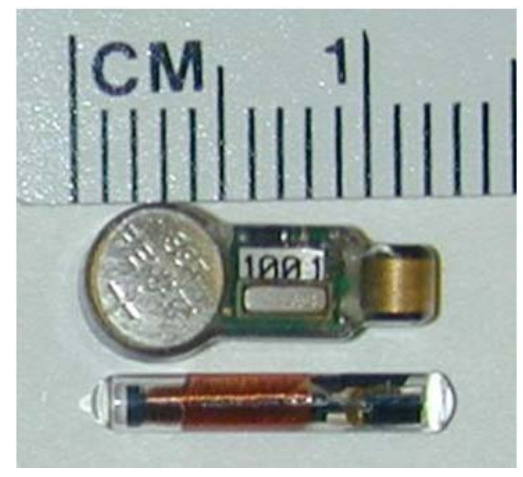

Figure 2.1. JSATS 0.43-g acoustic transmitter (above) and PIT tag (below)

\subsubsection{Tagging Procedures}

The tagging team followed the latest protocols for surgical implantation of acoustic transmitters in juvenile salmonids, including handling, anesthesia, surgery, recovery, and release (USACE 2011). Numerous steps were taken to minimize the handling impacts of collection, surgery, and transportation on the fish. Most smolts used for tagging were part of the routine collection for SMF monitoring and additional fish did not have to be collected to meet the tagging quota on most days.

A team of eight to nine people was needed to provide the most efficient and careful handling and tagging procedures as well as accurate data collection. One individual was responsible for anesthetizing fish and delivering them to the data station, where two people were responsible for obtaining fish lengths and weights and recording fish and tag data. Another person was responsible for taking lateral photographs with a high-resolution digital camera. Three people performed surgeries to implant tags in the fish, while one or two people were responsible for delivering fish to surgeons and moving tagged fish into the post-surgery recovery tanks.

Fish were netted in small groups from the $300-\mathrm{L}$ holding tanks and placed in a 19-L "knockdown" bucket with water and $20 \mathrm{~mL}$ of a $40-\mathrm{g} / \mathrm{L}$ stock solution of MS-222. Once a fish lost equilibrium, it was transferred to a processing table in a small container of river water. Each fish was measured (fork length $\pm 1 \mathrm{~mm}$ ), the species type and whether its adipose fin was intact or clipped were recorded on a GTCO CalComp Drawing Board VI digitizer board. Fish were weighed $( \pm 0.01 \mathrm{~g})$ on an Ohaus Navigator scale and returned to the small transfer container along with an assigned PIT tag and an activated acoustic transmitter. Length, weight, species type, tag codes, and fin clip were all added automatically to the tagging database by PIT Tag Information System P3 software to minimize human error. The transfer container, fish, and tags were assigned a recovery bucket number and delivered to the photo table. Photographs were taken of both sides of the fish while in the transfer container. The fish was then delivered to a surgeon for tag implantation. 
An established protocol was used in the tagging process to help minimize the handling impact on the tagged fish. All surgical instruments were sterilized daily in an autoclave and each surgeon rotated through four complete sets of instruments throughout the tagging day. When an instrument set was not being used, it was placed in a 70\% ethanol solution for approximately 10 minutes. The instruments were then transferred to a distilled water bath. Poly-Aqua, a water conditioner, was applied to the surgical pad, measuring board, and transfer container to minimize the disruption of the fish's mucus layer. Anesthesia and recovery buckets were kept within $\pm 1^{\circ} \mathrm{C}$ of river temperature. Anesthesia solutions were either replaced or cooled with ice to maintain temperatures within protocol requirements.

During surgery, each fish was placed ventral side up into a groove on a foam-rubber surgical pad. A maintenance dose of anesthesia (40 mg/L MS-222) was delivered into the fish's mouth via gravity-fed tubing. River water (no anesthesia) was also supplied via the tubing to adjust the sedation level of the fish during surgery. A 3-mm Micro-Sharp blade (Becton, Dickinson and Company) or a \#15 stainless steel surgical blade (depending on the surgeon's preference) was used to make a 6- to 8-mm incision on the linea alba (mid-ventral line) anterior of the pelvic girdle and posterior of the pectoral fin. The PIT tag was inserted into the incision first, followed by the acoustic transmitter. Both tags were placed slightly anterior tothe incision. The incision was closed with two simple interrupted stitches with $2 \times 2 \times 2 \times 2$ knots (Deters et al. In Press) using a 5-0 absorbable monofilament suture with an RB-1 needle. With the incision closed, fish were then taken to an aerated recovery bucket containing river water.

\subsubsection{Recovery and Holding}

Tagged fish were placed in 19-L aerated recovery buckets and closely monitored until fish had reestablished equilibrium. Each bucket held one to five fish depending on fish size and the number to be released at each site. The buckets were then carried to a larger holding tank where they were supplied with a continuous feed of river water. Fish were held and monitored for 18 to 30 hours prior to being released. The large holding tanks were insulated to keep the water temperature within acceptable limits (Figure 2.2).

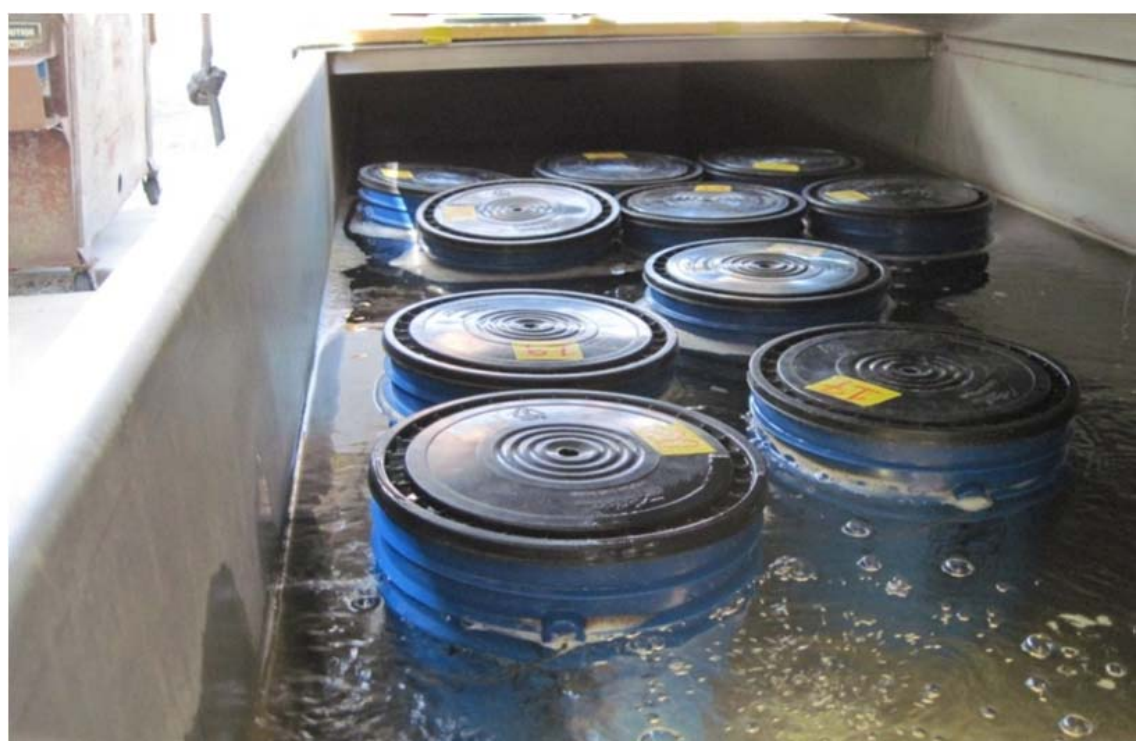

Figure 2.2. Post-surgery holding tank with recovery buckets. 


\subsubsection{Fish Transportation and Release}

To transport tagged fish, two $3 / 4$-ton trucks were each outfitted with one 680 -L Bonar insulated tote and one 265-L Bonar insulated tote. The 680-L tote could hold ten 19-L fish buckets, and the 265-L tote could hold four 19-L fish buckets. The totes had snug-fitting lids and some extra space inside so that ice could be added for cooling on hot days. A network of valves and plastic tubing was attached to an oxygen tank for delivering of oxygen to the totes from a 2200-psi oxygen tank during transport. The Bonar totes were filled with fresh river water before fish buckets were placed inside. The dissolved oxygen and water temperature in the totes were measured with a YSI meter before and after transport to ensure that these metrics stayed within acceptable limits.

All fish tagged at John Day Dam and released alive were transported to one of three release locations on the Columbia River: rkm 390 near Roosevelt, Washington, rkm 307 in The Dalles Dam tailrace, and rkm 275 near Hood River, Oregon (Appendix A). Transportation routes were adjusted to provide equal travel times to each release location from John Day Dam. Upon arriving at a release site, fish buckets were transferred to a boat for transport to the in-river release location. In preparation for fish release, the boat operator maneuvered the boat to the release waypoint using an on-board global positioning system (GPS) and put the motor in neutral. Each bucket was submerged in the water so that fish could swim out on their own volition. The release site and time were recorded to the nearest minute on field data sheets. Fish were typically released at five locations along a line transect across the river unless river conditions were too rough for safe boat operation. Equal numbers of buckets were released at each of the five locations.

Just before fish were released in the river, buckets were checked for dead fish. Dead fish were brought back to the SMF and recorded as mortalities. These fish were then added to the weekly releases of dead fish, which were used to determine whether or not dead fish were being detected on downstream survival-detection arrays. Reference releases of tagged dead fish were placed into the SMF outfall at JDA $(\mathrm{N}=39)$, into the spillway at TDA $(\mathrm{N}=41)$, and into the second powerhouse (B2) corner collector at BON $(\mathrm{N}=57$; Table 2.3) to validate the survival model assumption that dead fish would not arrive at and be detected on survival arrays. No dead fish were detected on any of the arrays used to estimate survival. Post-tagging, pre-release mortalities were low for each run of fish studied in $2010(\mathrm{CH} 1=0.10 \%$; $\mathrm{STH}=0.05 \% ; \mathrm{CH} 0=0.22 \%$ ).

During spring, a total of 3,880 implanted yearling Chinook salmon and 3,885 implanted steelhead were released over a 35-day period from 28 April to 1 June (Table 2.3 and Appendix A). During summer, a total of 4,449 implanted subyearling Chinook salmon were released over a 35-day period from 13 June to 17 July (Appendix A). Releases alternated between daytime and nighttime, every other day, over the course of the study. The timing of the releases at the three locations was staggered to help facilitate downstream mixing. An additional 1,392 acoustic-tagged yearling Snake River Chinook salmon were tagged at Lower Granite Dam and then released from fish transportation barges downstream of Bonneville Dam (rkm 224) between 30 April and 14 May 2010 for a different study of survival inside the barges (McMichael et al. 2011). These barged fish were used for the current study only to evaluate migratory behavior in the Columbia River plume. 
Table 2.3. Numbers of JSATS-tagged alive and dead yearling Chinook salmon (CH1), steelhead (STH), and subyearling Chinook salmon $(\mathrm{CH} 0)$ released at three alive-release sites and three deadrelease sites on the Columbia River in 2010.

\begin{tabular}{llcrrr}
\hline & \multicolumn{1}{c}{ Release Location } & Release rkm & CH1 & STH & CH0 \\
\hline Alive releases & Roosevelt & 393 & 2287 & 2288 & 2849 \\
& TDA tailrace & 307 & 796 & 799 & 800 \\
& Hood River & 275 & 797 & 798 & 800 \\
Dead releases & 347 & 10 & 10 & 19 \\
& JDA SMF & 309 & 6 & 14 & 21 \\
& TDA spillway & 233 & 17 & 13 & 27 \\
\hline
\end{tabular}

\subsection{Site Description and Array Locations}

The area in the Columbia River and estuary downstream of the FCRPS defines the study area. The array locations used in this study were chosen to differentiate survival among important reaches of the river and were selected because the associated river characteristics allow for good detection of acoustic tags. This section provides details about where detection arrays were placed.

\subsubsection{Site Description}

To accurately assess the effects of passage through the FCRPS on the survival of juvenile salmonids it is necessary to monitor the migration of these populations over a large enough area to detect delayed/latent mortality that may have been due to the passage history of these fishes. Therefore, the study area included the unimpounded main stem Columbia River and estuary from the Bonneville Dam tailrace to the Pacific Ocean, a distance of approximately $235 \mathrm{rkm}$ (Figure 2.3). This section of the (lower) Columbia River has six major tributaries. The first two major tributaries downstream of Bonneville Dam are the Sandy (Oregon) and Washougal (Washington) rivers, both entering the Columbia River at rkm 195; followed downstream by the Willamette River (rkm 164), Lewis River (rkm 140), Kalama River (rkm 114), and the Cowlitz River (rkm 109). An additional three tributaries enter the Columbia River estuary; they include the Grays River (rkm 24), Youngs River (rkm 19), and Lewis and Clark River, also at rkm 19.

Physical processes in the lower Columbia River are shaped by two dominant factors: channel bathymetry and flow. River flow is controlled by climate variation and anthropogenic effects such as water storage, irrigation withdrawals, and flood control/flow regulation (McComas et al. 2007). The annual discharge for the Columbia River ranges from a low of $2,970 \mathrm{~m}^{3} / \mathrm{s}$ during late summer and fall to a high of $17,000 \mathrm{~m}^{3} / \mathrm{s}$ during the spring freshet period (Sherwood and Greagar 1990). Under post-dam flow conditions, annual sediment discharge is about $7.6 \times 106 \mathrm{mt}^{3} / \mathrm{y}$, about $45 \%$ of which is sand (Sherwood et al. 1990). The authors also noted that much of the finer material is transported in suspension during periods of high river flow. Thus, both high flows and high suspended sediment loads coincide with the peak juvenile salmonid outmigration, particularly for yearling Chinook salmon and steelhead, which migrate through the system during the spring freshet (McComas et al. 2007).

The physical characteristics of the Columbia River estuary are different than most other estuaries, because the river discharge is relatively large (accounting for $77 \%$ of the freshwater drainage along the U.S. west coast north of San Francisco) and the river sediment is less stable (Fox et al. 1984; Hickey et al. 
2005). The estuary bottom is composed mostly of sand that constantly shifts — building sand waves that move in response to strong water flows and large waves, a process called bedload transport (White 1970; Fox et al. 1984). Sand waves cover approximately $45 \%$ of the channel near Bonneville Dam and increase to $86 \%$ at the mouth of the Columbia River (Woxell 1998). In addition, tidal exchange between high and low tide alters the estuary water level by an average of $2.4 \mathrm{~m}$ in approximately 6 hours (Fox et al. 1984). Tidal effects reach as far inland as Bonneville Dam (rkm 235). This large tidal exchange and river discharge significantly influences water velocity and direction in the Columbia River estuary (Fox et al. 1984), where water velocity consistently reaches $2 \mathrm{~m} / \mathrm{s}^{1}{ }^{1}$ Flood tides will actually reverse the river flow from an outgoing current to upstream current flow.

The Columbia River estuary contains numerous natural islands as well as several manmade islands constructed of dredge spoils (Sherwood et al. 1990). Collis et al. (2001) estimated that nine islands in the estuary supported up to 170,000 piscivorous water birds, including the largest nesting colonies of Caspian terns (Sterna caspia) and double-crested cormorants (Phalacrocorax auritus) in North America. Two of these islands were particularly important to survival studies of fish migrating through the study area. In 1998, Rice Island, a dredge spoils site at rkm 35, contained over 10,000 terns and more than 1,000 cormorants, which were estimated to be dependent on salmonids for $74 \%$ and $45 \%$ of their diets, respectively (Collis et al. 2002). Subsequent relocation efforts, conducted to reduce the proportion of salmonids in the diet of these birds, successfully moved a majority of the Rice Island colonies to East Sand Island, another dredge disposal site at $\mathrm{rkm} \mathrm{8,} \mathrm{where} \mathrm{tern} \mathrm{and} \mathrm{cormorant} \mathrm{colonies} \mathrm{of} \mathrm{about} \mathrm{8,000}$ breeding pairs each were established by 2002 (Ryan et al. 2005).

\subsubsection{Autonomous Acoustic Receiver Locations}

For this study, acoustic telemetry receivers were deployed at 125 locations that ranged from Knapp Point, Washington (rkm 153), downstream through the mouth of the Columbia River and into the Columbia River plume between 17 April and 9 August 2010 to detect acoustic-tagged Chinook salmon and steelhead smolts as they migrated through the lower Columbia River and its estuary (Figure 2.3). Receivers were deployed primarily in lines, referred to as arrays, which ran approximately perpendicular to the shore (Appendix B). Based on their effective detection range, receivers were spaced about 100 to $200 \mathrm{~m}$ apart. However, due to depth requirements, it was not possible to space receivers this closely across the entire width of the estuary at several of the array locations. Specifically, in areas that consisted of broad, shallow tidal flats, receivers were deployed only in water that was more than about $4 \mathrm{~m}$ deep (during low tide) to keep receiver hydrophones submerged.

A total of 11 receiver arrays were deployed (Figure 2.3). The array at Knapp Point (rkm 153) consisted of five receivers placed evenly across the river channel. Ten receivers were deployed at the Cottonwood Island (rkm 113.0) array, one of which was moored in Cottonwood Channel. Six receivers were positioned across the entire channel at the Oak Point array (rkm 86.0). The array at Three-Tree Point (rkm 49.6) included four receivers, three of which were deployed with overlapping detection range across the navigation channel and the fourth in Clifton Channel. Seven receivers made up the Harrington Point array ( $\mathrm{rkm} 37.3$ ); four of them were deployed across the navigation channel, and three deployed in were deployed the deeper channels of Cathlamet Bay (Figure 2.4). Two receivers were deployed

\footnotetext{
${ }^{1}$ Data are from the Columbia River Ecosystem (CORIE) observatory network operated by The Center for Coastal Margin Observation \& Prediction, Beaverton, Oregon.
} 


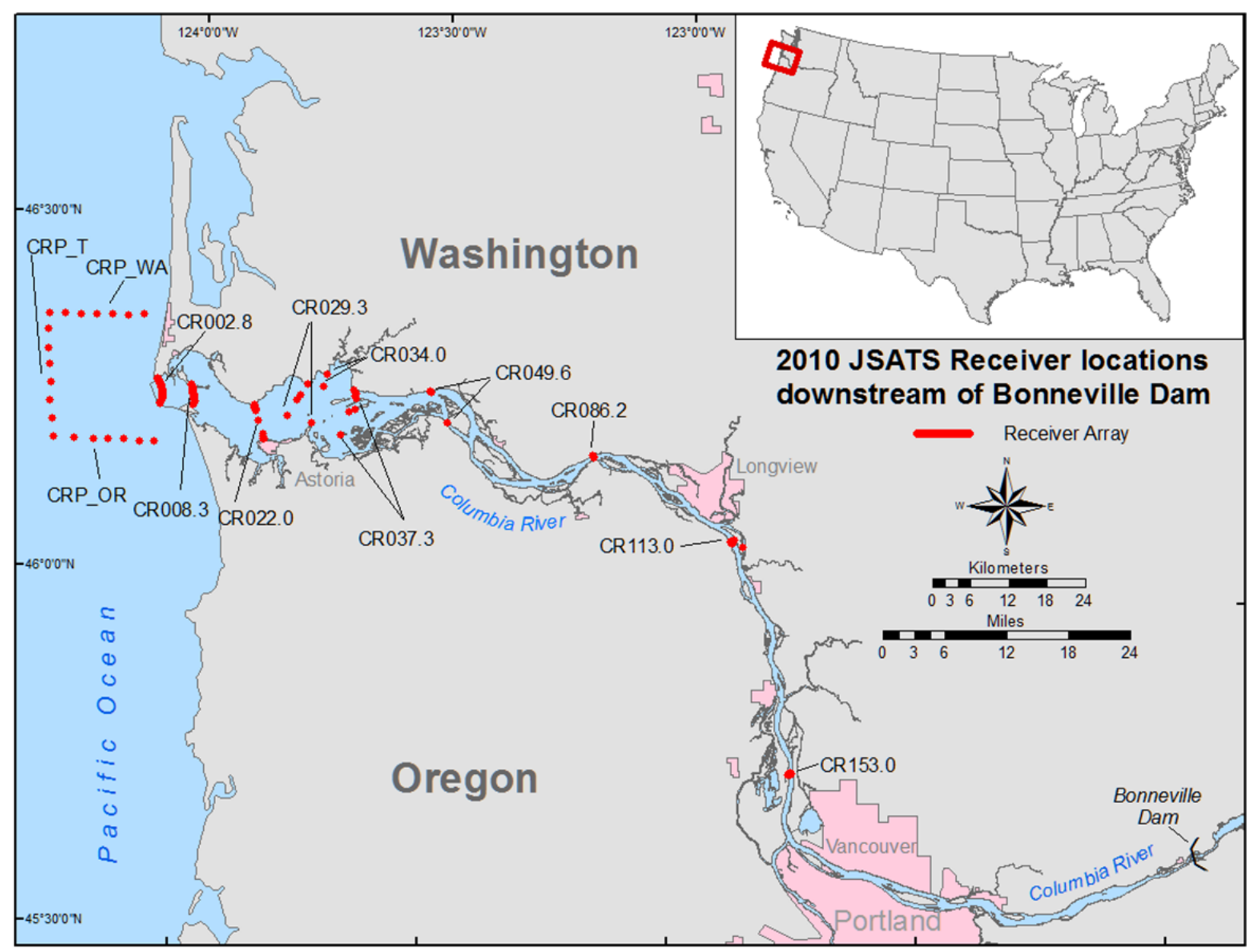

Figure 2.3. Study site and locations of acoustic telemetry receiver arrays (red) near Knapp Point (CR153.01), Cottonwood Island (CR113.0), Oak Point (CR086.2), Three Tree Point (CR049.6), Harrington Point (CR037.3), Rocky Point (CR34.0), Grays Point/Taylor Sands (CR29.3), Astoria Bridge (CR022.0), East Sand Island (CR008.3), Columbia River bar (CR002.8), and Columbia River Plume (CRP WA, CRP T, CRP OR) used to detect acoustic-tagged yearling and subyearling Chinook salmon and steelhead migrating through the Columbia River estuary in 2010.

in Grays Bay, near Rocky Point (rkm 34.0), to create a partial array. The Grays Point/Taylor Sands array (rkm 29.3) consisted of five receivers; one deployed in the deep channel along the Washington shoreline, one in the deep navigation channel along the Oregon shoreline, and three deployed in the deeper subchannels contained in the shallow tidal flat of Taylor Sands. The array at rkm 22.0 was located directly upstream of the Astoria-Megler Bridge and consisted of 16 receivers; 10 deployed in the deep channel along the Washington shoreline, 1 located near the middle of the bridge in a small channel that drained towards the Washington shoreline channel, and 5 receivers located in and around the navigation channel The array at East Sand Island (rkm 8.3) included 22 receivers, spaced 100 to $200 \mathrm{~m}$ apart, across the

\footnotetext{
${ }^{1}$ Receiver locations are named as a concatenation of "CR" for Columbia River, the river kilometer location of the receiver (measured upstream from the mouth of the Columbia River), followed by an underscore, and the receiver number (numbered from the Washington to the Oregon shore). For example, the receiver location CR002.8_01 is the concatenation of "CR" (for Columbia River), "002.8" describing the river kilometer of the receiver, and an underscore followed by " 01 ", which is the receiver location on that array.
} 


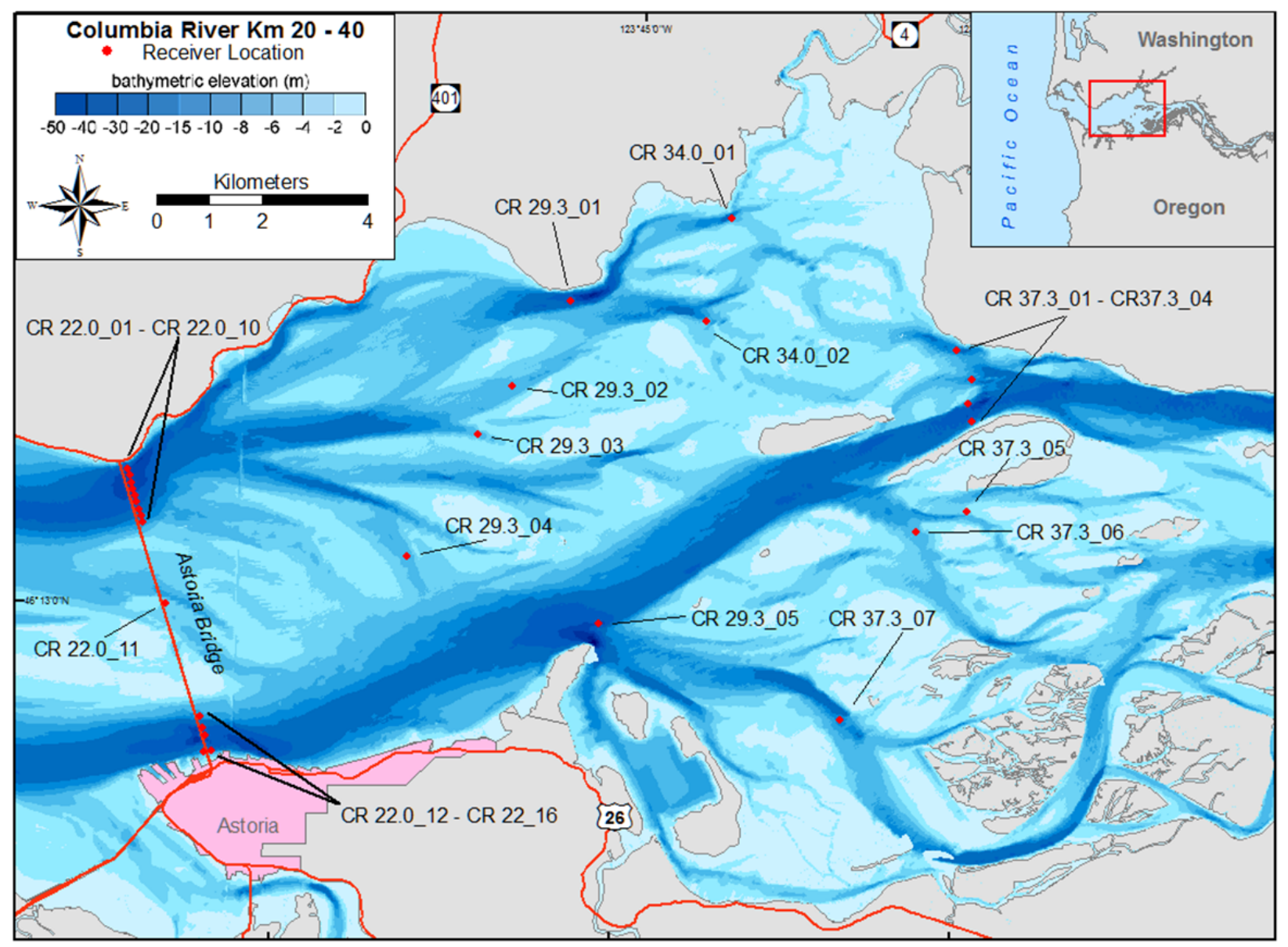

Figure 2.4. Locations of acoustic telemetry receiver arrays at Harrington Point (CR037.3), in Grays Bay (CR034.0_01, CR034.0_02, and CR029.3_01), Taylor Sand (CR029.3_02-CR029.3_04), at Tongue Point (CR029.3_05), and at the Astoria-Megler Bridge (CR022.0) in relation to bathymetry.

entire channel from East Sand Island to the Oregon shoreline. The Washington shoreline and navigation channels converge near $\mathrm{rkm} 8.3$, and 11 of the $\mathrm{rkm} 8.3$ array receivers were located in the Washington channel and the other 11 receivers were located in and around the navigation channel near the Oregon shoreline. The final downstream Columbia River array was located between the jetties on the Columbia River bar at rkm 2.8 and consisted of 27 receivers spaced 100 to $200 \mathrm{~m}$ apart. Finally, the plume array consisted of 20 receivers moored along a roughly 15 by $20 \mathrm{~km}$ "box" centered on the mouth of the Columbia River (west terminus at the 100-m depth contour, $\sim 15 \mathrm{~km}$ from end of South Jetty; Figure 2.5). Receivers deployed in the plume were approximately $3 \mathrm{~km}$ apart.

Receivers within arrays were numbered sequentially from the Washington shoreline to the Oregon shoreline except at arrays CR002.8 and CR008.3 where numbers representing past locations of receivers in the navigation channel were omitted. Receivers were not deployed in the navigation channel at CR002.8 and CR008.3 in 2010. Columbia River plume receiver positions are a concatenation of Columbia River plume (CRP), state of line running from the coast westward (OR or WA) or along the terminus of the plume array (T). Receiver positions are numbered lower toward the coast and on the north end of the terminus. 


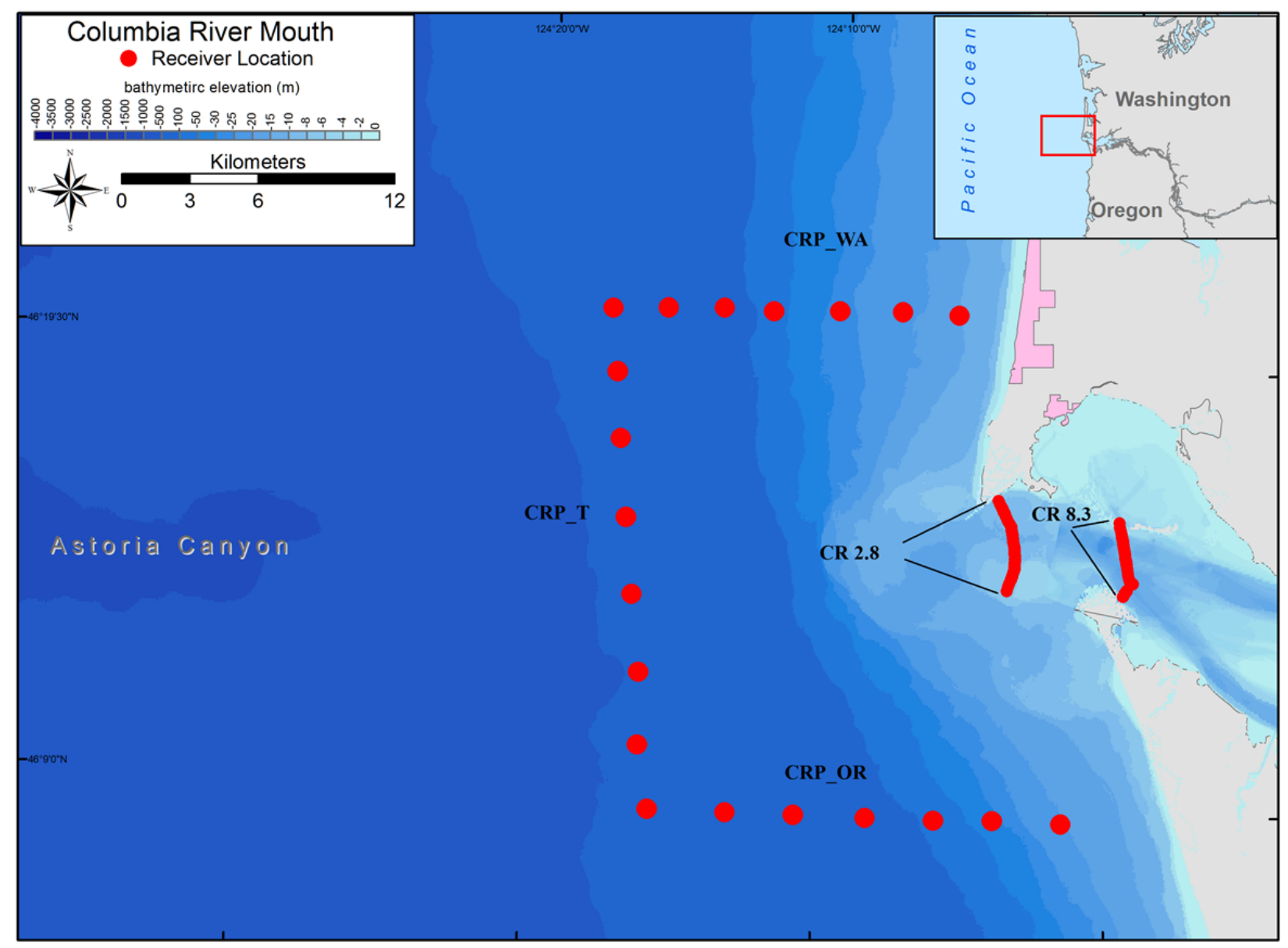

Figure 2.5. JSATS autonomous receivers in the Columbia River plume. The three sub-arrays are Washington (CRP_WA; $N=7)$, Terminus (CRP_T; $N=6)$, and Oregon (CRP_OR; $N=7$ ).

\subsection{Autonomous Receiver Deployment, Recovery, and Servicing}

Acoustic transmissions from implanted fish were detected and decoded by stationary JSATS autonomous receivers (Model N201, Sonic Concepts, Inc., Bothell, Washington; McMichael et al. 2010b; Titzler et al. 2010), which were deployed using methods described by McMichael et al. (2010b) and Titzler et al. (2010). Briefly, autonomous receivers were deployed with acoustic releases and 34- to 57$\mathrm{kg}$ anchors. InterOceans Systems, Inc. (San Diego, California) Model 111 acoustic releases were used in the river and estuary and Model 875A acoustic releases, manufactured by Teledyne-Benthos (North Falmouth, Massachusetts), were used in the plume. Depending on depth, the hydrophones on the receivers were between 3 and $8 \mathrm{~m}$ off the substrate. Recovery was accomplished by navigating to each receiver location and using an acoustic release command unit to transmit the release command to the acoustic releases. Upon release, the positively buoyant receiver ascended to the surface and was brought on board. A recently activated receiver was then re-deployed within 2 to 7 minutes in the same location. All receivers were opened in a shore-based trailer configured for this specific task. In the trailer, data cards were downloaded, batteries were replaced, and then receivers were tested to confirm their proper function prior to redeployment. 


\subsection{Autonomous Receiver Data Processing and Validation}

Signals received by JSATS autonomous receivers were processed and filtered to validate the presence of a tagged fish within the vicinity of a receiver at a specific time. Autonomous receivers recorded receptions of possible tag signals along with a timestamp for each reception. Raw files were timecorrected and filtered to remove spurious receptions prior to analysis. The time series of validated locations for individual fish were then used to estimate survival rates and passage characteristics, such as travel times. A laboratory study of tag life was conducted to allow estimates to be corrected for early tag failures if necessary.

\subsubsection{Time Correction}

Receiving nodes used in this study were subject to clock errors that resulted in timestamps being incorrect at unpredictable times throughout the file. Raw files were processed through a time correction application to repair incorrect timestamps based upon correct timestamps that preceded it. In many cases, the algorithm precisely identified a correction that was accurate to the second, whereas in others, the correction resulted in a difference of a few seconds for the block of data being corrected. The criteria for acceptance of a time-corrected file required that the time at the end of the file be within 1 hour of the correct time (relative to the time of node recovery). A file that failed to meet these criteria would be evaluated further to determine whether an improvement could be made to meet the criteria. Because the receivers were serviced about once a month, a file typically contained 30 days of timestamps, so that 1 hour represented approximately $1 / 10$ th of $1 \%$ of the total time. In practice, not all files require time correction and most that do differ by much less than 1 hour after correction. After time correction, the files are referred to as time-corrected files, whether or not a correction was needed and applied.

\subsubsection{Filtering}

Because JSATS autonomous receivers are configured to detect tag signals just above the acoustic noise floor, raw files often include spurious receptions that arise from noise in addition to valid tag signals. To improve the effective signal-to-noise ratio, spurious receptions were identified and removed in a process known as filtering. In the filtering step, time-corrected files were processed to validate the presence of individual tags based on the time series of tag code receptions. Filtering algorithms take advantage of the fact that spurious receptions do not exhibit the temporal consistency among pulses that is characteristic of an actively transmitting JSATS tag.

The nominal PRI of each tag was known, but the actual PRI of a nominally 3-second tag, for example, may be a few percent above or below the nominal value. In addition, the PRI may vary slightly through time with changes in battery voltage and temperature. This variation required that PRI be estimated at each point in time. After the PRI was estimated for a given starting reception, the estimate was used to develop a set of expected reception times to accept or reject individual receptions based upon when they were received. If enough hits were accepted within a short period of time following the initial reception, then the detections were deemed valid and were coded with an event number and output to a file. The processing steps follow below.

For each reception of a tag code do the following:

1. Select the set of receptions of the same code within 15 nominal PRIs after the initial reception. 
2. Estimate the actual PRI from the timing of receptions after the initial reception

3. Accept a reception within the set after the initial reception only if it falls within a narrow window around each whole interval of the estimated PRI from that initial reception. If multiple receptions fall within the same acceptance window, retain only the reception that most closely matches the estimated PRI.

4. If four or more receptions are accepted within 12 estimated PRIs from the initial reception (including the initial reception as an accepted hit), mark accepted receptions as belonging to a valid detection event.

5. Repeat the steps above for each reception in the file to identify all valid detection events for all tag codes.

6. If multiple valid detection events for a single tag code overlap in time, combine them into a single valid detection event.

7. Output the set of valid detection events.

When combined with information on receiving node location, the set of valid detection events for a given tag code composed a time series of locations for the fish implanted with that tag. These data provide the foundation for estimating various measures of the performance of fish migrating through the lower Columbia River, such as survival rates, travel times, and distributions.

\subsection{Route Assignments at Dams}

Cabled dam-face receivers were used together with PIT detections in the juvenile bypass systems (at John Day and Bonneville dams) and corner collector (at Bonneville Dam) to assign dam passage routes to acoustic-tagged yearling and subyearling Chinook salmon and steelhead as part of the Lower Columbia River Survival Study, 2010 (U.S. Army Corps of Engineers Study Codes SPE-P-08-03, SPE-P10-1, SPE-P-10-2).

For a detailed description of the methods related to assignment of routes of passage for JSATS-tagged fish at these dams please see Weiland et al. (2010) and Ploskey et al. (2011). To summarize, cabled arrays were deployed along the entire upstream face of JDA, TDA, and BON dams to detect approaching JSATS-tagged smolts. Multiple hydrophones were deployed at different depths on each main pier.

Additional hydrophones were attached to clump mounts and lowered to the bottom of the forebay directly upstream of the dam face to provide additional detections off of the plane of the dam face to increase the resolution of three-dimensional (3D) tracking. Filtering algorithms were applied to the raw results from the decoding utilities to exclude spurious data and false positives. Valid detections were used to track the movement of fish in 3D based on differences in the time of arrival of the acoustic signal among different hydrophones. Tracks of individual fish movement were used to assign fish to a passage route. All possible passage routes were monitored at JDA, TDA, and BON. Routes for our analyses included juvenile bypass systems (JBSs; JDA and BON only), temporary spillway weirs (TSWs; JDA only), nonTSW ("traditional") deep spill (all three dams), sluiceway (a surface passage route; included the ice-trash sluiceway at TDA and the combination of the B2 corner collector and first powerhouse (B1) sluiceway outlets at BON, and turbine passage (all three dams). 


\subsection{Tag Life}

For the tag-life study, 100 acoustic tags (3-second pulse rate) were randomly chosen from two manufacturing batches of Advanced Telemetry Systems tags used in this 2010 study. The acoustic tags were divided into two approximately equal size groups and tag life was monitored separately for each group, but tag-life data from both manufacturing batches were pooled for analysis within each season (i.e., two groups pooled for spring and two groups pooled for summer). All acoustic tags were enclosed in water-filled plastic bags and suspended from a rotating foam ring within a 2-m (diameter) fiberglass tank. Two $90^{\circ} \times 180^{\circ}$ hydrophones were positioned $90^{\circ}$ apart in the bottom of the tank and angled upward at approximately $60^{\circ}$ to maximize coverage for detecting acoustic signals. Hydrophones were cabled to a quad-channel receiver that amplified all acoustic signals, which were then saved, decoded, and post-processed. Post-processing software calculated the number of hourly decodes for each acoustic tag, allowing tag failure times to be determined within \pm 1 hour. Tag life expectancy was 30 days for all acoustic tags in this study.

The 99 acoustic tags ( 49 spring/50 summer) systematically sampled from the tags used in the yearling Chinook salmon and steelhead survival studies were monitored continuously until tag failure. Failure times for each seasonal group were fit to the four-parameter vitality model of Li and Anderson (2009). The vitality model tends to fit acoustic-tag failure times well, because it allows for both early onset of random failure due to manufacturing as well as systematic battery failure later on.

The probability density function for the vitality model can be rewritten as

$$
f(t)=1-\left(\Phi\left(\frac{1-r t}{\sqrt{u^{2}+s^{2} t}}\right)-e^{\left(\frac{2 u^{2} r^{2}}{s^{4}}+\frac{2 r}{s^{2}}\right)} \Phi\left(\frac{2 u^{2} r+r t+1}{\sqrt{u^{2}+s^{2} t}}\right)\right)^{e^{-k t}}
$$

where

$$
\begin{aligned}
\Phi & =\text { cumulative normal distribution } \\
r & =\text { average wear rate of components, } \\
s & =\text { standard deviation in wear rate } \\
k & =\text { rate of accidental failure, } \\
u & =\text { standard deviation in quality of original components. }
\end{aligned}
$$

The random failure component, in addition to battery discharge, gives the vitality model additional latitude to fit tag-life data not found in other failure-time distributions such as the Weibull or Gompertz. Parameter estimation was based on maximum likelihood estimation.

For the virtual-release group $\left(V_{1}\right)$ based on fish known to have arrived at the dam and with active tags, the conditional probability of a tag being alive, given the tag was active at the detection array at rkm 309, was used in the tag-life adjustment for that release group. The conditional probability of tag activation at time $t_{1}$, given it was active at time $t_{0}$, was computed by the quotient:

$$
P\left(t_{1} \mid t_{0}\right)=\frac{S\left(t_{1}\right)}{S\left(t_{0}\right)}
$$




\subsection{Survival Estimation}

The single release-recapture model of Skalski et al. (1998) was used to estimate reach survival for the various groups of fish evaluated. Survival $\left(s_{i}\right)$ and detection $\left(p_{i}\right)$ probabilities were differentiated in all reaches except the last where only the joint probability of surviving and being detected can be estimated (i.e., $\lambda_{i}=S_{i} p_{i}$ ).

Program ATLAS (Active Tag-Life Adjusted Survivals) was used to produce tag-life adjusted estimates of reach survival. Table 2.4 compares the parameterization of a two-reach survival study with and without adjustments for tag failure where

$$
\begin{aligned}
& L_{1}=\text { probability a tag is active at the first downstream detection site, } \\
& L_{2}=\text { probability a tag is active at the second downstream detection site. }
\end{aligned}
$$

The single release-recapture models used detection arrays at rkm 153, 113, 86.2, 49.6, 37.3, 22, and 8.3 , with arrays below 8.3 pooled as the final detection zone.

Estimates of tag life were treated as constants in calculations of survival and capture parameter estimates. However, to calculate a realistic variance estimator for the survival parameters, the error in the estimation of the tag-life probabilities was incorporated into an overall variance calculation (Townsend et al. 2006).

Table 2.4. Alternative parameterization for a two-release, release-recapture model with and without adjustments for probabilities of acoustic tags being active at downstream detection sites (i.e., $L_{1}$ and $\left.L_{2}\right)$.

\begin{tabular}{lll}
\hline & \multicolumn{2}{c}{ Expected Probabilities } \\
\cline { 2 - 3 } Detection History & \multicolumn{1}{c}{ No Adjustment } & \multicolumn{1}{c}{ Adjustment } \\
\hline 11 & $S_{1} p_{1} \lambda$ & $S_{1} p_{1} L_{2} \lambda$ \\
01 & $S_{1}\left(1-p_{1}\right) \lambda$ & $S_{1}\left(1-p_{1}\right) L_{2} \lambda$ \\
10 & $S_{1} p_{1} \lambda$ & $S_{1} p_{1}\left(L_{1}-L_{2} \lambda\right)$ \\
00 & $\left(1-S_{1}\right)+S_{1}\left(1-p_{1}\right)(1-\lambda)$ & $\left(1-S_{1}\right)+S_{1}\left[\left(1-L_{1}\right)+L_{1}\left(1-p_{1}\right)-L_{2}\left(1-p_{1}\right) \lambda\right]$ \\
\hline
\end{tabular}

The variance of the survival estimates was calculated using the total variance formula

$$
\operatorname{Var}(S)=\operatorname{Var}_{\hat{L}}[E(\hat{S} \mid \underset{\sim}{\hat{L}})]+E_{\hat{L}}[\operatorname{Var}(\hat{S} \mid \underset{\sim}{\hat{L}})]
$$

The above variance was therefore estimated in stages using the expression

$$
\widehat{\operatorname{Var}}(\hat{S})=s_{\hat{S} \mid \hat{L}}^{2}+\operatorname{Var}(\hat{S} \mid \hat{\sim})
$$


The second term in Equation 2.1 was derived from the maximum likelihood model for the tagging study, conditioning on the tag-life probabilities (i.e., $\underset{\sim}{\hat{L}}$ ). The first variance component in Equation 2.2 was calculated using bootstrap resampling techniques (Efron and Tibshirani 1993). Alternative estimates of $\underset{\sim}{\hat{L}}$ were computed by bootstrapping both the observed tag-life data and travel time data. For each estimated vector of tag-life parameters, survival was estimated using the likelihood model for the single release-recapture model. One thousand bootstrap estimates of the tag-life parameters were calculated along with the corresponding conditional maximum likelihood estimates of survival. The first variance component in Equation 2.2 was then estimated by the quantity

$$
s_{\hat{S} \mid \hat{L}}^{2}=\frac{\sum_{b=1}^{1000}\left(\hat{S}_{b}-\hat{\bar{S}}\right)^{2}}{(1000-1)}
$$

where $\quad \hat{S}_{b}=$ the $b$ th bootstrap estimate of survival $(b=1, \ldots, 1000)$;

$$
\hat{\bar{S}}=\frac{\sum_{b=1}^{1000} \hat{S}_{b}}{1000}
$$

Use of Equations 2.1 and 2.2 also permitted examination of the contribution of the sampling error in the tag-life parameters to the overall variance in survival estimates.

\subsubsection{Tests of Equal Survival}

A statistical test of equal survival among alternative groups of fish (i.e., $\hat{S}_{i} ; i=1, \ldots, n$ ) was performed using the $F$-test

$$
F_{n-1, \infty}=\frac{s_{\hat{S}_{i}}^{2}}{\widehat{\operatorname{Var}}\left(\hat{S}_{i} \mid S_{i}\right)}
$$

where

$$
\begin{aligned}
& s_{\hat{S}_{i}}^{2}=\frac{\sum_{i=1}^{n}\left(\hat{S}_{i}-\hat{\bar{S}}\right)^{2}}{(n-1)}, \\
& \hat{\bar{S}}=\frac{\sum_{i=1}^{n} \hat{S}_{i}}{n}, \\
& \widehat{\widehat{\operatorname{Var}}\left(\hat{S}_{i} \mid S_{i}\right)}=\frac{\sum_{i=1}^{n} \widehat{\operatorname{Var}}\left(\hat{S}_{i} \mid S_{i}\right)}{n} .
\end{aligned}
$$

This $F$-test has $n-1$ and $\infty$ degrees of freedom. $P$-values of the $F$-tests were reported and significance interpreted at $\alpha=0.05$. 


\subsection{Migration Behavior}

The behavior of fish as they migrate through the lower Columbia River and estuary can have important implications for survival. This section describes how migration behavior is measured and summarized for groups of individuals.

\subsubsection{Travel Time and Travel Rate}

Travel time was calculated for yearling and subyearling Chinook salmon and steelhead in the following reaches: from Knapp Point array (CR153.0) to the East Sand Island array (CR008.3), CR153.0 to the Cottonwood Island array (CR113.0), CR113.0 to the Oak Point array (CR086.2), CR086.2 to the Three Tree Point array (CR049.6), CR049.6 to the Astoria Bridge array (CR022.0), and CR022.0 to CR008.3 (

Table 2.5). Travel time was calculated for each fish detected at both the upstream and downstream arrays by subtracting the date and time of first detection at the upstream array from the date and time of first detection at the downstream array. Fish travel times were grouped into five virtual-release groups by date of first detection at rkm 153. Travel rate was calculated from each travel time by dividing the travel time by the distance between the arrays. Because calculation of travel time requires detection at both the upstream and downstream arrays, estimates of travel time and travel rate within each reach only consider fish that successfully migrated through the entire reach and were detected at both arrays.

Table 2.5. Reaches for travel rate calculations. Travel rates were calculated for five contiguous sections of the study area, beginning at the Knapp Point array at rkm 153 and ending at the East Sand Island array at rkm 8.3. Reaches are named for the array at their downstream end.

\begin{tabular}{ll}
\hline \multicolumn{1}{c}{ Reach } & \multicolumn{1}{c}{ Description of Downstream Array } \\
\hline CR153 to CR113 & Cottonwood Island Array \\
CR113 to CR086.2 & Oak Point Array \\
CR086.2 to CR049.6 & Three Tree Point Array \\
CR049.6 to CR022 & Astoria Bridge Array \\
CR022 to CR008.3 & East Sand Island Array \\
\hline
\end{tabular}

\subsubsection{Migratory Behavior}

Detections of acoustic-tagged fish on the six downstream-most arrays (CR086.2, CR049.6, CR037.3, CR022.0, CR008.3, and CR002.8) were used to identify the migration pathways used by fish to migrate through the lower $50 \mathrm{rkm}$ of the estuary and associated survival and travel time estimates. To identify the channels being used, the CR049.6, CR037.3, CR022.0, and CR008.3 arrays were divided into sub-arrays based on channel morphology (Figure 2.6). The three receivers in the CR049.6 array that were deployed across the navigation channel made up the Nav 50 sub-array and the single receiver in Clifton Channel made up the CC 50 sub-array. The four receivers in the CR037.3 array deployed across the navigation channel constituted the Nav 37 sub-array and the three receivers deployed in the deeper channels of Cathlamet Bay made up the CB 37 sub-array. At the CR022.0 array, the 10 receivers deployed in the Washington shoreline channel and the single receiver located near the middle of the Astoria-Megler bridge constituted the WA 22 sub-array. The remaining five receivers of the CR022.0 array, which were located in and around the navigation channel, made up the Nav 22 sub-array. Finally, at the CR008.3 array, the 11 receivers located in the Washington channel made up the WA 8 sub-array and the remaining 11 receivers, located in and around the navigation channel constituted the Nav 8 sub-array. 


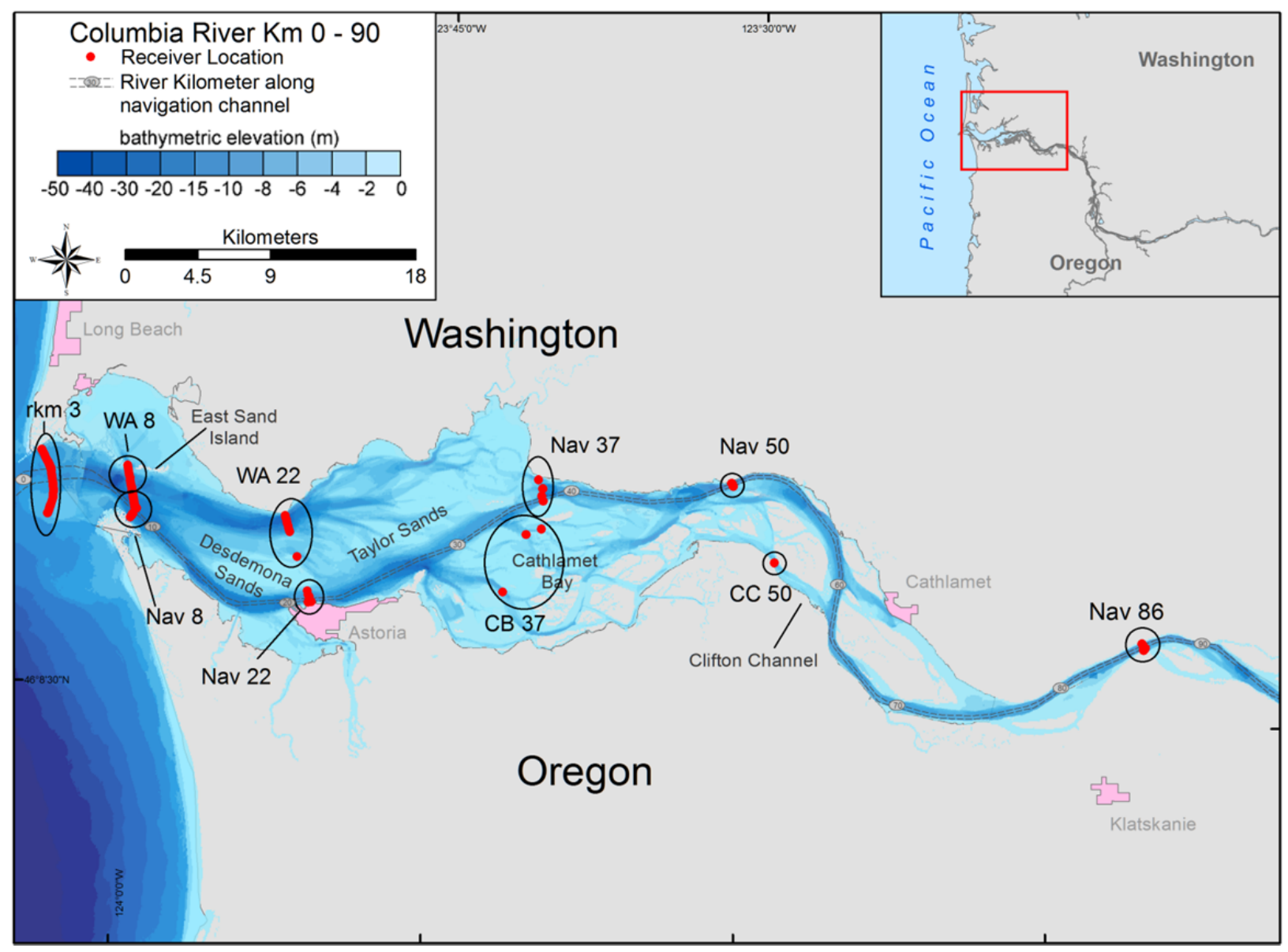

Figure 2.6. Locations of acoustic telemetry receiver sub-arrays (circled) used to determine migration pathways used by acoustic-tagged yearling and subyearling Chinook salmon and steelhead to migrate through the Columbia River estuary between river kilometer (rkm) 50 and the mouth. Sub-arrays are named with an abbreviation for their location followed by the rkm at which they were deployed. Sub-arrays in the navigation channel are labeled as Nav, and those in off-channel areas are labeled as CC (Clifton Channel), CB (Cathlamet Bay), and WA (Washington shoreline channel).

The date and time of detection were used to assign fish to a sub-array. At the array that marked the upstream boundary of a reach, fish were assigned to the sub-array at which the last valid detection occurred. This ensured that fish were assigned to the sub-array from which they migrated. At the array that marked the downstream boundary of a reach, fish were assigned to the sub-array at which the first valid detection occurred. This ensured that fish were assigned to the sub-array to which they initially migrated. All fish of the same species or run type that were assigned to a common sub-array at the upstream boundary of a reach formed a virtual release. The migration pathways, survival probabilities, and travel times were estimated for each virtual-release group from the upstream sub-array to the next downstream array in four reaches of the Columbia River estuary. The study reaches, as delineated by the arrays, were rkm 86.2 to 49.6 , rkm 49.6 to 37.3 , rkm $37.3-22.0$, and rkm 22.0 to 8.3 .

Because the detection probabilities of the sub-arrays may not have been equal due to differences in water depth or velocity, the proportion of fish from a virtual-release group that was detected at each subarray may not provide an accurate depiction of the real distribution of fish at an array. Therefore, the 
primary migration pathways were identified by calculating the joint probability of fish migrating to a downstream sub-array and being detected by that sub-array $(\zeta)$. This joint probability $(\zeta)$ was calculated at both downstream sub-arrays of each reach for each virtual-release group using the Cormack-JollySeber (CJS) model (Cormack 1964; Jolly 1965; Seber 1965).

To calculate $\zeta$, two separate detection histories (one for each downstream sub-array) were constructed for each virtual-release group; the sub-array of interest was treated as the primary array, and all downstream arrays were treated as the secondary arrays. For example, to calculate $\zeta$ at the Nav 37 subarray for a Nav 50 virtual-release group, fish that migrated from the Nav 50 sub-array that were first detected at the CR037.3 array by the Nav 37 sub-array would have a detection history of either " 11 " or "10," depending on whether or not they were detected by the secondary arrays (CR022.0, CR008.3, or CR002.8). Those same fish would have a detection history of " 01 " or " 00 " in the detection history used to calculate $\zeta$ at the CB 37 sub-array. Conversely, fish that migrated from the Nav 50 sub-array that were first detected at the CR037.3 array by the CB 37 sub-array would have a detection history of " 11 " or "10," and those same fish would have a detection history of " 01 " or " 00 " at the Nav 37 sub-array. Because some fish had a detection history of " 01 " at both sub-arrays, indicating they passed by one of the sub-arrays but went undetected or migrated through an area where receivers were not deployed, and because the sub-array past which undetected fish migrated cannot be determined, the probability of fish migrating through a sub-array area cannot be estimated separately from the detection probability.

Detection histories were loaded into program ATLAS (version 1.1.4) to calculate tag-life adjusted $\zeta$ values. Likelihood ratio tests were conducted, using program ATLAS, to determine whether $\zeta$ values differed significantly $(\alpha=0.05)$ between fish that migrated from different upstream sub-arrays to the same downstream sub-array. Because fish that migrated from different upstream sub-arrays would be expected to have equal probabilities of being detected by a downstream sub-array, significant differences in $\zeta$ values indicated that fish from one upstream sub-array were more likely to migrate to the downstream sub-array than fish that migrated from the other upstream sub-array. These differences were used to determine the primary migration pathway used by fish that migrated from each sub-array location.

Travel times were calculated and analyzed to determine the effect of migration pathway on the length of time Chinook salmon and steelhead smolts took to migrate through the Columbia River estuary. Travel times were calculated for each fish in each virtual-release group that was detected at the downstream array by subtracting the date and time of last detection at the upstream sub-array from the date and time of first detection at the downstream array. Because travel time data frequently were rightskewed, deviating from the normal distribution, median travel times were calculated for each virtualrelease group and nonparametric statistics were used. The Mann-Whitney rank sum test $(\alpha=0.05)$ was used to determine whether differences in travel times existed between virtual-release groups that migrated from different sub-arrays. Significant differences in travel time, coupled with differences in $\zeta$ values, would indicate that the migration pathway used to migrate through the reach affected travel time.

The probability of survival through a reach was estimated for each virtual-release group using the CJS model, adjusted for tag life by program ATLAS. Again, because the sub-array past which fish with a " 01 " detection history migrated undetected cannot be determined, survival could not be estimated to a sub-array. Therefore, survival probabilities were estimated for each virtual-release group from the upstream sub-array to the next downstream array using a single detection history, which combined detections from both downstream sub-arrays. Likelihood ratio tests were conducted, using program ATLAS, to determine whether survival probabilities differed significantly $(\alpha=0.05)$ between fish that 
migrated from different upstream sub-arrays to the next downstream array. Significant differences in survival probabilities, coupled with differences in $\zeta$ values, would suggest fish that migrated through different pathways had different probabilities of surviving through the reach.

Information regarding movement rates and array exit distributions of acoustic-tagged fish in the Columbia River plume was obtained from detections on the array of 20 autonomous receivers located off the mouth of the Columbia River to inform the experimental design of future studies to estimate survival of smolts in the near-shore ocean. Travel rate between the mouth of the Columbia River and the plume array were calculated based on the last detections on CR008.3 or CR002.8 and first detection on the plume array. Residence time in the mouth of the Columbia River/plume area was calculated based on the last detections on CR008.3 or CR002.8 and last detections on the plume array. To determine the spatial distribution of each acoustic-tagged group of juvenile salmonids, the array of 20 receivers was divided into three sub-arrays. The number of unique individuals last detected on each sub-array was divided by the total number of each group detected on the overall plume array.

\subsubsection{Cross-Channel Distribution}

The cross-channel distribution of each species/run type at arrays CR022.0, CR008.3, and CR002.8 was determined by analyzing the detections of acoustic-tagged fish on individual receivers within each array. The receiver location at which each fish was initially detected was considered the arrival point at the array. Receiver locations were based on the distance from reference points on the Oregon shore. The distance from the reference points to each receiver location was calculated using the Pythagorean Theorem. Tables of locations and distances for receivers of each array can be found in Appendix B and Appendix C.

The cross-channel distribution of each species and run type was calculated by dividing the number of fish that had their first detection at each receiver location by the total number of unique fish from that species and run type detected on the array. This proportion was multiplied by 100 for presentation as a percentage in the results section. The percentages of each species/run type that were first detected at each receiver location were then plotted against the calculated distance from the reference points at each array.

The locations of the three northernmost receivers in the Columbia River bar array (CR002.8) were moved upstream after 1 June 2010 due to a dredging project that precluded continued placement in that region. Receivers CR002.8_01, CR002.8_02, and CR002.8_03 were relocated upstream to a location near Jetty A (rkm 4.5). Therefore, the cross-channel distribution of subyearling Chinook salmon at the northernmost portion of the CR002.8 array was not presented.

\subsubsection{Diel Distribution}

To understand the timing of smolt presence in the study area, particularly as it may relate to avian predation exposure, we examined the diel distribution of tagged fish on JSATS arrays in the lower $50 \mathrm{~km}$ of the estuary. The diel distribution of smolt movements in the Columbia River estuary was determined from hourly fish detections on the Three Tree Point (CR049.6), Harrington Point (CR037.3), Astoria Bridge (CR022.0), East Sand Island (CR008.3), and Columbia River bar (CR002.8) arrays. Fish from all three release locations (Roosevelt, The Dalles, and Hood River) that were subsequently detected at the CR153.0 array and formed into virtual-release groups were used to determine diel distributions. A total 
of 2,596 yearling Chinook salmon, 2,438 steelhead, and 3,022 subyearling Chinook salmon were included in the virtual-release groups at rkm 153. The number of fish from each species/run type detected during each hour of the day at each array was determined. The number of fish from each species/run type that were first detected during each hour was then divided by the total number of fish from that species/run type detected at that array. This proportion was multiplied by 100 for presentation as a percentage in the results section. Plots of the percentage of fish detected each hour were created for each group of fish at each array. Bars indicating approximate hours of darkness were placed beginning 1 hour after sunset and ending 1 hour before sunrise. Average sunrise and sunset times were calculated from the sunrise and sunset times of the first and last day of detection for each group of fish, based on data downloaded from the U.S. Naval Observatory website for Astoria, Oregon (available at http://www.usno.navy.mil/USNO/astronomical-applications/data-services/rs-one-year-us).

\subsubsection{Tidal Influence}

Relationships between detections and tides were evaluated from detections of acoustic-tagged smolts at the Three Tree Point (CR049.6), Harrington Point (CR037.3), Astoria Bridge (CR022.0), East Sand Island (CR008.3), and Columbia River bar (CR002.8) arrays. First, the initial detection of each fish at each array was assigned to a 5-minute time window. Using the tide-generating software WXTide32 (http://www.wxtide32.com/), tide elevation estimates were generated in 5-minute increments for periods during which tagged fish were migrating through the estuary. The station "Knappa, Knappa Slough, Columbia River, Oregon (t)" was used to determine the tide at array CR049.6, station "Harrington Point, Columbia River, Washington (t)" was used for CR037.3, station "Astoria (Port Docks), station "Columbia River, Oregon (t)" was used for CR022.0, station "Columbia River: Chinook, Baker Bay (t)" was used for CR008.3, and station "Columbia River: Entrance, N. jetty (t)" was used for CR002.8. The rate of change between each 5-minute period was then calculated, and associated with each of the fish detections. Rates of tide change were grouped into bins $(0.5 \mathrm{~cm} / 5 \mathrm{~min})$ and the percentage of first detections that fell into each bin was calculated. Percentages of detections of yearling and subyearling Chinook salmon and steelhead were plotted against the change in tide. The frequency of each tide change $(0.5 \mathrm{~cm} / 5 \mathrm{~min})$ was also calculated during the time each species or run type was passing each array by dividing the number of tide changes in each bin that occurred between the first and last fish detections by the total number of tide changes $(0.5 \mathrm{~cm} / 5 \mathrm{~min})$ that occurred between the first and last detections. Fish were split into virtualrelease groups based on the date of first detection at CR153.0. The number of fish first detected during each tide change at a particular array was divided by the total number of fish from that group detected at that array and multiplied by 100 . Plots of the percentage of fish from each group detected during each tide change were created for each species/run type at each array.

\subsubsection{Avian Predation}

PIT-tag detections of acoustic-tagged fish at the East Sand Island bird colonies were obtained from NOAA Fisheries. Detections were summarized by the colony on which the tags were detected (Caspian tern or double-crested cormorant) and the week of virtual release at the CR153.0 array for each species and run-type. 


\subsection{Results}

The results section includes a brief summary of the environmental conditions in the lower Columbia River and estuary in the spring and summer of 2010 to provide context for the detailed results on the migratory behavior and estimated survival of the acoustic-tagged fish used in the this study. Further, to address the question of 'representativeness', the fish size information is presented to show how the fish that were tagged and used in this study related to the general run-at-large passing through the JBS at JDA. The tag life and detection probability information for the JSATS used in 2010 are presented to provide the necessary background information on system performance. Survival probability estimates are presented for each of three species/rear-types of juvenile salmonid smolts over a variety of temporal and spatial scales to elucidate the relationships between passage of these tagged fish through the lower three dams of the FCRPS and beyond the lowermost dam to the mouth of the Columbia River. Additional information on the migratory behavior of the tagged fish in the estuary and the Columbia River plume are provided to provide context for avian predation losses and to facilitate design of a survival estimation study design, respectively.

\subsection{Environmental Conditions}

For the duration of the study, between deployment of the first acoustic receiver and recovery of the final receiver (26 April to 9 August 2010), total daily discharge at the Beaver Army Terminal (rkm 86) ranged from 4,021 to $14,838 \mathrm{~m}^{3} / \mathrm{s}$ with a mean of $8,330 \mathrm{~m}^{3} / \mathrm{s}$ (Figure 3.1). Most ( $>90 \%$ ) of the yearling Chinook salmon and steelhead passed between rkm 153 and 2.8 prior to the spring freshet, while most of the subyearling Chinook salmon were detected on the declining limb of the spring freshet (Figure 3.1).

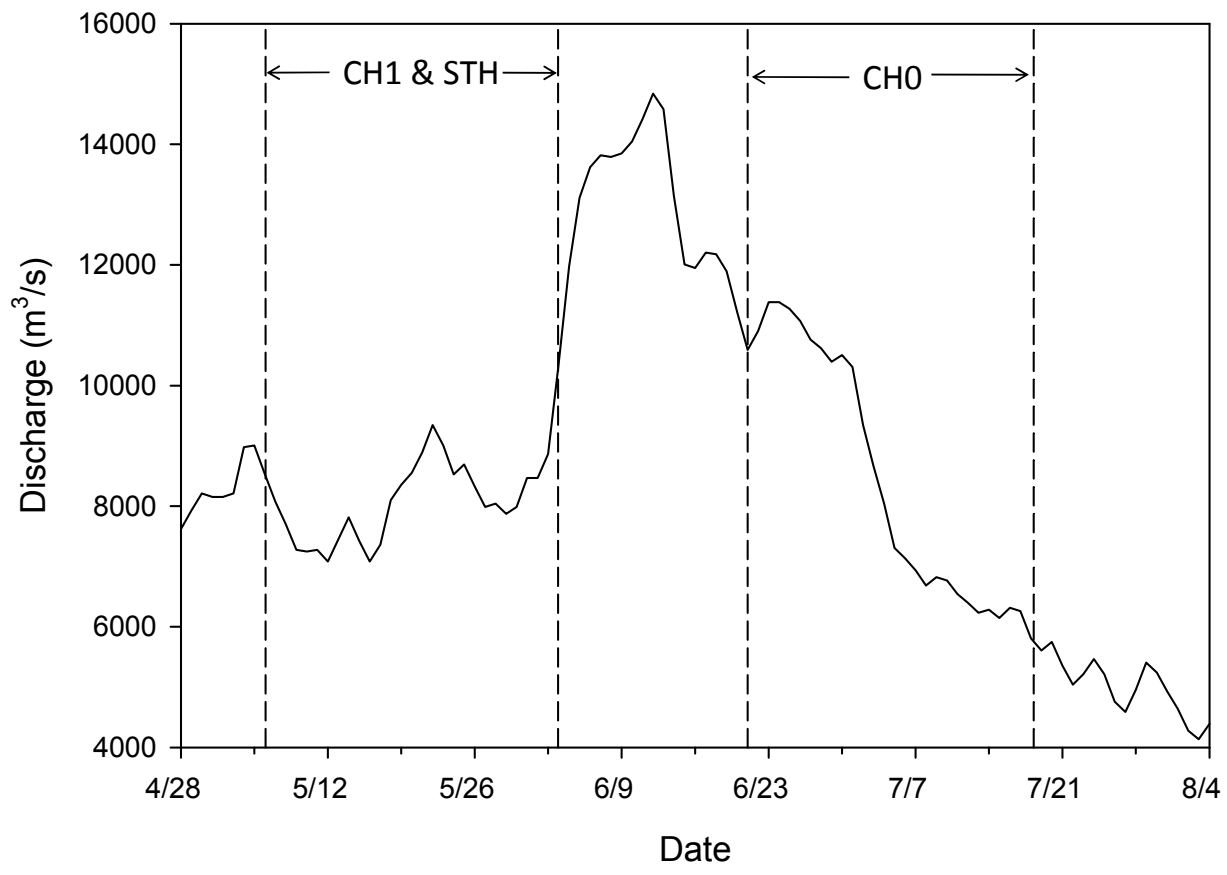

Figure 3.1. Average daily water discharge $\left(\mathrm{m}^{3} / \mathrm{s}\right)$ of the Columbia River at the Beaver Army Terminal (rkm 86) during the 2010 study period. The dashed lines represent the dates when the 90th percentile of acoustic-tagged fish from the two runs (spring; CH1 and STH and summer; $\mathrm{CH} 0$ ) were detected in the study area (CR153.0 and CR002.8). 
Daily water temperatures in the forebay of Bonneville Dam ranged from 10.6 to $21.7^{\circ} \mathrm{C}$ with a mean temperature of $16.0^{\circ} \mathrm{C}$ during the 2010 study period. For the majority of the 2010 spring and summer seasons, forebay water temperatures were at or below the 10-year average; however, the peak summer temperature was higher in 2010 than the 10-year average. Still, a temporal warming trend, similar to that of the 10-year average, was observed in 2010 (Figure 3.2).

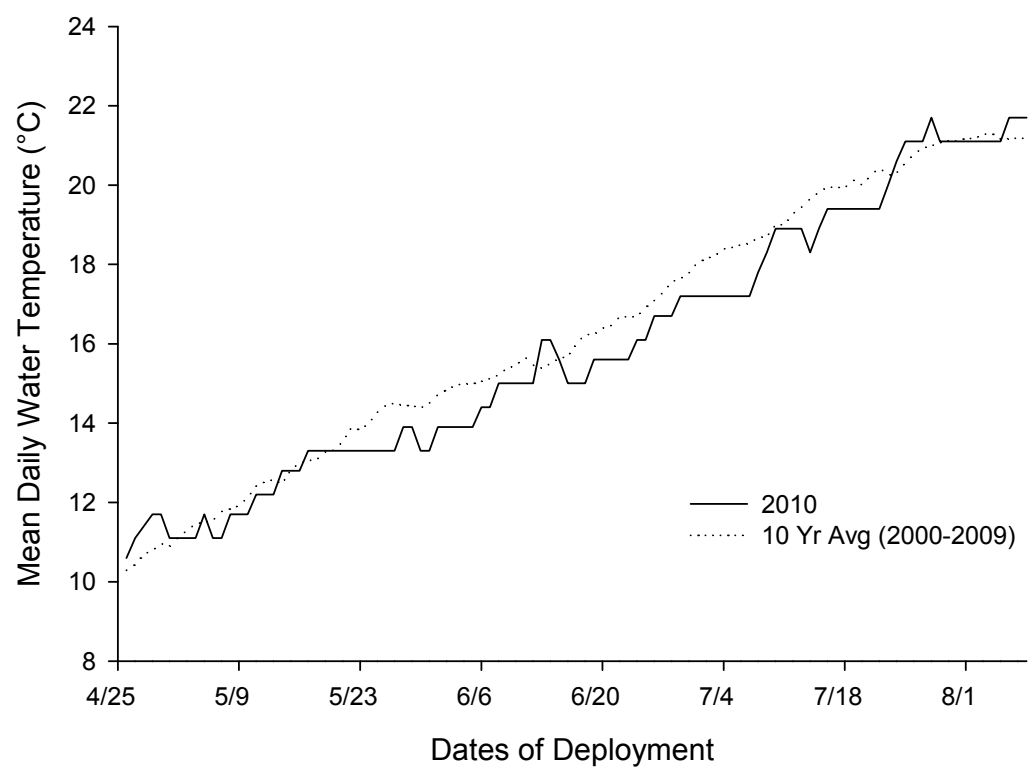

Figure 3.2. Average daily water temperature $\left({ }^{\circ} \mathrm{C}\right)$ in the Bonneville Dam forebay during the 2010 study period and the preceding 10-year average for the same range of dates.

\subsection{Smolt Migration Timing and Fish Size}

The spring and summer tagging seasons corresponded well with the run timing of the general population at John Day Dam. The release of tagged fish was initiated during the spring season after about $6 \%$ of the general yearling Chinook salmon and steelhead populations had passed John Day Dam (Figure 3.3). The releases of implanted yearling Chinook salmon and steelhead ended once about 84\% and $79 \%$ of the general yearling Chinook salmon and steelhead populations, respectively, had passed John Day Dam.

During the summer season, releases of tagged subyearling Chinook salmon began after about $9 \%$ of the general subyearling Chinook salmon population had passed John Day Dam and ended once about $88 \%$ of the general population had passed (Figure 3.3).

The distributions of lengths of tagged yearling and subyearling Chinook salmon and steelhead were similar to those of the untagged populations (Figure 3.4, Figure 3.5, and Figure 3.6). Of the fish sampled as part of the smolt monitoring program at John Day Dam, 100\% of yearling Chinook salmon and steelhead and $91 \%$ of subyearling Chinook salmon were larger than the 95 -mm transmitter implantation threshold. 


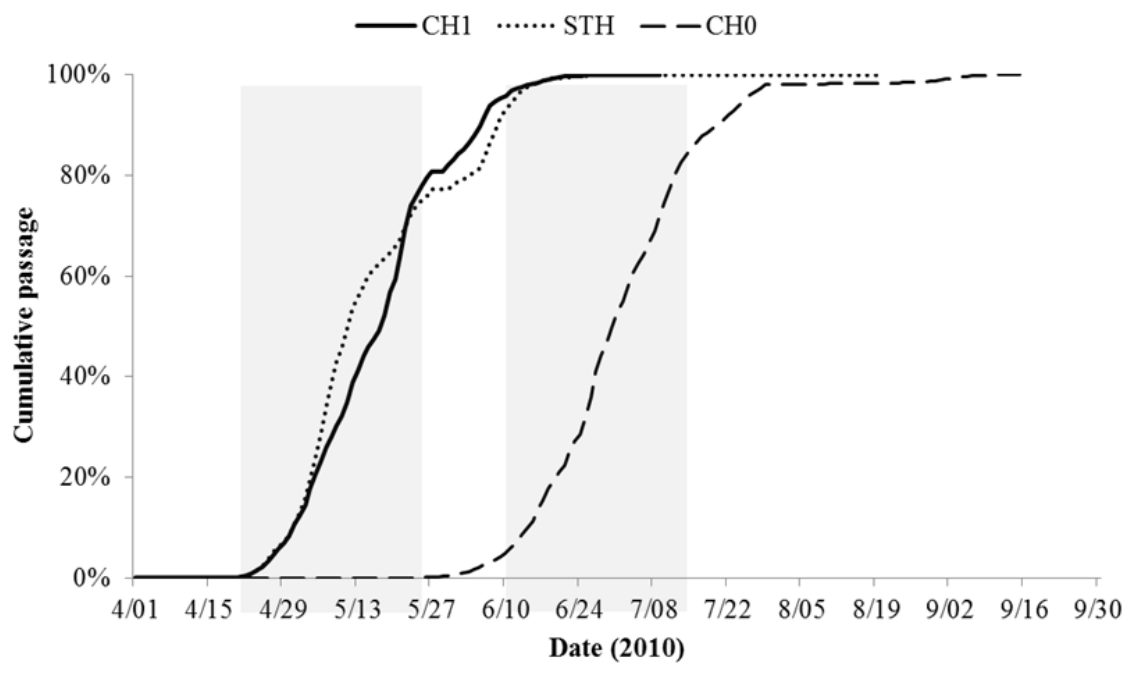

Figure 3.3. The cumulative passage percentage of yearling (CH1) and subyearling Chinook salmon (CH0) and steelhead (STH) smolts that emigrated past John Day Dam and the timing of tagging operations in 2010 (shaded areas).

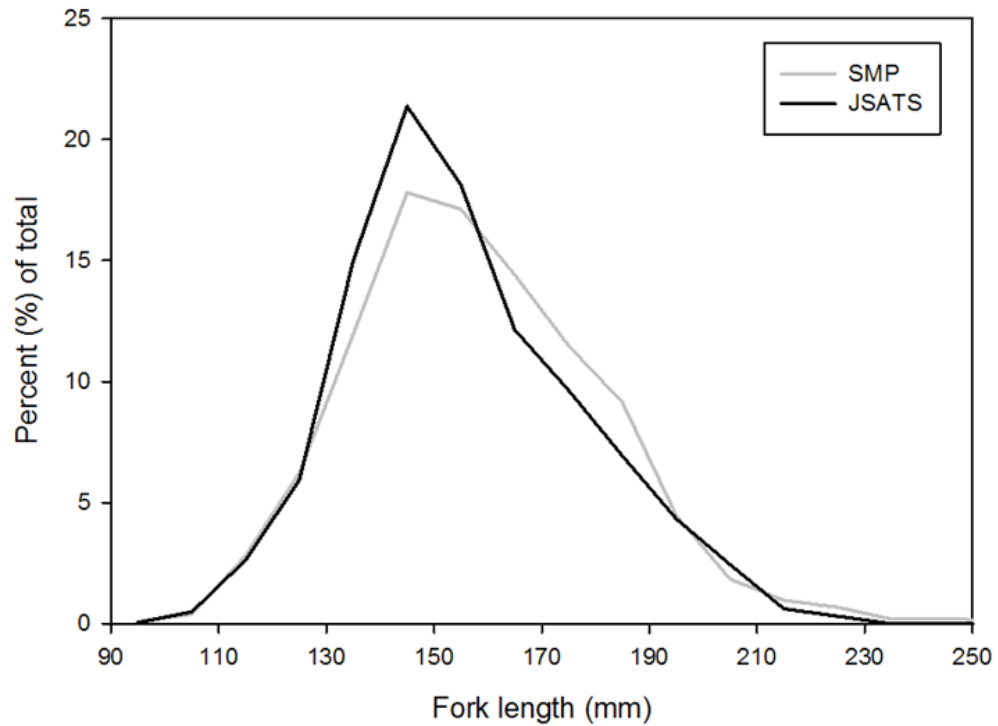

Figure 3.4. Length frequency distributions for tagged (JSATS) and untagged yearling Chinook salmon from the Smolt Monitoring Program (SMP) sampling at John Day Dam in 2010. 


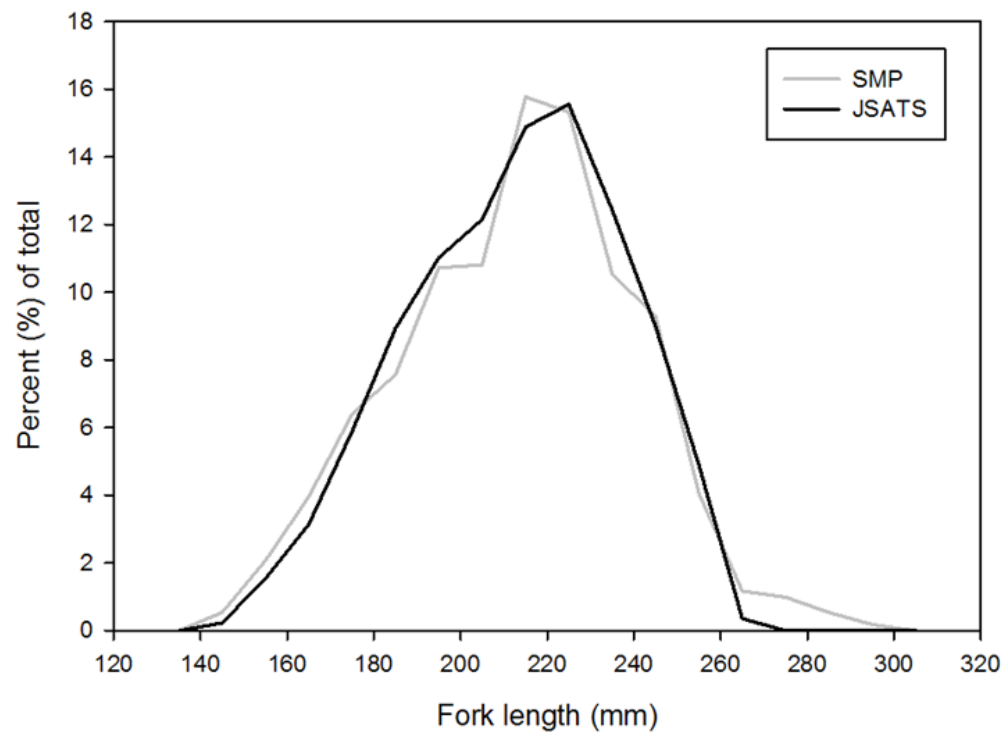

Figure 3.5. Length frequency distributions for tagged and untagged steelhead from the Smolt Monitoring Program (SMP) sampling at John Day Dam in 2010.

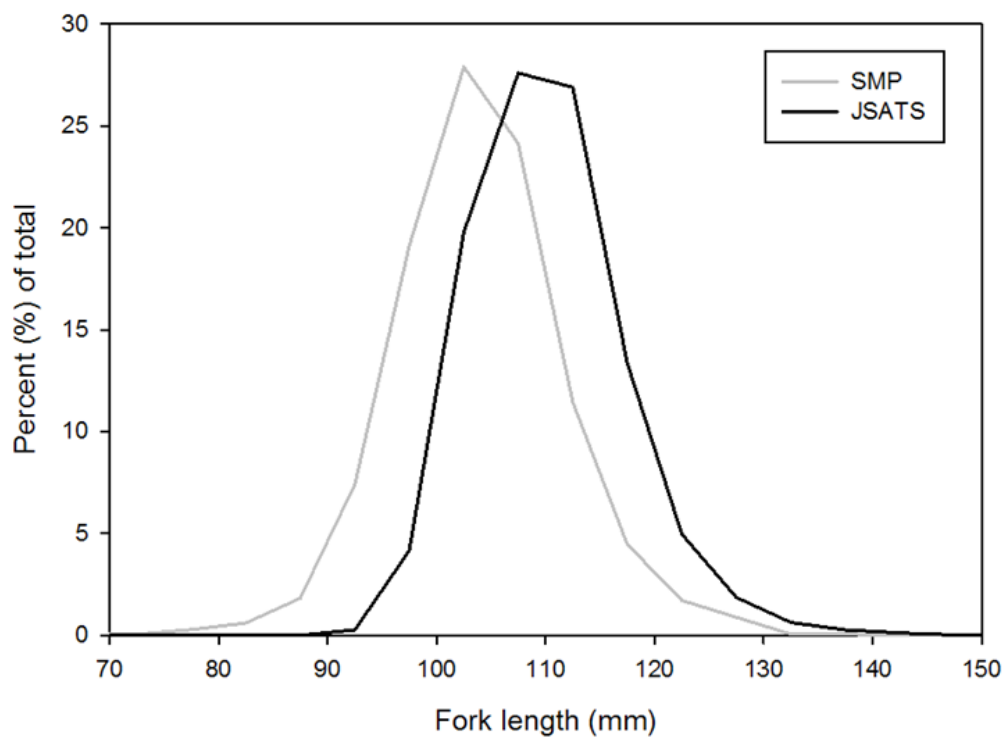

Figure 3.6. Length frequency distributions for tagged and untagged subyearling Chinook salmon from the Smolt Monitoring Program (SMP) sampling at John Day Dam in 2010.

\subsection{JSATS Performance}

Transmitter (tag) life and detection probability on receiver arrays used to estimate survival probabilities may have profound effects on the quality of these estimates. This section provides the results of tag life tests as well as details on the probability that JSATS transmitters were detected on the receiver arrays used to estimate survival probabilities in the lower Columbia River and estuary in 2010. 


\subsubsection{Tag-Life Studies}

Mean tag life for spring tags $(n=49)$ was $33.13(\mathrm{SE}=4.32)$ days. The earliest tag failure was at 7.8 days and the longest at 39.6 days. The failure-time data for the acoustic tags was fit to a fourparameter vitality model of $\mathrm{Li}$ and Anderson (2009). The maximum likelihood estimates for the four model parameters were $\hat{r}=0.02963, \hat{s}=-5.59145 \times 10^{-9}, \hat{k}=0.00173$, and $\hat{u}=0.05730$. This tag-life survivorship model was subsequently used to estimate the probabilities of tag failure and provide tag-life adjusted estimates of smolt survival for yearling Chinook salmon (Figure 3.7) and steelhead (Figure 3.8).

Mean tag life for summer tags $(n=50)$ was $35.54(\mathrm{SE}=2.10)$ days. The earliest tag failure was at 31.27 days and the longest at 40.13 days. The failure-time data for the acoustic tags was fit to a fourparameter vitality model of $\mathrm{Li}$ and Anderson (2009). The maximum likelihood estimates for the four model parameters were $\hat{r}=0.028261, \hat{s}=-2.91111 \times 10^{-9}, \hat{k}=0$, and $\hat{u}=0.058789$ (Figure 3.9). This tag-life survivorship model was subsequently used to estimate the probabilities of tag failure and provide tag-life adjusted estimates of smolt survival for subyearling Chinook salmon.

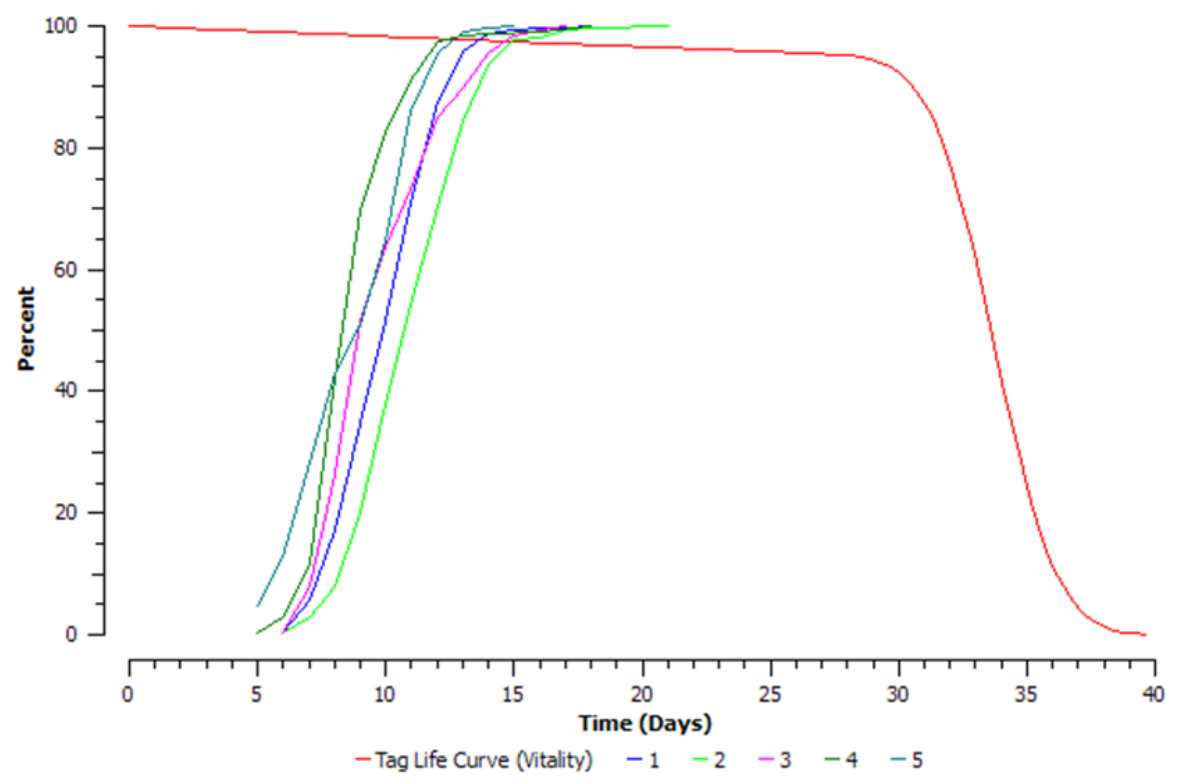

Figure 3.7. Percentage of acoustic transmitters still active by days since activation (tag life) and the percentage of yearling Chinook salmon first detections at the mouth of the Columbia River (arrays CR008.3 and CR002.8) by days since tag activation in 2010. Series numbers denote virtual-release groups. 


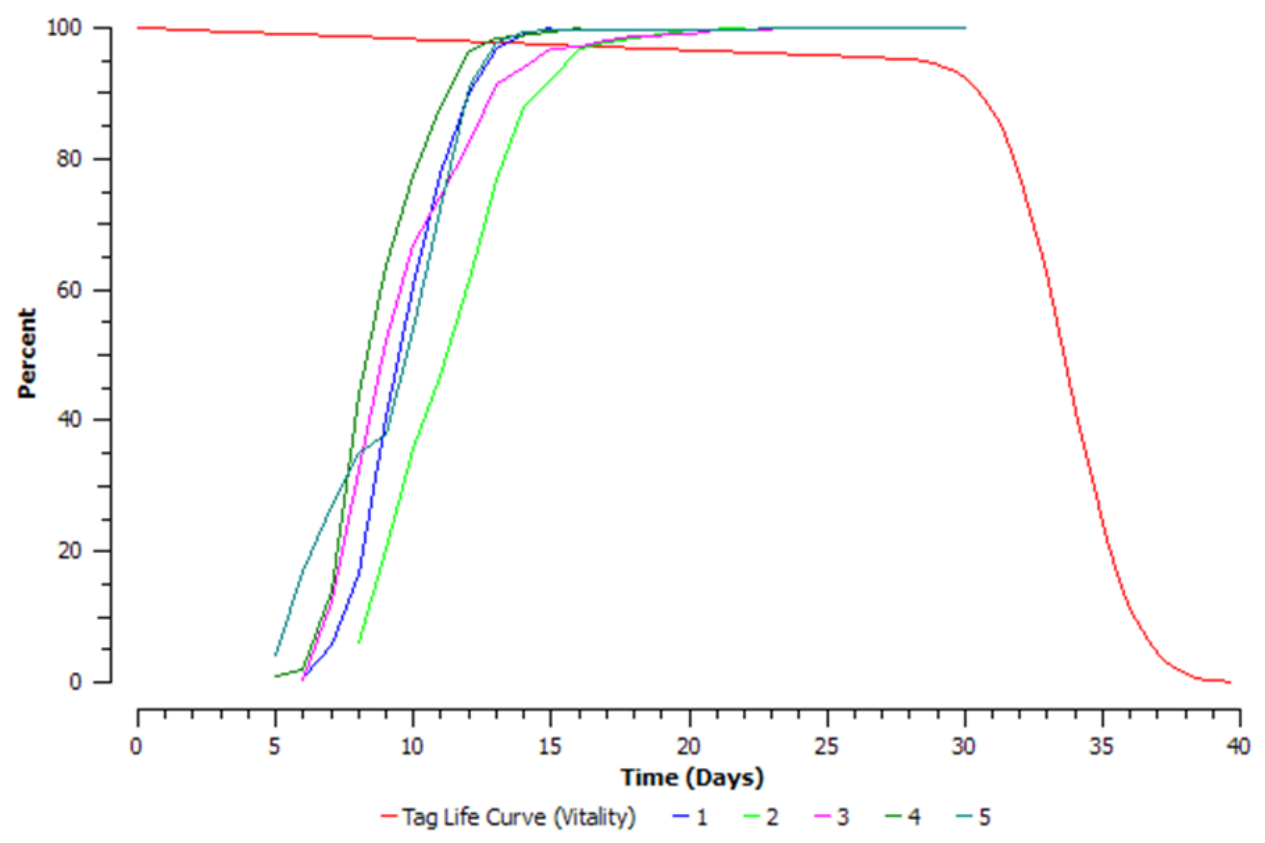

Figure 3.8. Percentage of acoustic transmitters still active by days since activation (tag life) and the percentage of steelhead first detections at the mouth of the Columbia River (arrays CR008.3 and CR002.8) by days since tag activation in 2010. Series numbers denote virtual-release groups.

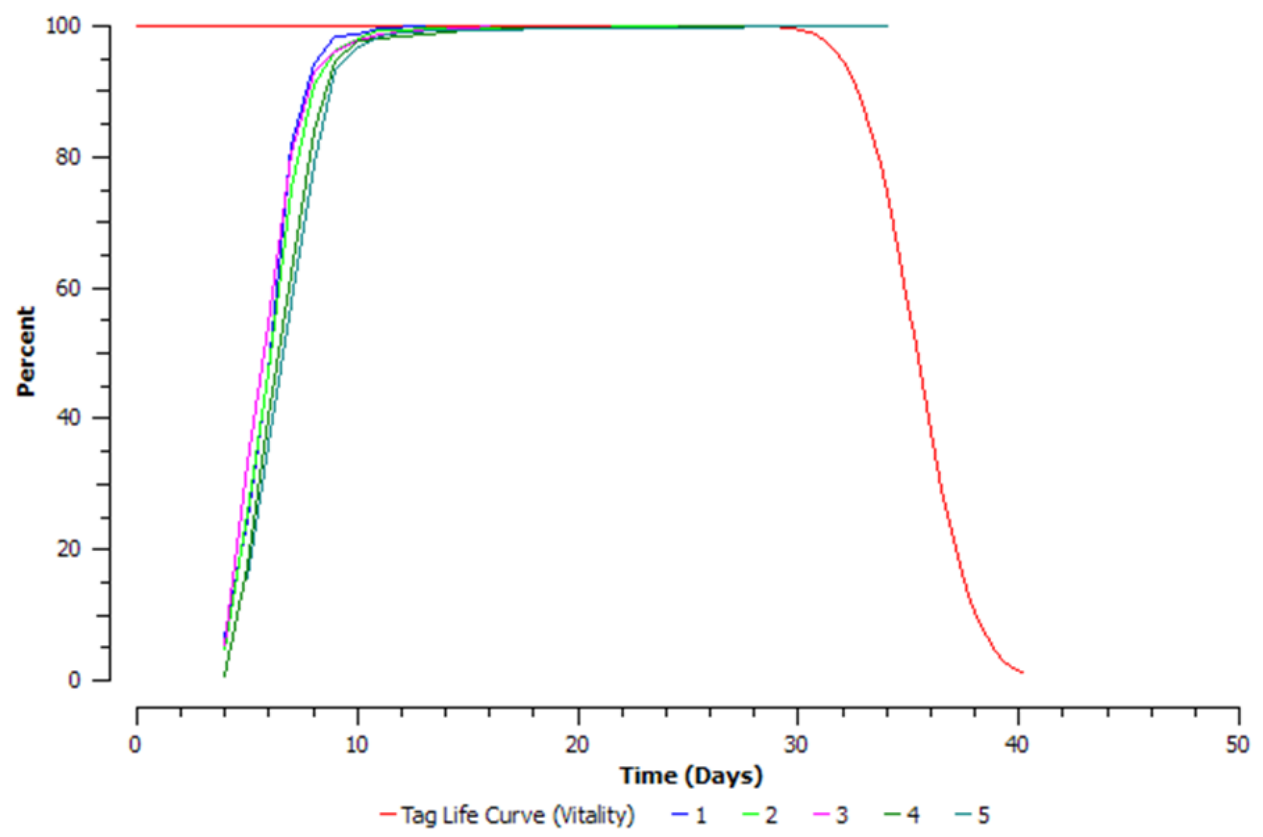

Figure 3.9. Percentage of acoustic transmitters still active by days since activation (tag life) and the percentage of subyearling Chinook salmon first detections at the mouth of the Columbia River (arrays CR008.3 and CR002.8) by days since tag activation in 2010. Series numbers denote virtual-release groups. 


\subsubsection{Array Detection Probability}

Detection probability varied by array, and for most arrays, by season (Table 3.1). The overall detection probability (all virtual-release groups pooled) of the CR113.0 array was 0.94 for yearling Chinook salmon and steelhead and 0.95 for subyearling Chinook salmon. Detection probability of the CR113.0 array remained relatively high throughout the spring season, varying from 0.86 to 0.98 for yearling Chinook salmon and steelhead virtual-release groups. Detection probability remained high throughout the summer season as well, varying from 0.92 to 0.97 for subyearling Chinook salmon virtualrelease groups. However, a trend was observed in which detection probability increased as the summer season progressed, which was correlated with decreasing discharge.

Table 3.1. Acoustic telemetry detection probability (and SE) of JSATS-tagged fish at autonomous receiver arrays in the lower Columbia River and estuary in 2010. Yearling Chinook salmon, steelhead, and subyearling Chinook salmon were grouped into virtual-release weeks based on their detection at rkm 153.

\begin{tabular}{|c|c|c|c|c|c|c|c|}
\hline Virtual release week & $\mathrm{N}$ & CR113.0 & CR086.2 & CR049.6 & CR037.3 & CR022.0 & CR008.3 \\
\hline \multicolumn{8}{|c|}{ Yearling Chinook salmon } \\
\hline $5 / 2-5 / 8$ & 584 & $0.98(0.01)$ & $0.98(0.01)$ & $0.80(0.02)$ & $0.75(0.02)$ & $0.72(0.02)$ & $0.89(0.02)$ \\
\hline $5 / 9-5 / 15$ & 611 & $0.97(0.01)$ & $0.97(0.01)$ & $0.69(0.02)$ & $0.60(0.02)$ & $0.67(0.02)$ & $0.79(0.02)$ \\
\hline $5 / 16-5 / 22$ & 485 & $0.97(0.01)$ & $0.97(0.01)$ & $0.71(0.02)$ & $0.64(0.02)$ & $0.79(0.02)$ & $0.90(0.02)$ \\
\hline $5 / 23-5 / 29$ & 500 & $0.86(0.02)$ & $0.98(0.01)$ & $0.69(0.02)$ & $0.51(0.02)$ & $0.69(0.02)$ & $0.76(0.03)$ \\
\hline $5 / 30-6 / 5$ & 427 & $0.88(0.02)$ & $0.95(0.01)$ & $0.69(0.02)$ & $0.65(0.02)$ & $0.68(0.02)$ & $0.94(0.02)$ \\
\hline Pooled & 2607 & $0.94(0.00)$ & $0.97(0.00)$ & $0.72(0.01)$ & $0.63(0.01)$ & $0.71(0.01)$ & $0.85(0.01)$ \\
\hline \multicolumn{8}{|c|}{ Steelhead } \\
\hline $5 / 2-5 / 8$ & 537 & $0.98(0.01)$ & $0.98(0.01)$ & $0.70(0.02)$ & $0.73(0.02)$ & $0.76(0.02)$ & $0.88(0.02)$ \\
\hline $5 / 9-5 / 15$ & 520 & $0.96(0.01)$ & $0.99(0.01)$ & $0.61(0.02)$ & $0.55(0.03)$ & $0.71(0.03)$ & $0.70(0.04)$ \\
\hline $5 / 16-5 / 22$ & 470 & $0.97(0.01)$ & $0.98(0.01)$ & $0.60(0.03)$ & $0.58(0.03)$ & $0.71(0.03)$ & $0.90(0.03)$ \\
\hline $5 / 23-5 / 29$ & 472 & $0.86(0.02)$ & $0.97(0.01)$ & $0.48(0.03)$ & $0.45(0.03)$ & $0.68(0.03)$ & $0.79(0.03)$ \\
\hline $5 / 30-6 / 5$ & 456 & $0.92(0.01)$ & $0.92(0.01)$ & $0.63(0.03)$ & $0.61(0.03)$ & $0.67(0.03)$ & $0.91(0.02)$ \\
\hline Pooled & 2455 & $0.94(0.00)$ & $0.97(0.00)$ & $0.61(0.01)$ & $0.59(0.01)$ & $0.71(0.01)$ & $0.83(0.01)$ \\
\hline \multicolumn{8}{|c|}{ Subyearling Chinook salmon } \\
\hline $6 / 14-6 / 20$ & 302 & $0.92(0.02)$ & $0.82(0.02)$ & $0.63(0.03)$ & $0.53(0.03)$ & $0.88(0.02)$ & $0.91(0.02)$ \\
\hline $6 / 21-6 / 27$ & 647 & $0.95(0.01)$ & $0.87(0.01)$ & $0.56(0.02)$ & $0.52(0.02)$ & $0.77(0.02)$ & $0.92(0.01)$ \\
\hline $6 / 28-7 / 4$ & 680 & $0.96(0.01)$ & $0.97(0.01)$ & $0.69(0.02)$ & $0.64(0.02)$ & $0.81(0.02)$ & $0.94(0.01)$ \\
\hline $7 / 5-7 / 11$ & 737 & $0.96(0.01)$ & $0.99(0.00)$ & $0.75(0.02)$ & $0.62(0.02)$ & $0.75(0.02)$ & $0.83(0.02)$ \\
\hline $7 / 12-7 / 18$ & 580 & $0.97(0.01)$ & $0.99(0.00)$ & $0.76(0.02)$ & $0.57(0.02)$ & $0.77(0.02)$ & $0.87(0.02)$ \\
\hline Pooled & 2946 & $0.95(0.00)$ & $0.94(0.00)$ & $0.68(0.01)$ & $0.58(0.01)$ & $0.79(0.01)$ & $0.89(0.01)$ \\
\hline
\end{tabular}


The overall detection probability of the CR086.2 array was also high for yearling Chinook salmon and steelhead (0.97) and subyearling Chinook salmon (0.94, Table 3.1). The detection probability of the CR086.2 array varied little throughout the spring season, ranging from 0.92 to 0.99 for yearling Chinook salmon and steelhead virtual-release groups. The detection probability remained relatively high throughout the summer, increasing from 0.82 to 0.99 as the season progressed. Similar to the CR113.0 array, the detection probability of the CR086.2 array was negatively correlated with discharge during the summer (Figure 3.10). Considerable seasonal variation in detection probability was observed at this array, with the highest probabilities recorded for the first virtual-release group of yearling Chinook salmon (0.80) and steelhead (0.70) before declining and leveling off around 0.70 for yearling Chinook and around 0.60 for steelhead.

At the CR049.6 array, the pooled detection probability was 0.72 for yearling Chinook salmon, 0.61 for steelhead, and 0.68 for subyearling Chinook salmon (Table 3.1). With the exception of the first subyearling Chinook salmon virtual-release group, the detection probability of the CR049.6 array increased as the summer season progressed and was negatively correlated with discharge during summer (Figure 3.11).

The CR037.3 array had the lowest overall detection probabilities of all the arrays in our study area, ranging from 0.58 for subyearling Chinook salmon to 0.63 for yearling Chinook salmon (Table 3.1). The detection probability of the CR037.3 array varied throughout the spring season from a high of 0.73 and 0.75 for the first steelhead and yearling Chinook salmon virtual-release groups, respectively, to a low of 0.45 and 0.51 for the fourth steelhead and yearling Chinook groups, respectively. The detection probability remained relatively stable throughout the summer season, ranging from 0.52 to 0.64 , with no clear seasonal trend. However, a moderately strong negative correlation was observed between the detection probability of the CR037.3 array and discharge during the summer season (Figure 3.11).

The pooled detection probability of the CR022.0 array was 0.71 for yearling Chinook salmon and steelhead and 0.79 for subyearling Chinook salmon (Table 3.1). Relatively little seasonal variation was observed; detection probability ranged from 0.67 to 0.79 for yearling Chinook salmon, 0.67 to 0.76 for steelhead, and 0.75 to 0.88 for subyearling Chinook salmon virtual-release groups. No clear seasonal trends in detection probability of the CR022.0 array were observed for the spring or summer seasons. The detection probability of the CR022.0 array was positively correlated with discharge (Figure 3.11). However, the correlation was relatively weak, being driven primarily by one data point.

The overall detection probability of the CR008.3 array was relatively high, ranging from 0.83 for steelhead to 0.89 for subyearling Chinook salmon (Table 3.1). Considerable seasonal variation in the detection probability of the CR008.3 array was observed, ranging from 0.70 to 0.94 for yearling Chinook salmon and steelhead virtual-release groups and from 0.83 to 0.94 for subyearling Chinook groups. No clear seasonal trends in detection probability and relatively weak to moderately strong positive correlations with discharge were observed for spring and summer migrants (Figure 3.11). 

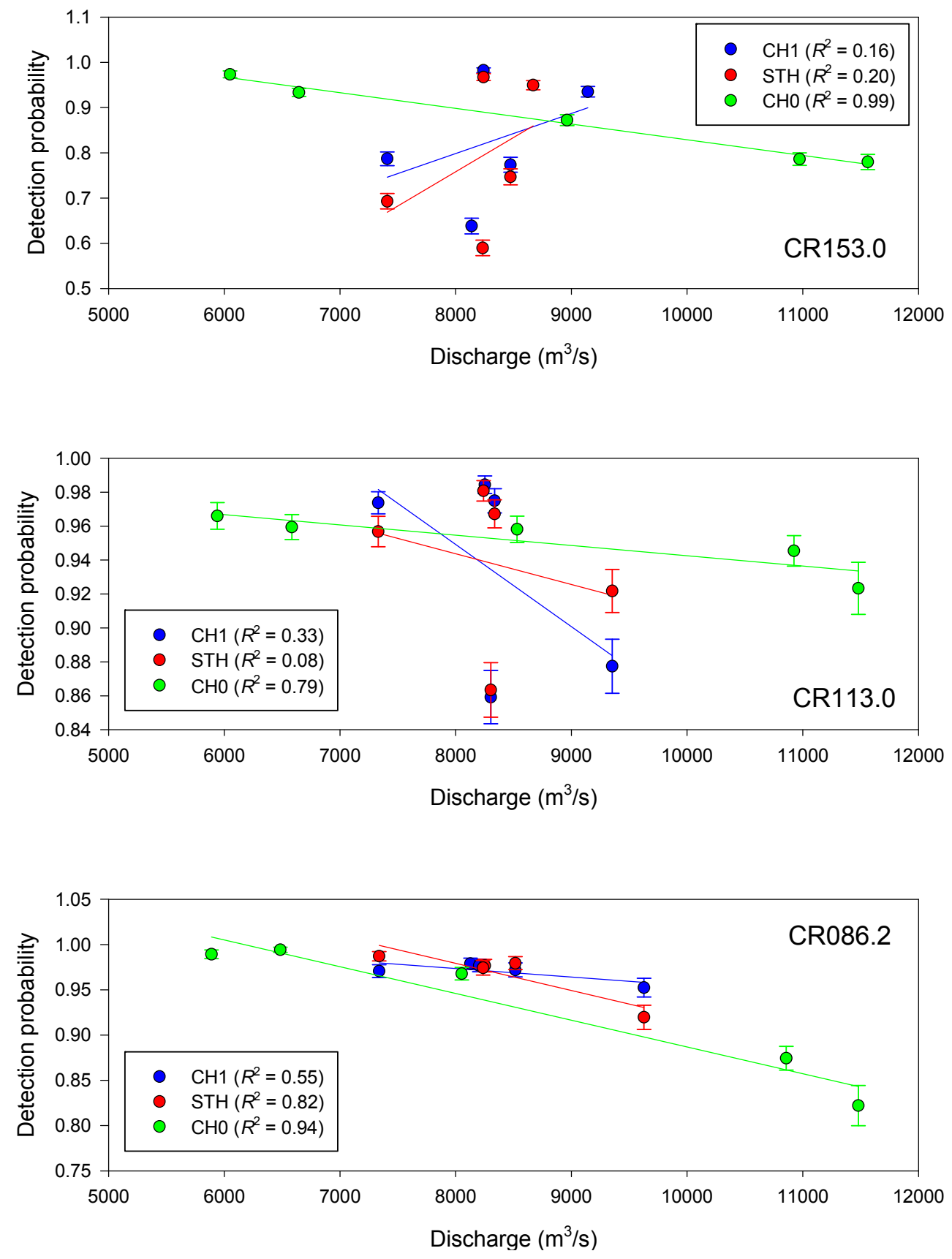

Figure 3.10. Detection probability of arrays at Knapp Point (CR153.0), Cottonwood Island (CR113.0), and Oak Point (CR086.2) for each virtual-release group of yearling Chinook salmon (CH1), steelhead (ST), and subyearling Chinook salmon (CH0) versus Columbia River discharge measured near Oak Point (rkm 86) in 2010. Error bars denote one standard error. 

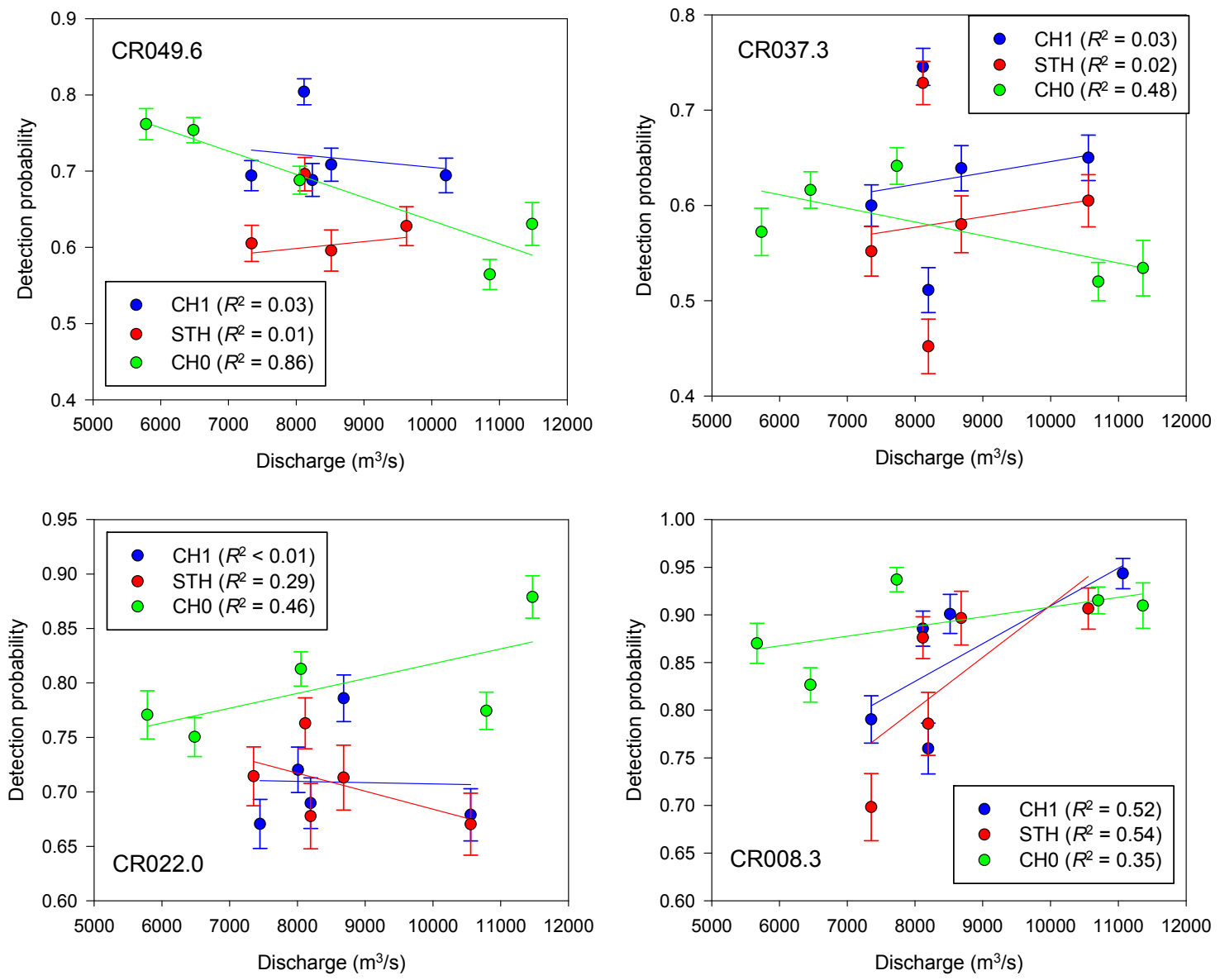

Figure 3.11. Detection probability of arrays at Three Tree Point (CR049.6), Harrington Point (CR037.3), the Astoria Bridge (CR022.0), and East Sand Island (CR008.3) for each virtual-release group of yearling Chinook salmon $(\mathrm{CH} 1)$, steelhead $(\mathrm{STH})$, and subyearling Chinook salmon (CH0) versus Columbia River discharge measured near Oak Point (rkm 86) in 2010. Error bars denote one standard error.

\subsection{Survival Probability}

Survival is an important metric for identifying when or where unfavorable conditions may exist. This section provides survival probability estimates focused on each time and place within the scope of the study.

\subsubsection{Seasonal and Spatial Trends in Survival}

The conditions fish experience differ both spatially and temporally. This section includes estimates of survival probability for weekly groups through each reach of the lower Columbia River and estuary. 


\subsubsection{Yearling Chinook Salmon}

Seasonal trends in yearling Chinook salmon smolt survival probability were calculated on a weekly basis over the outmigration season (Table 3.2). Cumulative survival probability estimates from rkm 153 to rkm 8.3 varied significantly between weeks $(P=0.0001$, Table 3.2), with weeks 2 and 3 (i.e., $9-15$ May and 16-22 May 2010) having the lowest survival probabilities, and week 5 (i.e., 30 May - 6 June 2010), the highest survival probability estimate. Reach-specific survival probability estimates for the weekly fish groups were significantly different in reach rkm 37.3 to rkm $22.0(P=0.0069$, Table 3.3) with the week 3 (16-22 May 2010) group having the lowest survival probabilities and week 4 (23-29 May 2010), the highest survival probability estimate. Inspection of the cumulative survival curves for these five weekly groups of fish indicate the survival probability estimates became increasingly disparate as the fish moved downriver (Table 3.4, Figure 3.12).

Table 3.2. Weekly cumulative survival probability estimates for yearling Chinook salmon smolts from rkm 153 to rkm 8.3 with associated standard errors (SEs). $P$-value for test of homogeneous survival.

\begin{tabular}{cccc}
\hline & & \multicolumn{2}{c}{$\mathrm{Rkm} 153-\mathrm{Rkm} 8.3$} \\
\cline { 3 - 4 } Week starting & \# Fish & $\hat{S}$ & $\widehat{\mathrm{SE}}$ \\
\hline $5 / 2 / 2010$ & 577 & 0.8348 & 0.0180 \\
$5 / 9 / 2010$ & 601 & 0.8031 & 0.0226 \\
$5 / 16 / 2010$ & 478 & 0.8079 & 0.0213 \\
$5 / 23 / 2010$ & 494 & 0.8769 & 0.0232 \\
$5 / 30 / 2010$ & 417 & 0.9198 & 0.0167 \\
\cline { 3 - 4 } & & \multicolumn{3}{c}{$P$-value $=0.0001$} \\
\hline
\end{tabular}


Table 3.3. Reach-specific survival probability estimates for yearling Chinook salmon smolts from rkm 153 to rkm 8.3 on a weekly basis, 2 May to 5 June 2010. The season-wide estimate is a weighted average of weekly survival probabilities by release size.

\begin{tabular}{|c|c|c|c|c|c|c|c|c|c|c|c|c|c|}
\hline \multirow[b]{2}{*}{ Week beginning } & \multirow[b]{2}{*}{$N$} & \multicolumn{2}{|c|}{ Rkm 153 to 113} & \multicolumn{2}{|c|}{ Rkm 113 to 86.2} & \multicolumn{2}{|c|}{$\mathrm{Rkm} 86.2$ to 49.6} & \multicolumn{2}{|c|}{ Rkm 49.6 to 37.3} & \multicolumn{2}{|c|}{$\mathrm{Rkm} 37.3$ to 22.0} & \multicolumn{2}{|c|}{ Rkm 22.0 to 8.3} \\
\hline & & Estimate & SE & Estimate & SE & Estimate & SE & Estimate & SE & Estimate & SE & Estimate & SE \\
\hline $5 / 2 / 2010$ & 577 & 0.9957 & 0.0030 & 0.9973 & 0.0025 & 1.0015 & 0.0051 & 0.9684 & 0.0119 & 0.9266 & 0.0159 & 0.9354 & 0.0168 \\
\hline $5 / 9 / 2010$ & 601 & 0.9976 & 0.0024 & 1.0002 & 0.0018 & 0.9755 & 0.0102 & 0.9597 & 0.0155 & 0.9712 & 0.0193 & 0.8852 & 0.0253 \\
\hline $5 / 16 / 2010$ & 478 & 0.9969 & 0.0030 & 0.9929 & 0.0043 & 0.9898 & 0.0098 & 0.9599 & 0.0167 & 0.9197 & 0.0187 & 0.9340 & 0.0195 \\
\hline $5 / 23 / 2010$ & 494 & 0.9876 & 0.0054 & 0.9941 & 0.0041 & 0.9826 & 0.0086 & 0.9919 & 0.0133 & 0.9893 & 0.0178 & 0.9262 & 0.0252 \\
\hline $5 / 30 / 2010$ & 417 & 0.9991 & 0.0025 & 0.9955 & 0.0039 & 0.9982 & 0.0059 & 0.9901 & 0.0104 & 0.9817 & 0.0137 & 0.9534 & 0.0171 \\
\hline \multicolumn{2}{|l|}{ Season-wide } & 0.9954 & 0.0020 & 0.9963 & 0.0013 & 0.9891 & 0.0050 & 0.9728 & 0.0070 & 0.9568 & 0.0143 & 0.9245 & 0.0116 \\
\hline \multicolumn{2}{|l|}{$P$-value $(F$-test $)$} & \multicolumn{2}{|c|}{0.1405} & \multicolumn{2}{|c|}{0.6326} & \multicolumn{2}{|c|}{0.1701} & \multicolumn{2}{|c|}{0.2516} & \multicolumn{2}{|c|}{0.0069} & \multicolumn{2}{|c|}{0.2190} \\
\hline
\end{tabular}

Table 3.4. Cumulative reach survival probability estimates for yearling Chinook salmon smolts from rkm 153 to rkm 8.3 on a weekly basis, 2 May to 5 June 2010. The season-wide estimate is a weighted average of weekly survival probabilities by release size.

\begin{tabular}{|c|c|c|c|c|c|c|c|c|c|c|c|c|c|}
\hline \multirow[b]{2}{*}{ Week beginning } & \multirow[b]{2}{*}{$N$} & \multicolumn{2}{|c|}{ Rkm 153 to 113} & \multicolumn{2}{|c|}{ Rkm 153 to 86.2} & \multicolumn{2}{|c|}{ Rkm 153 to 49.6} & \multicolumn{2}{|c|}{ Rkm 153 to 37.3} & \multicolumn{2}{|c|}{ Rkm 153 to 22.0} & \multicolumn{2}{|c|}{ Rkm 153 to 8.3} \\
\hline & & Estimate & $\mathrm{SE}$ & Estimate & $\mathrm{SE}$ & Estimate & $\mathrm{SE}$ & Estimate & SE & Estimate & $\mathrm{SE}$ & Estimate & $\mathrm{SE}$ \\
\hline $5 / 2 / 2010$ & 577 & 0.9957 & 0.0030 & 0.9930 & 0.0040 & 0.9944 & 0.0063 & 0.9629 & 0.0115 & 0.8923 & 0.0155 & 0.8348 & 0.0180 \\
\hline $5 / 9 / 2010$ & 601 & 0.9976 & 0.0024 & 0.9978 & 0.0030 & 0.9732 & 0.0105 & 0.9340 & 0.0148 & 0.9072 & 0.0180 & 0.8031 & 0.0226 \\
\hline $5 / 16 / 2010$ & 478 & 0.9969 & 0.0030 & 0.9897 & 0.0052 & 0.9797 & 0.0108 & 0.9404 & 0.0158 & 0.8650 & 0.0175 & 0.8079 & 0.0213 \\
\hline $5 / 23 / 2010$ & 494 & 0.9876 & 0.0054 & 0.9818 & 0.0063 & 0.9645 & 0.0104 & 0.9569 & 0.0143 & 0.9466 & 0.0163 & 0.8769 & 0.0232 \\
\hline $5 / 30 / 2010$ & 417 & 0.9991 & 0.0025 & 0.9945 & 0.0042 & 0.9927 & 0.0071 & 0.9828 & 0.0101 & 0.9648 & 0.0133 & 0.9198 & 0.0167 \\
\hline Season-wide & & 0.9954 & 0.0020 & 0.9916 & 0.0027 & 0.9807 & 0.0057 & 0.9540 & 0.0084 & 0.9129 & 0.0172 & 0.8443 & 0.0212 \\
\hline$P$-value ( $F$-test $)$ & & \multicolumn{2}{|c|}{0.1405} & \multicolumn{2}{|c|}{0.1483} & \multicolumn{2}{|c|}{0.1049} & \multicolumn{2}{|c|}{0.0838} & \multicolumn{2}{|c|}{0.0001} & \multicolumn{2}{|c|}{0.0001} \\
\hline
\end{tabular}




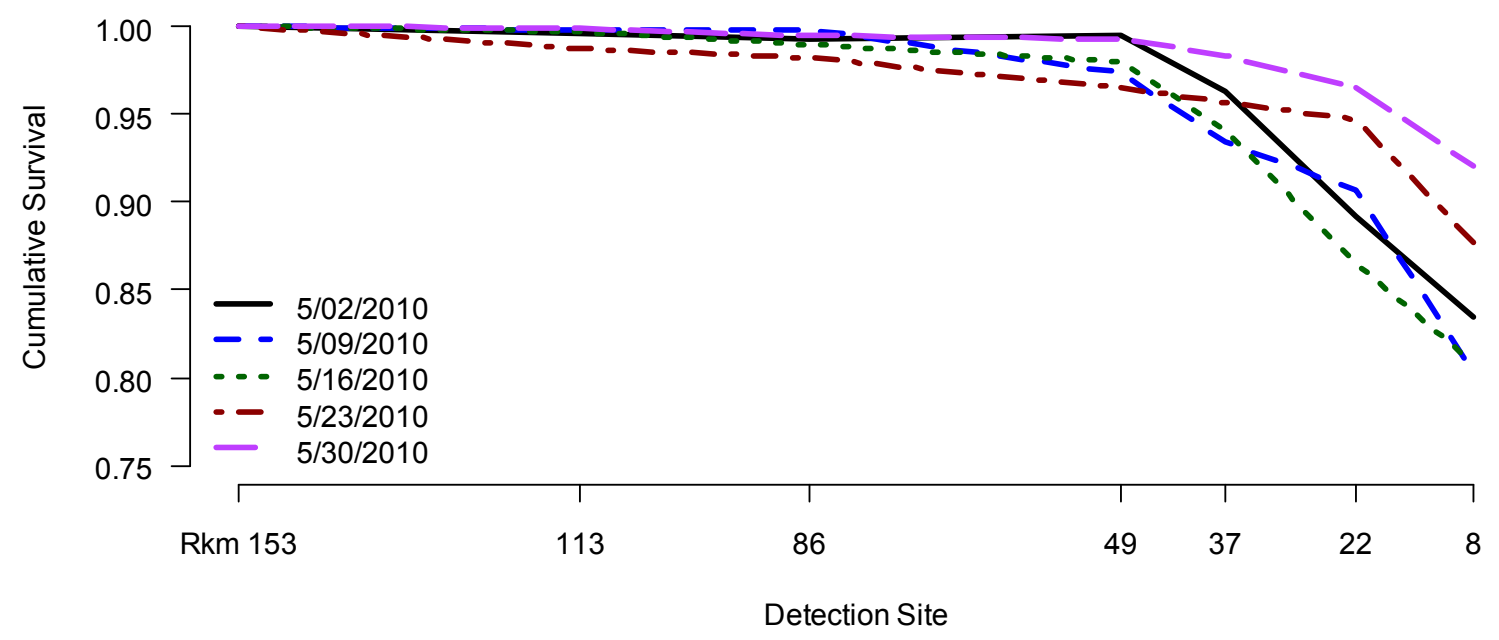

Figure 3.12. Cumulative survival probability estimate curves for yearling Chinook salmon smolts from rkm 153 to rkm 8.3 by week over the outmigration season.

\subsubsection{Steelhead}

Survival probability estimates from $\mathrm{rkm} 153$ to $\mathrm{rkm} 8.3$ were calculated weekly over the course of the steelhead spring survival study. Survival probabilities to rkm 8.3 were significantly different between weeks $(P=0.0038$, Table 3.5$)$. Similar to the trend observed for yearling Chinook salmon, survival probability was estimated to be the lowest in mid-season. No significant differences in reach-specific survival probability estimates were observed between the virtual-release groups in any of the individual reaches between rkm 153 and $\mathrm{rkm} 8.3$ ( $P \geq 0.0664$, Table 3.6). However, cumulative survival probabilities became more significant as fish migrated farther downriver (Table 3.7). The survivorship curves illustrate that the cumulative survivals on a weekly basis became more disparate as fish migrated below rkm 49.6 (Figure 3.13).

Table 3.5. Weekly cumulative survival probability estimates for steelhead smolts from rkm 153 rkm 8.3 with associated standard errors (SEs). $P$-value for test of homogeneous survival.

\begin{tabular}{cccc}
\hline & \multicolumn{3}{c}{ Rkm 153-Rkm 8.3 } \\
\cline { 2 - 4 } Week starting & \# Fish & $\hat{S}$ & $\widehat{\mathrm{SE}}$ \\
\hline $5 / 2 / 2010$ & 534 & 0.6446 & 0.0227 \\
$5 / 9 / 2010$ & 505 & 0.6472 & 0.0303 \\
$5 / 16 / 2010$ & 464 & 0.5246 & 0.0258 \\
$5 / 23 / 2010$ & 468 & 0.5763 & 0.0270 \\
$5 / 30 / 2010$ & 437 & 0.6147 & 0.0248 \\
& \multicolumn{3}{c}{$P$-value $=0.0038$} \\
\hline
\end{tabular}


Table 3.6. Reach-specific survival probability estimates for steelhead smolts from rkm 153 to rkm 8.3 on a weekly basis, 2 May to 30 May 2010 . The season-wide estimate is a weighted average of weekly survival probabilities by release size.

\begin{tabular}{|c|c|c|c|c|c|c|c|c|c|c|c|c|c|}
\hline \multirow[b]{2}{*}{ Week beginning } & \multirow[b]{2}{*}{$N$} & \multicolumn{2}{|c|}{$\mathrm{Rkm} 153$ to 113} & \multicolumn{2}{|c|}{ Rkm 113 to 86.2} & \multicolumn{2}{|c|}{$\mathrm{Rkm} 86.2$ to 49.6} & \multicolumn{2}{|c|}{$\mathrm{Rkm} 49.6$ to 37.3} & \multicolumn{2}{|c|}{ Rkm 37.3 to 22.0} & \multicolumn{2}{|c|}{ Rkm 22.0 to 8.3} \\
\hline & & Estimate & SE & Estimate & $\mathrm{SE}$ & Estimate & $\mathrm{SE}$ & Estimate & $\mathrm{SE}$ & Estimate & SE & Estimate & SE \\
\hline $5 / 2 / 2010$ & 534 & 0.9880 & 0.0050 & 0.9872 & 0.0055 & 0.9315 & 0.0144 & 0.9562 & 0.0180 & 0.8660 & 0.0226 & 0.8566 & 0.0241 \\
\hline $5 / 9 / 2010$ & 505 & 0.9874 & 0.0052 & 0.9933 & 0.0042 & 0.9790 & 0.0163 & 0.9439 & 0.0272 & 0.8584 & 0.0303 & 0.8319 & 0.0373 \\
\hline $5 / 16 / 2010$ & 464 & 0.9951 & 0.0038 & 0.9856 & 0.0064 & 0.9432 & 0.0242 & 0.8508 & 0.0341 & 0.7889 & 0.0331 & 0.8450 & 0.0320 \\
\hline $5 / 23 / 2010$ & 468 & 0.9843 & 0.0065 & 0.9839 & 0.0072 & 0.9658 & 0.0267 & 0.8974 & 0.0388 & 0.8325 & 0.0363 & 0.8247 & 0.0341 \\
\hline $5 / 30 / 2010$ & 437 & 0.9923 & 0.0046 & 0.9961 & 0.0052 & 0.9781 & 0.0192 & 0.8763 & 0.0280 & 0.8831 & 0.0295 & 0.8216 & 0.0288 \\
\hline Season-wide & & 0.9893 & 0.0019 & 0.9891 & 0.0023 & 0.9588 & 0.0097 & 0.9074 & 0.0201 & 0.8461 & 0.0161 & 0.8366 & 0.0066 \\
\hline$P$-value ( $F$-test) & & \multicolumn{2}{|c|}{0.5893} & \multicolumn{2}{|c|}{0.5183} & \multicolumn{2}{|c|}{0.3731} & \multicolumn{2}{|c|}{0.0664} & \multicolumn{2}{|c|}{0.2229} & \multicolumn{2}{|c|}{0.9304} \\
\hline
\end{tabular}

Table 3.7. Cumulative reach survival probability estimates for steelhead smolts from rkm 153 to $\mathrm{rkm} 8.3$ on a weekly basis, 2 May to 30 May 2010. The season-wide estimate is a weighted average of weekly survival probabilities by release size.

\begin{tabular}{|c|c|c|c|c|c|c|c|c|c|c|c|c|c|}
\hline \multirow[b]{2}{*}{ Week beginning } & \multirow[b]{2}{*}{$N$} & \multicolumn{2}{|c|}{ Rkm 153 to 113} & \multicolumn{2}{|c|}{ Rkm 153 to 86.2} & \multicolumn{2}{|c|}{ Rkm 153 to 49.6} & \multicolumn{2}{|c|}{ Rkm 153 to 37.3} & \multicolumn{2}{|c|}{ Rkm 153 to 22.0} & \multicolumn{2}{|c|}{$\mathrm{Rkm} 153$ to 8.3} \\
\hline & & Estimate & SE & Estimate & SE & Estimate & SE & Estimate & SE & Estimate & SE & Estimate & SE \\
\hline $5 / 2 / 2010$ & 534 & 0.9880 & 0.0050 & 0.9755 & 0.0072 & 0.9086 & 0.0153 & 0.8687 & 0.0186 & 0.7524 & 0.0213 & 0.6446 & 0.0227 \\
\hline $5 / 9 / 2010$ & 505 & 0.9874 & 0.0052 & 0.9807 & 0.0065 & 0.9601 & 0.0171 & 0.9061 & 0.0239 & 0.7779 & 0.0243 & 0.6472 & 0.0303 \\
\hline $5 / 16 / 2010$ & 464 & 0.9951 & 0.0038 & 0.9806 & 0.0072 & 0.9248 & 0.0244 & 0.7868 & 0.0281 & 0.6207 & 0.0254 & 0.5246 & 0.0258 \\
\hline $5 / 23 / 2010$ & 468 & 0.9843 & 0.0065 & 0.9686 & 0.0088 & 0.9354 & 0.0269 & 0.8394 & 0.0309 & 0.6988 & 0.0260 & 0.5763 & 0.0270 \\
\hline $5 / 30 / 2010$ & 437 & 0.9923 & 0.0046 & 0.9884 & 0.0066 & 0.9668 & 0.0193 & 0.8473 & 0.0238 & 0.7483 & 0.0255 & 0.6147 & 0.0248 \\
\hline Season-wide & & 0.9893 & 0.0019 & 0.9786 & 0.0032 & 0.9383 & 0.0109 & 0.8512 & 0.0196 & 0.7212 & 0.0277 & 0.6033 & 0.0231 \\
\hline \multicolumn{2}{|c|}{$P$-value $(F$-test $)$} & \multicolumn{2}{|c|}{0.5893} & \multicolumn{2}{|c|}{0.4050} & \multicolumn{2}{|c|}{0.2567} & \multicolumn{2}{|c|}{0.0190} & \multicolumn{2}{|c|}{$<0.0001$} & \multicolumn{2}{|c|}{0.0038} \\
\hline
\end{tabular}




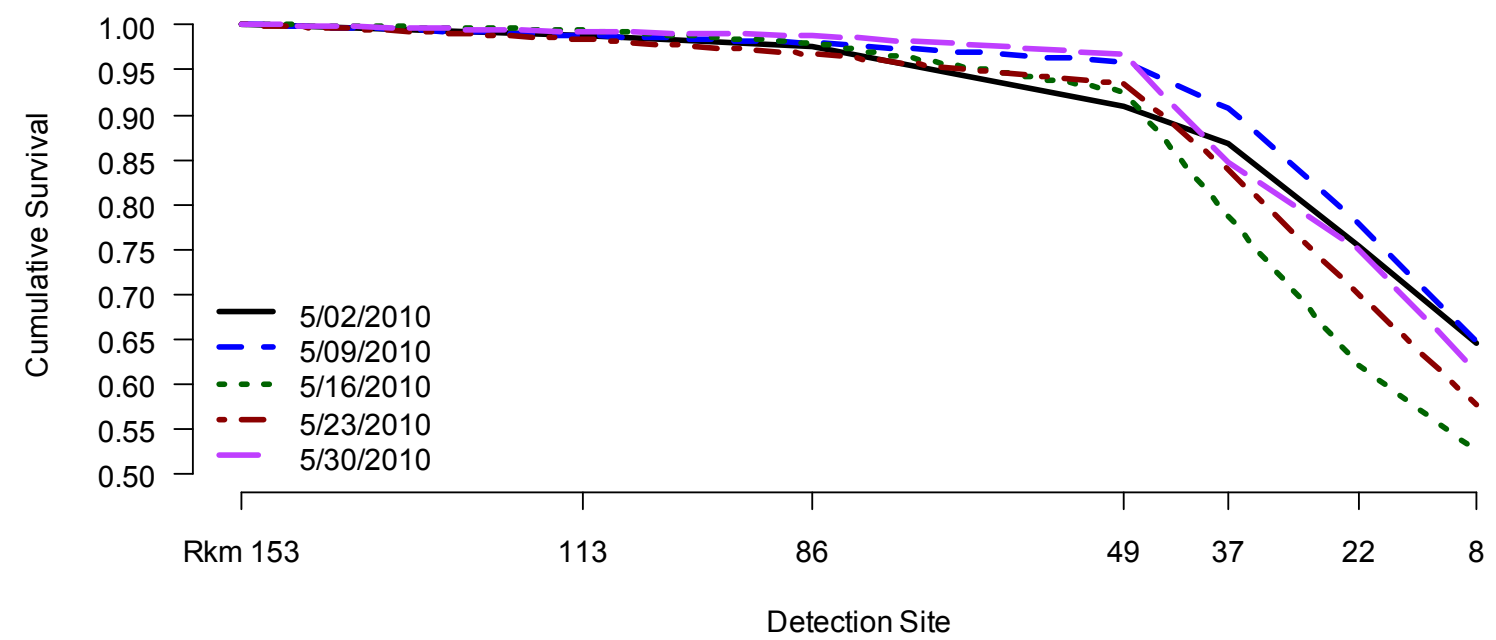

Figure 3.13. Cumulative survival probability estimate curves of steelhead smolts from rkm 153 to rkm 8.3 by week over the outmigration season.

\subsubsection{Subyearling Chinook Salmon}

Seasonal trends in cumulative survival probability between rkm 153 and 8.3 showed marked differences over the course of the study (Table 3.8, Table 3.9, Figure 3.14). Survival probabilities in the lower river monotonically declined over the course of the season. During the first week, cumulative survival probability was $\hat{S}=0.9791(\widehat{\mathrm{SE}}=0.0168)$, and by the last week, it had declined to $\hat{S}=0.6612$ ( $\widehat{\mathrm{SE}}=0.0210)$. Reach-specific survival probability estimates were significantly different between virtualrelease groups in four of six reaches (Table 3.9) and cumulative survivals were different in all reaches (Table 3.10). Cumulative survival probability curves calculated on a weekly basis illustrate the dramatic changes in apparent subyearling Chinook salmon survival probability over the 6-week study (Figure 3.14).

Table 3.8. Weekly cumulative survivals for subyearling Chinook salmon smolts from rkm 153 to rkm 8.3 with associated standard errors (SEs). $P$-value for test of homogeneous survival.

\begin{tabular}{cccc}
\hline & \multicolumn{3}{c}{ Rkm 153-Rkm 8.3 } \\
\cline { 2 - 4 } Week starting & \# Fish & $\hat{S}$ & $\widehat{\mathrm{SE}}$ \\
\hline $6 / 14 / 2010$ & 300 & 0.9791 & 0.0168 \\
$6 / 21 / 2010$ & 645 & 0.9508 & 0.0109 \\
$6 / 28 / 2010$ & 675 & 0.9174 & 0.0124 \\
$7 / 5 / 2010$ & 733 & 0.8393 & 0.0158 \\
$7 / 12 / 2010$ & 578 & 0.6612 & 0.0210 \\
& & \multicolumn{3}{c}{$P$-value $<0.0001$} \\
\hline
\end{tabular}


Table 3.9. Reach-specific survival probability estimates for subyearling Chinook salmon smolts from rkm 153 to rkm 8.3 on a weekly basis, 14 June to 19 July 2010 . The season-wide estimate is a weighted average of weekly survival probabilities by release size.

\begin{tabular}{|c|c|c|c|c|c|c|c|c|c|c|c|c|c|}
\hline \multirow[b]{2}{*}{ Week beginning } & \multirow[b]{2}{*}{$N$} & \multicolumn{2}{|c|}{ Rkm 153 to 113} & \multicolumn{2}{|c|}{ Rkm 113 to 86.2} & \multicolumn{2}{|c|}{$\mathrm{Rkm} 86.2$ to 49.6} & \multicolumn{2}{|c|}{$\mathrm{Rkm} 49.6$ to 37.3} & \multicolumn{2}{|c|}{ Rkm 37.3 to 22.0} & \multicolumn{2}{|c|}{$\mathrm{Rkm} 22.0$ to 8.3} \\
\hline & & Estimate & SE & Estimate & SE & Estimate & SE & Estimate & SE & Estimate & SE & Estimate & SE \\
\hline $6 / 14 / 2010$ & 300 & 0.9969 & 0.0033 & 0.9978 & 0.0038 & 0.9957 & 0.0064 & 0.9983 & 0.0091 & 0.9848 & 0.0110 & 1.0055 & 0.0150 \\
\hline $6 / 21 / 2010$ & 645 & 0.9940 & 0.0031 & 0.9976 & 0.0024 & 1.0000 & 0.0047 & 0.9921 & 0.0077 & 0.9924 & 0.0078 & 0.9739 & 0.0105 \\
\hline $6 / 28 / 2010$ & 675 & 0.9930 & 0.0033 & 0.9914 & 0.0038 & 0.9856 & 0.0065 & 0.9865 & 0.0089 & 0.9605 & 0.0101 & 0.9979 & 0.0079 \\
\hline $7 / 5 / 2010$ & 733 & 0.9814 & 0.0051 & 0.9871 & 0.0043 & 0.9870 & 0.0061 & 0.9868 & 0.0102 & 0.9548 & 0.0134 & 0.9317 & 0.0152 \\
\hline $7 / 12 / 2010$ & 578 & 0.9602 & 0.0083 & 0.9509 & 0.0095 & 0.9046 & 0.0150 & 0.9592 & 0.0199 & 0.8736 & 0.0222 & 0.9556 & 0.0165 \\
\hline Season-wide & & 0.9843 & 0.0065 & 0.9844 & 0.0085 & 0.9742 & 0.0175 & 0.9836 & 0.0063 & 0.9514 & 0.0206 & 0.9685 & 0.0134 \\
\hline$P$-value ( $F$-test) & & \multicolumn{2}{|c|}{$<0.0001$} & \multicolumn{2}{|c|}{$<0.0001$} & \multicolumn{2}{|c|}{$<0.0001$} & \multicolumn{2}{|c|}{0.1821} & \multicolumn{2}{|c|}{$<0.0001$} & \multicolumn{2}{|c|}{0.0009} \\
\hline
\end{tabular}

Table 3.10.Cumulative reach survival probability estimates for subyearling Chinook salmon smolts from rkm 153 to rkm 8.3 on a weekly basis, 14 June to 19 July 2010 . The season-wide estimate is a weighted average of weekly survival probabilities by release size.

\begin{tabular}{|c|c|c|c|c|c|c|c|c|c|c|c|c|c|}
\hline \multirow[b]{2}{*}{ Week beginning } & \multirow[b]{2}{*}{$N$} & \multicolumn{2}{|c|}{ Rkm 153 to 113} & \multicolumn{2}{|c|}{ Rkm 153 to 86.2} & \multicolumn{2}{|c|}{ Rkm 153 to 49.6} & \multicolumn{2}{|c|}{$\mathrm{Rkm} 153$ to 37.3} & \multicolumn{2}{|c|}{ Rkm 153 to 22.0} & \multicolumn{2}{|c|}{ Rkm 153 to 8.3} \\
\hline & & Estimate & $\mathrm{SE}$ & Estimate & SE & Estimate & SE & Estimate & $\mathrm{SE}$ & Estimate & SE & Estimate & SE \\
\hline $6 / 14 / 2010$ & 300 & 0.9969 & 0.0033 & 0.9947 & 0.0048 & 0.9904 & 0.0072 & 0.9887 & 0.0096 & 0.9737 & 0.0100 & 0.9791 & 0.0168 \\
\hline $6 / 21 / 2010$ & 645 & 0.9940 & 0.0031 & 0.9916 & 0.0038 & 0.9916 & 0.0057 & 0.9838 & 0.0071 & 0.9763 & 0.0076 & 0.9508 & 0.0109 \\
\hline $6 / 28 / 2010$ & 675 & 0.9930 & 0.0030 & 0.9845 & 0.0049 & 0.9703 & 0.0079 & 0.9572 & 0.0098 & 0.9194 & 0.0108 & 0.9174 & 0.0124 \\
\hline $7 / 5 / 2010$ & 733 & 0.9814 & 0.0051 & 0.9687 & 0.0064 & 0.9561 & 0.0087 & 0.9435 & 0.0115 & 0.9009 & 0.0130 & 0.8393 & 0.0158 \\
\hline $7 / 12 / 2010$ & 578 & 0.9602 & 0.0083 & 0.9130 & 0.0118 & 0.8258 & 0.0173 & 0.7921 & 0.0213 & 0.6920 & 0.0199 & 0.6612 & 0.0210 \\
\hline$P$-value (F-test) & & \multicolumn{2}{|c|}{$<0.0001$} & \multicolumn{2}{|c|}{$<0.0001$} & \multicolumn{2}{|c|}{$<0.0001$} & \multicolumn{2}{|c|}{$<0.0001$} & \multicolumn{2}{|c|}{$<0.0001$} & \multicolumn{2}{|c|}{$<0.0001$} \\
\hline
\end{tabular}




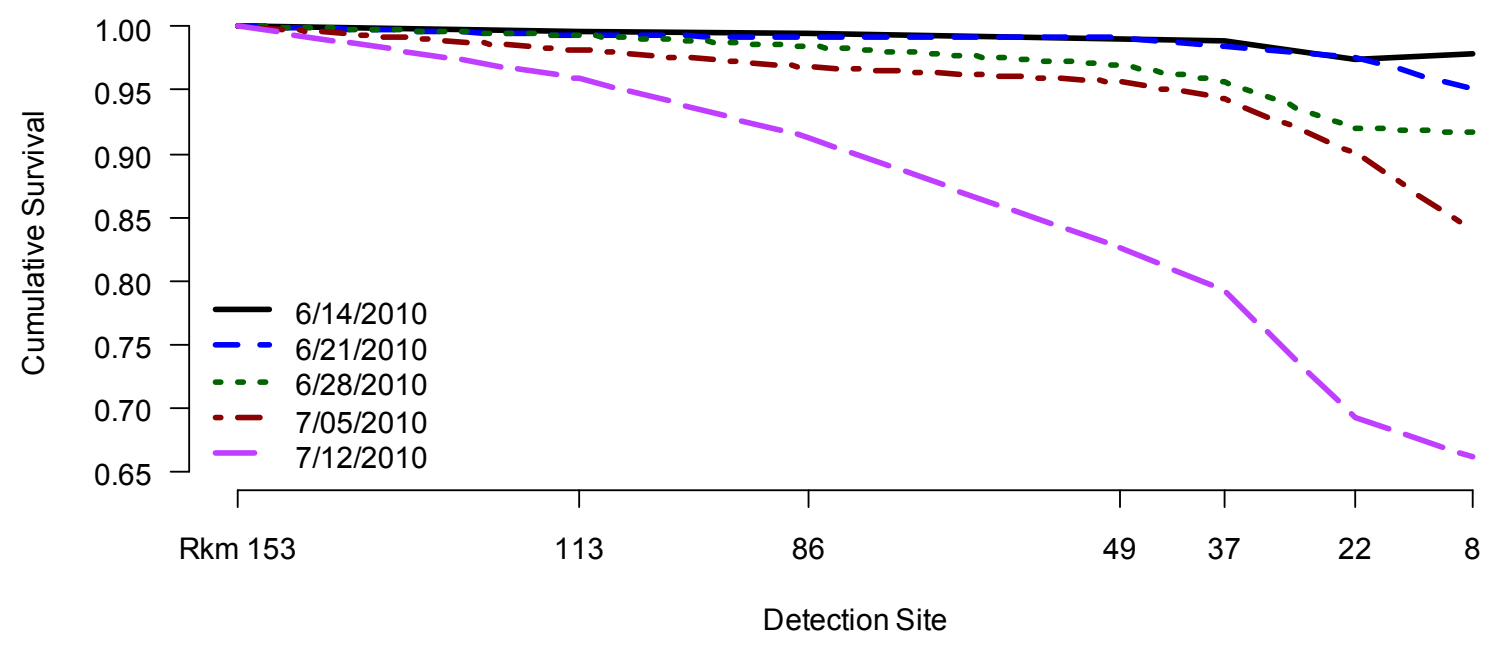

Figure 3.14. Cumulative survival probability estimate curves of subyearling Chinook salmon smolts from rkm 153 to rkm 8.3 by week over the outmigration season.

\subsubsection{Survival by Dam Passage Routes}

Results are presented by species. Within each species analysis, the effects of route-specific passage on downstream survival probability are examined. The main effects of passage at each individual dam are examined first. The effects of route-specific passage at two, then three, dams are examined next.

\subsubsection{Yearling Chinook Salmon}

Yearling Chinook salmon approach and pass a dam slightly differently than other species or runs. As a result, the proportion of fish passing via particular routes or combinations of routes at multiple dams may differ from that of other species or runs. This section presents estimates of survival probability for groups of yearling Chinook salmon with a variety of passage histories at dams and follows those groups as they travel through the lower Columbia River and estuary.

\section{Effects of Route-Specific Passage at One Dam on Yearling Chinook Salmon}

The survival probability of yearling Chinook salmon smolts from specific dam passage routes to rkm 153 and from rkm 153 to rkm 8.3 were estimated starting at John Day Dam, The Dalles Dam, or Bonneville Dam. For yearling Chinook salmon smolts passing through the different routes at John Day Dam (i.e., JBS, non-TSW, TSW, turbine), survival probabilities were significantly different to rkm 153 ( $P$ $=0.0012)$, but not different between rkm 153 and $8.3(P=0.9637$, Table 3.11). Yearling Chinook salmon that passed through the JBS at John Day Dam had the lowest survival probability to rkm 153 ( $\hat{S}=0.7231$ ). Fish that passed John Day Dam through the TSW and non-routes had survival probability estimates to rkm 153 more than 0.10 higher. Between rkm 153 and 8.3, reach-specific survival probabilities were not significantly different $(P \geq 0.2472)$ for fish passing through any of the routes at John Day Dam (Table 3.12). Plots of the cumulative survival probabilities for fish by different passage routes at John Day Dam illustrate the differences in survival probability trends to rkm 153 and homogeneity from rkm 153 to rkm 8.3 (Table 3.13, Figure 3.15a, Figure 3.16a). 
From The Dalles Dam, significant differences $(P=0.0083)$ in survival probability to rkm 153 were observed between groups of fish that took different passage routes. Yearling Chinook salmon that passed through turbines at The Dalles Dam had the lowest survival probability to rkm 153. Between rkm 153 and 8.3, there was no significant difference in cumulative survival probabilities among fish that took different passage routes $(P=0.3114$, Table 3.11). A significant difference in reach-specific survival probability was observed between fish of different passage routes in only one reach (rkm 49.6 to $\mathrm{rkm}$ 37.3; $P=0.0388$, Table 3.12). Cumulative survival probability estimates were significantly different at rkm $22(P=0.0195)$, with sluiceway-passed fish having the lowest survival probability, but differences disappeared by rkm 8.3 (Table 3.13).

For fish with different passage routes at Bonneville Dam, significant differences were detected to rkm $153(P<0.0001)$, but no significant differences were detected between rkm 153 and 8.3 for cumulative survival $(P=0.9754)$ or any of the reach-specific survival probability estimates $(P \geq 0.5978)$ (Table 3.11, Table 3.12, Figure 3.15c, Figure 3.16c). Yearling Chinook salmon that passed through non-TSW routes had the lowest survival probability to rkm 153 of all passage routes at Bonneville Dam.

Table 3.11. Reach survival probability estimates for yearling Chinook salmon smolts passage routes at a particular dam to rkm 153 and from rkm 153 to rkm 8.3 with associated standard errors (SEs). $P$-values are for tests of homogeneous survival.

\begin{tabular}{|c|c|c|c|c|c|c|}
\hline \multirow[b]{2}{*}{ Dam } & \multirow[b]{2}{*}{ Route } & \multirow[b]{2}{*}{ \# Fish } & \multicolumn{2}{|c|}{ Route - Rkm 153} & \multicolumn{2}{|c|}{ Rkm 153 - Rkm 8.3} \\
\hline & & & $\hat{S}$ & $\widehat{\mathrm{SE}}$ & $\hat{S}$ & $\widehat{\mathrm{SE}}$ \\
\hline \multirow[t]{5}{*}{ John Day } & JBS & 133 & 0.7231 & 0.0397 & 0.8546 & 0.0473 \\
\hline & Non-TSW & 690 & 0.8332 & 0.0145 & 0.8508 & 0.0202 \\
\hline & TSW & 1201 & 0.8465 & 0.0106 & 0.8429 & 0.0157 \\
\hline & Turbine & 79 & NA & NA & NA & NA \\
\hline & & & \multicolumn{2}{|c|}{$P$-value $=0.0007$} & \multicolumn{2}{|c|}{$P$-value $=0.9637$} \\
\hline \multirow[t]{4}{*}{ The Dalles } & Non-TSW & 1656 & 0.8845 & 0.0080 & 0.8569 & 0.0127 \\
\hline & Sluiceway & 209 & 0.9012 & 0.0216 & 0.7778 & 0.0381 \\
\hline & Turbine & 108 & 0.7932 & 0.0398 & 0.8209 & 0.0492 \\
\hline & & & \multicolumn{2}{|c|}{$P$-value $=0.0083$} & \multicolumn{2}{|c|}{$P$-value $=0.3114$} \\
\hline \multirow[t]{5}{*}{ Bonneville } & JBS & 217 & 0.9802 & 0.0103 & 0.8344 & 0.0366 \\
\hline & Non-TSW & 1757 & 0.9357 & 0.0060 & 0.8362 & 0.0117 \\
\hline & Sluiceway & 697 & 0.9889 & 0.0046 & 0.8450 & 0.0183 \\
\hline & Turbine & 659 & 0.9628 & 0.0076 & 0.8468 & 0.0189 \\
\hline & & & \multicolumn{2}{|c|}{$P$-value $=0.0001$} & \multicolumn{2}{|c|}{$P$-value $=0.9754$} \\
\hline
\end{tabular}


Table 3.12. Reach-specific survival probability estimates and associated standard errors (SEs) for yearling Chinook salmon smolts by passage route at a particular dam to rkm 153 and six reach-specific survivals between rkm 153 and $\mathrm{rkm}$ 8.3. Results are presented for four routes at John Day Dam, three routes at The Dalles Dam, and four routes at Bonneville Dam, along with standard errors (SEs) and Pvalues associated with $F$-tests of homogeneous survival.

\begin{tabular}{|c|c|c|c|c|c|c|c|c|c|c|c|c|c|c|c|c|}
\hline \multirow[b]{2}{*}{ Dam } & \multirow[b]{2}{*}{ Route } & \multirow[b]{2}{*}{$N$} & \multicolumn{2}{|c|}{ Release to Rkm 153} & \multicolumn{2}{|c|}{$\mathrm{Rkm} 153$ to 113} & \multicolumn{2}{|c|}{$\mathrm{Rkm} 113$ to 86.2} & \multicolumn{2}{|c|}{$\mathrm{Rkm} 86.2$ to 49.6} & \multicolumn{2}{|c|}{$\mathrm{Rkm} 49.6$ to 37.3} & \multicolumn{2}{|c|}{ Rkm 37.3 to 22} & \multicolumn{2}{|c|}{ Rkm 22 to 8.3} \\
\hline & & & Estimate & $\mathrm{SE}$ & Estimate & $\mathrm{SE}$ & Estimate & SE & Estimate & $\mathrm{SE}$ & Estimate & $\mathrm{SE}$ & Estimate & $\mathrm{SE}$ & Estimate & $\mathrm{SE}$ \\
\hline \multirow[t]{5}{*}{ John Day } & JBS & 133 & 0.7231 & 0.0397 & 0.9762 & 0.0182 & 0.9795 & 0.0160 & 0.9832 & 0.0175 & 0.9848 & 0.0228 & 1.0148 & 0.0335 & 0.9096 & 0.0518 \\
\hline & Non-TSW & 690 & 0.8332 & 0.0145 & 0.9948 & 0.0040 & 0.9900 & 0.0046 & 0.9937 & 0.0080 & 0.9653 & 0.0140 & 0.9489 & 0.0158 & 0.9491 & 0.0195 \\
\hline & TSW & 1201 & 0.8465 & 0.0106 & 0.9939 & 0.0031 & 0.9984 & 0.0020 & 0.9855 & 0.0065 & 0.9719 & 0.0104 & 0.9606 & 0.0130 & 0.9233 & 0.0165 \\
\hline & Turbine & 79 & NA & NA & NA & NA & NA & NA & NA & NA & NA & NA & NA & NA & NA & NA \\
\hline & \multicolumn{2}{|c|}{$P$-value (F-test) } & \multicolumn{2}{|c|}{0.0007} & \multicolumn{2}{|c|}{0.3978} & \multicolumn{2}{|c|}{0.3848} & \multicolumn{2}{|c|}{0.8016} & \multicolumn{2}{|c|}{0.6988} & \multicolumn{2}{|c|}{0.2472} & \multicolumn{2}{|c|}{0.6969} \\
\hline \multirow[t]{4}{*}{ The Dalles } & Non-TSW & 1656 & 0.8845 & 0.0080 & 0.9946 & 0.0024 & 0.9941 & 0.0023 & 0.9901 & 0.0050 & 0.9742 & 0.0083 & 0.9579 & 0.0102 & 0.9380 & 0.0130 \\
\hline & Sluiceway & 209 & $0.9012^{1}$ & 0.0216 & 0.9870 & 0.0098 & 1.0026 & 0.0011 & 0.9835 & 0.0181 & 0.9191 & 0.0307 & 0.9328 & 0.0329 & 0.9324 & 0.0384 \\
\hline & Turbine & 108 & 0.7932 & 0.0398 & 0.9868 & 0.0149 & 0.9763 & 0.0175 & 0.9796 & 0.0179 & 0.9920 & 0.0180 & 1.0018 & 0.0229 & 0.8753 & 0.0487 \\
\hline & \multicolumn{2}{|c|}{$P$-value $(F$-test $)$} & \multicolumn{2}{|c|}{0.0083} & \multicolumn{2}{|c|}{0.8324} & \multicolumn{2}{|c|}{0.2323} & \multicolumn{2}{|c|}{0.8823} & \multicolumn{2}{|c|}{0.0388} & \multicolumn{2}{|c|}{0.1319} & \multicolumn{2}{|c|}{0.4066} \\
\hline \multirow[t]{5}{*}{ Bonneville } & JBS & 217 & 0.9802 & 0.0103 & 0.9952 & 0.0060 & 0.9962 & 0.0051 & 0.9837 & 0.0157 & 0.9657 & 0.0249 & 0.9384 & 0.0304 & 0.9441 & 0.0385 \\
\hline & Non-TSW & 1757 & 0.9357 & 0.0060 & 0.9954 & 0.0022 & 0.9933 & 0.0024 & 0.9842 & 0.0054 & 0.9637 & 0.0083 & 0.9618 & 0.0096 & 0.9271 & 0.0118 \\
\hline & Sluiceway & 697 & 0.9889 & 0.0046 & 0.9924 & 0.0039 & 0.9933 & 0.0034 & 1.0012 & 0.0067 & 0.9577 & 0.0132 & 0.9475 & 0.0148 & 0.9434 & 0.0182 \\
\hline & Turbine & 659 & 0.9628 & 0.0076 & 0.9991 & 0.0021 & 0.9979 & 0.0024 & 0.9901 & 0.0068 & 0.9809 & 0.0115 & 0.9512 & 0.0154 & 0.9193 & 0.0195 \\
\hline & \multicolumn{2}{|c|}{$P$-value $(F$-test $)$} & \multicolumn{2}{|c|}{$<0.0001$} & \multicolumn{2}{|c|}{0.6823} & \multicolumn{2}{|c|}{0.7378} & 0.59 & & 0.7 & & 0.85 & & 0.85 & \\
\hline
\end{tabular}

\footnotetext{
${ }^{1}$ Estimated using the closed form parameter estimator.
} 
Table 3.13. Cumulative reach survival probability estimates and associated standard errors (SEs) for yearling Chinook salmon smolts by passage route at a particular dam from rkm 153 to $\mathrm{rkm}$ 8.3. Results are presented for four routes at John Day Dam, three routes at The Dalles Dam, and four routes at Bonneville Dam, along with standard errors (SEs) and $P$-values associated with $F$-tests of homogeneous survival.

\begin{tabular}{|c|c|c|c|c|c|c|c|c|c|c|c|c|c|c|}
\hline \multirow[b]{2}{*}{ Dam } & \multirow[b]{2}{*}{ Route } & \multirow[b]{2}{*}{$N$} & \multicolumn{2}{|c|}{ Rkm 153 to 113} & \multicolumn{2}{|c|}{ Rkm 153 to 86.2} & \multicolumn{2}{|c|}{ Rkm 153 to 49.6} & \multicolumn{2}{|c|}{ Rkm 153 to 37.3} & \multicolumn{2}{|c|}{$\mathrm{Rkm} 153$ to 22} & \multicolumn{2}{|c|}{ Rkm 153 to 8.3} \\
\hline & & & Estimate & SE & Estimate & SE & Estimate & SE & Estimate & SE & Estimate & SE & Estimate & SE \\
\hline \multirow[t]{5}{*}{ John Day } & JBS & 133 & 0.9762 & 0.0182 & 0.9561 & 0.0232 & 0.9401 & 0.0275 & 0.9258 & 0.0320 & 0.9395 & 0.0395 & 0.8546 & 0.0473 \\
\hline & Non-TSW & 690 & 0.9948 & 0.0040 & 0.9849 & 0.0058 & 0.9786 & 0.0097 & 0.9446 & 0.0136 & 0.8963 & 0.0154 & 0.8508 & 0.0202 \\
\hline & TSW & 1201 & 0.9939 & 0.0031 & 0.9923 & 0.0036 & 0.9779 & 0.0072 & 0.9505 & 0.0102 & 0.9130 & 0.0124 & 0.8429 & 0.0157 \\
\hline & Turbine & 79 & NA & NA & NA & NA & NA & NA & NA & NA & NA & NA & NA & NA \\
\hline & \multicolumn{2}{|c|}{$P$-value $(F$-test $)$} & \multicolumn{2}{|c|}{0.3978} & \multicolumn{2}{|c|}{0.1532} & \multicolumn{2}{|c|}{0.1992} & \multicolumn{2}{|c|}{0.6837} & \multicolumn{2}{|c|}{0.4821} & \multicolumn{2}{|c|}{0.9637} \\
\hline \multirow[t]{4}{*}{ The Dalles } & Non-TSW & 1656 & 0.9946 & 0.0024 & 0.9888 & 0.0033 & 0.9790 & 0.0058 & 0.9537 & 0.0082 & 0.9136 & 0.0099 & 0.8569 & 0.0127 \\
\hline & Sluiceway & 209 & 0.9870 & 0.0098 & 0.9895 & 0.0099 & 0.9730 & 0.0198 & 0.8943 & 0.0293 & 0.8343 & 0.0324 & 0.7778 & 0.0381 \\
\hline & Turbine & 108 & 0.9868 & 0.0149 & 0.9634 & 0.0219 & 0.9437 & 0.0273 & 0.9362 & 0.0303 & 0.9381 & 0.0331 & 0.8209 & 0.0492 \\
\hline & \multicolumn{2}{|c|}{$P$-value $(F$-test $)$} & \multicolumn{2}{|c|}{0.8324} & \multicolumn{2}{|c|}{0.3239} & \multicolumn{2}{|c|}{0.4009} & \multicolumn{2}{|c|}{0.2196} & \multicolumn{2}{|c|}{0.0195} & \multicolumn{2}{|c|}{0.3114} \\
\hline \multirow[t]{5}{*}{ Bonneville } & JBS & 217 & 0.9952 & 0.0060 & 0.9914 & 0.0076 & 0.9753 & 0.0171 & 0.9418 & 0.0238 & 0.8838 & 0.0285 & 0.8344 & 0.0366 \\
\hline & Non-TSW & 1757 & 0.9954 & 0.0022 & 0.9887 & 0.0032 & 0.9730 & 0.0060 & 0.9377 & 0.0082 & 0.9019 & 0.0096 & 0.8362 & 0.0117 \\
\hline & Sluiceway & 697 & 0.9924 & 0.0039 & 0.9858 & 0.0052 & 0.9870 & 0.0083 & 0.9451 & 0.0124 & 0.8957 & 0.0144 & 0.8450 & 0.0183 \\
\hline & Turbine & 659 & 0.9991 & 0.0021 & 0.9970 & 0.0031 & 0.9872 & 0.0073 & 0.9682 & 0.0113 & 0.9212 & 0.0145 & 0.8468 & 0.0189 \\
\hline & \multicolumn{2}{|c|}{$P$-value ( $F$-test) } & \multicolumn{2}{|c|}{0.6823} & \multicolumn{2}{|c|}{0.4564} & \multicolumn{2}{|c|}{0.6794} & \multicolumn{2}{|c|}{0.4842} & \multicolumn{2}{|c|}{0.5289} & \multicolumn{2}{|c|}{0.9754} \\
\hline
\end{tabular}


a. John Day

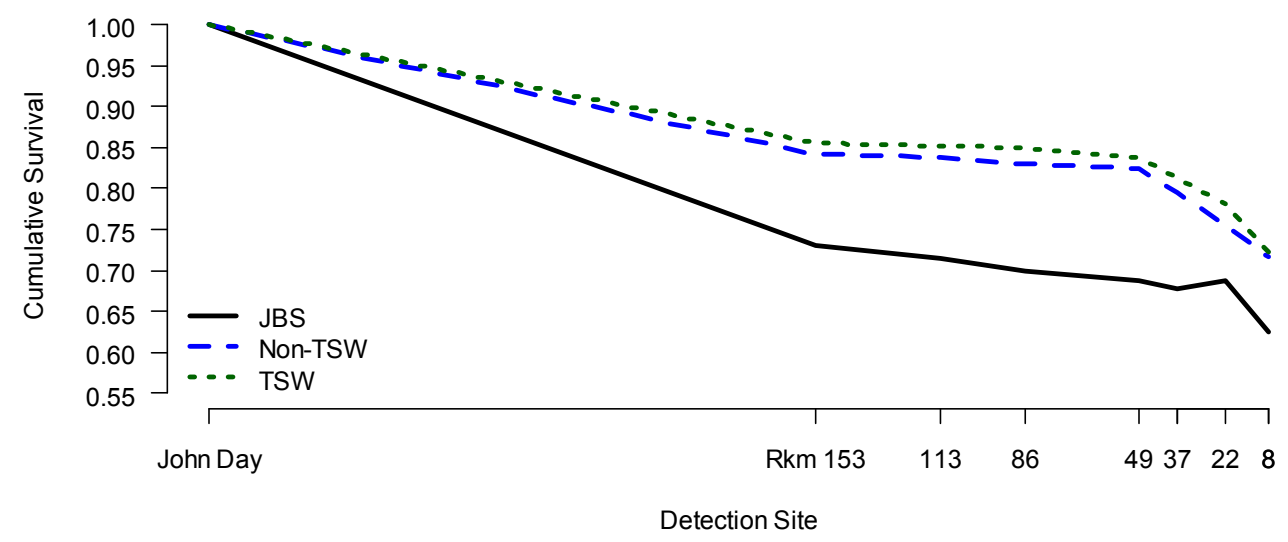

b. The Dalles

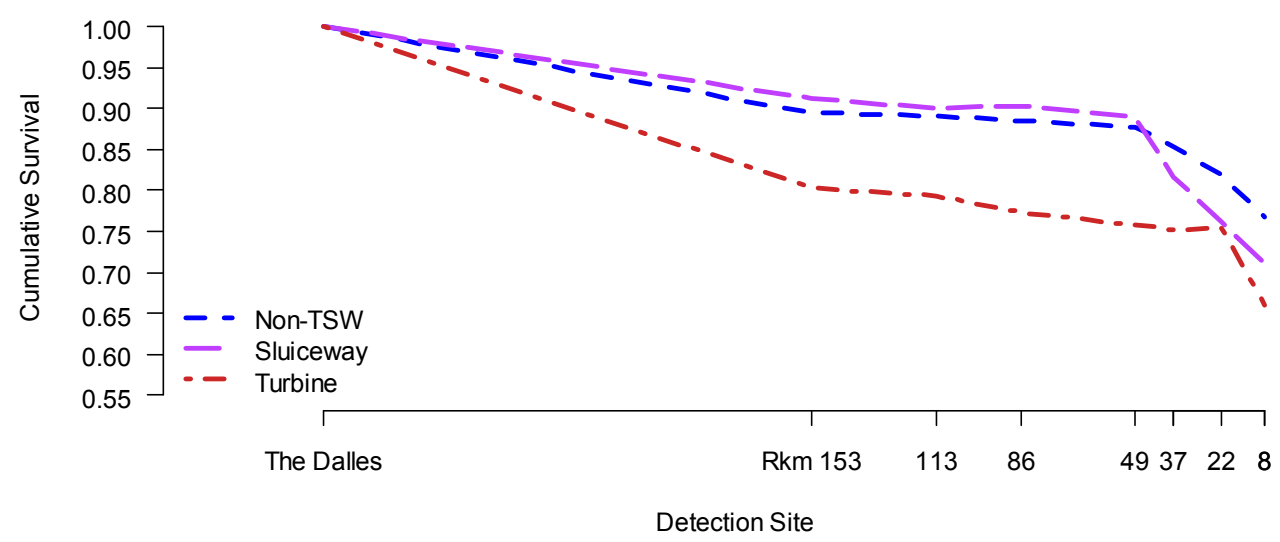

c. Bonneville
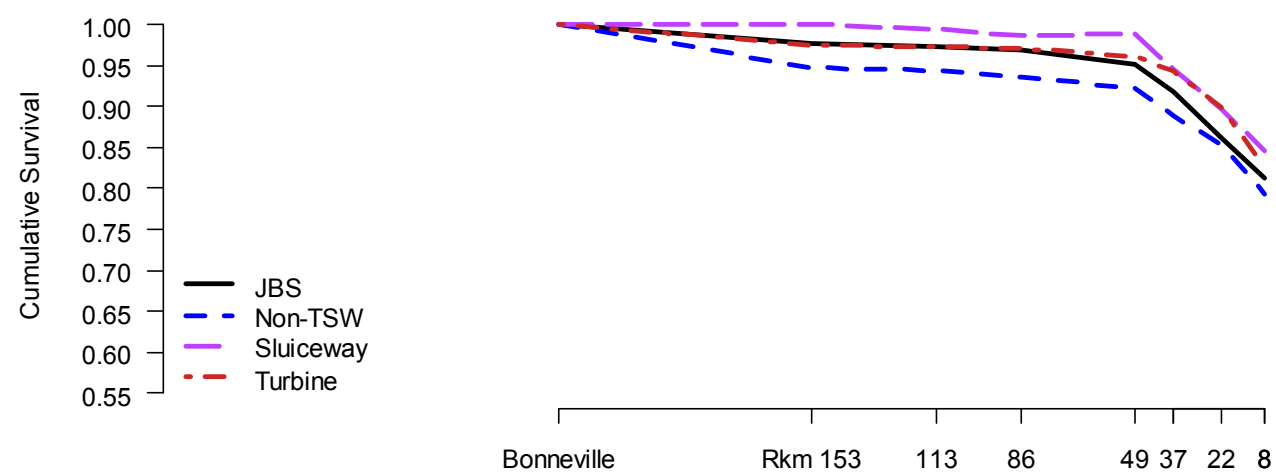

Detection Site

Figure 3.15. Cumulative survival probability estimates for yearling Chinook salmon by passage route from dam face to rkm 153 and below to rkm 8.3 for at a) John Day, b) The Dalles, and c) Bonneville dams. 
a. John Day

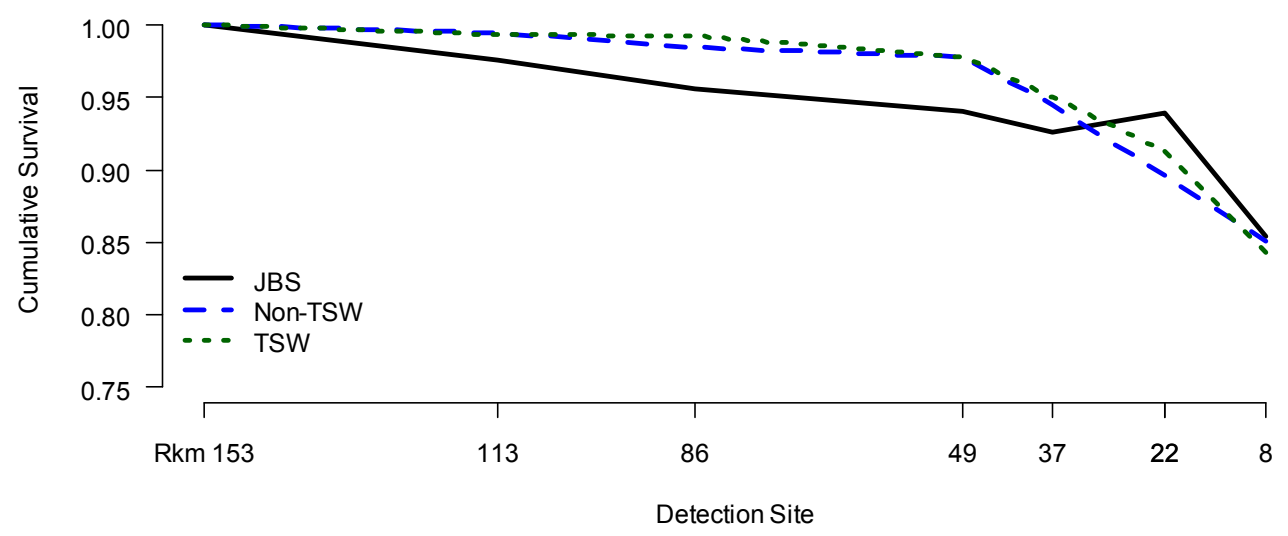

b. The Dalles

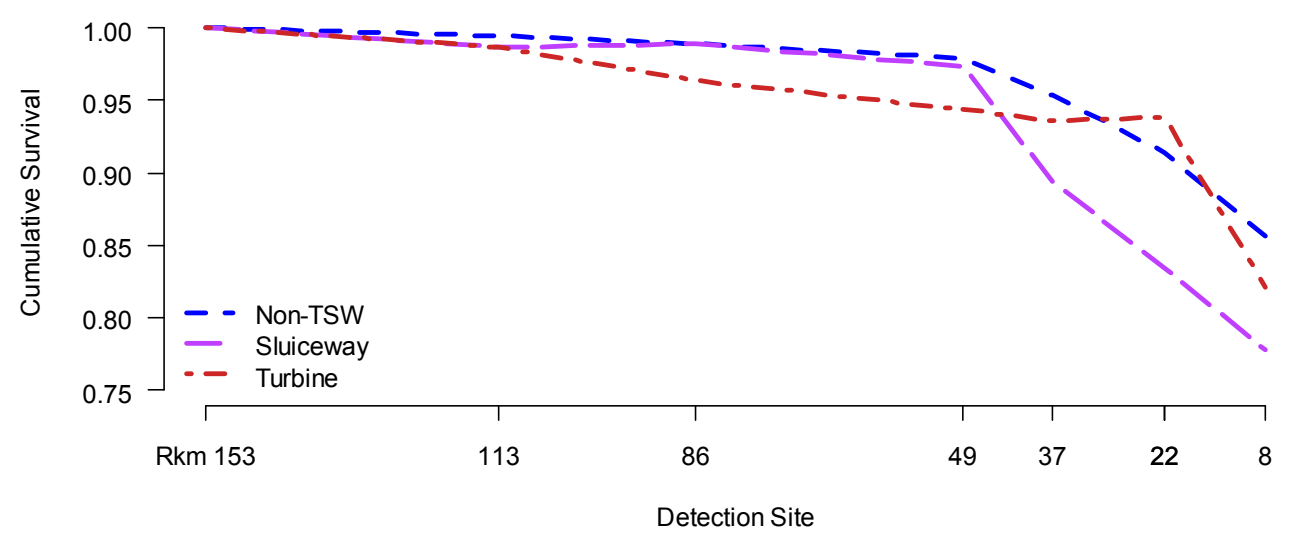

c. Bonneville

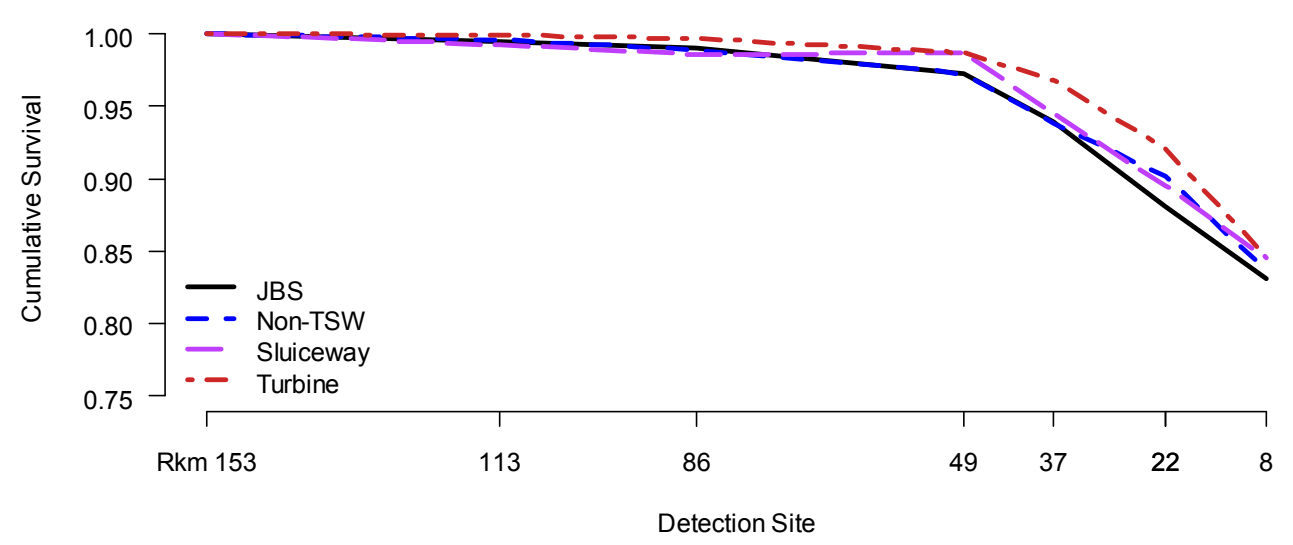

Figure 3.16. Cumulative survival probability estimates for yearling Chinook salmon smolts from rkm 153 to rkm 8.3 by different passage routes at a) John Day, b) The Dalles, and c) Bonneville dams. 


\section{Effects of Route-Specific Passage at Two Dams on Yearling Chinook Salmon}

Despite the thousands of JSATS-tagged yearling Chinook salmon smolts released, too few fish went through many of the combinations of passage routes at both John Day and The Dalles dams or both The Dalles and Bonneville dams to perform comparative survival analyses (Table 3.14). A minimum sample size of 90 fish with a joint passage history at John Day and The Dalles or The Dalles and Bonneville was selected for analysis, which left four route combinations from John Day Dam to The Dalles Dam and four route combinations from The Dalles Dam to Bonneville Dam (Table 3.14).

There were nearly significant differences in survival probability to $\mathrm{rkm} 153(P=0.0357)$ but no significant differences in cumulative survival probabilities from rkm 153 to $\mathrm{rkm} 8.3(P=0.5202)$ for yearling Chinook salmon with different passage histories at John Day and The Dalles dams (Table 3.15). Fish that passed through the JBS at John Day Dam and through non-TSW routes at The Dalles Dam had the lowest reach survival probability to $\mathrm{rkm} 153(\hat{S}=0.8381, \widehat{\mathrm{SE}}=0.0393)$. Fish that passed John Day Dam via the TSW and through The Dalles Dam via sluiceway passage had the highest reach survival probability to $\mathrm{rkm} 153$ ( $\hat{S}=0.9395, \widehat{\mathrm{SE}}=0.0237$; Table 3.15$)$. None of the reach-specific survival probability estimates between rkm 153 and rkm 8.3 were significantly different $(P \geq 0.2221$, Table 3.16). Cumulative survival probabilities between rkm 153 and rkm 86.2 were significantly different $(P=$ 0.0309 ) but differences disappeared by $\mathrm{rkm} 8.3$ (Table 3.17). Figure 3.17a and Figure 3.18a illustrate the cumulative survival probabilities of these fish groups from The Dalles Dam to rkm 8.3 and from rkm 153 to $\mathrm{rkm} 8.3$. These plots clearly indicate the greatest differences in survival probability occurred before arrival at rkm 153 and smaller differences thereafter.

Table 3.14. Sample sizes of yearling Chinook salmon smolts available for survival analyses based on their joint passage history at a) John Day and The Dalles dams or b) The Dalles and Bonneville dams. Combinations that are shaded were used in subsequent estimates of reach survivals.

\begin{tabular}{|c|c|c|c|c|c|}
\hline & \multicolumn{4}{|c|}{ John Day } & \multirow{6}{*}{$\begin{array}{r}1655 \\
209 \\
108 \\
\mathbf{1 9 7 2}\end{array}$} \\
\hline & JBS & Non-TSW & TSW & Turbine & \\
\hline Non-TSW & 94 & 533 & 979 & 49 & \\
\hline Sluiceway & 13 & 81 & 109 & 6 & \\
\hline \multirow[t]{4}{*}{ Turbine } & 12 & 39 & 51 & 6 & \\
\hline & 119 & 653 & 1139 & 61 & \\
\hline & \multicolumn{3}{|c|}{ The Dalles } & & \\
\hline & Non-TSW & Sluiceway & Turbine & & \\
\hline JBS & 67 & 8 & 1 & 76 & \\
\hline Non-TSW & 804 & 107 & 52 & 968 & \\
\hline Sluiceway & 336 & 41 & 22 & 399 & \\
\hline \multirow[t]{2}{*}{ Turbine } & 306 & 39 & 12 & 359 & \\
\hline & 1520 & 195 & 87 & 1802 & \\
\hline
\end{tabular}


Table 3.15. Reach survival probability estimates for combinations of yearling Chinook salmon smolts by passage routes at John Day/The Dalles dams or The Dalles/Bonneville dams to rkm 153 and from rkm 153 to rkm 8.3 with associated standard errors (SEs). $P$-values are for tests of homogeneous survival.

\begin{tabular}{|c|c|c|c|c|c|c|}
\hline \multicolumn{2}{|c|}{ Routes } & \multirow[b]{2}{*}{ \# Fish } & \multicolumn{2}{|c|}{ To Rkm 153} & \multicolumn{2}{|c|}{ Rkm 153 - Rkm 8.3} \\
\hline John Day & The Dalles & & $\hat{S}$ & $\widehat{\mathrm{SE}}$ & $\hat{S}$ & $\widehat{\mathrm{SE}}$ \\
\hline JBS & Non-TSW & 94 & 0.8381 & 0.0393 & 0.8453 & 0.0550 \\
\hline Non-TSW & Non-TSW & 533 & 0.8896 & 0.0139 & 0.8731 & 0.0219 \\
\hline TSW & Non-TSW & 979 & 0.8951 & 0.0104 & 0.8525 & 0.0166 \\
\hline \multirow[t]{2}{*}{ TSW } & Sluiceway & 109 & 0.9395 & 0.0237 & 0.7917 & 0.0511 \\
\hline & & & \multicolumn{2}{|c|}{$P$-value $=0.0337$} & \multicolumn{2}{|c|}{$P$-value $=0.5202$} \\
\hline The Dalles & Bonneville & & & & & \\
\hline Non-TSW & Non-TSW & 804 & 0.9345 & 0.0090 & 0.8518 & 0.0173 \\
\hline Non-TSW & Sluiceway & 336 & 0.9913 & 0.0060 & 0.8966 & 0.0279 \\
\hline Non-TSW & Turbine & 306 & 0.9723 & 0.0097 & 0.8530 & 0.0273 \\
\hline \multirow[t]{2}{*}{ Sluiceway } & Non-Turbine & 107 & 0.9396 & 0.0243 & 0.8162 & 0.0486 \\
\hline & & & \multicolumn{2}{|c|}{$P$-value $=0.0120$} & \multicolumn{2}{|c|}{$P$-value $=0.3757$} \\
\hline
\end{tabular}

For the four joint passage histories at The Dalles and Bonneville dams that were compared, survival probability estimates to $\mathrm{rkm} 153$ were significantly different $(P=0.0120)$, but there were no significant differences between rkm 153 and $\mathrm{rkm} 8.3(P=0.3757)$. Neither reach-specific survival probabilities $(P \geq 0.1723$, Table 3.16$)$ nor cumulative survival probabilities $(P \geq 0.2002$, Table 3.17$)$ were significantly different between rkm 153 and 8.3 . Figure $3.17 \mathrm{~b}$ and Figure $3.18 \mathrm{~b}$ illustrate the cumulative survival probabilities of these fish groups from Bonneville Dam to rkm 153 and from rkm 153 to rkm 8.3. The survival probability curves illustrate the general homogeneity throughout the lower river and estuary. 
Table 3.16. Reach-specific survival probability estimates and associated standard errors (SEs) for yearling Chinook salmon smolts for combinations of passage routes at John Day/The Dalles dams or The Dalles/Bonneville dams to rkm 153 and six reach-specific survivals between rkm 153 and $\mathrm{rkm} 8.3$. $P$-values associated with $F$-tests of homogeneous survival.

\begin{tabular}{|c|c|c|c|c|c|c|c|c|c|c|c|c|c|c|c|c|}
\hline \multicolumn{2}{|c|}{ Route } & \multirow[b]{2}{*}{$N$} & \multicolumn{2}{|c|}{ Release to Rkm 153} & \multicolumn{2}{|c|}{ Rkm 153 to 113} & \multicolumn{2}{|c|}{ Rkm 113 to 86.2} & \multicolumn{2}{|c|}{$\mathrm{Rkm} 86.2$ to 49.6} & \multicolumn{2}{|c|}{ Rkm 49.6 to 37.3} & \multicolumn{2}{|c|}{ Rkm 37.3 to 22} & \multicolumn{2}{|c|}{$\mathrm{Rkm} 22$ to 8.3} \\
\hline Dam 1 & Dam 2 & & Estimate & SE & Estimate & SE & Estimate & SE & Estimate & $\mathrm{SE}$ & Estimate & $\mathrm{SE}$ & Estimate & SE & Estimate & SE \\
\hline John Day & The Dalles & & & & & & & & & & & & & & & \\
\hline JBS & Non-TSW & 94 & 0.8381 & 0.0393 & 0.9712 & 0.0218 & 0.9739 & 0.0194 & 0.9949 & 0.0163 & 0.9803 & 0.0284 & 1.0114 & 0.0403 & 0.9058 & 0.0606 \\
\hline Non-TSW & Non-TSW & 533 & 0.8896 & 0.0139 & 0.9988 & 0.0028 & 0.9920 & 0.0046 & 0.9951 & 0.0082 & 0.9730 & 0.0145 & 0.9479 & 0.0170 & 0.9599 & 0.0213 \\
\hline TSW & Non-TSW & 979 & 0.8851 & 0.0104 & 0.9942 & 0.0032 & 0.9978 & 0.0022 & 0.9861 & 0.0068 & 0.9777 & 0.0107 & 0.9624 & 0.0138 & 0.9262 & 0.0177 \\
\hline \multirow[t]{2}{*}{ TSW } & Sluiceway & 109 & $0.9395^{1}$ & 0.0237 & 1.0009 & 0.0005 & 1.0022 & 0.0012 & 0.9874 & 0.0233 & 0.9154 & 0.0404 & 0.9298 & 0.0450 & 0.9391 & 0.0530 \\
\hline & \multicolumn{2}{|c|}{$P$-value $(F$-test $)$} & \multicolumn{2}{|c|}{0.0357} & \multicolumn{2}{|c|}{0.2221} & \multicolumn{2}{|c|}{0.2453} & \multicolumn{2}{|c|}{0.9602} & \multicolumn{2}{|c|}{0.2455} & \multicolumn{2}{|c|}{0.4610} & \multicolumn{2}{|c|}{0.8366} \\
\hline The Dalles & Bonneville & & & & & & & & & & & & & & & \\
\hline Non-TSW & Non-TSW & 804 & 0.9345 & 0.0090 & 0.9935 & 0.0036 & 0.9927 & 0.0035 & 0.9929 & 0.0071 & 0.9700 & 0.0124 & 0.9562 & 0.0146 & 0.9378 & 0.0176 \\
\hline Non-TSW & Sluiceway & 336 & 0.9913 & 0.0060 & 0.9935 & 0.0053 & 0.9950 & 0.0045 & 0.9943 & 0.0096 & 0.9650 & 0.0164 & 0.9734 & 0.0186 & 0.9711 & 0.0286 \\
\hline Non-TSW & Turbine & 306 & $0.9723^{1}$ & 0.0097 & 1.0013 & 0.0010 & 0.9977 & 0.0036 & 0.9945 & 0.0089 & 0.9863 & 0.0160 & 0.9553 & 0.0224 & 0.9111 & 0.0289 \\
\hline \multirow[t]{2}{*}{ Sluiceway } & Non-TSW & 107 & $0.9396^{1}$ & 0.0243 & 0.9874 & 0.0134 & 1.0039 & 0.0021 & 0.9541 & 0.0270 & 0.9663 & 0.0363 & 0.9431 & 0.0441 & 0.9472 & 0.0484 \\
\hline & \multicolumn{2}{|c|}{$P$-value $(F$-test $)$} & \multicolumn{2}{|c|}{0.0120} & \multicolumn{2}{|c|}{0.6991} & \multicolumn{2}{|c|}{0.4897} & \multicolumn{2}{|c|}{0.1723} & \multicolumn{2}{|c|}{0.9007} & \multicolumn{2}{|c|}{0.8921} & \multicolumn{2}{|c|}{0.6334} \\
\hline
\end{tabular}

Table 3.17. Cumulative reach survival probability estimates and associated standard errors (SEs) for yearling Chinook salmon smolts for combinations of passage routes at John Day/The Dalles dams or The Dalles/Bonneville dams from rkm 153 to rkm 8.3. $P$-values associated with $F$-tests of homogeneous survival.

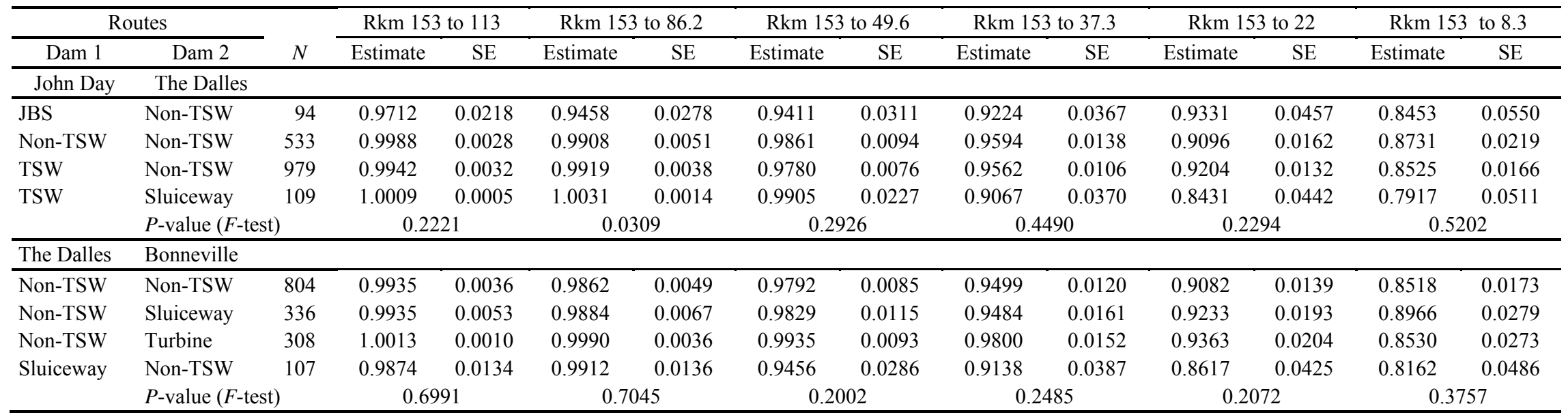

\footnotetext{
${ }^{1}$ Estimated using the closed form parameter estimator.
} 
a. John Day/The Dalles

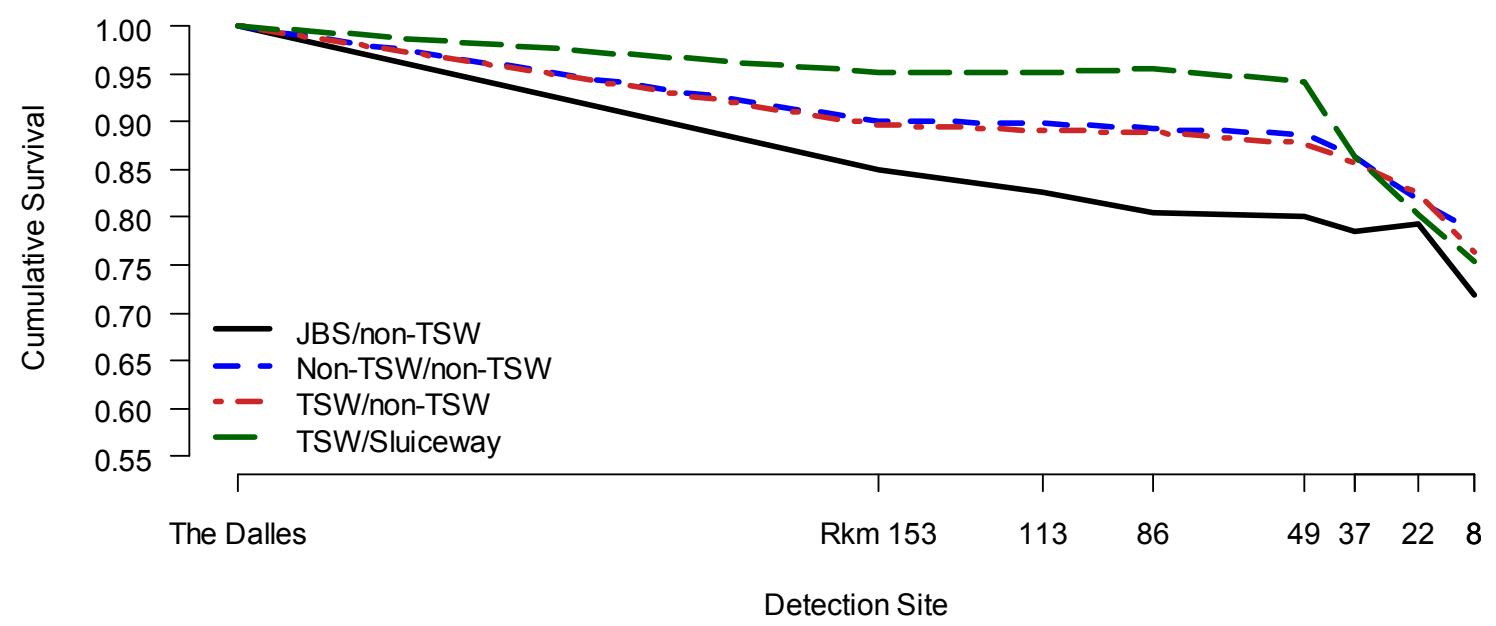

b. The Dalles/Bonneville

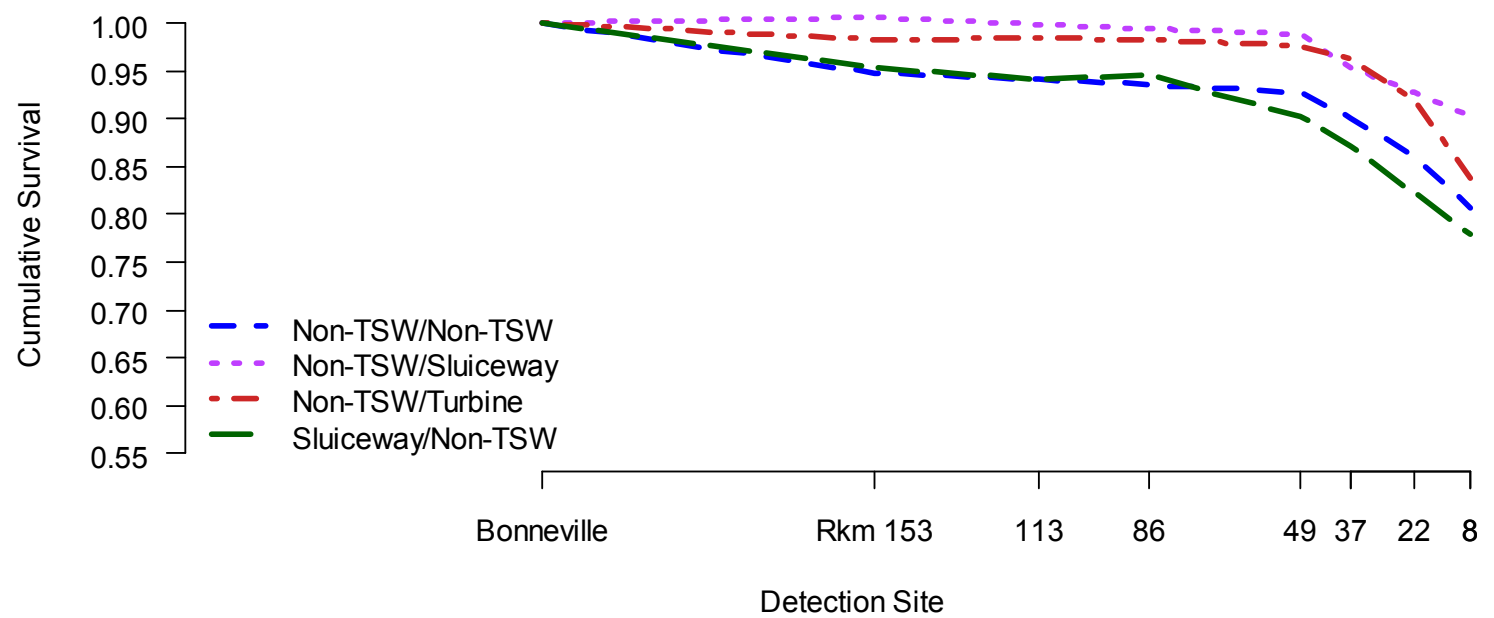

Figure 3.17. Cumulative survival probability estimates for yearling Chinook salmon smolts for various combinations of passage routes at a) John Day and The Dalles dams and b) The Dalles and Bonneville dams, from the dam face of the downriver dam in the pair to rkm 153 and below to rkm 8.3. 
a. John Day/The Dalles

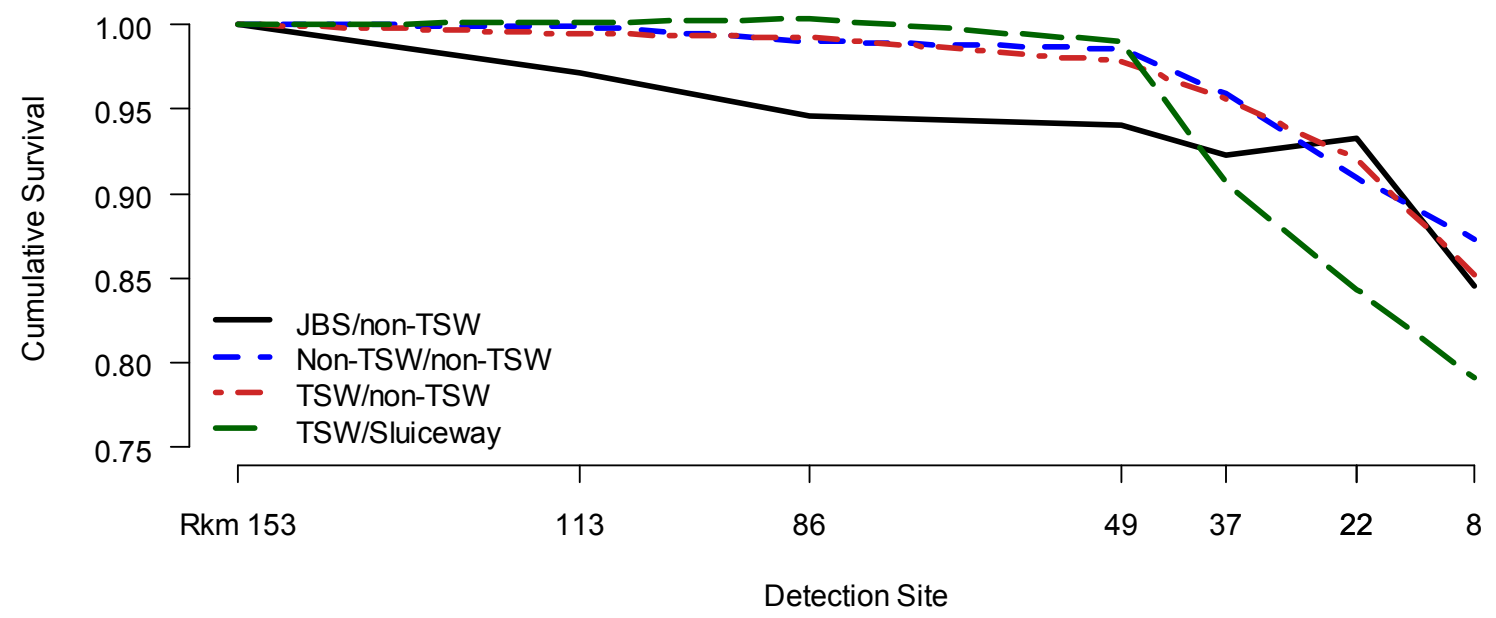

b. The Dalles/Bonneville

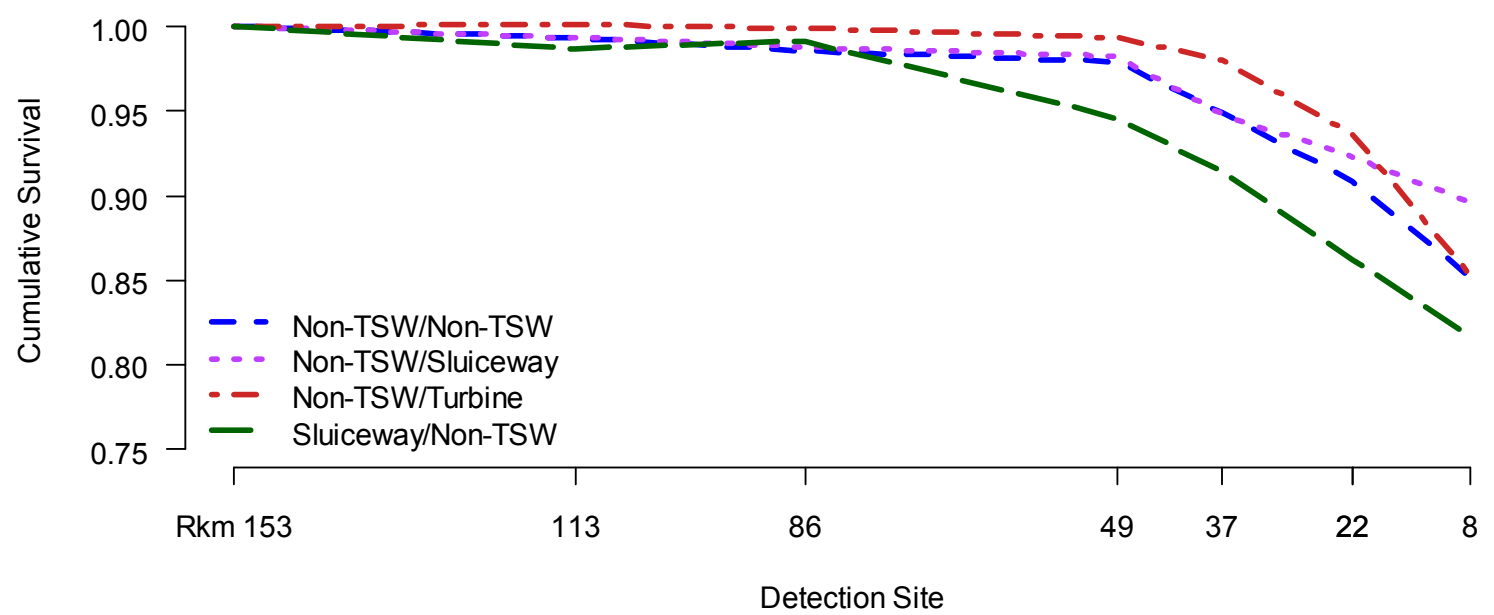

Figure 3.18. Cumulative survival probability estimates of yearling Chinook salmon smolts for various combinations of passage routes at a) John Day and The Dalles dams and b) The Dalles and Bonneville dams between rkm 153 and rkm 8.3. 


\section{Effects of Route-Specific Passage at Three Dams on Yearling Chinook Salmon}

There were only five route combinations at John Day - The Dalles - Bonneville dams that had virtual-release sizes at Bonneville Dam $\geq 90$ fish (Table 3.18). All of those fish groups went through the non-TSW route at The Dalles Dam. At John Day Dam, the passage routes included in the analysis were the TSW or non-TSW. At Bonneville Dam, the passage routes included were non-TSW, sluiceway, or turbines (Table 3.18).

Between Bonneville Dam and rkm 153, survival probabilities were significantly different $(P=$ 0.0001 ) for the five groups of fish with different passage histories (Table 3.19). Cumulative survival probabilities between rkm 153 and 8.3 were not significantly different $(P=0.3654$, Table 3.19), nor were the reach-specific survival probability estimates $(P \geq 0.3869$, Table 3.20) or cumulative survival probabilities as the fish migrated between $\mathrm{rkm} 153$ and $8.3(P \geq 0.3654$, Table 3.21). Figure 3.19 and Figure 3.20 illustrate the pattern of differences in survival probability to rkm 153, but little or no differences between rkm 153 and 8.3. It should be noted that this triple-route analysis could only examine 5 of 48 possible route combinations. Of the five route combinations examined, we included fish that passed through either the TSW or non-TSW routes at John Day Dam and only fish that passed through the non-TSW at The Dalles Dam. Many of the route combinations of interest (e.g., turbine/turbine/turbine) could not be examined because of inadequate sample sizes.

Table 3.18. Sample sizes of yearling Chinook salmon smolts available for survival analyses based on their joint passage history starting at the John Day a) JBS, b) TSW, c) non-TSW, or d) turbine passage routes and their subsequent passage through both The Dalles and Bonneville dams. Combinations that are shaded were used in subsequent estimation of reach survivals.

(a) John Day JBS

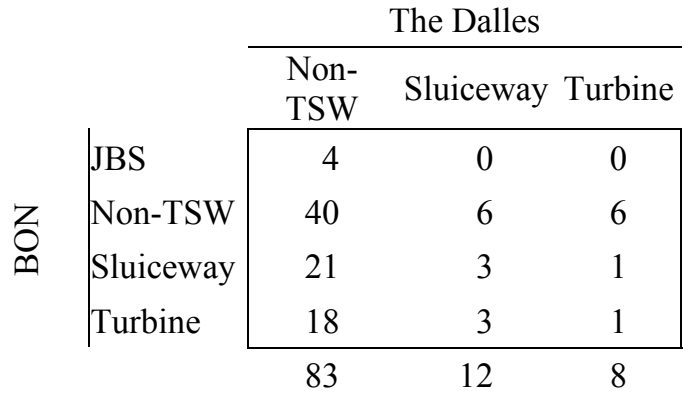

(c) John Day non-TSW

\begin{tabular}{|c|c|c|c|c|c|}
\hline & \multicolumn{3}{|c|}{ The Dalles } & \\
\hline & & $\begin{array}{l}\text { Non- } \\
\text { TSW }\end{array}$ & Sluiceway & Turbine & \\
\hline \multirow{5}{*}{ Z̆ } & JBS & 19 & 3 & 0 & 22 \\
\hline & Non-TSW & 264 & 38 & 17 & 319 \\
\hline & Sluiceway & 111 & 20 & 9 & 140 \\
\hline & Turbine & 88 & 12 & 5 & 105 \\
\hline & & 482 & 73 & 31 & 586 \\
\hline
\end{tabular}

(b) John Day TSW

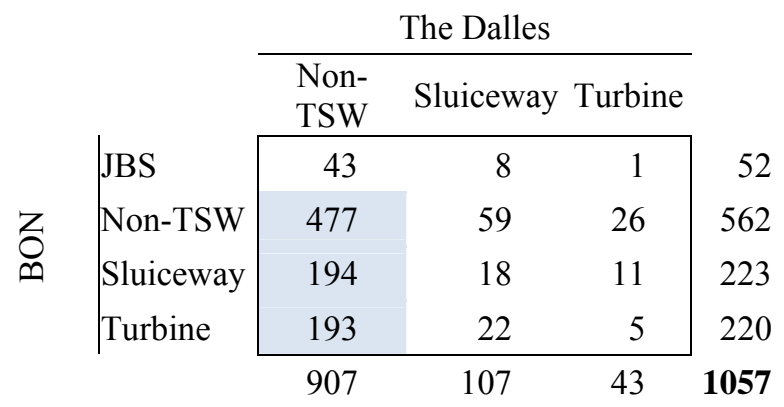

(d) John Day Turbine

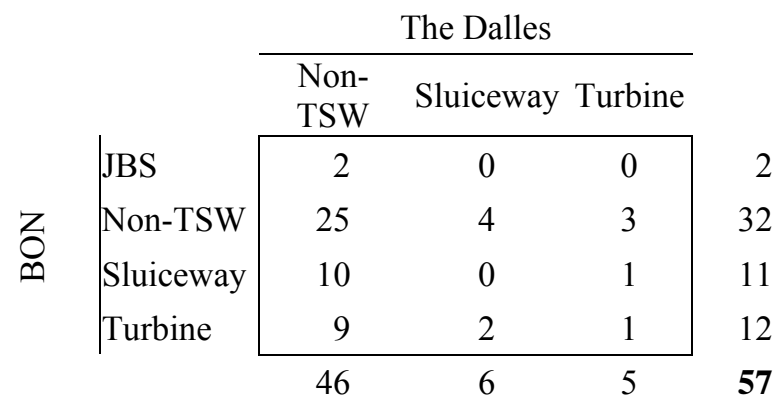


Table 3.19. Cumulative survival probability estimates for yearling Chinook salmon smolts with known passage routes at each dam measured from Bonneville Dam to rkm 153 and from rkm 153 to rkm 8.3 with associated standard errors (SEs). $P$-values are for tests of homogeneous survival.

\begin{tabular}{|c|c|c|c|c|c|c|c|}
\hline \multicolumn{3}{|c|}{ Route } & \multirow[b]{2}{*}{ \# Fish } & \multicolumn{2}{|c|}{ Route - Rkm 153} & \multicolumn{2}{|c|}{ Rkm $153-\mathrm{Rkm} 8.3$} \\
\hline John Day & The Dalles & Bonneville & & $\hat{S}$ & $\widehat{\mathrm{SE}}$ & $\hat{S}$ & $\widehat{\mathrm{SE}}$ \\
\hline \multirow[t]{2}{*}{ Non-TSW } & Non-TSW & Non-TSW & 264 & 0.9534 & 0.0134 & 0.8643 & 0.0288 \\
\hline & & Sluiceway & 111 & 0.9927 & 0.0090 & 0.9132 & 0.0472 \\
\hline \multirow[t]{4}{*}{ TSW } & Non-TSW & Non-TSW & 474 & 0.9252 & 0.0124 & 0.8349 & 0.0236 \\
\hline & & Sluiceway & 194 & 0.9925 & 0.0074 & 0.9157 & 0.0353 \\
\hline & & Turbine & 193 & 0.9551 & 0.0152 & 0.8546 & 0.0349 \\
\hline & & & Overal & $P$-value $=$ & & $P$-valu & 3654 \\
\hline
\end{tabular}


Table 3.20. Reach-specific survival probability estimates and associated standard errors (SEs) for yearling Chinook salmon smolts for combinations of passage routes at John Day/The Dalles/Bonneville dams to rkm 153 and six reach-specific survivals between rkm 153 and rkm 8.3. $P$-values associated with $F$-tests of homogeneous survival.

\begin{tabular}{|c|c|c|c|c|c|c|c|c|c|c|c|c|c|c|c|c|c|}
\hline \multicolumn{3}{|c|}{ Routes } & \multirow[b]{2}{*}{$N$} & \multicolumn{2}{|c|}{ BON to Rkm 153} & \multicolumn{2}{|c|}{ Rkm 153 to 113} & \multicolumn{2}{|c|}{ Rkm 113 to 86.2} & \multicolumn{2}{|c|}{$\mathrm{Rkm} 86.2$ to 49.6} & \multicolumn{2}{|c|}{ Rkm 49.6 to 37.3} & \multicolumn{2}{|c|}{$\mathrm{Rkm} 37.3$ to 22.0} & \multicolumn{2}{|c|}{ Rkm 22.0 to 8.3} \\
\hline JDA & TDA & $\mathrm{BON}$ & & Estimate & SE & Estimate & SE & Estimate & SE & Estimate & SE & Estimate & SE & Estimate & SE & Estimate & SE \\
\hline \multirow[t]{2}{*}{ Non-TSW } & Non-TSW & Non-TSW & 264 & 0.9534 & 0.0134 & 0.9967 & 0.0052 & 0.9920 & 0.0062 & 1.0060 & 0.0095 & 0.9787 & 0.0212 & 0.9327 & 0.0258 & 0.9518 & 0.0281 \\
\hline & & Sluiceway & 111 & $0.9927^{1}$ & 0.0090 & 1.0011 & 0.0005 & 0.9914 & 0.0094 & 1.0064 & 0.0124 & 0.9594 & 0.0264 & 0.9964 & 0.0236 & 0.9564 & 0.0483 \\
\hline \multirow[t]{4}{*}{ TSW } & Non-TSW & Non-TSW & 474 & 0.9252 & 0.0124 & 0.9904 & 0.0054 & 0.9969 & 0.0035 & 0.9848 & 0.0106 & 0.9666 & 0.0168 & 0.9671 & 0.0201 & 0.9186 & 0.0253 \\
\hline & & Sluiceway & 194 & 0.9925 & 0.0074 & 0.9947 & 0.0064 & 0.9959 & 0.0055 & 0.9846 & 0.0132 & 0.9876 & 0.0194 & 0.9606 & 0.0259 & 0.9898 & 0.0358 \\
\hline & & Turbine & 193 & 0.9551 & 0.0152 & 1.0012 & 0.0006 & 1.0010 & 0.0004 & 0.9945 & 0.0109 & 0.9870 & 0.0192 & 0.9708 & 0.0279 & 0.8946 & 0.0381 \\
\hline & \multicolumn{3}{|c|}{ Overall $P$-value $(F$-test $)$} & \multicolumn{2}{|c|}{0.0001} & \multicolumn{2}{|c|}{0.5081} & \multicolumn{2}{|c|}{0.8264} & \multicolumn{2}{|c|}{0.7673} & \multicolumn{2}{|c|}{0.8367} & \multicolumn{2}{|c|}{0.4951} & \multicolumn{2}{|c|}{0.3869} \\
\hline
\end{tabular}

Table 3.21. Cumulative reach survival probability estimates and associated standard errors (SEs) for yearling Chinook salmon smolts for combinations of passage routes at John Day/The Dalles/Bonneville dams from rkm 153 to rkm 8.3. $P$-values associated with $F$-tests of homogeneous survival.

\begin{tabular}{|c|c|c|c|c|c|c|c|c|c|c|c|c|c|c|c|}
\hline \multicolumn{3}{|c|}{ Routes } & \multirow[b]{2}{*}{$N$} & \multicolumn{2}{|c|}{ Rkm 153 to 113} & \multicolumn{2}{|c|}{$\mathrm{Rkm} 153$ to 86.2} & \multicolumn{2}{|c|}{$\mathrm{Rkm} 153$ to 49.6} & \multicolumn{2}{|c|}{$\mathrm{Rkm} 153$ to 37.3} & \multicolumn{2}{|c|}{ Rkm 153 to 22.0} & \multicolumn{2}{|c|}{$\mathrm{Rkm} 153$ to 8.3} \\
\hline JDA & TDA & $\mathrm{BON}$ & & Estimate & SE & Estimate & $\mathrm{SE}$ & Estimate & SE & Estimate & $\mathrm{SE}$ & Estimate & $\mathrm{SE}$ & Estimate & SE \\
\hline \multirow[t]{2}{*}{ Non-TSW } & Non-TSW & Non-TSW & 264 & 0.9967 & 0.0052 & 0.9887 & 0.0076 & 0.9947 & 0.0120 & 0.9734 & 0.0195 & 0.9081 & 0.0226 & 0.8643 & 0.0288 \\
\hline & & Sluiceway & 111 & 1.0011 & 0.0005 & 0.9924 & 0.0091 & 0.9986 & 0.0153 & 0.9581 & 0.0233 & 0.9547 & 0.0274 & 0.9132 & 0.0472 \\
\hline \multirow[t]{4}{*}{ TSW } & Non-TSW & Non-TSW & 474 & 0.9904 & 0.0054 & 0.9872 & 0.0063 & 0.9722 & 0.0120 & 0.9396 & 0.0164 & 0.9088 & 0.0193 & 0.8349 & 0.0236 \\
\hline & & Sluiceway & 194 & 0.9947 & 0.0064 & 0.9906 & 0.0082 & 0.9752 & 0.0151 & 0.9632 & 0.0205 & 0.9251 & 0.0248 & 0.9157 & 0.0353 \\
\hline & & Turbine & 193 & 1.0012 & 0.0006 & 1.0023 & 0.0010 & 0.9968 & 0.0108 & 0.9839 & 0.0178 & 0.9552 & 0.0256 & 0.8546 & 0.0349 \\
\hline & & \multicolumn{2}{|c|}{ Overall $P$-value ( $F$-test) } & \multicolumn{2}{|c|}{0.5081} & \multicolumn{2}{|c|}{0.7342} & \multicolumn{2}{|c|}{0.4435} & \multicolumn{2}{|c|}{0.5766} & \multicolumn{2}{|c|}{0.4362} & \multicolumn{2}{|c|}{0.3654} \\
\hline
\end{tabular}

\footnotetext{
${ }^{1}$ Estimated using the closed form parameter estimator.
} 


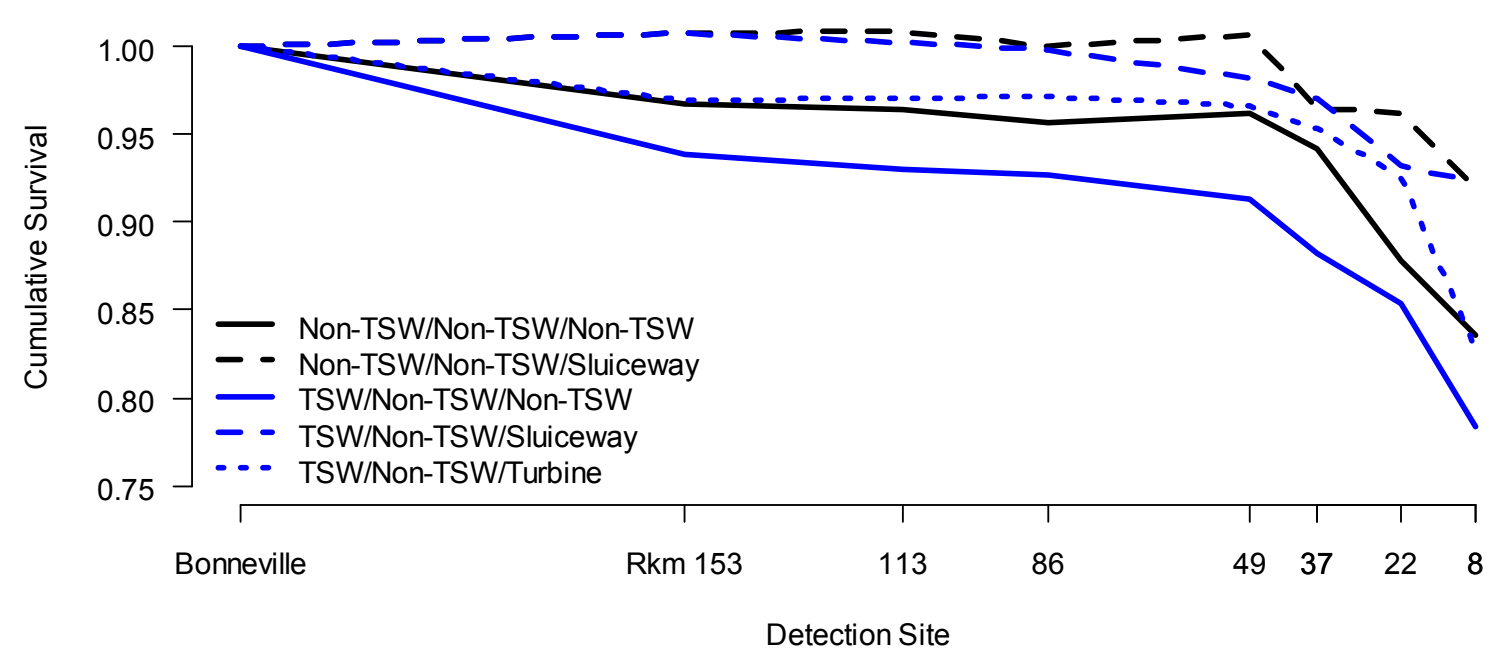

Figure 3.19. Cumulative survival probability estimates for yearling Chinook salmon smolts for various combinations of passage routes at John Day, The Dalles, and Bonneville dams from Bonneville Dam to rkm 8.3.

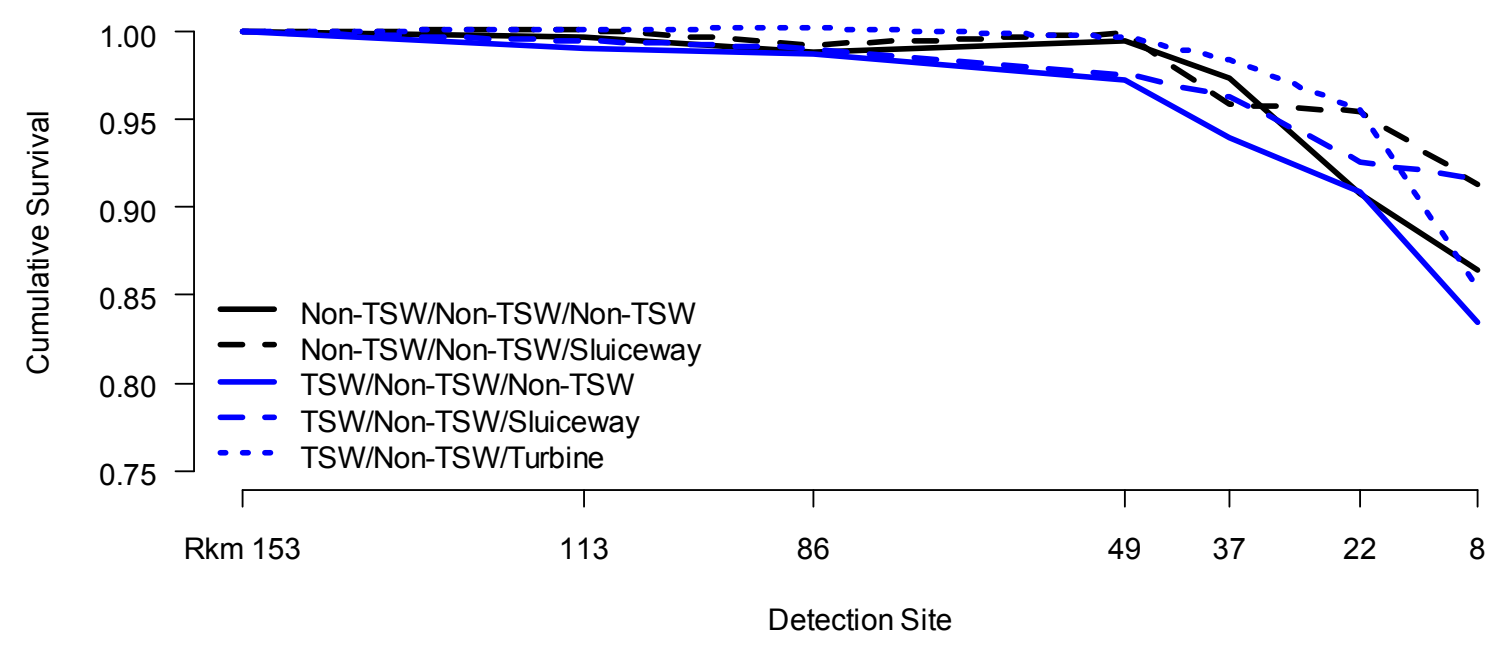

Figure 3.20. Cumulative survival probability estimates for yearling Chinook salmon smolts for various combinations of passage routes at John Day, The Dalles, and Bonneville dams from rkm 153 to $\mathrm{rkm} 8.3$.

\subsubsection{Steelhead Passage}

Steelhead smolts pass through the FCRPS and lower Columbia River and estuary in the spring, but most passage in 2010 was prior to the freshet and high levels of spill. Their surface-oriented behavior causes the proportion of steelhead passing via particular routes or combinations of routes at multiple dams to differ from that of other species or runs. This section presents estimates of survival probability for groups with a variety of passage histories at dams and follows those groups as they travel through the lower Columbia River and estuary. 


\section{Effects of Route-Specific Passage at One Dam on Steelhead}

Steelhead that had passed through different routes at John Day Dam had no significant differences in survival probability to rkm $153(P=0.1313)$, but nearly significant differences between rkm 153 and $\mathrm{rkm}$ $8.3(P=0.0551$, Table 3.22). Fish that went through the JBS had the highest downriver survival probability between rkm 153 and rkm 8.3. There were too few tagged fish that passed through the turbines at John Day Dam to estimate survival probability for steelhead for that passage route. Reachspecific survival probabilities in individual reaches were not significantly different $(P \geq 0.1550$, Table 3.23). Cumulative survival probability estimates were nearly significant at the final survival array (CR008.3; $P \geq 0.0551$; Table 3.24). The survivorship curves support the general impression of homogeneity to rkm 153, followed by some divergence below (Figure 3.21a, Figure 3.22a).

Table 3.22. Reach survival probability estimates for steelhead smolts by passage routes at a particular dam to rkm 153 and from rkm 153 to rkm 8.3 with associated standard errors (SEs). $P$-values are for tests of homogeneous survival.

\begin{tabular}{|c|c|c|c|c|c|c|}
\hline \multirow[b]{2}{*}{ Dam } & \multirow[b]{2}{*}{ Route } & \multirow[b]{2}{*}{ \# Fish } & \multicolumn{2}{|c|}{ Route - Rkm 153} & \multicolumn{2}{|c|}{ Rkm 153 - Rkm 8.3} \\
\hline & & & $\hat{S}$ & $\widehat{\mathrm{SE}}$ & $\hat{S}$ & $\widehat{\mathrm{SE}}$ \\
\hline \multirow{5}{*}{ John Day } & JBS & 194 & 0.8143 & 0.0290 & 0.6876 & 0.0572 \\
\hline & Non-TSW & 347 & 0.7915 & 0.0224 & 0.5714 & 0.0346 \\
\hline & TSW & 1485 & 0.8531 & 0.0095 & 0.5696 & 0.0162 \\
\hline & Turbine & 36 & \multicolumn{2}{|c|}{ NA } & \multicolumn{2}{|c|}{ NA } \\
\hline & & & \multicolumn{2}{|c|}{$P$-value $=0.1313$} & \multicolumn{2}{|c|}{$P$-value $=0.0551$} \\
\hline \multirow{4}{*}{ The Dalles } & Non-TSW & 1725 & 0.8828 & 0.0080 & 0.5845 & 0.0150 \\
\hline & Sluiceway & 152 & 0.8271 & 0.0322 & 0.5498 & 0.0525 \\
\hline & Turbine & 93 & 0.7382 & 0.0484 & 0.5008 & 0.0686 \\
\hline & & & \multicolumn{2}{|c|}{$P$-value $=0.0097$} & \multicolumn{2}{|c|}{$P$-value $=0.5015$} \\
\hline \multirow{5}{*}{ Bonneville } & JBS & 199 & 0.9867 & 0.0062 & 0.5823 & 0.0398 \\
\hline & Non-TSW & 1356 & 0.9403 & 0.0068 & 0.5680 & 0.0159 \\
\hline & Sluiceway & 1107 & 0.9738 & 0.0052 & 0.6227 & 0.0175 \\
\hline & Turbine & 687 & 0.9137 & 0.0112 & 0.6085 & 0.0240 \\
\hline & & & \multicolumn{2}{|c|}{$P$-value $<0.0001$} & \multicolumn{2}{|c|}{$P$-value $=0.4393$} \\
\hline
\end{tabular}

From The Dalles Dam, steelhead survival probability estimates to rkm 153 were significantly different $(P=0.0097)$ but not from rkm 153 to rkm $8.3(P=0.5015$; Table 3.22). Steelhead that went through the turbines at The Dalles Dam had the lowest probability of survival in both reaches. Survival probability estimates for individual reaches between rkm 153 and 8.3 showed nearly significant differences for fish with different passage histories $(P \geq 0.0510$, Table 3.23) but with no consistent pattern. No significant differences were observed in cumulative survival probability estimates between fish with different passage histories ( $P \geq 0.1097$, Table 3.24). The survivorship curves illustrate the differences to rkm 153 but general homogeneity between rkm 153 and 8.3 (Figure 3.21b, Figure 3.22b). 
Table 3.23. Reach-specific survival probability estimates and associated standard errors (SEs) for steelhead smolts by passage route at a particular dam to rkm 153 and six reach-specific survivals between rkm 153 and rkm 8.3. Results are presented for three routes at John Day Dam, three routes at The Dalles Dam, and four routes at Bonneville Dam, along with SEs and P-values associated with Ftests of homogeneous survival.

\begin{tabular}{|c|c|c|c|c|c|c|c|c|c|c|c|c|c|c|c|c|}
\hline \multirow[b]{2}{*}{ Dam } & \multirow[b]{2}{*}{ Route } & \multirow[b]{2}{*}{$N$} & \multicolumn{2}{|c|}{ Release to Rkm 153} & \multicolumn{2}{|c|}{ Rkm 153 to 113} & \multicolumn{2}{|c|}{ Rkm 113 to 86.2} & \multicolumn{2}{|c|}{$\mathrm{Rkm} 86.2$ to 49.6} & \multicolumn{2}{|c|}{$\mathrm{Rkm} 49.6$ to 37.3} & \multicolumn{2}{|c|}{ Rkm 37.3 to 22} & \multicolumn{2}{|c|}{ Rkm 22 to 8.3} \\
\hline & & & Estimate & SE & Estimate & SE & Estimate & SE & Estimate & SE & Estimate & SE & Estimate & SE & Estimate & SE \\
\hline \multirow[t]{4}{*}{ John Day } & JBS & 194 & 0.8143 & 0.0290 & 0.9716 & 0.0156 & 0.9750 & 0.0144 & 0.9188 & 0.0294 & 0.9926 & 0.0425 & 0.8681 & 0.0509 & 0.9169 & 0.0688 \\
\hline & Non-TSW & 347 & 0.7915 & 0.0224 & 0.9863 & 0.0091 & 0.9920 & 0.0073 & 0.9244 & 0.0250 & 0.9366 & 0.0393 & 0.7889 & 0.0420 & 0.8551 & 0.0417 \\
\hline & TSW & 1485 & 0.8531 & 0.0095 & 0.9882 & 0.0041 & 0.9855 & 0.0042 & 0.9538 & 0.0125 & 0.8973 & 0.0187 & 0.8097 & 0.0193 & 0.8438 & 0.0198 \\
\hline & \multicolumn{2}{|c|}{$P$-value ( $F$-test) } & \multicolumn{2}{|c|}{0.1313} & \multicolumn{2}{|c|}{0.4857} & \multicolumn{2}{|c|}{0.4503} & \multicolumn{2}{|c|}{0.5255} & \multicolumn{2}{|c|}{0.1550} & \multicolumn{2}{|c|}{0.3426} & \multicolumn{2}{|c|}{0.5086} \\
\hline \multirow[t]{4}{*}{ The Dalles } & Non-TSW & 1725 & 0.8828 & 0.0080 & 0.9898 & 0.0034 & 0.9864 & 0.0037 & 0.9472 & 0.0111 & 0.9009 & 0.0165 & 0.8108 & 0.0171 & 0.8651 & 0.0180 \\
\hline & Sluiceway & 152 & 0.8271 & 0.0322 & 0.9683 & 0.0192 & 0.9853 & 0.0128 & 0.8919 & 0.0370 & 1.0867 & 0.0798 & 0.7371 & 0.0771 & 0.8065 & 0.0702 \\
\hline & Turbine & 93 & 0.7382 & 0.0484 & 0.9243 & 0.0378 & 0.9703 & 0.0238 & 0.9911 & 0.0468 & 0.9106 & 0.0680 & 0.9671 & 0.0923 & 0.6399 & 0.0922 \\
\hline & \multicolumn{2}{|c|}{$P$-value $(F$-test $)$} & \multicolumn{2}{|c|}{0.0097} & \multicolumn{2}{|c|}{0.1576} & \multicolumn{2}{|c|}{0.7223} & \multicolumn{2}{|c|}{0.1339} & \multicolumn{2}{|c|}{0.4519} & \multicolumn{2}{|c|}{0.0606} & \multicolumn{2}{|c|}{0.0510} \\
\hline \multirow[t]{5}{*}{ Bonneville } & JBS & 199 & $0.9867^{1}$ & 0.0062 & 1.0020 & 0.0015 & 0.9935 & 0.0083 & 0.9342 & 0.0289 & 0.9333 & 0.0452 & 0.8283 & 0.0496 & 0.8098 & 0.0486 \\
\hline & Non-TSW & 1356 & 0.9403 & 0.0068 & 0.9858 & 0.0042 & 0.9848 & 0.0041 & 0.9619 & 0.0124 & 0.9136 & 0.0188 & 0.8014 & 0.0193 & 0.8307 & 0.0194 \\
\hline & Sluiceway & 1107 & 0.9738 & 0.0052 & 0.9931 & 0.0035 & 0.9904 & 0.0037 & 0.9537 & 0.0131 & 0.8983 & 0.0189 & 0.8588 & 0.0195 & 0.8604 & 0.0205 \\
\hline & Turbine & 687 & 0.9137 & 0.0112 & 0.9859 & 0.0058 & 1.0020 & 0.0028 & 0.9332 & 0.0158 & 0.9286 & 0.0226 & 0.8512 & 0.0254 & 0.8350 & 0.0290 \\
\hline & \multicolumn{2}{|c|}{$P$-value ( $F$-test) } & \multicolumn{2}{|c|}{$<0.0001$} & \multicolumn{2}{|c|}{0.0381} & \multicolumn{2}{|c|}{0.2102} & 0.6 & & 0.8 & & 0.5 & & 0.7 & \\
\hline
\end{tabular}

\footnotetext{
${ }^{1}$ Estimated by individual closed form estimators and weighted average by release size.
} 
Table 3.24. Cumulative reach survival probability estimates and associated standard errors (SEs) for steelhead smolts by passage route at a particular dam from rkm 153 to rkm 8.3. Results are presented for three routes at John Day Dam, three routes at The Dalles Dam, and four routes at Bonneville Dam, along with standard errors (SEs) and $P$-values associated with $F$-tests of homogeneous survival.

\begin{tabular}{|c|c|c|c|c|c|c|c|c|c|c|c|c|c|c|}
\hline \multirow[b]{2}{*}{ Dam } & \multirow[b]{2}{*}{ Route } & \multirow[b]{2}{*}{$N$} & \multicolumn{2}{|c|}{$\mathrm{Rkm} 153$ to 113} & \multicolumn{2}{|c|}{ Rkm 153 to 86.2} & \multicolumn{2}{|c|}{ Rkm 153 to 49.6} & \multicolumn{2}{|c|}{$\mathrm{Rkm} 153$ to 37.3} & \multicolumn{2}{|c|}{$\mathrm{Rkm} 153$ to 22} & \multicolumn{2}{|c|}{$\mathrm{Rkm} 153$ to 8.3} \\
\hline & & & Estimate & SE & Estimate & SE & Estimate & SE & Estimate & SE & Estimate & SE & Estimate & SE \\
\hline \multirow[t]{4}{*}{ John Day } & JBS & 194 & 0.9716 & 0.0156 & 0.9473 & 0.0198 & 0.8704 & 0.0328 & 0.8639 & 0.0426 & 0.7500 & 0.0420 & 0.6876 & 0.0572 \\
\hline & Non-TSW & 347 & 0.9863 & 0.0091 & 0.9784 & 0.0111 & 0.9044 & 0.0260 & 0.8470 & 0.0357 & 0.6682 & 0.0331 & 0.5714 & 0.0346 \\
\hline & TSW & 1485 & 0.9882 & 0.0041 & 0.9741 & 0.0055 & 0.9290 & 0.0130 & 0.8336 & 0.0162 & 0.6751 & 0.0155 & 0.5696 & 0.0162 \\
\hline & \multicolumn{2}{|c|}{$P$-value $(F$-test $)$} & \multicolumn{2}{|c|}{0.4857} & \multicolumn{2}{|c|}{0.2098} & \multicolumn{2}{|c|}{0.2586} & \multicolumn{2}{|c|}{0.8135} & \multicolumn{2}{|c|}{0.1364} & \multicolumn{2}{|c|}{0.0551} \\
\hline \multirow[t]{4}{*}{ The Dalles } & Non-TSW & 1725 & 0.9898 & 0.0034 & 0.9763 & 0.0048 & 0.9247 & 0.0115 & 0.8331 & 0.0145 & 0.6756 & 0.0139 & 0.5845 & 0.0150 \\
\hline & Sluiceway & 152 & 0.9683 & 0.0192 & 0.9541 & 0.0221 & 0.8509 & 0.0399 & 0.9247 & 0.0732 & 0.6817 & 0.0539 & 0.5498 & 0.0525 \\
\hline & Turbine & 93 & 0.9243 & 0.0378 & 0.8968 & 0.0421 & 0.8887 & 0.0582 & 0.8093 & 0.0619 & 0.7827 & 0.0825 & 0.5008 & 0.0686 \\
\hline & \multicolumn{2}{|c|}{$P$-value $(F$-test $)$} & \multicolumn{2}{|c|}{0.1576} & \multicolumn{2}{|c|}{0.1097} & \multicolumn{2}{|c|}{0.4496} & \multicolumn{2}{|c|}{0.3058} & \multicolumn{2}{|c|}{0.3342} & \multicolumn{2}{|c|}{0.5015} \\
\hline \multirow[t]{5}{*}{ Bonneville } & JBS & 199 & 1.0020 & 0.0015 & 0.9954 & 0.0076 & 0.9298 & 0.0289 & 0.8679 & 0.0406 & 0.7190 & 0.0395 & 0.5823 & 0.0398 \\
\hline & Non-TSW & 1356 & 0.9858 & 0.0042 & 0.9709 & 0.0056 & 0.9339 & 0.0130 & 0.8531 & 0.0161 & 0.6838 & 0.0154 & 0.5680 & 0.0159 \\
\hline & Sluiceway & 1107 & 0.9931 & 0.0035 & 0.9837 & 0.0049 & 0.9381 & 0.0135 & 0.8427 & 0.0162 & 0.7237 & 0.0163 & 0.6227 & 0.0175 \\
\hline & Turbine & 687 & 0.9859 & 0.0058 & 0.9879 & 0.0063 & 0.9219 & 0.0162 & 0.8561 & 0.0207 & 0.7288 & 0.0216 & 0.6085 & 0.0240 \\
\hline & \multicolumn{2}{|c|}{$P$-value ( $F$-test $)$} & \multicolumn{2}{|c|}{0.0381} & \multicolumn{2}{|c|}{0.0407} & \multicolumn{2}{|c|}{0.9413} & \multicolumn{2}{|c|}{0.9197} & \multicolumn{2}{|c|}{0.5773} & \multicolumn{2}{|c|}{0.4393} \\
\hline
\end{tabular}


a. John Day

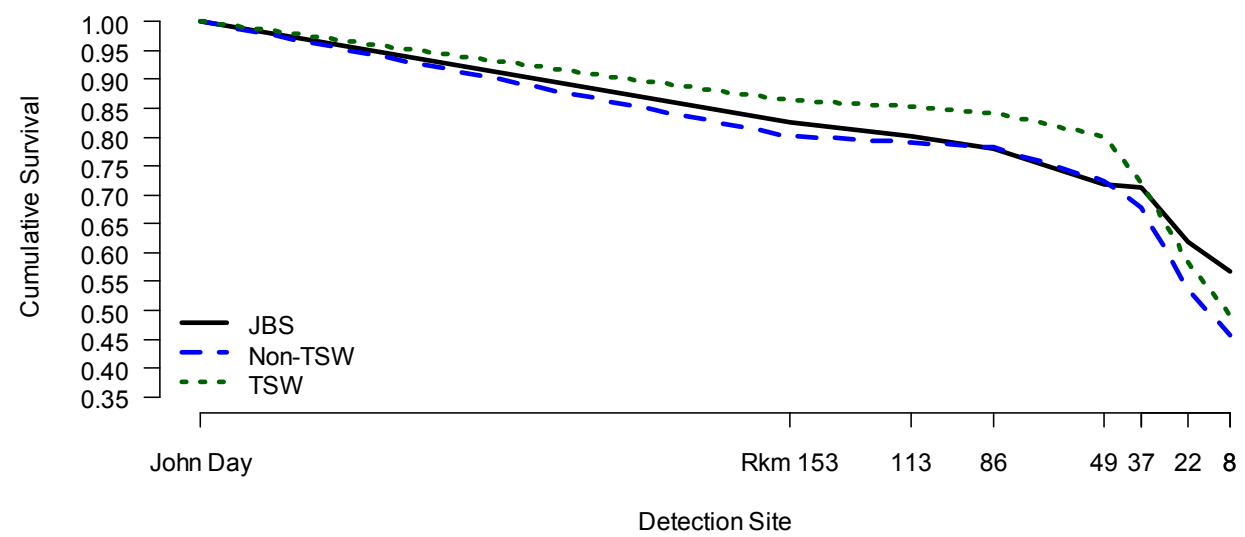

b. The Dalles

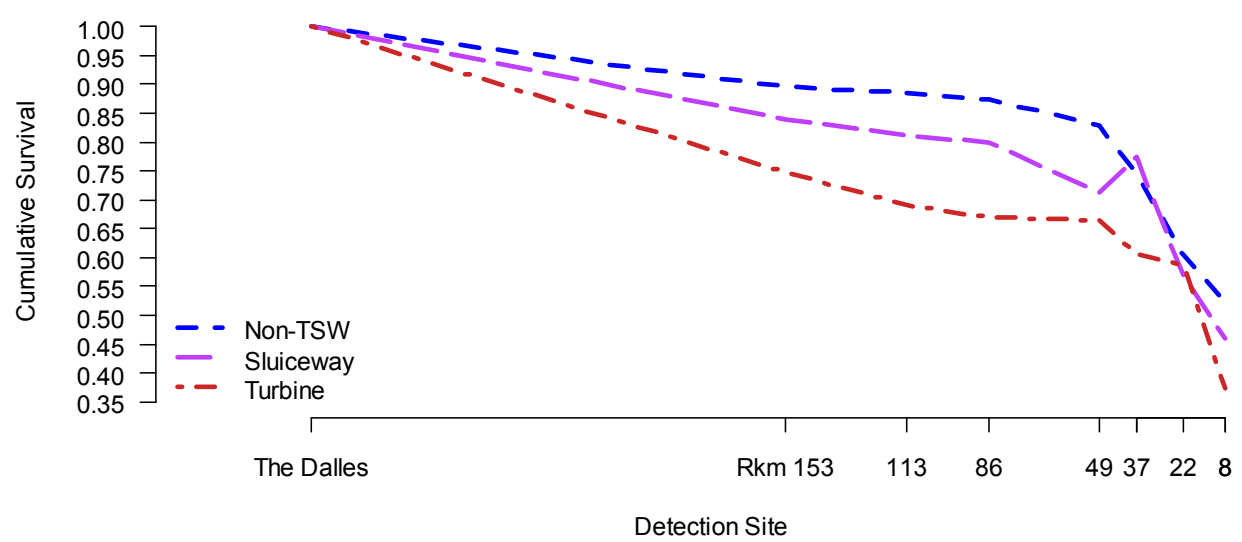

c. Bonneville
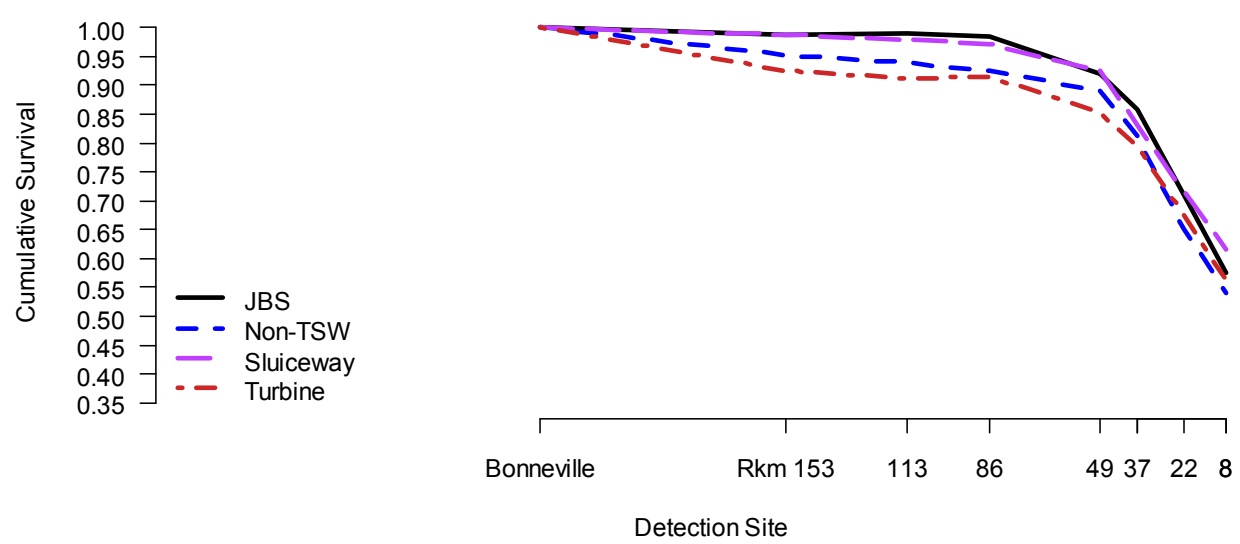

Figure 3.21. Cumulative survival probability estimates for steelhead smolts by passage route from dam face to rkm 153 to rkm 8.3 for at a) John Day, b) The Dalles, and c) Bonneville dams. 
a. John Day

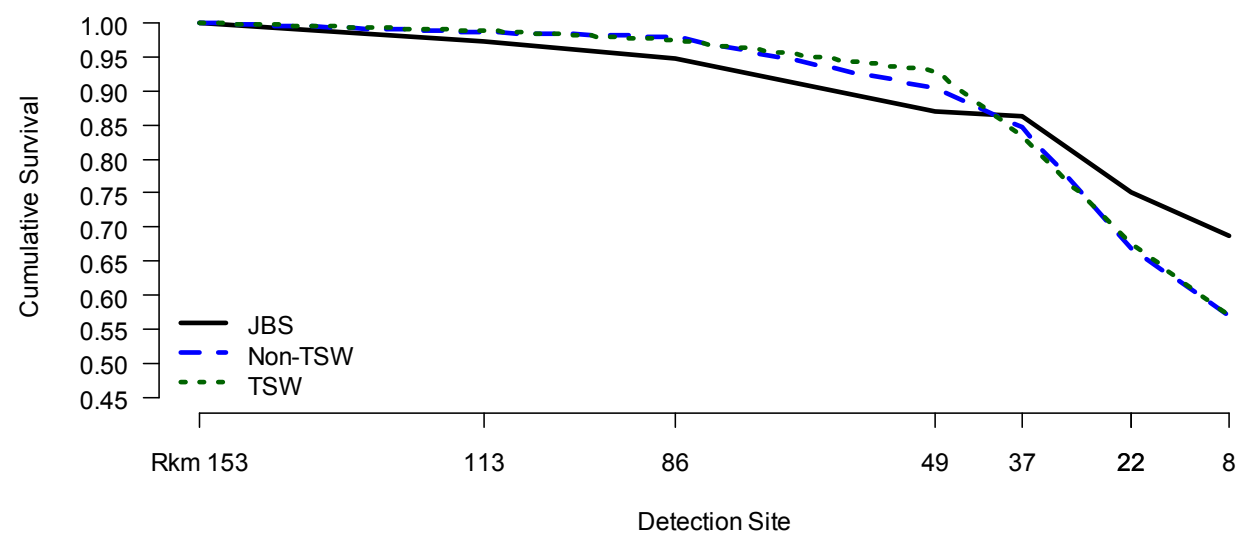

b. The Dalles

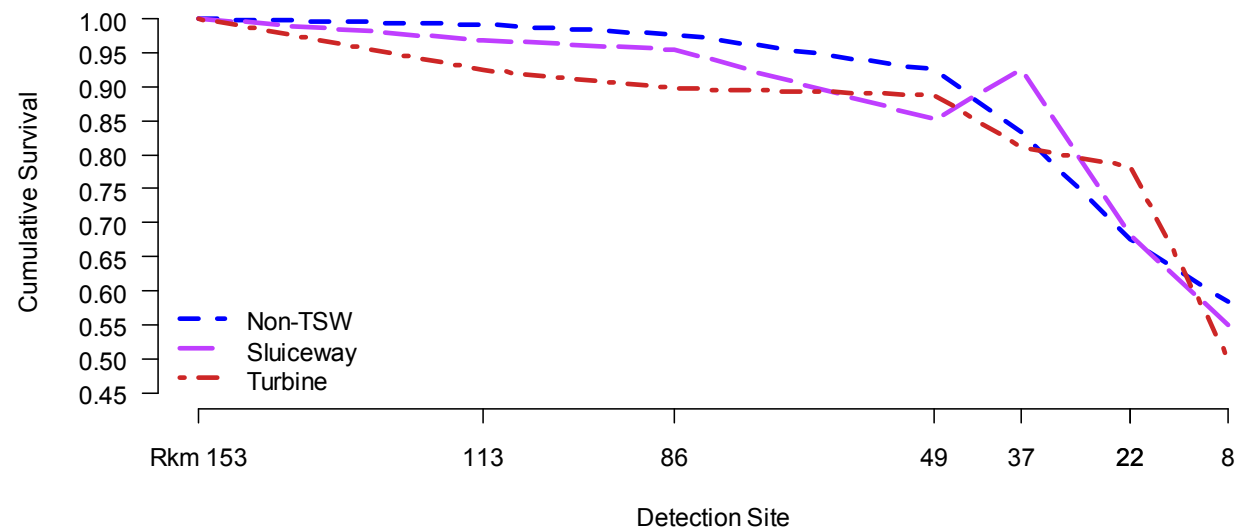

c. Bonneville

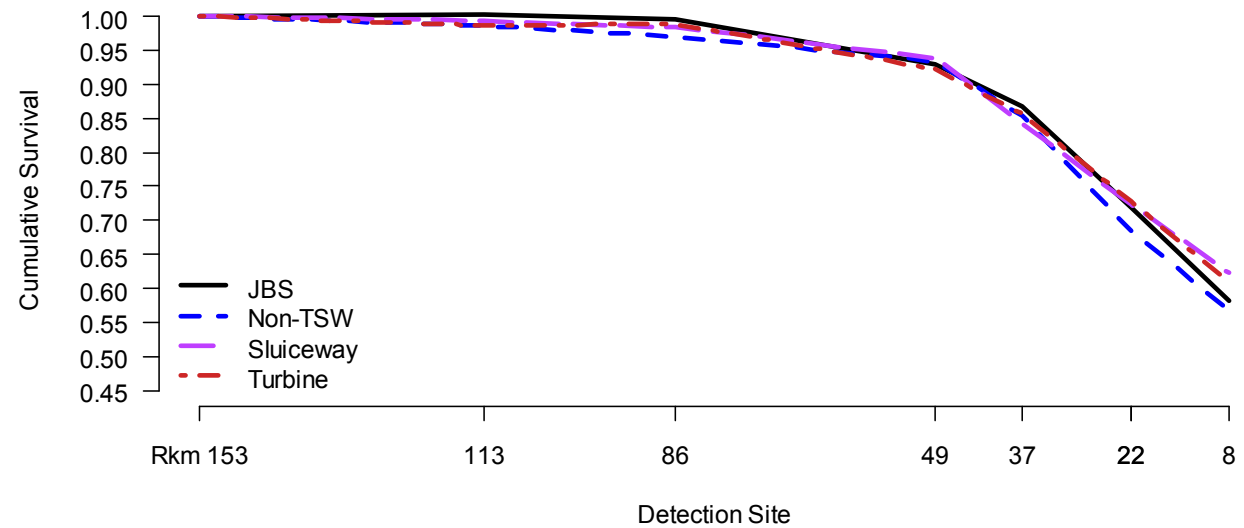

Figure 3.22. Cumulative survival probability estimates for steelhead smolts from rkm 153 to rkm 8.3 by different passage routes at a) John Day, b) The Dalles, and c) Bonneville dams. 
Steelhead smolts with different passage routes at Bonneville Dam had significant differences in survival probability to $\mathrm{rkm} 153(P=0.0001)$ but no differences between $\mathrm{rkm} 153$ and $8.3(P=0.4393$, Table 3.22). Steelhead that passed through turbines at Bonneville Dam had the lowest probability of survival to rkm 153. Reach-specific survival probabilities in the reach from rkm 153 to rkm 113 were significantly different with survivals ranging from 0.9858 to $1.0020(P=0.0381$, Table 3.23$)$. Cumulative survival probability estimates were significantly different to rkm $86.2(P=0.0407)$ with steelhead that passed through the JBS at Bonneville Dam having the highest survival probability and fish that passed through the non-TSW and turbine routes having the lowest survival probability. The significance in cumulative survival probability estimates disappeared further downriver (Table 3.24). The survivorship curves reflect these patterns of different survivals to rkm 153 and general homogeneity thereafter (Figure 3.21c, Figure 3.22c).

\section{Effects of Route-Specific Passage at Two Dams for Steelhead}

Examining steelhead smolts with joint passage histories at John Day and The Dalles dams indicates only four route combinations had adequate sample sizes for survival analysis (Table 3.25). Three of the four route combinations include passage through the non-TSW route at The Dalles Dam. No significant differences in survival probability were observed between any of the four routes from The Dalles Dam to rkm $153(P=0.9152)$, nor between rkm 153 and $8.3(P=0.2176$, Table 3.26). Examination of reachspecific survival probability estimates in individual reaches between rkm 153 and $\mathrm{rkm} 8.3$ found no significant differences $(P \geq 0.4076$, Table 3.27). Cumulative survival probabilities between rkm 153 and 8.3 were also not significantly different $(P \geq 0.2176$, Table 3.28$)$. Survivorship curves support these observations (Figure 3.23, Figure 3.24).

For steelhead with joint passage histories through The Dalles and Bonneville dams, only three route combinations had adequate sample sizes, all with passage through the non-TSW route at The Dalles Dam (Table 3.25). Survival probability estimates were significantly different to rkm $153(P=0.0012$, Table 3.26), with steelhead going through the turbines at Bonneville Dam having the lowest survival probability. Survival probability estimates between rkm 153 and 8.3 were also significantly different $(P=$ 0.0152); steelhead with a non-TSW passage history at Bonneville had lower survival probabilities. Survival probability estimates in the reach from rkm 113 to $\mathrm{rkm} 86.2$ were significantly different $(P=$ 0.0043, Table 3.27) as were cumulative survivals in three of six reaches (Table 3.28). Downstream of rkm 153, steelhead with non-TSW passage histories at The Dalles and Bonneville dams generally had the lowest survival probability where significant differences were observed. Survivorship curves support these general trends of divergent survival probabilities throughout the course of the outmigration (Figure 3.23, Figure 3.24). 
Table 3.25. Sample sizes of steelhead smolts available for survival analyses based on their joint passage history at a) John Day and The Dalles dams or b) The Dalles and Bonneville dams.

Combinations that are shaded were used in subsequent estimates of reach survivals.

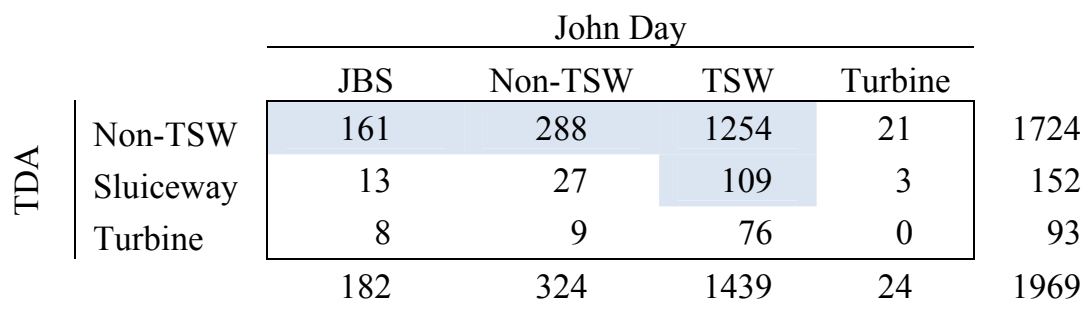

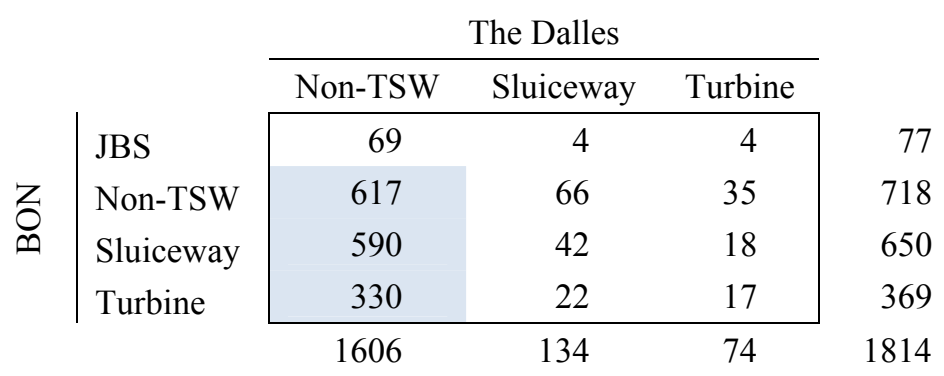

Table 3.26. Reach survival probability estimates for combinations of steelhead smolts by passage routes at John Day/The Dalles dams or The Dalles/Bonneville dams to rkm 153 and from rkm 153 to rkm 8.3 with associated standard errors (SEs). $P$-values are for tests of homogeneous survival.

\begin{tabular}{|c|c|c|c|c|c|c|}
\hline \multicolumn{2}{|c|}{ Routes } & \multirow[b]{2}{*}{ \# Fish } & \multicolumn{2}{|c|}{ To Rkm 153} & \multicolumn{2}{|c|}{ Rkm 153 - Rkm 8.3} \\
\hline John Day & The Dalles & & $\hat{S}$ & $\widehat{\mathrm{SE}}$ & $\hat{S}$ & $\widehat{\mathrm{SE}}$ \\
\hline JBS & Non-TSW & 161 & 0.8834 & 0.0263 & 0.7005 & 0.0613 \\
\hline Non-TSW & Non-TSW & 288 & 0.8726 & 0.0205 & 0.5852 & 0.0367 \\
\hline TSW & Non-TSW & 1254 & 0.8866 & 0.0092 & 0.5723 & 0.0172 \\
\hline \multirow[t]{2}{*}{ TSW } & Sluiceway & 109 & 0.8644 & 0.0348 & 0.5883 & 0.0650 \\
\hline & & & \multicolumn{2}{|c|}{$P$-value $=0.9152$} & \multicolumn{2}{|c|}{$P$-value $=0.2176$} \\
\hline The Dalles & Bonneville & & & & & \\
\hline Non-TSW & Non-TSW & 617 & 0.9256 & 0.0110 & 0.5332 & 0.0245 \\
\hline Non-TSW & Sluiceway & 590 & 0.9715 & 0.0074 & 0.6035 & 0.0237 \\
\hline \multirow[t]{2}{*}{ Non-TSW } & Turbine & 330 & 0.9115 & 0.0163 & 0.6500 & 0.0363 \\
\hline & & & \multicolumn{2}{|c|}{$P$-value $=0.0012$} & \multicolumn{2}{|c|}{$P$-value $=0.0152$} \\
\hline
\end{tabular}


Table 3.27. Reach-specific survival probability estimates and associated standard errors (SEs) for steelhead smolts for combinations of passage routes at John Day/The Dalles dams or The Dalles/Bonneville dams to rkm 153 and six reach-specific survivals between rkm 153 and rkm 8.3. $P$-values associated with $F$-tests of homogeneous survival.

\begin{tabular}{|c|c|c|c|c|c|c|c|c|c|c|c|c|c|c|c|c|}
\hline \multicolumn{2}{|c|}{ Route } & \multirow[b]{2}{*}{$N$} & \multicolumn{2}{|c|}{ Release to Rkm 153} & \multicolumn{2}{|c|}{ Rkm 153 to 113} & \multicolumn{2}{|c|}{$\mathrm{Rkm} 113$ to 86.2} & \multicolumn{2}{|c|}{$\mathrm{Rkm} 86.2$ to 49.6} & \multicolumn{2}{|c|}{$\mathrm{Rkm} 49.6$ to 37.3} & \multicolumn{2}{|c|}{$\mathrm{Rkm} 37.3$ to 22} & \multicolumn{2}{|c|}{ Rkm 22 to 8.3} \\
\hline Dam 1 & Dam 2 & & Estimate & SE & Estimate & SE & Estimate & SE & Estimate & SE & Estimate & SE & Estimate & SE & Estimate & SE \\
\hline John Day & The Dalles & & & & & & & & & & & & & & & \\
\hline JBS & TSW & 161 & 0.8834 & 0.0263 & 0.9776 & 0.0149 & 0.9712 & 0.0158 & 0.9349 & 0.0303 & 0.9780 & 0.0448 & 0.8748 & 0.0518 & 0.9225 & 0.0730 \\
\hline Non-TSW & Non-TSW & 288 & 0.8726 & 0.0205 & 0.9851 & 0.0099 & 0.9911 & 0.0080 & 0.9279 & 0.0265 & 0.9151 & 0.0398 & 0.7974 & 0.0423 & 0.8851 & 0.0433 \\
\hline TSW & Non-TSW & 1254 & 0.8866 & 0.0092 & 0.9935 & 0.0032 & 0.9871 & 0.0042 & 0.9549 & 0.0133 & 0.8885 & 0.0198 & 0.8048 & 0.0201 & 0.8546 & 0.0205 \\
\hline \multirow[t]{2}{*}{ TSW } & Sluiceway & 109 & 0.8644 & 0.0348 & 0.9728 & 0.0213 & 0.9796 & 0.0173 & 0.9041 & 0.0432 & 1.0571 & 0.0856 & 0.7552 & 0.0847 & 0.8552 & 0.0845 \\
\hline & \multicolumn{2}{|c|}{$P$-value $(F$-test $)$} & \multicolumn{2}{|c|}{0.9152} & \multicolumn{2}{|c|}{0.7399} & \multicolumn{2}{|c|}{0.6901} & \multicolumn{2}{|c|}{0.6961} & \multicolumn{2}{|c|}{0.4076} & \multicolumn{2}{|c|}{0.4850} & \multicolumn{2}{|c|}{0.8405} \\
\hline The Dalles & \multicolumn{16}{|l|}{ Bonneville } \\
\hline Non-TSW & Non-TSW & 617 & 0.9256 & 0.0110 & 0.9867 & 0.0061 & 0.9729 & 0.0076 & 0.9725 & 0.0202 & 0.8840 & 0.0306 & 0.7572 & 0.0299 & 0.8533 & 0.0311 \\
\hline Non-TSW & Sluiceway & 590 & 0.9715 & 0.0074 & 0.9925 & 0.0047 & 0.9898 & 0.0055 & 0.9345 & 0.0180 & 0.9122 & 0.0265 & 0.8282 & 0.0277 & 0.8703 & 0.0277 \\
\hline \multirow[t]{2}{*}{ Non-TSW } & Turbine & 330 & 0.9115 & 0.0163 & 0.9869 & 0.0082 & 1.0010 & 0.0040 & 0.9458 & 0.0216 & 0.8973 & 0.0306 & 0.8655 & 0.0331 & 0.8958 & 0.0422 \\
\hline & \multicolumn{2}{|c|}{$P$-value $(F$-test $)$} & \multicolumn{2}{|c|}{0.0012} & \multicolumn{2}{|c|}{0.7741} & \multicolumn{2}{|c|}{0.0043} & \multicolumn{2}{|c|}{0.3859} & \multicolumn{2}{|c|}{0.7929} & \multicolumn{2}{|c|}{0.0369} & \multicolumn{2}{|c|}{0.6764} \\
\hline
\end{tabular}

Table 3.28. Cumulative reach survival probability estimates and associated standard errors (SEs) for steelhead smolts for combinations of passage routes at John Day/The Dalles dams or The Dalles/Bonneville dams from rkm 153 to rkm 8.3. P-values associated with $F$ tests of homogeneous survival.

\begin{tabular}{|c|c|c|c|c|c|c|c|c|c|c|c|c|c|c|}
\hline \multicolumn{2}{|c|}{ Route } & & \multicolumn{2}{|c|}{ Rkm 153 to 113} & \multicolumn{2}{|c|}{ Rkm 153 to 86.2} & \multicolumn{2}{|c|}{ Rkm 153 to 49.6} & \multicolumn{2}{|c|}{ Rkm 153 to 37.3} & \multicolumn{2}{|c|}{$\mathrm{Rkm} 153$ to 22} & \multicolumn{2}{|c|}{ Rkm 153 to 8.3} \\
\hline Dam 1 & Dam 2 & $N$ & Estimate & SE & Estimate & SE & Estimate & SE & Estimate & SE & Estimate & SE & Estimate & SE \\
\hline John Day & The Dalles & & & & & & & & & & & & & \\
\hline JBS & TSW & 161 & 0.9776 & 0.0149 & 0.9493 & 0.0202 & 0.8876 & 0.0339 & 0.8680 & 0.0438 & 0.7593 & 0.0432 & 0.7005 & 0.0613 \\
\hline Non-TSW & Non-TSW & 288 & 0.9851 & 0.0099 & 0.9764 & 0.0121 & 0.9060 & 0.0276 & 0.8291 & 0.0359 & 0.6611 & 0.0342 & 0.5852 & 0.0367 \\
\hline TSW & Non-TSW & 1254 & 0.9935 & 0.0032 & 0.9806 & 0.0051 & 0.9364 & 0.0137 & 0.8320 & 0.0170 & 0.6696 & 0.0163 & 0.5723 & 0.0172 \\
\hline \multirow[t]{2}{*}{ TSW } & Sluiceway & 109 & 0.9728 & 0.0213 & 0.9529 & 0.0257 & 0.8615 & 0.0465 & 0.9106 & 0.0783 & 0.6878 & 0.0600 & 0.5883 & 0.0650 \\
\hline & \multicolumn{2}{|c|}{$P$-value $(F$-test $)$} & \multicolumn{2}{|c|}{0.7399} & \multicolumn{2}{|c|}{0.4809} & \multicolumn{2}{|c|}{0.4241} & \multicolumn{2}{|c|}{0.6121} & \multicolumn{2}{|c|}{0.3253} & \multicolumn{2}{|c|}{0.2176} \\
\hline The Dalles & Bonneville & & & & & & & & & & & & & \\
\hline Non-TSW & Non-TSW & 617 & 0.9867 & 0.0061 & 0.9600 & 0.0091 & 0.9337 & 0.0211 & 0.8252 & 0.0257 & 0.6249 & 0.0231 & 0.5332 & 0.0245 \\
\hline Non-TSW & Sluiceway & 590 & 0.9925 & 0.0047 & 0.9824 & 0.0069 & 0.9179 & 0.0183 & 0.8374 & 0.0233 & 0.6935 & 0.0224 & 0.6035 & 0.0237 \\
\hline \multirow[t]{2}{*}{ Non-TSW } & Turbine & 330 & 0.9869 & 0.0082 & 0.9879 & 0.0091 & 0.9344 & 0.0224 & 0.8385 & 0.0280 & 0.7257 & 0.0299 & 0.6500 & 0.0363 \\
\hline & \multicolumn{2}{|c|}{$P$-value $(F$-test $)$} & \multicolumn{2}{|c|}{0.7741} & \multicolumn{2}{|c|}{0.0463} & \multicolumn{2}{|c|}{0.8157} & \multicolumn{2}{|c|}{0.9210} & \multicolumn{2}{|c|}{0.0162} & \multicolumn{2}{|c|}{0.0152} \\
\hline
\end{tabular}


a. John Day/The Dalles

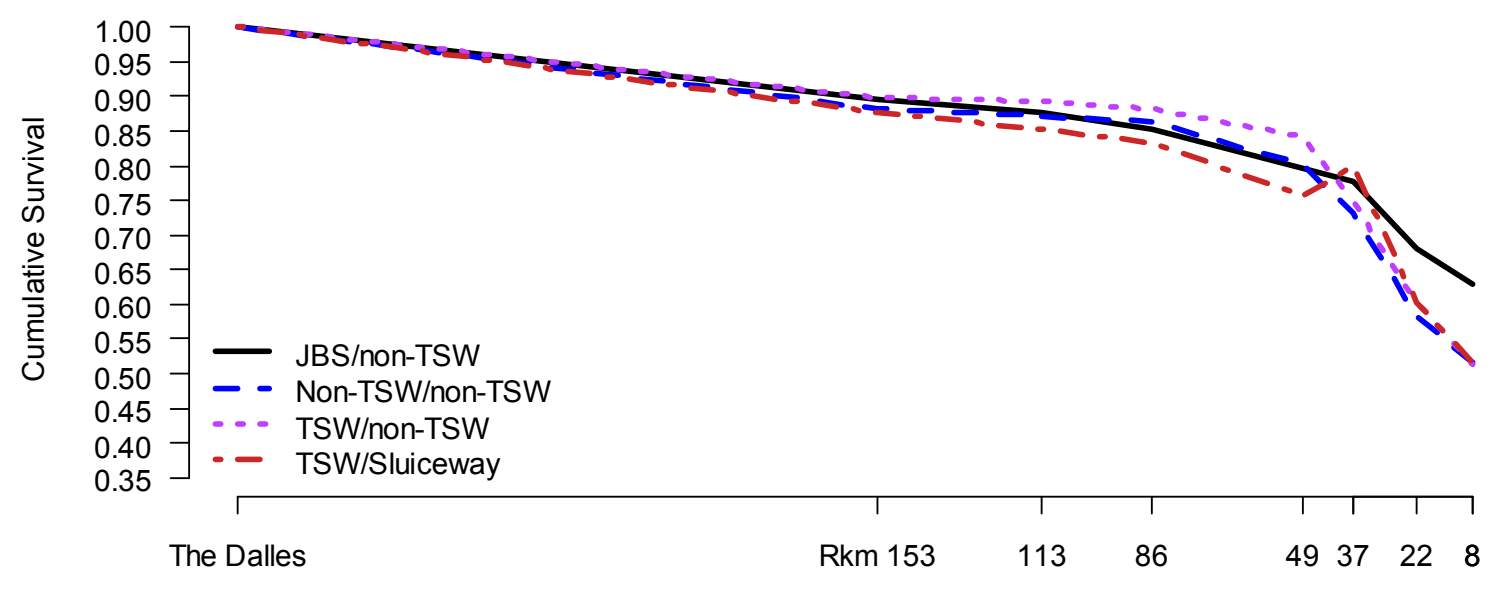

b. The Dalles/Bonneville

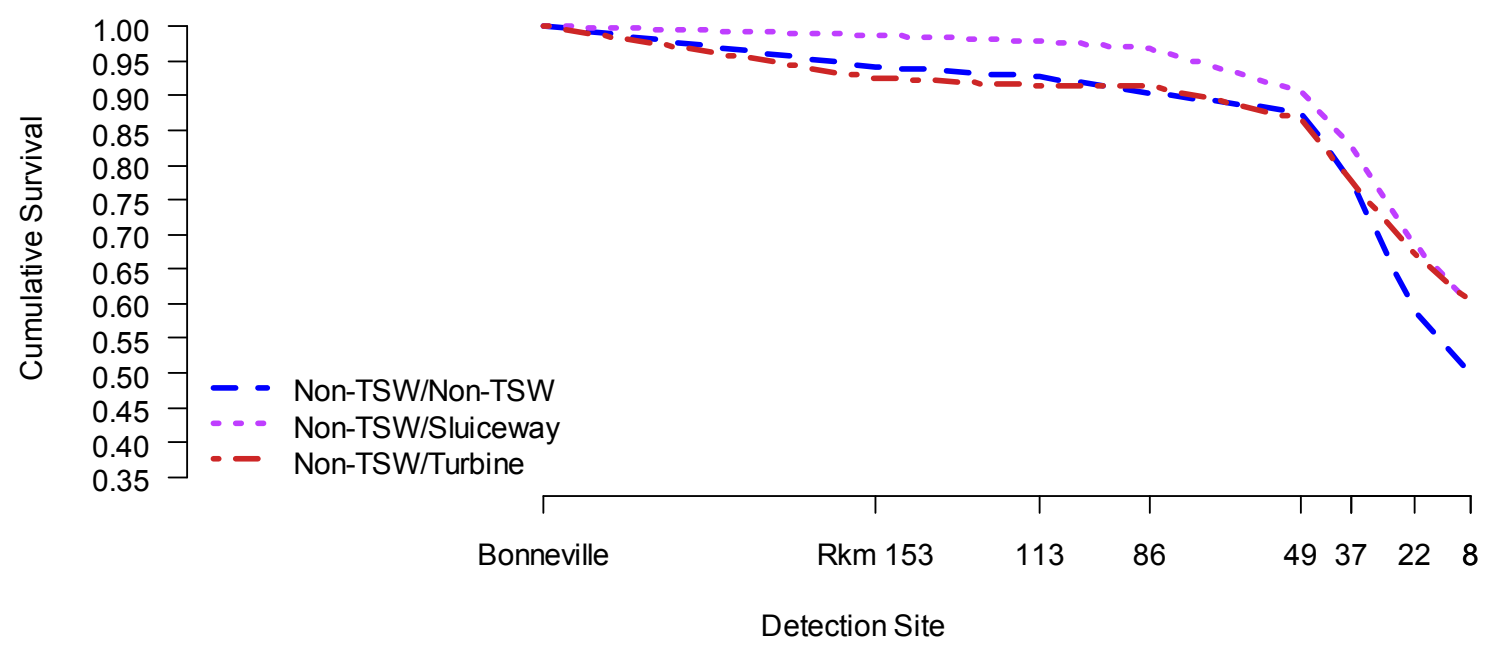

Figure 3.23. Cumulative survival probability estimates for steelhead smolts for various combinations of passage routes at a) John Day and The Dalles dams and b) The Dalles and Bonneville dams, from the dam face of the downriver dam in the pair to rkm 153 and below to rkm 8.3. 
a. John Day/The Dalles

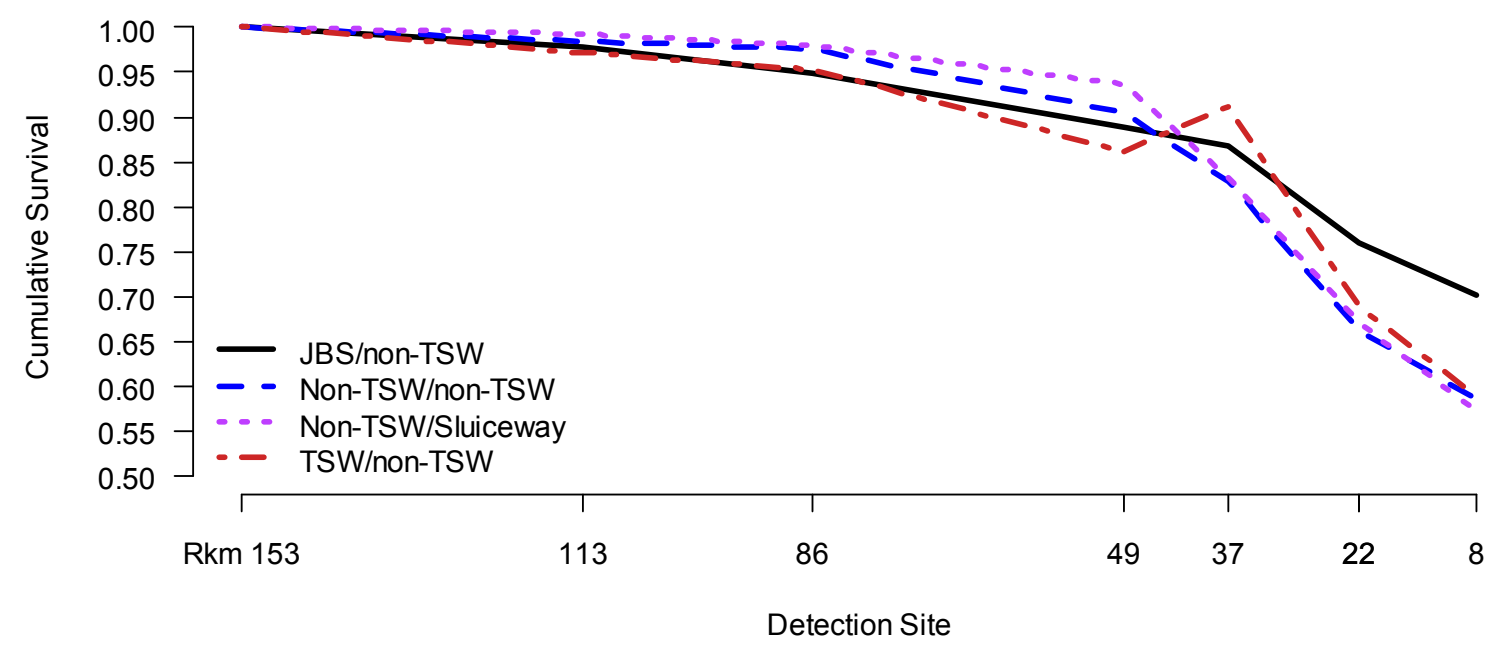

b. The Dalles/Bonneville

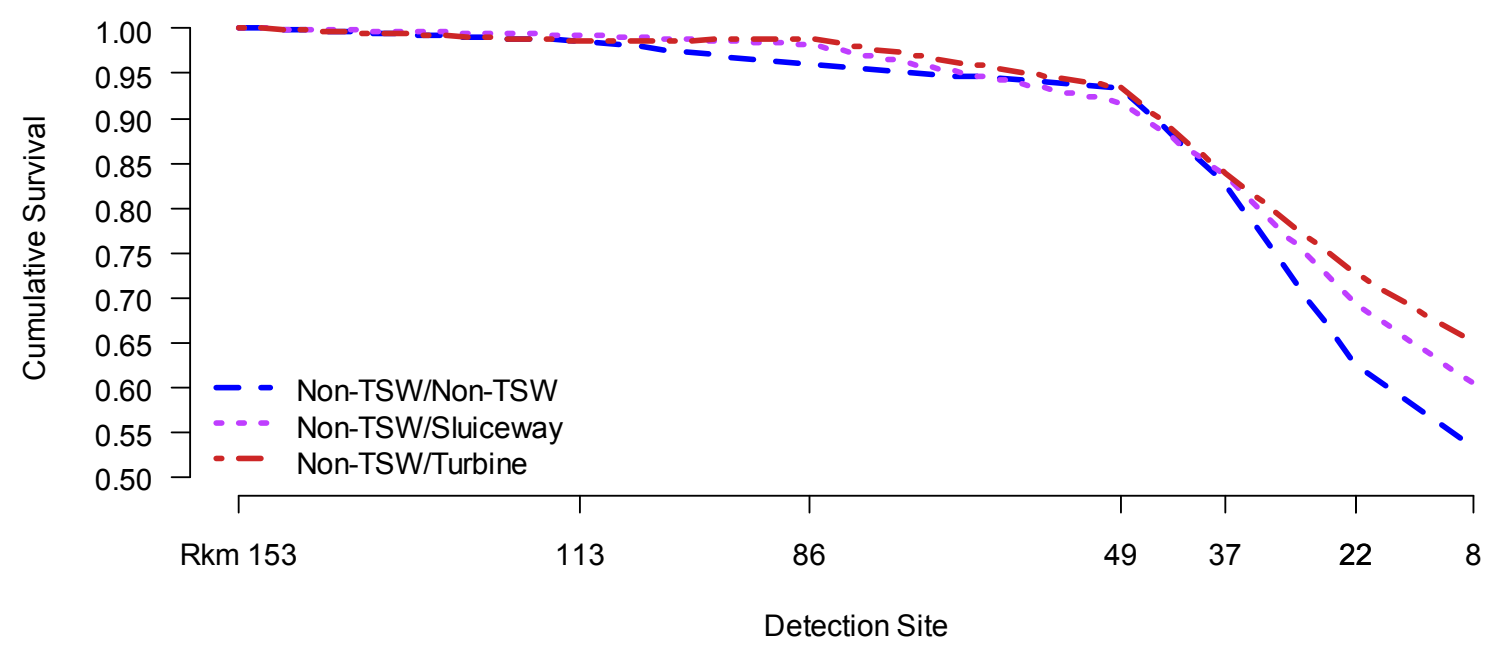

Figure 3.24. Cumulative survival probability estimates for steelhead smolts for various combinations of passage routes at a) John Day and The Dalles dams and b) The Dalles and Bonneville dams between rkm 153 and rkm 8.3.

\section{Effects of Route-Specific Passage at Three Dams for Steelhead}

Only four joint passage histories at John Day/The Dalles/Bonneville dams had sufficient sample sizes for survival analysis (Table 3.29). All four of these histories had non-TSW passage at The Dalles Dam, and TSW or non-TSW passage at John Day Dam. For these four passage histories, survival probabilities were not significantly different to rkm $153(P=0.1575)$, nor from rkm 153 to rkm $8.3(P=0.1480$, Table 3.30). Individual reach-specific survival probability estimates between rkm 153 and rkm 8.3 were not significantly different $(P \geq 0.0656$, Table 3.31), nor were cumulative survival probabilities as the steelhead migrated downriver $(P \geq 0.0910$, Table 3.32). Cumulative survivorship curves for steelhead reflect these survival patterns (Figure 3.25, Figure 3.26). 
Table 3.29. Sample sizes of steelhead smolts available for survival analyses based on their joint passage history starting at the John Day a) JBS, b) TSW, c) non-TSW, or d) turbine passage routes and their subsequent passage through both The Dalles and Bonneville dams. Combinations that are shaded were used in subsequent estimation of reach survivals.

(a) John Day JBS

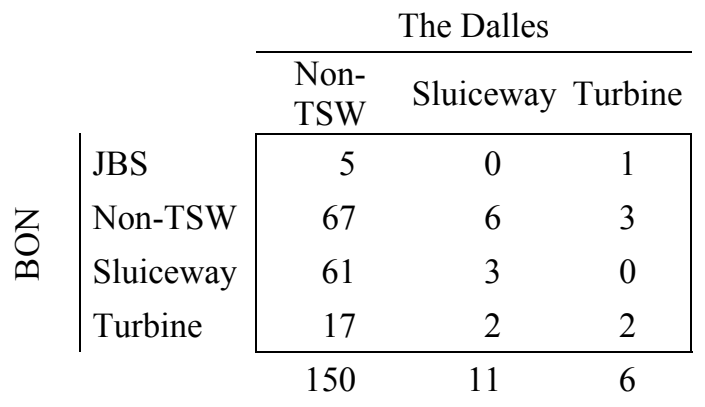

(b) John Day TSW

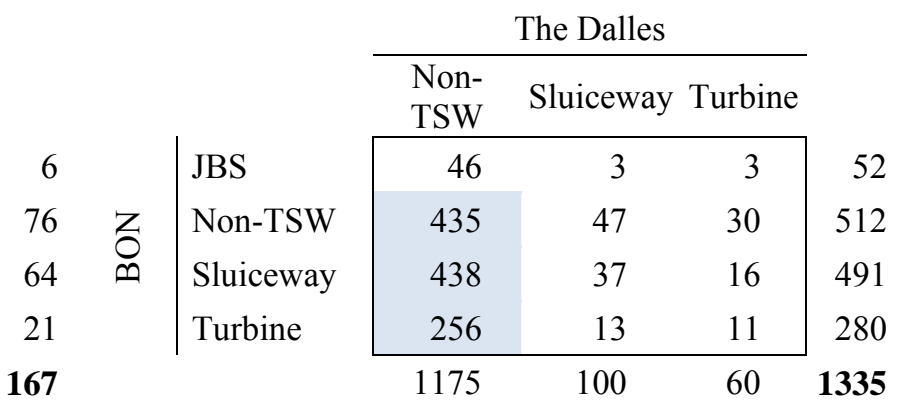

(c) John Day non-TSW

\begin{tabular}{|c|c|c|c|}
\hline & & The Dalles & \\
\hline & $\begin{array}{l}\text { Non- } \\
\text { TSW }\end{array}$ & Sluiceway & Turbine \\
\hline JBS & 18 & 1 & 0 \\
\hline Non-TSW & 108 & 12 & 2 \\
\hline Sluiceway & 85 & 2 & 2 \\
\hline Turbine & 54 & 6 & 4 \\
\hline & 265 & 21 & 8 \\
\hline
\end{tabular}

(d) John Day Turbine

\begin{tabular}{|c|c|c|c|c|c|}
\hline & & & & The Dalles & \\
\hline & & & $\begin{array}{l}\text { Non- } \\
\text { TSW }\end{array}$ & Sluiceway & Turbine \\
\hline 19 & & JBS & 0 & 0 & 0 \\
\hline 122 & $z$ & Non-TSW & 7 & 1 & 0 \\
\hline 89 & 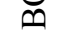 & Sluiceway & 7 & 0 & 0 \\
\hline 64 & & Turbine & 3 & 1 & 0 \\
\hline 294 & & & 17 & 2 & 0 \\
\hline
\end{tabular}

Table 3.30. Cumulative survival probability estimates for steelhead smolts with known passage routes at each dam measured from Bonneville Dam to rkm 153 and from rkm 153 to rkm 8.3 with associated standard errors (SEs). $P$-values are for tests of homogeneous survival.

\begin{tabular}{|c|c|c|c|c|c|c|c|}
\hline \multicolumn{3}{|c|}{ Route } & \multirow[b]{2}{*}{ \# Fish } & \multicolumn{2}{|c|}{ Route - Rkm 153} & \multicolumn{2}{|c|}{ Rkm 153 - Rkm 8.3} \\
\hline John Day & The Dalles & Bonneville & & $\hat{S}$ & $\widehat{\mathrm{SE}}$ & $\hat{S}$ & $\widehat{\mathrm{SE}}$ \\
\hline Non-TSW & Non-TSW & Non-TSW & 108 & 0.9402 & 0.0241 & 0.5415 & 0.0584 \\
\hline TSW & Non-TSW & Non-TSW & 435 & 0.9270 & 0.0131 & 0.5260 & 0.0284 \\
\hline TSW & Non-TSW & Sluiceway & 438 & 0.9672 & 0.0088 & 0.5758 & 0.0266 \\
\hline \multirow[t]{2}{*}{ TSW } & Non-TSW & Turbine & 256 & 0.9150 & 0.0181 & 0.6482 & 0.0413 \\
\hline & & & Overall & $P$-value $=$ & & $P$-value & 1480 \\
\hline
\end{tabular}


Table 3.31. Reach-specific survival probability estimates and associated standard errors (SEs) for steelhead smolts for combinations of passage routes at John Day/The Dalles/Bonneville dams to rkm 153 and six reach-specific survivals between rkm 153 and rkm 8.3. $P$-values associated with $F$-tests of homogeneous survival.

\begin{tabular}{|c|c|c|c|c|c|c|c|c|c|c|c|c|c|c|c|c|c|}
\hline \multicolumn{3}{|c|}{ Routes } & \multirow[b]{2}{*}{$N$} & \multicolumn{2}{|c|}{ Release to Rkm 153} & \multicolumn{2}{|c|}{ Rkm 153 to 113} & \multicolumn{2}{|c|}{ Rkm 113 to 86.2} & \multicolumn{2}{|c|}{$\mathrm{Rkm} 86.2$ to 49.6} & \multicolumn{2}{|c|}{$\mathrm{Rkm} 49.6$ to 37.3} & \multicolumn{2}{|c|}{$\mathrm{Rkm} 37.3$ to 22.0} & \multicolumn{2}{|c|}{$\mathrm{Rkm} 22.0$ to 8.3} \\
\hline JDA & TDA & BON & & Estimate & $\mathrm{SE}$ & Estimate & SE & Estimate & $\mathrm{SE}$ & Estimate & SE & Estimate & SE & Estimate & SE & Estimate & $\mathrm{SE}$ \\
\hline Non-TSW & Non-TSW & Non-TSW & 108 & 0.9402 & 0.0241 & 0.9886 & 0.0135 & 0.9825 & 0.0151 & 0.9179 & 0.0433 & 0.9739 & 0.0647 & 0.7018 & 0.0657 & 0.8885 & 0.0703 \\
\hline TSW & Non-TSW & Non-TSW & 435 & 0.9270 & 0.0131 & 0.9862 & 0.0074 & 0.9738 & 0.0088 & 0.9927 & 0.0245 & 0.8590 & 0.0367 & 0.7716 & 0.0364 & 0.8323 & 0.0368 \\
\hline TSW & Non-TSW & Sluiceway & 438 & $0.9672^{1}$ & 0.0088 & 1.0015 & 0.0010 & 0.9907 & 0.0063 & 0.9352 & 0.0222 & 0.9024 & 0.0321 & 0.7967 & 0.0322 & 0.8631 & 0.0306 \\
\hline \multirow[t]{2}{*}{ TSW } & Non-TSW & Turbine & 256 & 0.9150 & 0.0181 & 0.9891 & 0.0086 & 0.9996 & 0.0049 & 0.9507 & 0.0244 & 0.8951 & 0.0352 & 0.8707 & 0.0376 & 0.8847 & 0.0480 \\
\hline & \multicolumn{3}{|c|}{ Overall $P$-value $(F$-test $)$} & \multicolumn{2}{|c|}{0.1575} & \multicolumn{2}{|c|}{0.6923} & \multicolumn{2}{|c|}{0.2666} & \multicolumn{2}{|c|}{0.3283} & \multicolumn{2}{|c|}{0.3136} & \multicolumn{2}{|c|}{0.0656} & \multicolumn{2}{|c|}{0.8408} \\
\hline
\end{tabular}

Table 3.32. Cumulative reach survival probability estimates and associated standard errors (SEs) for steelhead smolts for combinations of passage routes at John Day/The Dalles/Bonneville dams from rkm 153 to rkm 8.3. P-values associated with $F$-tests of homogeneous survival.

\begin{tabular}{|c|c|c|c|c|c|c|c|c|c|c|c|c|c|c|c|}
\hline \multicolumn{3}{|c|}{ Routes } & \multirow[b]{2}{*}{$N$} & \multicolumn{2}{|c|}{ Rkm 153 to 113} & \multicolumn{2}{|c|}{ Rkm 153 to 86.2} & \multicolumn{2}{|c|}{$\mathrm{Rkm} 153$ to 49.6} & \multicolumn{2}{|c|}{ Rkm 153 to 37.3} & \multicolumn{2}{|c|}{ Rkm 153 to 22.0} & \multicolumn{2}{|c|}{$\mathrm{Rkm} 153$ to 8.3} \\
\hline JDA & TDA & BON & & Estimate & SE & Estimate & $\mathrm{SE}$ & Estimate & $\mathrm{SE}$ & Estimate & $\mathrm{SE}$ & Estimate & SE & Estimate & $\mathrm{SE}$ \\
\hline Non-TSW & Non-TSW & Non-TSW & 108 & 0.9886 & 0.0135 & 0.9714 & 0.0193 & 0.8915 & 0.0450 & 0.8685 & 0.0578 & 0.6094 & 0.0528 & 0.5415 & 0.0584 \\
\hline TSW & Non-TSW & Non-TSW & 435 & 0.9862 & 0.0074 & 0.9603 & 0.0109 & 0.9533 & 0.0256 & 0.8190 & 0.0306 & 0.6319 & 0.0281 & 0.5260 & 0.0284 \\
\hline TSW & Non-TSW & Sluiceway & 438 & 1.0015 & 0.0010 & 0.9922 & 0.0061 & 0.9279 & 0.0222 & 0.8373 & 0.0274 & 0.6671 & 0.0258 & 0.5758 & 0.0266 \\
\hline \multirow[t]{2}{*}{ TSW } & Non-TSW & Turbine & 256 & 0.9891 & 0.0086 & 0.9887 & 0.0097 & 0.9400 & 0.0252 & 0.8414 & 0.0320 & 0.7327 & 0.0336 & 0.6482 & 0.0413 \\
\hline & \multicolumn{3}{|c|}{ Overall $P$-value ( $F$-test) } & \multicolumn{2}{|c|}{0.6923} & \multicolumn{2}{|c|}{0.2286} & \multicolumn{2}{|c|}{0.5275} & \multicolumn{2}{|c|}{0.8427} & \multicolumn{2}{|c|}{0.0910} & \multicolumn{2}{|c|}{0.1480} \\
\hline
\end{tabular}

\footnotetext{
${ }^{1}$ Estimated using the closed form parameter estimator.
} 


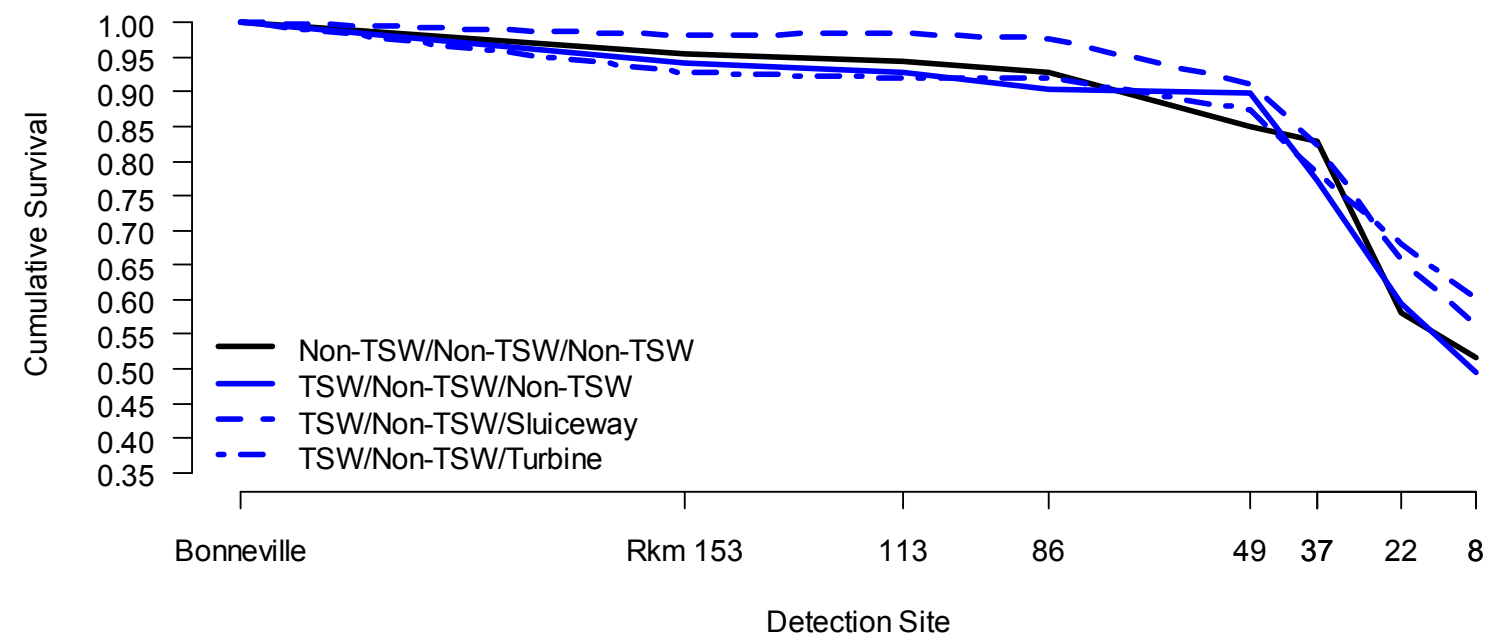

Figure 3.25. Cumulative survival probability estimates for steelhead smolts for various combinations of passage routes at John Day, The Dalles, and Bonneville dams from Bonneville Dam to rkm 8.3.

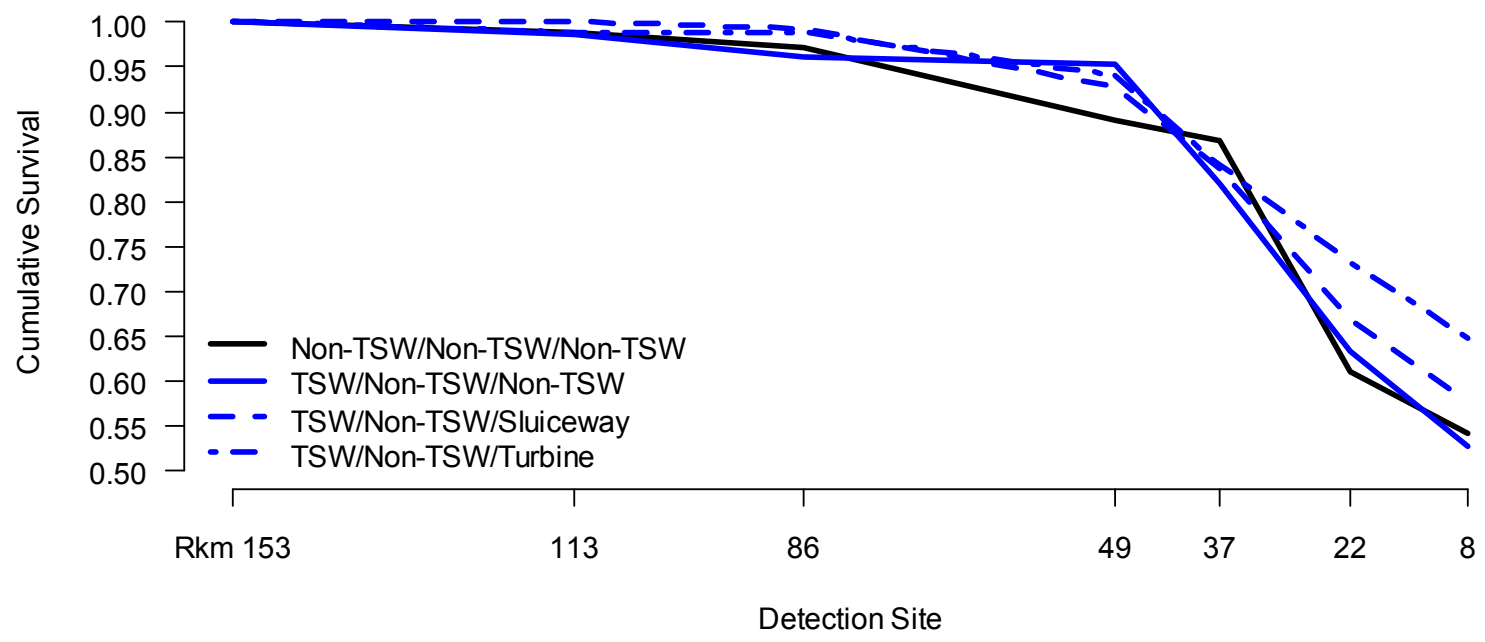

Figure 3.26. Cumulative survival probability estimates for steelhead smolts for various combinations of passage routes at John Day, The Dalles, and Bonneville dams from rkm 153 to rkm 8.3.

\subsubsection{Subyearling Chinook Salmon Passage}

\section{Effects of Route-Specific Passage at One Dam on Subyearling Chinook Salmon}

Subyearling Chinook salmon that passed through the different routes at John Day Dam had significantly different survival probabilities to $\mathrm{rkm} 153(P=0.0001$, Table 3.33$)$ with turbine-passed fish having the lowest survival ( $\hat{S}=0.7033, \widehat{\mathrm{SE}}=0.0263$ ) and JBS-passed fish having the highest survival probability ( $\hat{S}=0.8157, \widehat{\mathrm{SE}}=0.0237$ ). There was no significant difference in cumulative survival probability between rkm 153 and 8.3 for fish that passed through different routes at John Day Dam $(P=$ 0.4472 , Table 3.33$)$. Reach-specific survival probability estimates were not significantly different $(P \geq$ 
0.2515, Table 3.34) among the passage routes, nor were cumulative survival probabilities $(P \geq 0.2979$, Table 3.35) from rkm 153 to rkm 8.3. Cumulative survival probability plots illustrate the differences to rkm 153 and homogeneity thereafter (Figure 3.27a, Figure 3.28a).

For subyearling Chinook salmon smolts that passed through The Dalles Dam, survival probabilities to rkm 153 were significantly different for fish with different passage routes $(P<0.0001$, Table 3.33); turbine-passed fish had the lowest survival probability and sluiceway-passed fish had the highest survival probability. Between rkm 153 and 8.3, cumulative survival probabilities were not different for fish with different passage histories at The Dalles Dam $(P=0.2523$, Table 3.33). Reach-specific survival probabilities in individual reaches between $\mathrm{rkm} 153$ and 8.3 were significantly different for the reach from rkm 86.2 to rkm 49.6 ( $P=0.0008$, Table 3.34), but cumulative survival probabilities were never significantly different for subyearlings with different passage routes through The Dalles Dam $(P \geq$ 0.0790, Table 3.35). Survivorship plots illustrate the large differences to rkm 153 and general homogeneity thereafter (Figure 3.27b, Figure 3.28b).

Subyearling Chinook salmon smolts with different passage histories through Bonneville Dam had significantly different $(P=0.0177)$ survival probabilities to rkm 153 but homogeneity from there to rkm $8.3(P=0.8652$, Table 3.33). Subyearling smolts that went through the non-TSW route at Bonneville had lower survival probability to rkm 153 than fish with other passage histories. Fish that went through the JBS at Bonneville Dam had the highest survival probability to rkm 153. Individual reach-specific survival probabilities between rkm 153 and 8.3 were not significantly different $(P \geq 0.5776$, Table 3.34), nor were cumulative survival probabilities $(P \geq 0.5694$, Table 3.35). Survivorship plots confirm the appreciable differences to rkm 153 and homogeneity thereafter (Figure 3.27c, Figure 3.28c).

Table 3.33. Reach survival probability estimates for subyearling Chinook salmon smolts by passage routes at a particular dam to rkm 153 and from rkm 153 to $\mathrm{rkm} 8.3$ with associated standard errors (SEs). $P$-values are for tests of homogeneous survival.

\begin{tabular}{|c|c|c|c|c|c|c|}
\hline \multirow[b]{2}{*}{ Dam } & \multirow[b]{2}{*}{ Route } & \multirow[b]{2}{*}{ \# Fish } & \multicolumn{2}{|c|}{ Route - Rkm 153} & \multicolumn{2}{|c|}{ Rkm 153 - Rkm 8.3} \\
\hline & & & $\hat{S}$ & $\widehat{\mathrm{SE}}$ & $\hat{S}$ & $\widehat{\mathrm{SE}}$ \\
\hline \multirow[t]{5}{*}{ John Day } & JBS & 279 & 0.8157 & 0.0237 & 0.8436 & 0.0264 \\
\hline & Non-TSW & 1207 & 0.8005 & 0.0116 & 0.8922 & 0.0122 \\
\hline & TSW & 810 & 0.7328 & 0.0156 & 0.8550 & 0.0179 \\
\hline & Turbine & 305 & 0.7033 & 0.0263 & 0.8647 & 0.0279 \\
\hline & & & \multicolumn{2}{|c|}{$P$-value $=0.0001$} & \multicolumn{2}{|c|}{$P$-value $=0.4472$} \\
\hline \multirow[t]{4}{*}{ The Dalles } & Non-TSW & 1696 & 0.8485 & 0.0088 & 0.8623 & 0.0108 \\
\hline & Sluiceway & 279 & 0.8892 & 0.0193 & 0.8835 & 0.0229 \\
\hline & Turbine & 405 & 0.7817 & 0.0208 & 0.9072 & 0.0214 \\
\hline & & & \multicolumn{2}{|c|}{$P$-value $<0.0001$} & \multicolumn{2}{|c|}{$P$-value $=0.2523$} \\
\hline \multirow[t]{5}{*}{ Bonneville } & JBS & 111 & 0.9757 & 0.0156 & 0.8563 & 0.0389 \\
\hline & Non-TSW & 1782 & 0.9306 & 0.0062 & 0.8664 & 0.0100 \\
\hline & Sluiceway & 505 & 0.9586 & 0.0091 & 0.8610 & 0.0179 \\
\hline & Turbine & 1001 & 0.9525 & 0.0069 & 0.8822 & 0.0119 \\
\hline & & & \multicolumn{2}{|c|}{$P$-value $=0.0177$} & \multicolumn{2}{|c|}{$P$-value $=0.8652$} \\
\hline
\end{tabular}


Table 3.34. Reach-specific survival probability estimates and associated standard errors (SEs) for subyearling Chinook salmon smolts by passage route at a particular dam to $\mathrm{rkm} 153$ and six reach-specific survivals between rkm 153 and rkm 8.3. Results are presented for four routes at John Day Dam, three routes at The Dalles Dam, and four routes at Bonneville Dam, along with SEs and P-values associated with $F$-tests of homogeneous survival.

\begin{tabular}{|c|c|c|c|c|c|c|c|c|c|c|c|c|c|c|c|c|}
\hline \multirow[b]{2}{*}{ Dam } & \multirow[b]{2}{*}{ Route } & \multirow[b]{2}{*}{$N$} & \multicolumn{2}{|c|}{ Release to Rkm 153} & \multicolumn{2}{|c|}{ Rkm 153 to 113} & \multicolumn{2}{|c|}{ Rkm 113 to 86.2} & \multicolumn{2}{|c|}{$\mathrm{Rkm} 86.2$ to 49.6} & \multicolumn{2}{|c|}{ Rkm 49.6 to 37.3} & \multicolumn{2}{|c|}{$\mathrm{Rkm} 37.3$ to 22} & \multicolumn{2}{|c|}{$\mathrm{Rkm} 22$ to 8.3} \\
\hline & & & Estimate & $\mathrm{SE}$ & Estimate & $\mathrm{SE}$ & Estimate & $\mathrm{SE}$ & Estimate & $\mathrm{SE}$ & Estimate & SE & Estimate & $\overline{\mathrm{SE}}$ & Estimate & $\mathrm{SE}$ \\
\hline \multirow[t]{5}{*}{ John Day } & JBS & 279 & 0.8157 & 0.0237 & 0.9903 & 0.0071 & 0.9879 & 0.0080 & 0.9897 & 0.0140 & 0.9855 & 0.0225 & 0.9176 & 0.0259 & 0.9635 & 0.0197 \\
\hline & Non-TSW & 1207 & 0.8005 & 0.0116 & 0.9797 & 0.0050 & 0.9906 & 0.0035 & 0.9853 & 0.0059 & 0.9835 & 0.0082 & 0.9712 & 0.0088 & 0.9766 & 0.0097 \\
\hline & TSW & 810 & 0.7328 & 0.0156 & 0.9780 & 0.0065 & 0.9837 & 0.0057 & 0.9752 & 0.0085 & 1.0006 & 0.0127 & 0.9252 & 0.0164 & 0.9844 & 0.0143 \\
\hline & Turbine & 305 & 0.7033 & 0.0263 & 0.9889 & 0.0082 & 0.9841 & 0.0098 & 0.9650 & 0.0152 & 1.0120 & 0.0188 & 0.9433 & 0.0254 & 0.9645 & 0.0231 \\
\hline & \multicolumn{2}{|c|}{$P$-value $(F$-test $)$} & \multicolumn{2}{|c|}{0.0001} & \multicolumn{2}{|c|}{0.4676} & \multicolumn{2}{|c|}{0.8887} & \multicolumn{2}{|c|}{0.4328} & \multicolumn{2}{|c|}{0.8279} & \multicolumn{2}{|c|}{0.2515} & \multicolumn{2}{|c|}{0.8031} \\
\hline \multirow[t]{4}{*}{ The Dalles } & Non-TSW & 1696 & 0.8485 & 0.0088 & 0.9838 & 0.0036 & 0.9882 & 0.0032 & 0.9719 & 0.0058 & 0.9908 & 0.0077 & 0.9426 & 0.0094 & 0.9772 & 0.0085 \\
\hline & Sluiceway & 279 & $0.8892^{1}$ & 0.0193 & 0.9809 & 0.0101 & 0.9744 & 0.0104 & 1.0068 & 0.0034 & 0.9978 & 0.0146 & 0.9674 & 0.0190 & 0.9511 & 0.0195 \\
\hline & Turbine & 405 & 0.7817 & 0.0208 & 0.9701 & 0.0106 & 0.9940 & 0.0050 & 1.0013 & 0.0081 & 0.9904 & 0.0157 & 0.9620 & 0.0171 & 0.9862 & 0.0170 \\
\hline & \multicolumn{2}{|c|}{$P$-value $(F$-test $)$} & \multicolumn{2}{|c|}{$<0.0001$} & \multicolumn{2}{|c|}{0.5011} & \multicolumn{2}{|c|}{0.1186} & \multicolumn{2}{|c|}{0.0008} & \multicolumn{2}{|c|}{0.9045} & \multicolumn{2}{|c|}{0.5027} & \multicolumn{2}{|c|}{0.2605} \\
\hline \multirow[t]{5}{*}{ Bonneville } & JBS & 111 & 0.9757 & 0.0156 & 0.9805 & 0.0150 & 0.9821 & 0.0146 & 0.9799 & 0.0195 & 0.9717 & 0.0253 & 0.9807 & 0.0245 & 0.9523 & 0.0330 \\
\hline & Non-TSW & 1782 & 0.9306 & 0.0062 & 0.9807 & 0.0037 & 0.9849 & 0.0034 & 0.9745 & 0.0053 & 0.9843 & 0.0071 & 0.9541 & 0.0080 & 0.9801 & 0.0077 \\
\hline & Sluiceway & 505 & 0.9586 & 0.0091 & 0.9816 & 0.0066 & 0.9953 & 0.0039 & 0.9726 & 0.0093 & 0.9951 & 0.0114 & 0.9580 & 0.0147 & 0.9505 & 0.0153 \\
\hline & Turbine & 1001 & 0.9525 & 0.0069 & 0.9916 & 0.0033 & 0.9903 & 0.0037 & 0.9785 & 0.0068 & 0.9835 & 0.0091 & 0.9564 & 0.0100 & 0.9760 & 0.0089 \\
\hline & \multicolumn{2}{|c|}{$P$-value $(F$-test $)$} & \multicolumn{2}{|c|}{0.0177} & \multicolumn{2}{|c|}{0.7587} & \multicolumn{2}{|c|}{0.6529} & 0.9 & & 0.7 & & 0.5 & & 0.5 & \\
\hline
\end{tabular}

\footnotetext{
${ }^{1}$ Estimated using the closed form parameter estimator.
} 
Table 3.35. Cumulative reach survival probability estimates and associated standard errors (SEs) for subyearling Chinook salmon smolts by passage route at a particular dam from rkm 153 to $\mathrm{rkm}$ 8.3. Results are presented for four routes at John Day Dam, three routes at The Dalles Dam, and four routes at Bonneville Dam, along with standard errors (SEs) and $P$-values associated with $F$-tests of homogeneous survival.

\begin{tabular}{|c|c|c|c|c|c|c|c|c|c|c|c|c|c|c|}
\hline \multirow[b]{2}{*}{ Dam } & \multirow[b]{2}{*}{ Route } & \multirow[b]{2}{*}{$N$} & \multicolumn{2}{|c|}{$\mathrm{Rkm} 153$ to 113} & \multicolumn{2}{|c|}{$\mathrm{Rkm} 153$ to 86.2} & \multicolumn{2}{|c|}{$\mathrm{Rkm} 153$ to 49.6} & \multicolumn{2}{|c|}{$\mathrm{Rkm} 153$ to 37.3} & \multicolumn{2}{|c|}{ Rkm 153 to 22} & \multicolumn{2}{|c|}{$\mathrm{Rkm} 153$ to 8.3} \\
\hline & & & Estimate & SE & Estimate & SE & Estimate & SE & Estimate & SE & Estimate & SE & Estimate & SE \\
\hline \multirow[t]{5}{*}{ John Day } & JBS & 279 & 0.9903 & 0.0071 & 0.9783 & 0.0104 & 0.9682 & 0.0166 & 0.9542 & 0.0220 & 0.8756 & 0.0233 & 0.8436 & 0.0264 \\
\hline & Non-TSW & 1207 & 0.9797 & 0.0050 & 0.9706 & 0.0059 & 0.9563 & 0.0079 & 0.9406 & 0.0096 & 0.9136 & 0.0099 & 0.8922 & 0.0122 \\
\hline & TSW & 810 & 0.9780 & 0.0065 & 0.9621 & 0.0083 & 0.9382 & 0.0112 & 0.9388 & 0.0148 & 0.8685 & 0.0149 & 0.8550 & 0.0179 \\
\hline & Turbine & 305 & 0.9889 & 0.0082 & 0.9732 & 0.0124 & 0.9391 & 0.0181 & 0.9504 & 0.0234 & 0.8965 & 0.0225 & 0.8647 & 0.0279 \\
\hline & \multicolumn{2}{|c|}{$P$-value ( $F$-test) } & \multicolumn{2}{|c|}{0.4676} & \multicolumn{2}{|c|}{0.6813} & \multicolumn{2}{|c|}{0.3652} & \multicolumn{2}{|c|}{0.9191} & \multicolumn{2}{|c|}{0.2979} & \multicolumn{2}{|c|}{0.4472} \\
\hline \multirow[t]{4}{*}{ The Dalles } & Non-TSW & 1696 & 0.9838 & 0.0036 & 0.9722 & 0.0047 & 0.9449 & 0.0070 & 0.9362 & 0.0089 & 0.8824 & 0.0091 & 0.8623 & 0.0108 \\
\hline & Sluiceway & 279 & 0.9809 & 0.0101 & 0.9557 & 0.0138 & 0.9623 & 0.0143 & 0.9601 & 0.0182 & 0.9289 & 0.0189 & 0.8835 & 0.0229 \\
\hline & Turbine & 405 & 0.9701 & 0.0106 & 0.9643 & 0.0114 & 0.9655 & 0.0136 & 0.9563 & 0.0170 & 0.9199 & 0.0167 & 0.9072 & 0.0214 \\
\hline & \multicolumn{2}{|c|}{$P$-value $(F$-test $)$} & \multicolumn{2}{|c|}{0.5011} & \multicolumn{2}{|c|}{0.5507} & \multicolumn{2}{|c|}{0.4313} & \multicolumn{2}{|c|}{0.4929} & \multicolumn{2}{|c|}{0.0790} & \multicolumn{2}{|c|}{0.2523} \\
\hline \multirow[t]{5}{*}{ Bonneville } & JBS & 111 & 0.9805 & 0.0150 & 0.9629 & 0.0196 & 0.9436 & 0.0258 & 0.9169 & 0.0303 & 0.8992 & 0.0319 & 0.8563 & 0.0389 \\
\hline & Non-TSW & 1782 & 0.9807 & 0.0037 & 0.9659 & 0.0048 & 0.9413 & 0.0067 & 0.9265 & 0.0083 & 0.8840 & 0.0084 & 0.8664 & 0.0100 \\
\hline & Sluiceway & 505 & 0.9816 & 0.0066 & 0.9770 & 0.0075 & 0.9502 & 0.0113 & 0.9456 & 0.0139 & 0.9058 & 0.0148 & 0.8610 & 0.0179 \\
\hline & Turbine & 1001 & 0.9916 & 0.0033 & 0.9820 & 0.0048 & 0.9609 & 0.0079 & 0.9450 & 0.0098 & 0.9038 & 0.0103 & 0.8822 & 0.0119 \\
\hline & \multicolumn{2}{|c|}{$P$-value $(F$-test $)$} & \multicolumn{2}{|c|}{0.7587} & \multicolumn{2}{|c|}{0.5694} & \multicolumn{2}{|c|}{0.7944} & \multicolumn{2}{|c|}{0.5954} & \multicolumn{2}{|c|}{0.8433} & \multicolumn{2}{|c|}{0.8652} \\
\hline
\end{tabular}


a. John Day

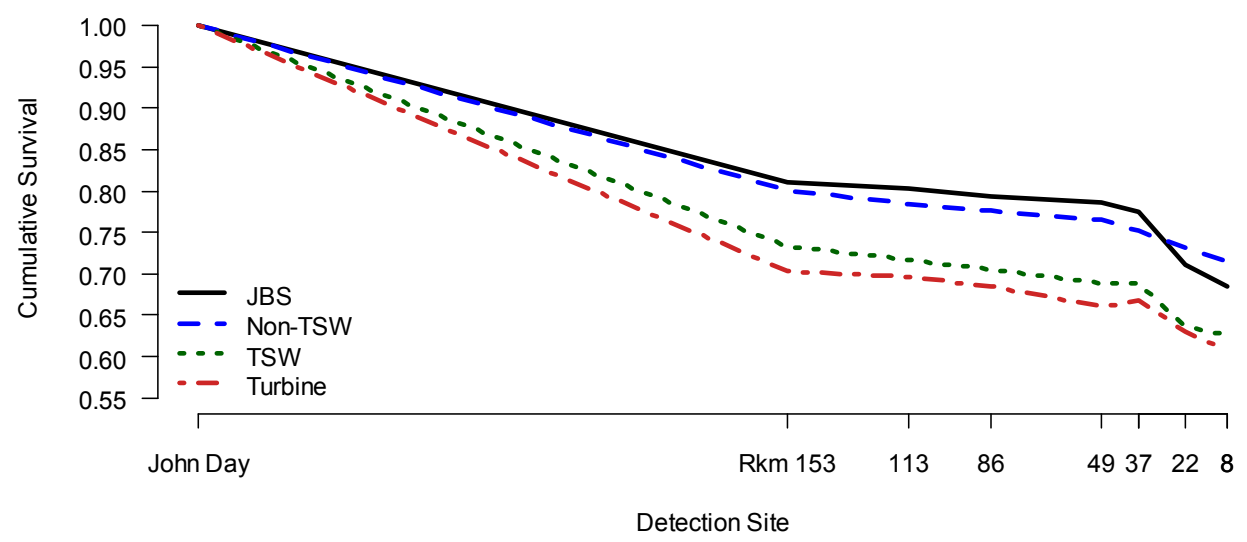

b. The Dalles

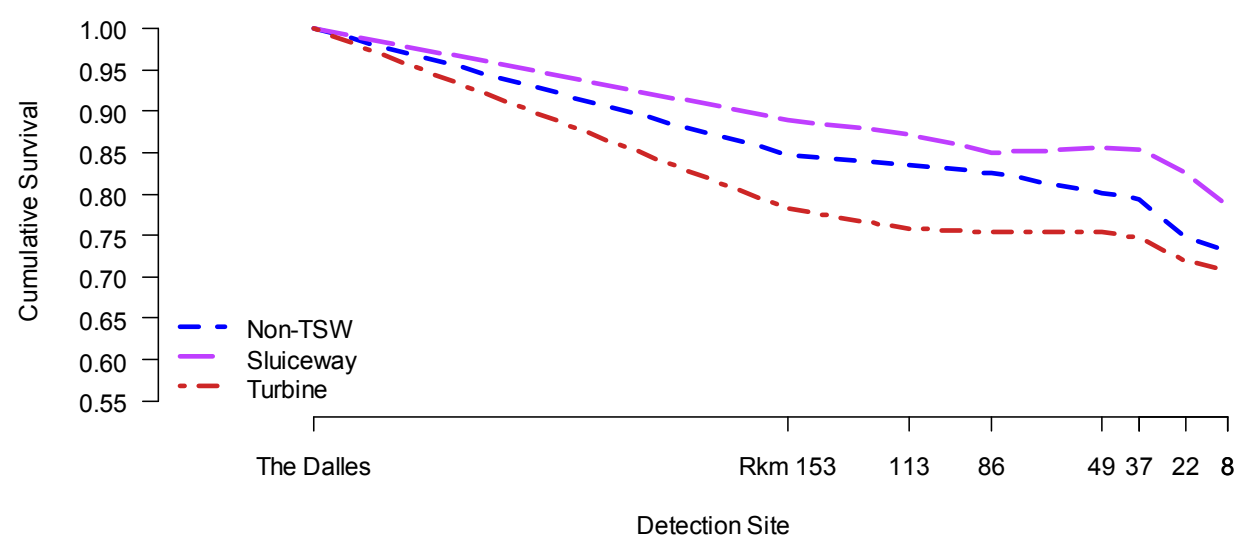

c. Bonneville
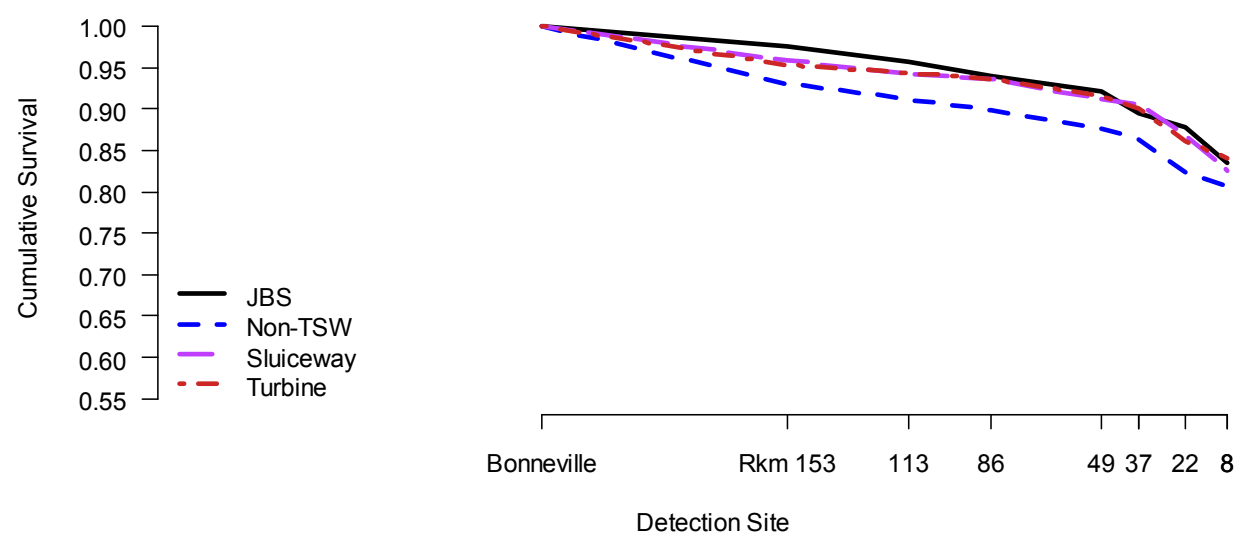

Figure 3.27. Cumulative survival probability estimates for subyearling Chinook salmon smolts by passage route from the dam face to rkm 153 and to rkm 8.3 at a) John Day, b) The Dalles, and c) Bonneville dams. 
a. John Day

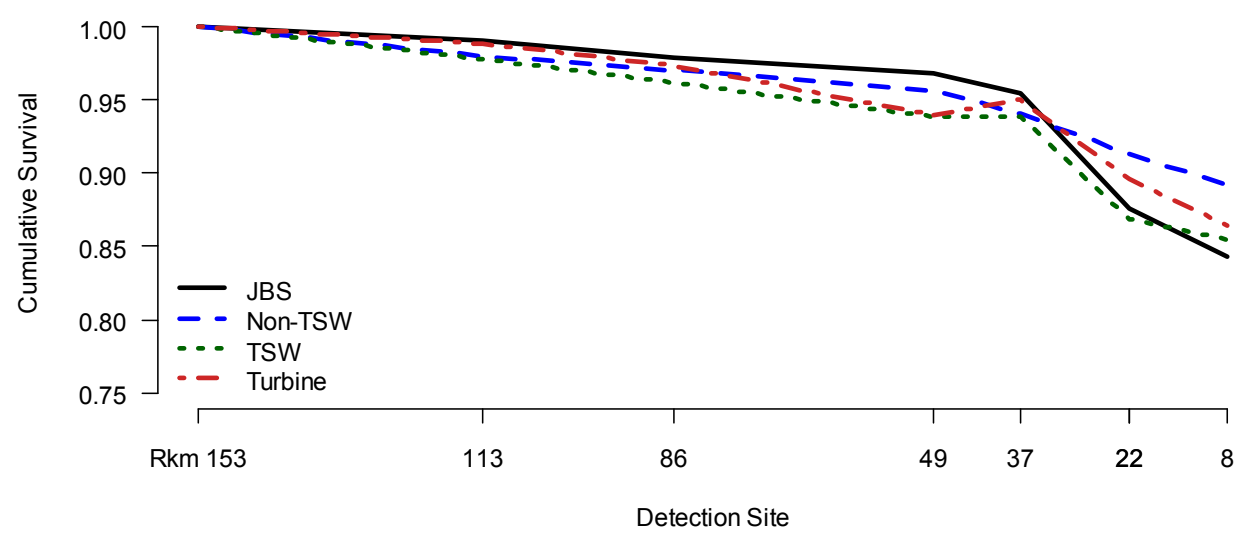

b. The Dalles

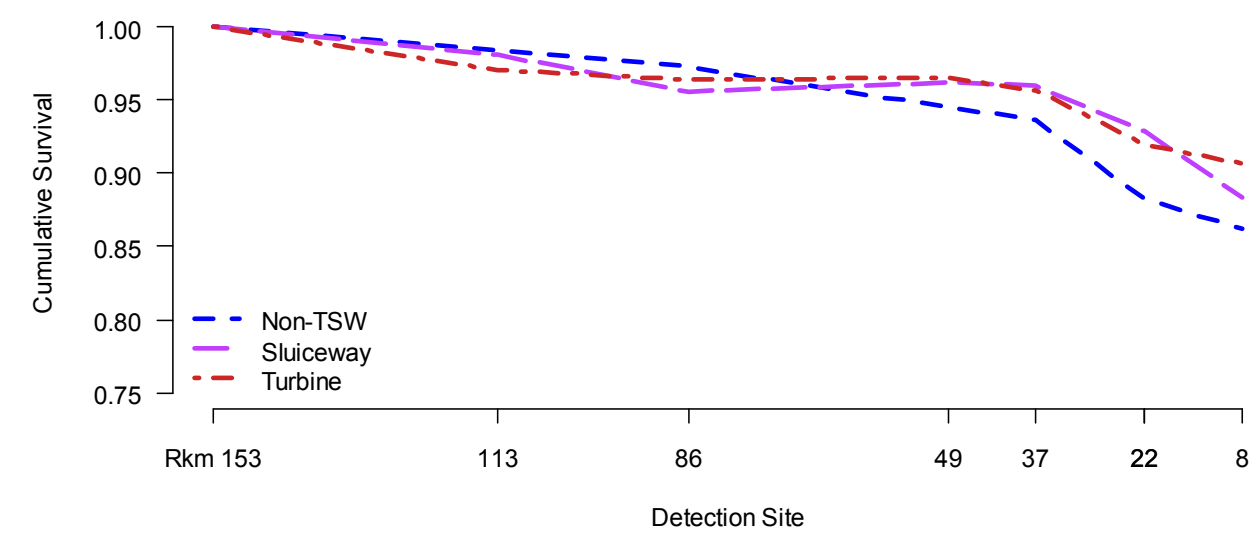

c. Bonneville

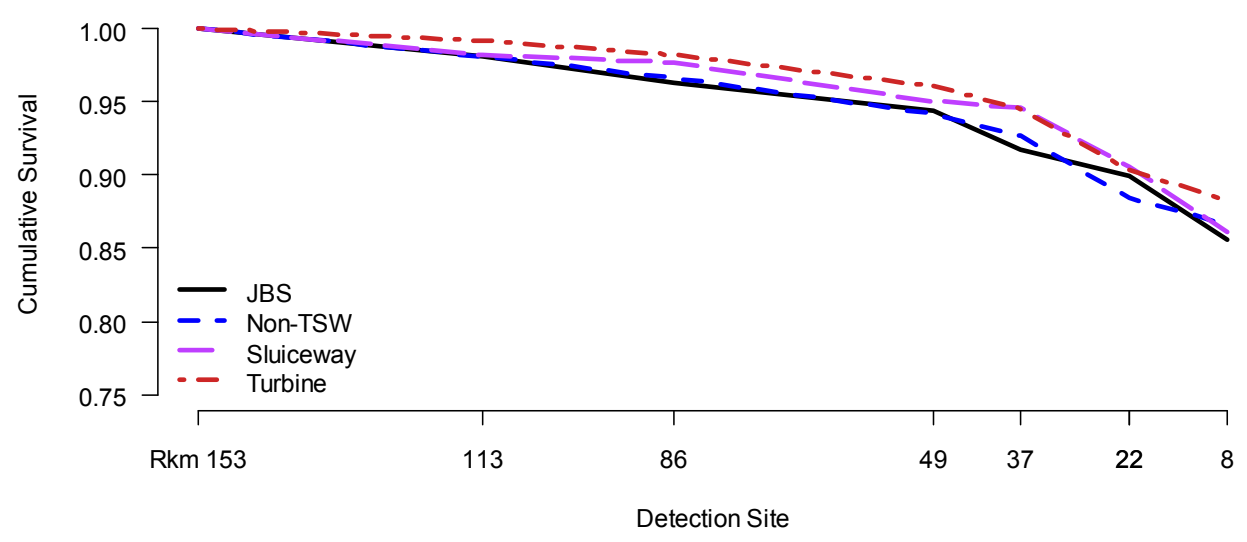

Figure 3.28. Cumulative survival probability estimates for subyearling Chinook salmon smolts from rkm 153 to rkm 8.3 by different passage routes at a) John Day, b) The Dalles, and c) Bonneville dams. 


\section{Effects of Route-Specific Passage at Two Dams on Subyearling Chinook Salmon}

A total of seven route combinations through John Day and The Dalles dams were examined for differences in subyearling Chinook salmon survival probabilities. Between The Dalles Dam and rkm 153, survival probabilities were significantly different $(P=0.0003$, Table 3.36$)$, but they were homogeneous between rkm 153 and rkm $8.3(P=0.2474$, Table 3.36). The route combination TSW/turbine at John Day and The Dalles dams, respectively, had the lowest survival probabilities to rkm 153 . The survival probabilities within the reach from $\mathrm{rkm} 86.2$ to $\mathrm{rkm} 49.6$ were nearly significantly different $(P \geq 0.0521$, Table 3.38). Cumulative survival probabilities from rkm 153 to $\mathrm{rkm} 22$ were also significantly different $(P=0.0495)$, but the significance disappeared by $\mathrm{rkm} 8.3$ (Table 3.39). Cumulative survival probability curves illustrate the difference in survivals to rkm 153 and homogeneity thereafter (Figure 3.29a, Figure 3.30a).

Six different passage route combinations were examined at The Dalles and Bonneville dams (Table 3.37). Of the six route combinations with adequate sample sizes to estimate passage survival probability, there were no significant differences in survival probability to rkm $153(P=0.0984)$, nor were there differences from rkm 153 to $\mathrm{rkm} 8.3(P=0.1294)$. Reach-specific survival probabilities between rkm 86.2 and 49.6 were nearly significantly different $(P=0.0511$, Table 3.38$)$, and cumulative survival probabilities as the subyearlings migrated downriver were not different at any of the arrays ( $P \geq 0.1138$, Table 3.39). The survivorship curves show divergence in survival probabilities by rkm 8.3, although differences were not significant for fish with different passage histories through The Dalles and Bonneville dams (Figure 3.29b, Figure 3.30b).

Table 3.36. Cumulative survival probability estimates for combinations of subyearling Chinook salmon smolts by passage routes at John Day/The Dalles dams or The Dalles/Bonneville dams to rkm 153 and from rkm 153 to $\mathrm{rkm} 8.3$ with associated standard errors (SEs). P-values are for tests of homogeneous survival.

\begin{tabular}{|c|c|c|c|c|c|c|}
\hline \multicolumn{2}{|c|}{ Routes } & \multirow[b]{2}{*}{ \# Fish } & \multicolumn{2}{|c|}{ To Rkm 153} & \multicolumn{2}{|c|}{$\mathrm{Rkm} 153-\mathrm{Rkm} 8.3$} \\
\hline John Day & The Dalles & & $\hat{S}$ & $\widehat{\mathrm{SE}}$ & $\hat{S}$ & $\widehat{\mathrm{SE}}$ \\
\hline JBS & Non-TSW & 186 & 0.8608 & 0.0255 & 0.8601 & 0.0312 \\
\hline Non-TSW & Non-TSW & 780 & 0.8650 & 0.0124 & 0.8829 & 0.0149 \\
\hline Non-TSW & Sluiceway & 122 & 0.9119 & 0.0261 & 0.9236 & 0.0311 \\
\hline Non-TSW & Turbine & 226 & 0.7976 & 0.0273 & 0.9071 & 0.0280 \\
\hline TSW & Non-TSW & 542 & 0.8174 & 0.0167 & 0.8386 & 0.0212 \\
\hline TSW & Turbine & 118 & 0.7473 & 0.0402 & 0.9107 & 0.0424 \\
\hline \multirow[t]{2}{*}{ Turbine } & Non-TSW & 187 & 0.8567 & 0.0258 & 0.8421 & 0.0338 \\
\hline & & & \multicolumn{2}{|c|}{$P$-value $=0.0003$} & \multicolumn{2}{|c|}{$P$-value $=0.2474$} \\
\hline The Dalles & Bonneville & & & & & \\
\hline Non-TSW & Non-TSW & 768 & 0.9076 & 0.0106 & 0.8584 & 0.0158 \\
\hline Non-TSW & Sluiceway & 232 & 0.9323 & 0.0167 & 0.8710 & 0.0266 \\
\hline Non-TSW & Turbine & 407 & 0.9592 & 0.0100 & 0.8592 & 0.0202 \\
\hline Sluiceway & Non-TSW & 135 & 0.9596 & 0.0181 & 0.8847 & 0.0342 \\
\hline Turbine & Non-TSW & 173 & 0.9166 & 0.0216 & 0.9527 & 0.0267 \\
\hline \multirow[t]{2}{*}{ Turbine } & Turbine & 90 & 0.9581 & 0.0219 & 0.8997 & 0.0347 \\
\hline & & & \multicolumn{2}{|c|}{$P$-value $=0.0984$} & \multicolumn{2}{|c|}{$P$-value $=0.1294$} \\
\hline
\end{tabular}


Table 3.37. Sample sizes of subyearling Chinook salmon smolts available for survival analyses based on their joint passage history at a) John Day and The Dalles dams or b) The Dalles and Bonneville dams. Combinations that are shaded were used in subsequent estimates of reach survivals.

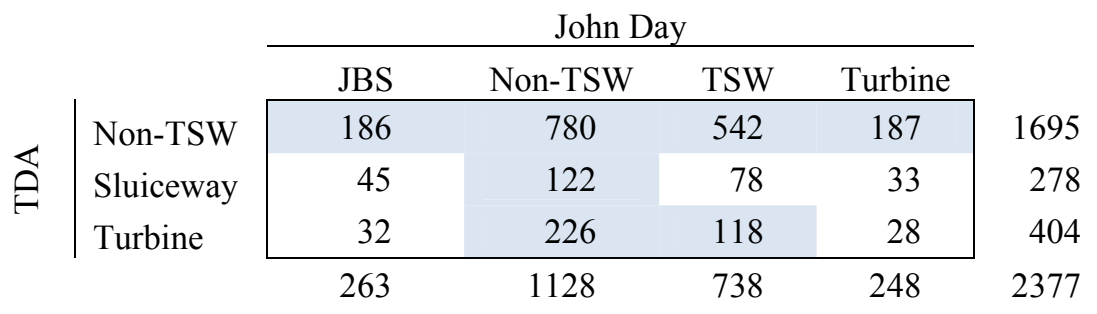

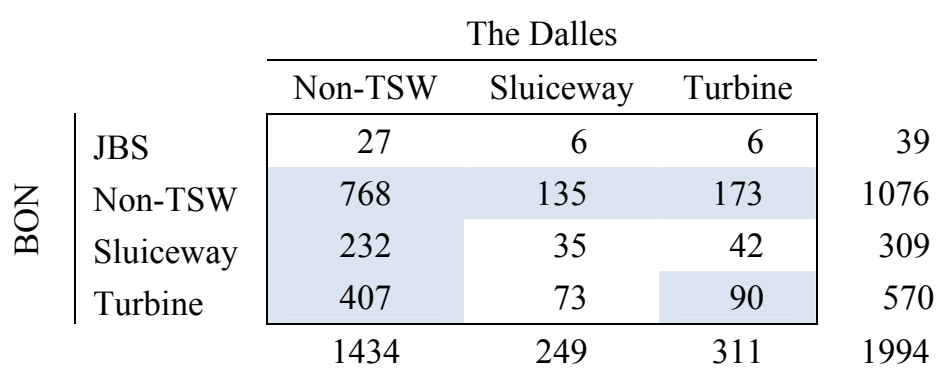


Table 3.38. Reach-specific survival probability estimates and associated standard errors (SEs) for subyearling Chinook salmon smolts for various combinations of passage routes at John Day/The Dalles dams or The Dalles/Bonneville dams to rkm 153 and six reach-specific survivals between rkm 153 and $\mathrm{rkm} 8.3$. $P$-values associated with $F$-tests of homogeneous survival.

\begin{tabular}{|c|c|c|c|c|c|c|c|c|c|c|c|c|c|c|c|c|}
\hline \multicolumn{2}{|c|}{ Routes } & \multirow[b]{2}{*}{$N$} & \multicolumn{2}{|c|}{ Release to $\mathrm{Rkm} 153$} & \multicolumn{2}{|c|}{ Rkm 153 to 113} & \multicolumn{2}{|c|}{ Rkm 113 to 86.2} & \multicolumn{2}{|c|}{$\mathrm{Rkm} 86.2$ to 49.6} & \multicolumn{2}{|c|}{ Rkm 49.6 to 37.3} & \multicolumn{2}{|c|}{ Rkm 37.3 to 22} & \multicolumn{2}{|c|}{$\mathrm{Rkm} 22$ to 8.3} \\
\hline Dam 1 & $\operatorname{Dam} 2$ & & Estimate & SE & Estimate & $\mathrm{SE}$ & Estimate & SE & Estimate & SE & Estimate & SE & Estimate & SE & Estimate & SE \\
\hline John Day & The Dalles & & & & & & & & & & & & & & & \\
\hline JBS & Non-TSW & 186 & 0.8608 & 0.0255 & 0.9936 & 0.0069 & 0.9885 & 0.0092 & 0.9800 & 0.0187 & 0.9797 & 0.0268 & 0.9204 & 0.0295 & 0.9910 & 0.0204 \\
\hline Non-TSW & Non-TSW & 780 & 0.8650 & 0.0124 & 0.9831 & 0.0055 & 0.9910 & 0.0042 & 0.9804 & 0.0077 & 0.9793 & 0.0103 & 0.9706 & 0.0109 & 0.9725 & 0.0122 \\
\hline Non-TSW & Sluiceway & 122 & $0.9119^{1}$ & 0.0261 & 0.9901 & 0.0108 & 0.9723 & 0.0160 & 1.0010 & 0.0014 & 1.0212 & 0.0126 & 0.9616 & 0.0276 & 0.9760 & 0.0256 \\
\hline Non-TSW & Turbine & 226 & $0.7976^{1}$ & 0.0273 & 0.9597 & 0.0161 & 1.0012 & 0.0008 & 0.9949 & 0.0128 & 0.9738 & 0.0197 & 0.9828 & 0.0162 & 0.9915 & 0.0206 \\
\hline TSW & Non-TSW & 542 & 0.8174 & 0.0167 & 0.9779 & 0.0075 & 0.9851 & 0.0063 & 0.9638 & 0.0110 & 1.0053 & 0.0150 & 0.9106 & 0.0199 & 0.9867 & 0.0164 \\
\hline TSW & Turbine & 118 & 0.7473 & 0.0402 & 0.9894 & 0.0134 & 0.9744 & 0.0179 & 1.0101 & 0.0075 & 0.9930 & 0.0307 & 0.9623 & 0.0356 & 0.9787 & 0.0379 \\
\hline \multirow[t]{2}{*}{ Turbine } & Non-TSW & 187 & 0.8567 & 0.0258 & 0.9932 & 0.0075 & 0.9846 & 0.0113 & 0.9524 & 0.0196 & 1.0083 & 0.0229 & 0.9369 & 0.0306 & 0.9571 & 0.0283 \\
\hline & \multicolumn{2}{|c|}{$P$-value $(F$-test $)$} & \multicolumn{2}{|c|}{0.0003} & \multicolumn{2}{|c|}{0.2261} & \multicolumn{2}{|c|}{0.6069} & \multicolumn{2}{|c|}{0.0521} & \multicolumn{2}{|c|}{0.9366} & \multicolumn{2}{|c|}{0.3544} & \multicolumn{2}{|c|}{0.9594} \\
\hline The Dalles & \multicolumn{16}{|c|}{ Bonneville } \\
\hline Non-TSW & Non-TSW & 768 & 0.9076 & 0.0106 & 0.9761 & 0.0062 & 0.9901 & 0.0044 & 0.9723 & 0.0084 & 0.9881 & 0.0114 & 0.9423 & 0.0135 & 0.9811 & 0.0122 \\
\hline Non-TSW & Sluiceway & 232 & 0.9323 & 0.0167 & 0.9899 & 0.0075 & 0.9915 & 0.0070 & 0.9854 & 0.0122 & 0.9857 & 0.0177 & 0.9659 & 0.0207 & 0.9459 & 0.0238 \\
\hline Non-TSW & Turbine & 407 & 0.9592 & 0.0100 & 0.9943 & 0.0043 & 0.9842 & 0.0070 & 0.9595 & 0.0121 & 0.9994 & 0.0135 & 0.9425 & 0.0177 & 0.9715 & 0.0158 \\
\hline Sluiceway & Non-TSW & 135 & $0.9596^{1}$ & 0.0181 & 0.9812 & 0.0138 & 0.9677 & 0.0159 & 1.0085 & 0.0052 & 0.9746 & 0.0200 & 1.0007 & 0.0172 & 0.9473 & 0.0312 \\
\hline Turbine & Non-TSW & 173 & $0.9166^{1}$ & 0.0216 & 0.9774 & 0.0129 & 1.0006 & 0.0006 & 1.0040 & 0.0097 & 0.9767 & 0.0187 & 0.9919 & 0.0140 & 1.0015 & 0.0220 \\
\hline \multirow[t]{2}{*}{ Turbine } & Turbine & 90 & 0.9581 & 0.0219 & 0.9863 & 0.0142 & 0.9891 & 0.0124 & 0.9955 & 0.0161 & 1.0124 & 0.0294 & 0.9353 & 0.0382 & 0.9784 & 0.0217 \\
\hline & \multicolumn{2}{|c|}{$P$-value (F-test) } & \multicolumn{2}{|c|}{0.0984} & \multicolumn{2}{|c|}{0.8034} & \multicolumn{2}{|c|}{0.2456} & \multicolumn{2}{|c|}{0.0511} & \multicolumn{2}{|c|}{0.9053} & \multicolumn{2}{|c|}{0.1571} & \multicolumn{2}{|c|}{0.4745} \\
\hline
\end{tabular}

\footnotetext{
${ }^{1}$ Estimated using the closed form parameter estimator.
} 
Table 3.39. Cumulative reach survival probability estimates and associated standard errors (SEs) for subyearling Chinook salmon smolts for various combinations of passage routes at John Day/The Dalles dams or The Dalles/Bonneville dams from rkm 153 to $\mathrm{rkm} 8.3$. Pvalues associated with $F$-tests of homogeneous survival.

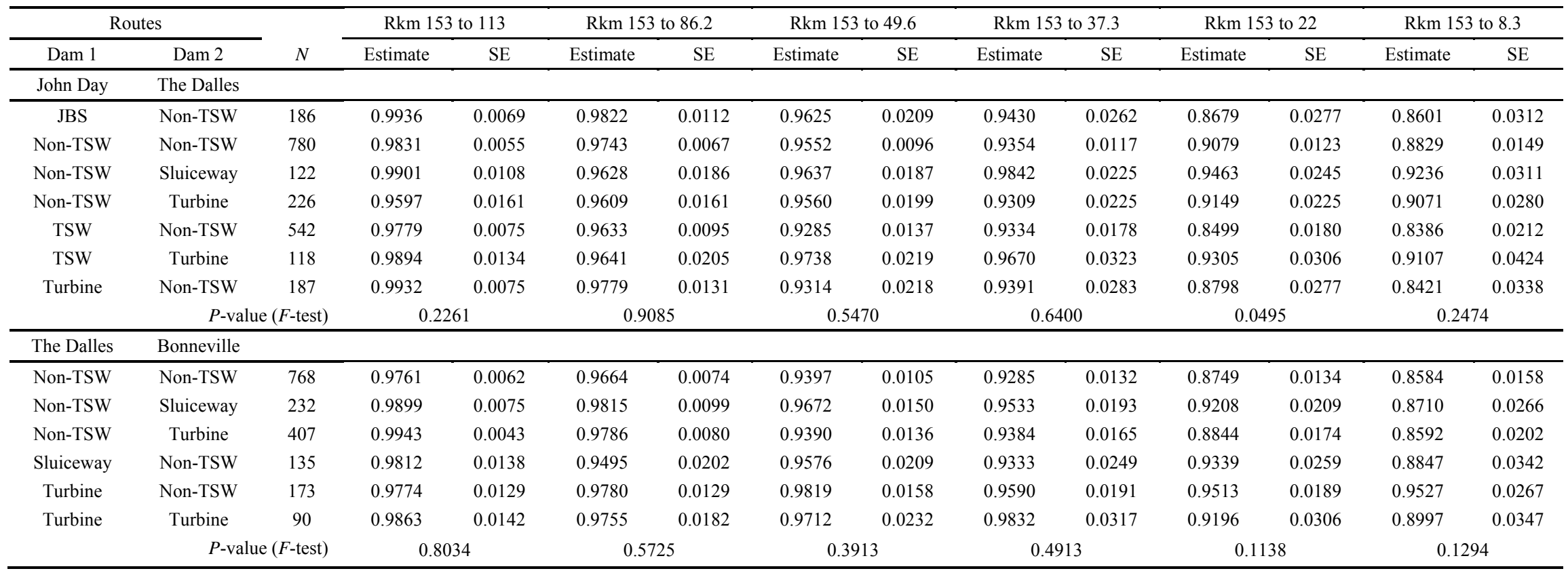


a. John Day/The Dalles

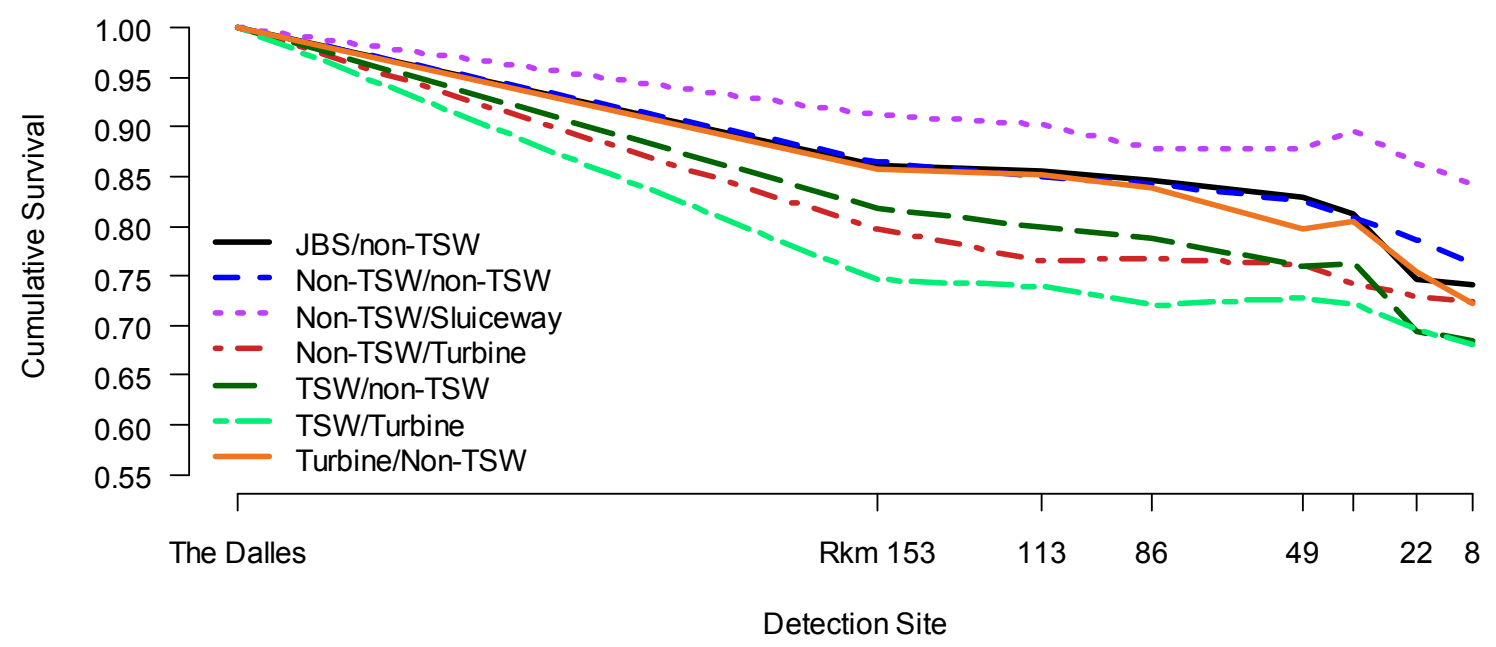

b. The Dalles/Bonneville

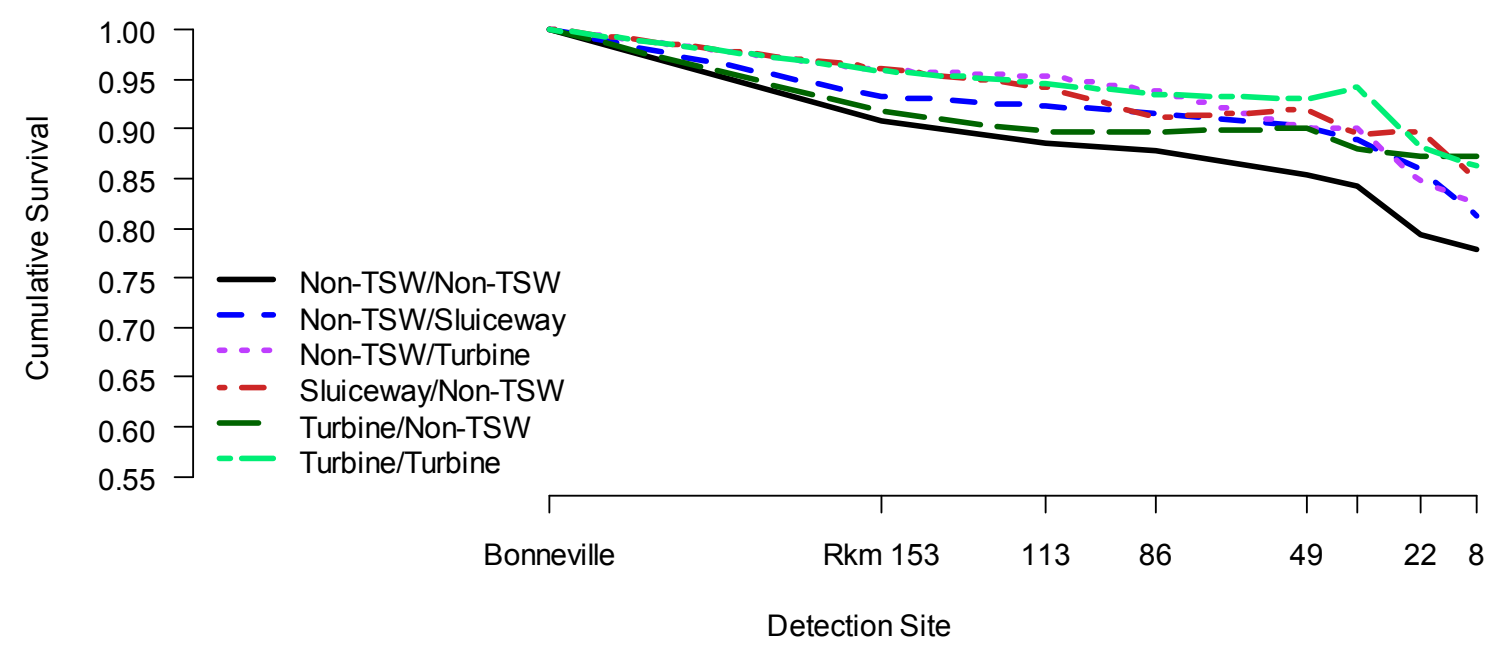

Figure 3.29. Cumulative survival probability estimates for subyearling Chinook salmon smolts for various combinations of passage routes at a) John Day and The Dalles dams and b) The Dalles and Bonneville dams, from the dam face of the downriver dam in the pair to rkm 153 and below to rkm 8.3. 


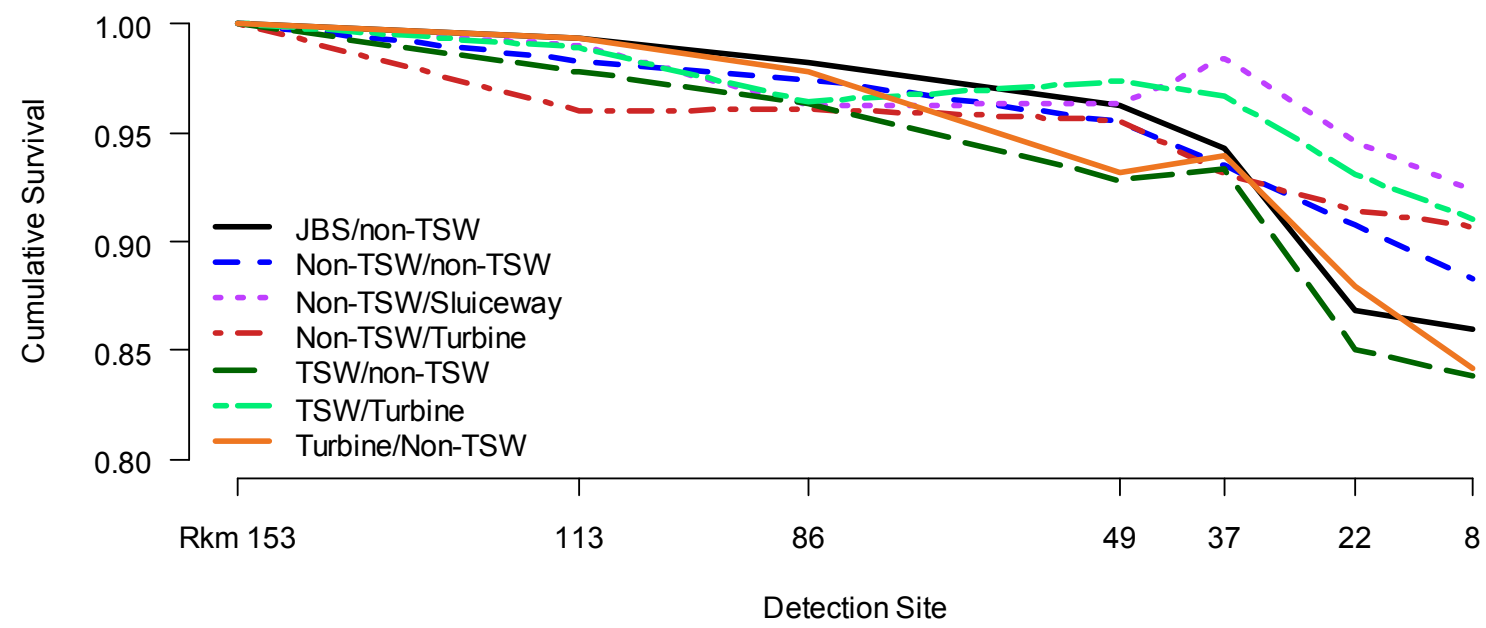

b. The Dalles/Bonneville

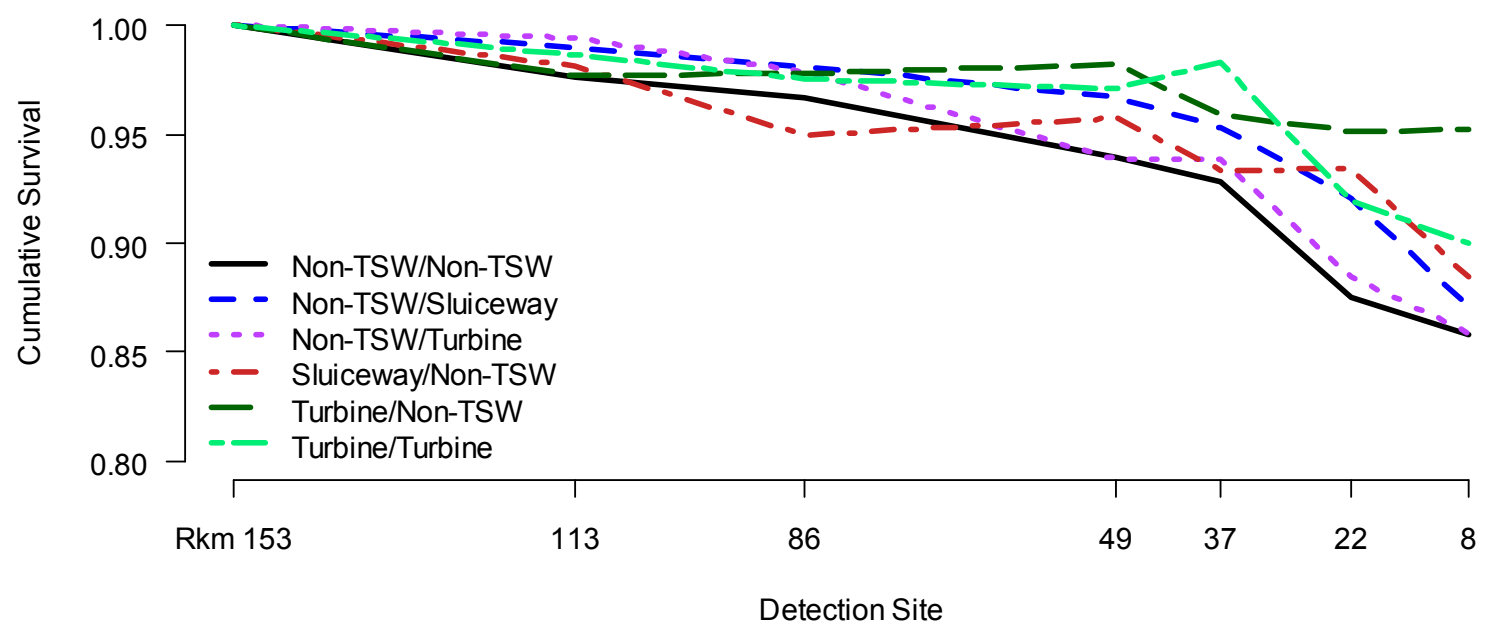

Figure 3.30. Cumulative survival probability estimates for subyearling Chinook salmon smolts for various combinations of passage routes at a) John Day and The Dalles dams and b) The Dalles and Bonneville dams between rkm 153 and rkm 8.3.

\section{Effects of Route-Specific Passage at Three Dams on Subyearling Chinook Salmon}

Seven route combinations at John Day, The Dalles, and Bonneville dams had adequate sample sizes for subsequent survival analyses (Table 3.40). Survival probabilities from Bonneville Dam to rkm 153 were homogeneous among all route combinations $(P=0.1670$, Table 3.41$)$, as were survival probabilities between rkm 153 and $8.3(P=0.3139$, Table 3.41). Reach-specific survival probabilities in individual reaches between rkm 153 and 8.3 were not significant, except for the reach from rkm 37.3 to $\mathrm{rkm} 22(P=$ 0.0289, Table 3.42). In that reach, the TSW/non-TSW/non-TSW route history had the lowest survival probability. That route history also had the lowest cumulative survival probability to rkm 8.3 , although the difference was not significant $(P=0.3139$, Table 3.43). Cumulative survivorship curves (Figure 3.31, Figure 3.32) illustrate homogeneity among the various route histories, with the TSW/non-TSW/non-TSW history diverging in the lowest part of the river. 
Table 3.40. Sample sizes of subyearling Chinook salmon smolts available for survival analyses based on their joint passage history starting at the John Day a) JBS, b) TSW, c) non-TSW, or d) turbine passage routes and their subsequent passage through both The Dalles and Bonneville dams. Combinations that are shaded were used in subsequent estimation of reach survivals.

(a) John Day JBS

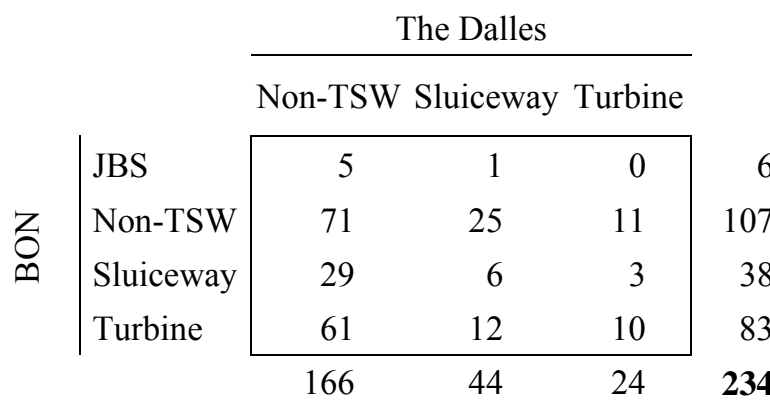

(b) John Day TSW

\begin{tabular}{|c|c|c|c|c|}
\hline & \multicolumn{3}{|c|}{ The Dalles } & \\
\hline & $\begin{array}{l}\text { Non- } \\
\text { TSW }\end{array}$ & Sluiceway & Turbine & \\
\hline JBS & 10 & 1 & 1 & 12 \\
\hline Non-TSW & 247 & 36 & 46 & 329 \\
\hline Sluiceway & 62 & 11 & 9 & 82 \\
\hline Turbine & 114 & 15 & 25 & 154 \\
\hline & 433 & 63 & 81 & 577 \\
\hline
\end{tabular}

(c) John Day non-TSW

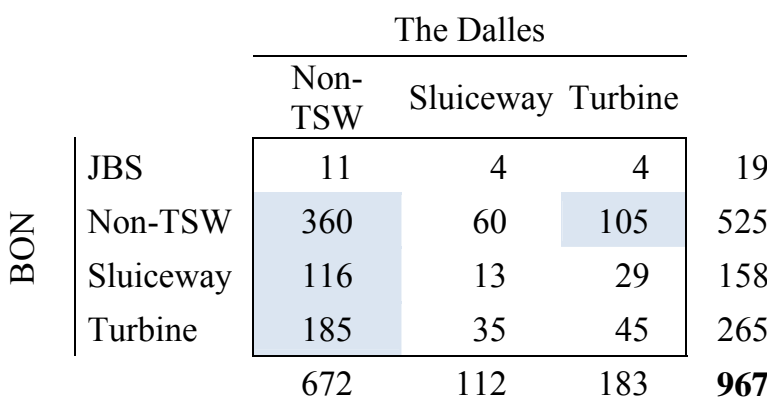

(d) John Day Turbine

\begin{tabular}{|c|c|c|c|c|c|}
\hline & & \multicolumn{3}{|c|}{ The Dalles } & \\
\hline & & $\begin{array}{l}\text { Non- } \\
\text { TSW }\end{array}$ & Sluiceway & Turbine & \\
\hline & JBS & 1 & 0 & 1 & 2 \\
\hline & Non-TSW & 90 & 14 & 11 & 115 \\
\hline & Sluiceway & 25 & 5 & 1 & 3 \\
\hline & Turbine & 47 & 10 & 9 & 66 \\
\hline & & 163 & 29 & 22 & 21 \\
\hline
\end{tabular}

Table 3.41. Cumulative survival probability estimates for subyearling Chinook salmon smolts with known passage routes at each dam measured from Bonneville Dam to rkm 153 and from rkm 153 to $\mathrm{rkm} 8.3$ with associated standard errors (SEs). $P$-values are for tests of homogeneous survival.

\begin{tabular}{|c|c|c|c|c|c|c|c|}
\hline \multicolumn{3}{|c|}{ Route } & \multirow[b]{2}{*}{ \# Fish } & \multicolumn{2}{|c|}{ Route - Rkm 153} & \multicolumn{2}{|c|}{ Rkm 153 - Rkm 8.3} \\
\hline John Day & The Dalles & Bonneville & & $\hat{S}$ & $\widehat{\mathrm{SE}}$ & $\hat{S}$ & $\widehat{\mathrm{SE}}$ \\
\hline Non-TSW & Non-TSW & Non-TSW & 360 & 0.9200 & 0.0147 & 0.8779 & 0.0214 \\
\hline Non-TSW & Non-TSW & Sluiceway & 116 & 0.9310 & 0.0235 & 0.8728 & 0.0384 \\
\hline Non-TSW & Non-TSW & Turbine & 185 & 0.9797 & 0.0108 & 0.8931 & 0.0268 \\
\hline Non-TSW & Turbine & Non-TSW & 105 & 0.9099 & 0.0290 & 0.9375 & 0.0361 \\
\hline TSW & Non-TSW & Non-TSW & 247 & 0.8925 & 0.0199 & 0.8114 & 0.0317 \\
\hline TSW & Non-TSW & Turbine & 114 & 0.9049 & 0.0277 & 0.8553 & 0.0393 \\
\hline \multirow[t]{2}{*}{ Turbine } & Non-TSW & Non-TSW & 90 & 0.9024 & 0.0318 & 0.8616 & 0.0472 \\
\hline & & & Overall & \multicolumn{2}{|c|}{$P$-value $=0.1670$} & \multicolumn{2}{|c|}{$P$-value $=0.3139$} \\
\hline
\end{tabular}


Table 3.42. Reach-specific survival probability estimates and associated standard errors (SEs) for subyearling Chinook salmon smolts for various combinations of passage routes at John Day/The Dalles/Bonneville dams to rkm 153 and six reach-specific survivals between rkm 153 and rkm 8.3. $P$-values associated with $F$-tests of homogeneous survival.

\begin{tabular}{|c|c|c|c|c|c|c|c|c|c|c|c|c|c|c|c|c|c|}
\hline \multicolumn{3}{|c|}{ Routes } & \multirow[b]{2}{*}{$N$} & \multicolumn{2}{|c|}{$\mathrm{BON}$ to $\mathrm{Rkm} 153$} & \multicolumn{2}{|c|}{ Rkm 153 to 113} & \multicolumn{2}{|c|}{ Rkm 113 to 86.2} & \multicolumn{2}{|c|}{$\mathrm{Rkm} 86.2$ to 49.6} & \multicolumn{2}{|c|}{$\mathrm{Rkm} 49.6$ to 37.3} & \multicolumn{2}{|c|}{$\mathrm{Rkm} 37.3$ to 22.0} & \multicolumn{2}{|c|}{$\mathrm{Rkm} 22.0$ to 8.3} \\
\hline JDA & TDA & BON & & Estimate & SE & Estimate & SE & Estimate & SE & Estimate & SE & Estimate & SE & Estimate & SE & Estimate & SE \\
\hline Non-TSW & Non-TSW & Non-TSW & 360 & 0.9200 & 0.0147 & 0.9726 & 0.0097 & 0.9955 & 0.0047 & 0.9841 & 0.0103 & 0.9738 & 0.0144 & 0.9788 & 0.0141 & 0.9666 & 0.0176 \\
\hline Non-TSW & Non-TSW & Sluiceway & 116 & 0.9310 & 0.0235 & 1.0000 & 0.0002 & 1.0023 & 0.0015 & 0.9689 & 0.0203 & 0.9957 & 0.0231 & 0.9586 & 0.0317 & 0.9416 & 0.0365 \\
\hline Non-TSW & Non-TSW & Turbine & 185 & 0.9797 & 0.0108 & 0.9941 & 0.0069 & 0.9738 & 0.0128 & 0.9736 & 0.0162 & 0.9863 & 0.0185 & 0.9761 & 0.0192 & 0.9843 & 0.0197 \\
\hline Non-TSW & Turbine & Non-TSW & 105 & 0.9099 & 0.0290 & 0.9630 & 0.0210 & 1.0006 & 0.0007 & 0.9948 & 0.0132 & 0.9934 & 0.0204 & 0.9816 & 0.0217 & 1.0030 & 0.0270 \\
\hline TSW & Non-TSW & Non-TSW & 247 & 0.8925 & 0.0199 & 0.9757 & 0.0109 & 0.9877 & 0.0083 & 0.9608 & 0.0171 & 1.0158 & 0.0269 & 0.8691 & 0.0335 & 0.9926 & 0.0242 \\
\hline TSW & Non-TSW & Turbine & 114 & 0.9049 & 0.0277 & 0.9889 & 0.0112 & 0.9917 & 0.0099 & 0.9521 & 0.0225 & 1.0123 & 0.0189 & 0.9355 & 0.0342 & 0.9673 & 0.0309 \\
\hline \multirow[t]{2}{*}{ Turbine } & Non-TSW & Non-TSW & 90 & 0.9024 & 0.0318 & 0.9861 & 0.0149 & 0.9784 & 0.0184 & 0.9523 & 0.0279 & 0.9787 & 0.0284 & 0.9842 & 0.0286 & 0.9736 & 0.0388 \\
\hline & \multicolumn{3}{|c|}{ Overall $P$-value $(F$-test $)$} & \multicolumn{2}{|c|}{0.1670} & \multicolumn{2}{|c|}{0.3394} & \multicolumn{2}{|c|}{0.3819} & \multicolumn{2}{|c|}{0.6393} & \multicolumn{2}{|c|}{0.9696} & \multicolumn{2}{|c|}{0.0289} & \multicolumn{2}{|c|}{0.8414} \\
\hline
\end{tabular}

Table 3.43. Cumulative reach survival probability estimates and associated standard errors (SEs) for subyearling Chinook salmon smolts for various combinations of passage routes at John Day/The Dalles/Bonneville dams from rkm 153 to rkm 8.3. $P$-values associated with $F$-tests of homogeneous survival.

\begin{tabular}{|c|c|c|c|c|c|c|c|c|c|c|c|c|c|c|c|}
\hline \multicolumn{3}{|c|}{ Routes } & \multirow[b]{2}{*}{$N$} & \multicolumn{2}{|c|}{ Rkm 153 to 113} & \multicolumn{2}{|c|}{ Rkm 153 to 86.2} & \multicolumn{2}{|c|}{ Rkm 153 to 49.6} & \multicolumn{2}{|c|}{ Rkm 153 to 37.3} & \multicolumn{2}{|c|}{ Rkm 153 to 22.0} & \multicolumn{2}{|c|}{$\mathrm{Rkm} 153$ to 8.3} \\
\hline JDA & TDA & BON & & Estimate & SE & Estimate & SE & Estimate & SE & Estimate & SE & Estimate & SE & Estimate & $\mathrm{SE}$ \\
\hline Non-TSW & Non-TSW & Non-TSW & 360 & 0.9726 & 0.0097 & 0.9682 & 0.0106 & 0.9528 & 0.0140 & 0.9279 & 0.0168 & 0.9082 & 0.0176 & 0.8779 & 0.0214 \\
\hline Non-TSW & Non-TSW & Sluiceway & 116 & 1.0000 & 0.0002 & 1.0023 & 0.0015 & 0.9711 & 0.0193 & 0.9670 & 0.0255 & 0.9269 & 0.0298 & 0.8728 & 0.0384 \\
\hline Non-TSW & Non-TSW & Turbine & 185 & 0.9941 & 0.0069 & 0.9681 & 0.0140 & 0.9425 & 0.0200 & 0.9296 & 0.0226 & 0.9074 & 0.0231 & 0.8931 & 0.0268 \\
\hline Non-TSW & Turbine & Non-TSW & 105 & 0.9630 & 0.0210 & 0.9636 & 0.0210 & 0.9586 & 0.0242 & 0.9522 & 0.0275 & 0.9347 & 0.0272 & 0.9375 & 0.0361 \\
\hline TSW & Non-TSW & Non-TSW & 247 & 0.9757 & 0.0109 & 0.9637 & 0.0134 & 0.9259 & 0.0205 & 0.9406 & 0.0292 & 0.8174 & 0.0273 & 0.8114 & 0.0317 \\
\hline TSW & Non-TSW & Turbine & 114 & 0.9889 & 0.0112 & 0.9807 & 0.0147 & 0.9337 & 0.0256 & 0.9452 & 0.0300 & 0.8842 & 0.0341 & 0.8553 & 0.0393 \\
\hline \multirow[t]{2}{*}{ Turbine } & Non-TSW & Non-TSW & 90 & 0.9861 & 0.0149 & 0.9648 & 0.0227 & 0.9188 & 0.0329 & 0.8992 & 0.0384 & 0.8850 & 0.0382 & 0.8616 & 0.0472 \\
\hline & \multicolumn{3}{|c|}{ Overall $P$-value $(F$-test $)$} & \multicolumn{2}{|c|}{0.3394} & \multicolumn{2}{|c|}{0.6048} & \multicolumn{2}{|c|}{0.6839} & \multicolumn{2}{|c|}{0.7331} & \multicolumn{2}{|c|}{0.0889} & \multicolumn{2}{|c|}{0.3139} \\
\hline
\end{tabular}




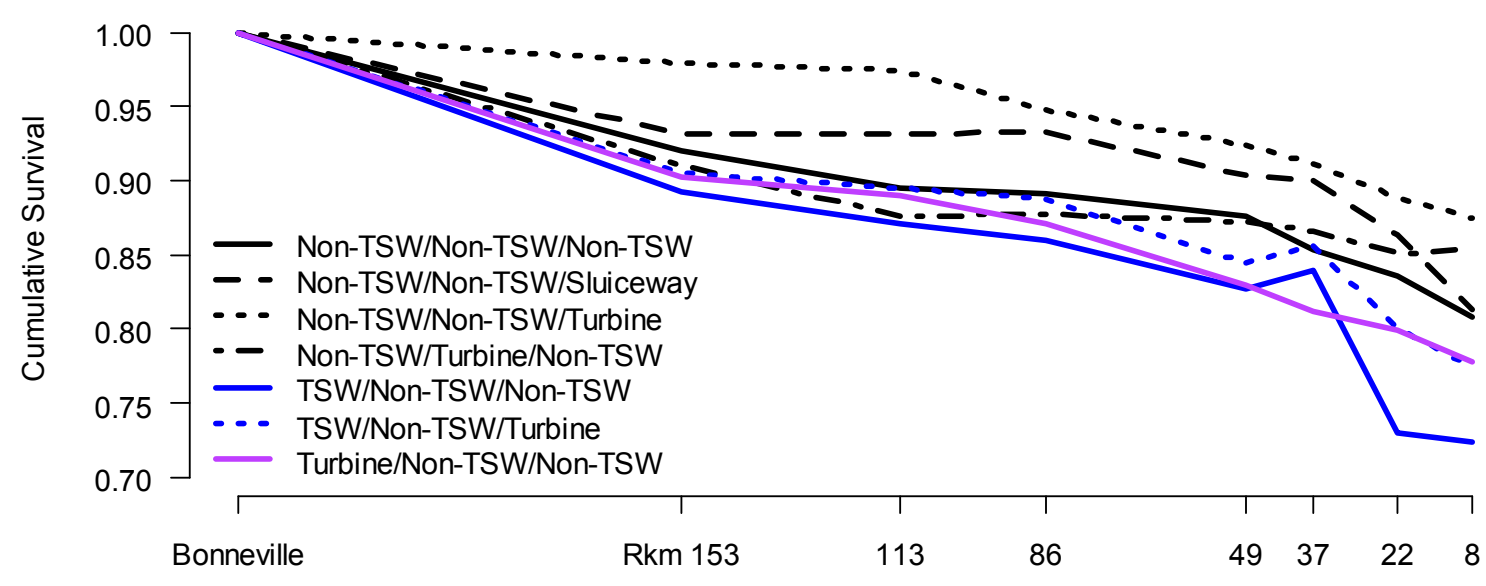

Detection Site

Figure 3.31. Cumulative survival probability estimates for subyearling Chinook salmon smolts for various combinations of passage routes at John Day, The Dalles, and Bonneville dams from Bonneville Dam to rkm 8.3 .

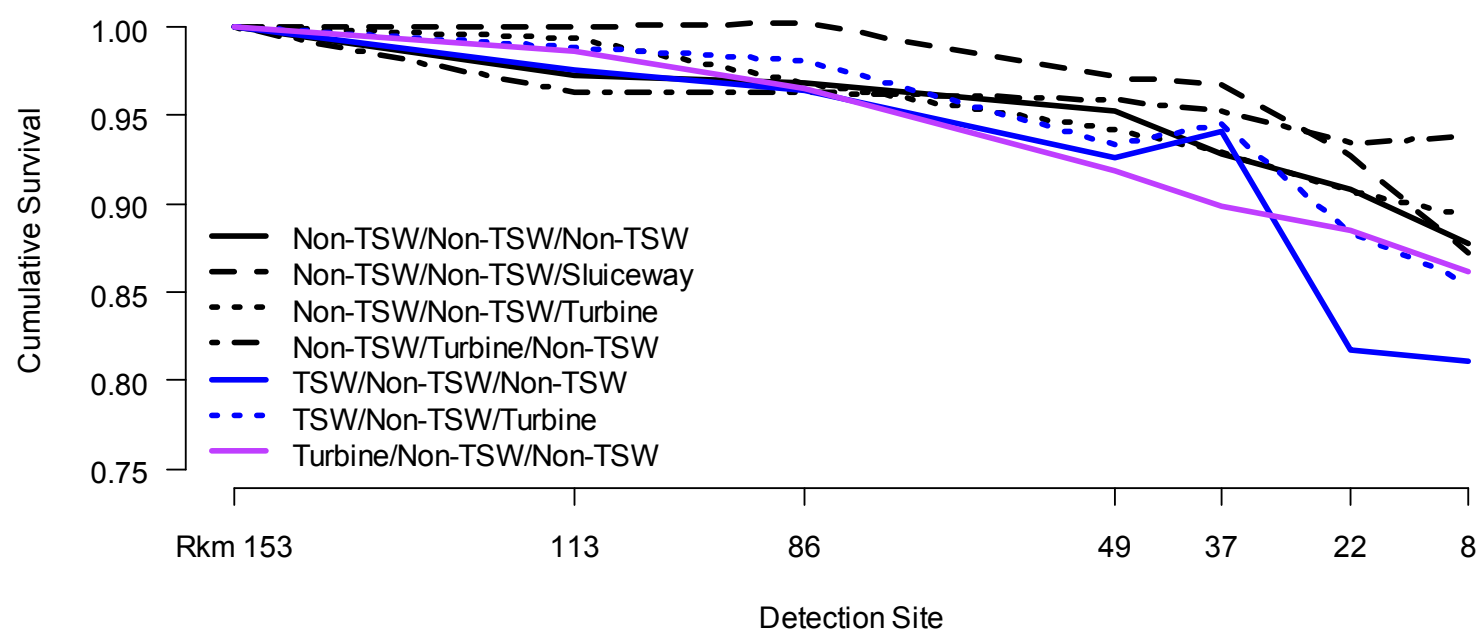

Figure 3.32. Cumulative survival probability estimates for subyearling Chinook salmon smolts for various combinations of passage routes at John Day, The Dalles, and Bonneville dams from rkm 153 to rkm 8.3. 


\subsection{Migration Behavior}

Migration behavior is often linked to survival probability. This section describes migration behavior results for 2010 migrants.

\subsubsection{Travel Time}

Acoustic-tagged juvenile salmonids traveled through the lower Columbia River and estuary rapidly in 2010. Acoustic-tagged yearling Chinook salmon detected at the virtual-release location at Knapp Point (CR153.0) and at the East Sand Island array (CR008.3) had a mean travel time of 2.42 days (SE $=0.012)$ and a median travel time of $2.36 \mathrm{~d}$. Travel times fluctuated moderately and generally decreased as the season progressed, with a median of 2.41 days for the earliest migrants to a median of 2.13 days for the latest migrants. The 9 May to 15 May virtual-release group had the longest median travel time of 2.34 days (Figure 3.33).

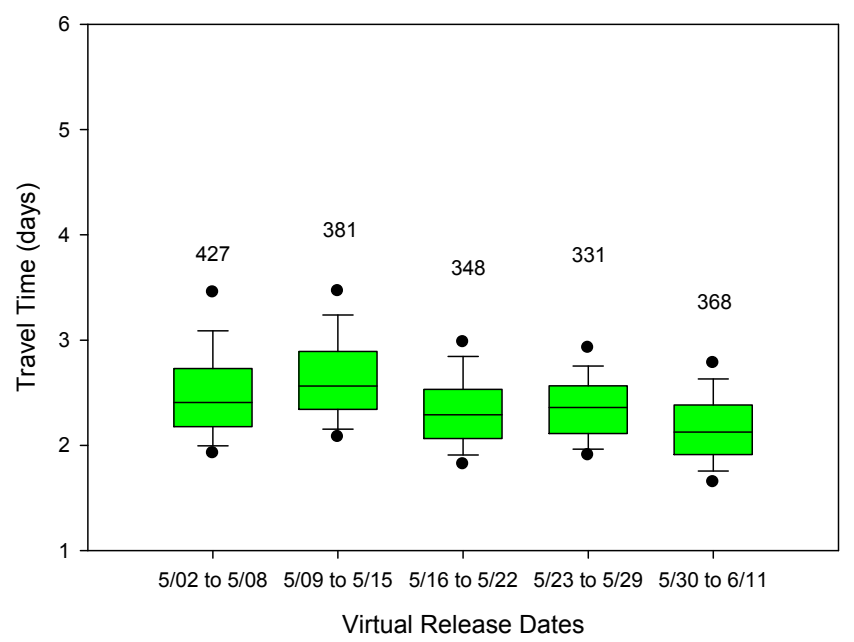

Figure 3.33. Travel time (days) of juvenile yearling Chinook salmon by virtual-release group from detection at the Knapp Point array (rkm 153) to detection at the Columbia River mouth, East Sand Island array (rkm 8.3). Solid lines within boxes are medians, the box boundary represents the 25th and 75th percentiles, whiskers indicate the 10th and 90th percentiles, and dots represent the 5 th and 95 th percentiles.

Acoustic-tagged yearling Chinook salmon had a median travel rate of $77.9 \mathrm{~km} / \mathrm{d}$ from rkm 153 to rkm 8.3. However, travel rates varied by reach, decreasing moderately between rkm 153 and 49.6, then dropping sharply between $\mathrm{rkm} 49.6$ and 22, before increasing in the final reach ( $\mathrm{rkm} 22$ to 8.3; Figure 3.34). In addition, the variability in travel rate increased substantially in the final reach at the mouth of the river.

Acoustic-tagged juvenile steelhead detected at the virtual-release location at Knapp Point (CR153.0) and at the East Sand Island array (CR008.3) had a mean travel time of 2.24 days ( $\mathrm{SE}=0.01)$ and a median travel time of 2.17 days. Travel times fluctuated moderately throughout the migration period with the 9 May to 15 May virtual-release group having the slowest travel time median 2.36 days. The latest virtual-release group, 30 May to 11 June, traveled the fastest with a median travel time of 2.01 days (Figure 3.35). 


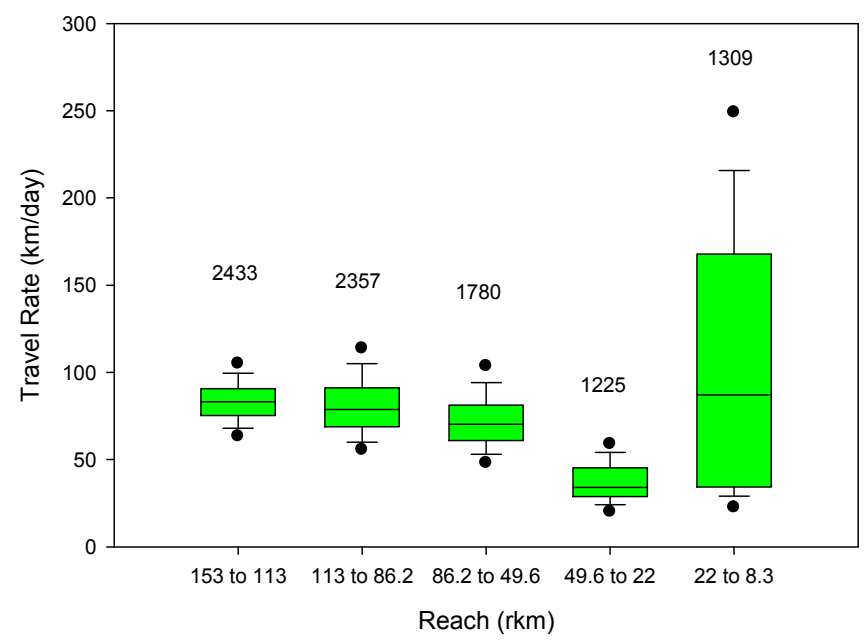

Figure 3.34. Travel rate $(\mathrm{km} / \mathrm{d})$ of yearling Chinook salmon in reaches from the Knapp Point array (rkm 153 ) to detection at the Columbia River mouth, East Sand Island array (rkm 8.3). Solid lines within boxes are medians, the box boundary represents the 25 th and 75 th percentiles, whiskers indicate the 10th and 90th percentiles, and dots represent the 5th and 95th percentiles.

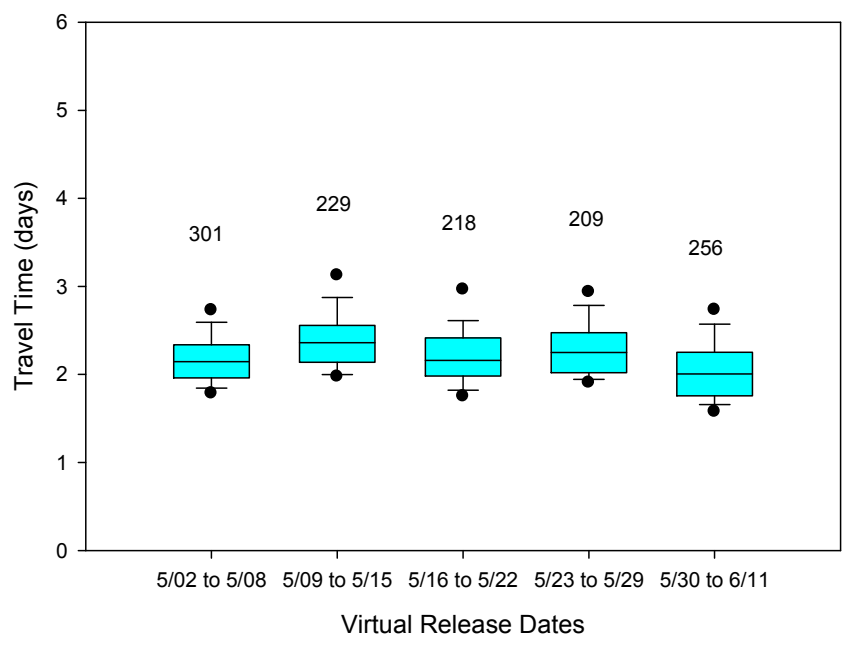

Figure 3.35. Travel time (days) of juvenile steelhead by virtual-release group from detection at the Knapp Point array (rkm 153) to detection at the Columbia River mouth, East Sand Island array (rkm 8.3). Solid lines within boxes are medians, the box boundary represents the 25th and 75th percentiles, whiskers indicate the 10th and 90th percentiles, and dots represent the 5th and 95th percentiles.

Travel rates of acoustic-tagged steelhead through the estuary also varied by reach, with a median travel rate of $78.0 \mathrm{~km} / \mathrm{d}$ from rkm 153 to 8.3 , decreasing to $40.7 \mathrm{~km} / \mathrm{d}$ at the Astoria Bridge reach (rkm 49.6 to 22), then increasing to $106.2 \mathrm{~km} / \mathrm{d}$ in the East Sand Island reach (rkm 22 to 8.3) (Figure 3.36). Similar to yearling Chinook salmon, the variability in travel rate of acoustic-tagged steelhead was greatest in the downstream-most reach at the mouth of the Columbia River. 


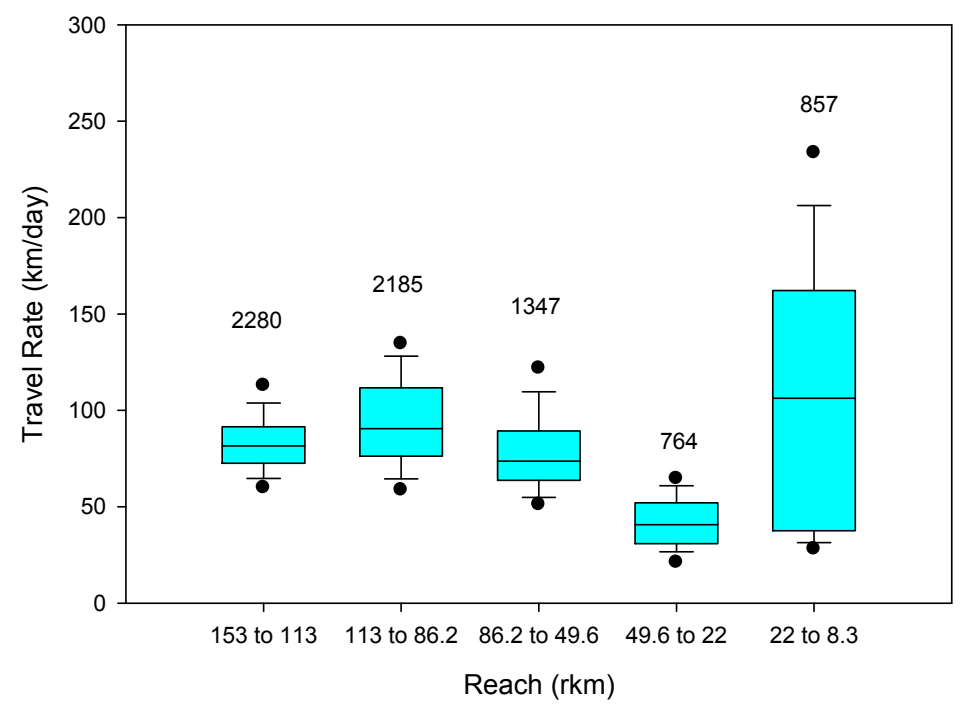

Figure 3.36. Travel rate $(\mathrm{km} / \mathrm{d})$ of juvenile steelhead in reaches from the Knapp Point array (rkm 153) to detection at the Columbia River mouth, East Sand Island array (rkm 8.3). Solid lines within boxes are medians, the box boundary represents the 25 th and 75 th percentiles, whiskers indicate the 10th and 90th percentiles, and dots represent the 5th and 95th percentiles.

Acoustic-tagged subyearling Chinook salmon detected at the virtual-release location at Knapp Point (CR153.0) and at the East Sand Island array (CR008.3) had a mean travel time of 2.50 days ( $\mathrm{SE}=0.018$ ) and a median travel time of 2.38 days. Travel times increased between early and late release groups from a median of 2.21 days for the earliest migrants to a median of 2.81 days for the latest migrants, with the 23 June to 29 June virtual-release group having the fastest median travel time, 2.11 days (Figure 3.37).

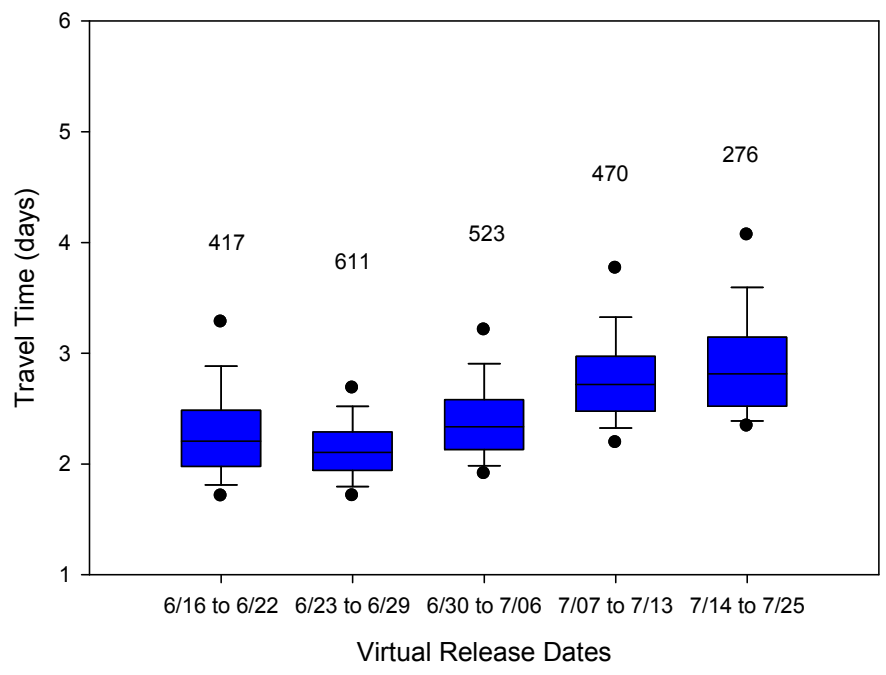

Figure 3.37. Travel time (days) of juvenile subyearling Chinook salmon by virtual-release group from detection at the Knapp Point array (rkm 153) to detection at the Columbia River mouth, East Sand Island array (rkm 8.3). Solid lines within boxes are medians, the box boundary represents the 25 th and 75 th percentiles, whiskers indicate the 10th and 90th percentiles, and dots represent the 5th and 95th percentile. 
Acoustic-tagged subyearling Chinook salmon had a median travel rate of $77.7 \mathrm{~km} / \mathrm{d}$ through all five reaches (rkm 153 to 8.3). Median travel rates through the estuary varied by reach. Travel rate decreased sharply in the Astoria Bridge reach (rkm 49.6 to 22.0) with a median of $32.1 \mathrm{~km} / \mathrm{d}$. The median travel rate was highest in the two reaches farthest upstream, the Cottonwood Island reach (rkm 153 to 113) and the Oak Point reach (rkm 113 to 86.2; Figure 3.38). Similar to the trend observed for spring migrants, median travel rate and variability in travel rates increased in the final reach, near the mouth of the river.

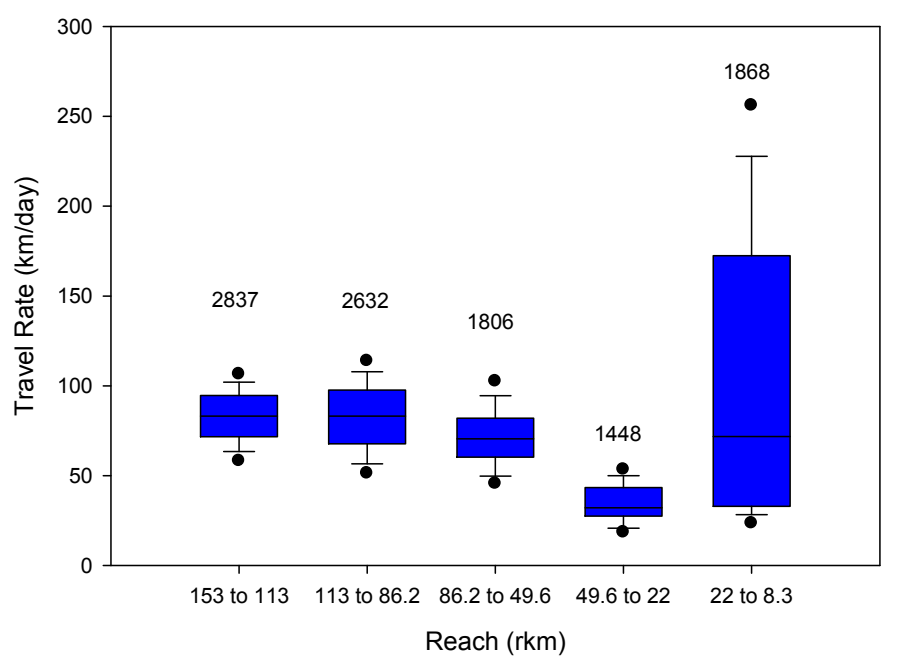

Figure 3.38. Travel rate $(\mathrm{km} / \mathrm{d})$ of juvenile subyearling Chinook salmon in reaches from Knapp Point array (rkm 153) to detection at the Columbia River mouth, East Sand Island array (rkm 8.3). Solid lines within boxes are medians, the box boundary represents the 25 th and 75 th percentiles, whiskers indicate the 10th and 90th percentiles, and dots represent the 5th and 95 th percentiles.

\subsubsection{Migratory Behavior in the Estuary}

More than $80 \%$ of the yearling and subyearling Chinook salmon and steelhead detected on the CR049.6 and CR037.3 arrays were detected at sub-arrays located in the navigation channel (Nav 50, Nav 37). The remainder were detected at sub-arrays located outside the navigation channel in Clifton Channel (CC 50) and Cathlamet Bay (CB 37). However, at CR022.0, most yearling Chinook (79\%), subyearling Chinook (87\%), and steelhead (59\%) were detected outside the main navigation channel by the sub-array located in the Washington shoreline channel (WA 22). A total of 779 yearling Chinook salmon, 381 steelhead, and 839 subyearling Chinook salmon were detected at all arrays. Of those detected, $11 \%$ of yearling Chinook, $24 \%$ of steelhead, and $6 \%$ of subyearling Chinook were only detected by navigation channel sub-arrays. The remainder were detected by at least one off-channel sub-array.

Yearling and subyearling Chinook salmon and steelhead that migrated from the CR086.2 array had higher $\zeta$ values (the joint probability of migrating to and being detected at a particular sub-array) at the Nav 50 sub-array $(\zeta=0.51-0.58)$ than at the off-channel CC 50 sub-array $(\zeta=0.09-0.11$; Figure 3.39). This indicates juvenile Chinook salmon and steelhead were more likely to migrate to, and be detected in, the navigation channel than in Clifton Channel at rkm 50. 

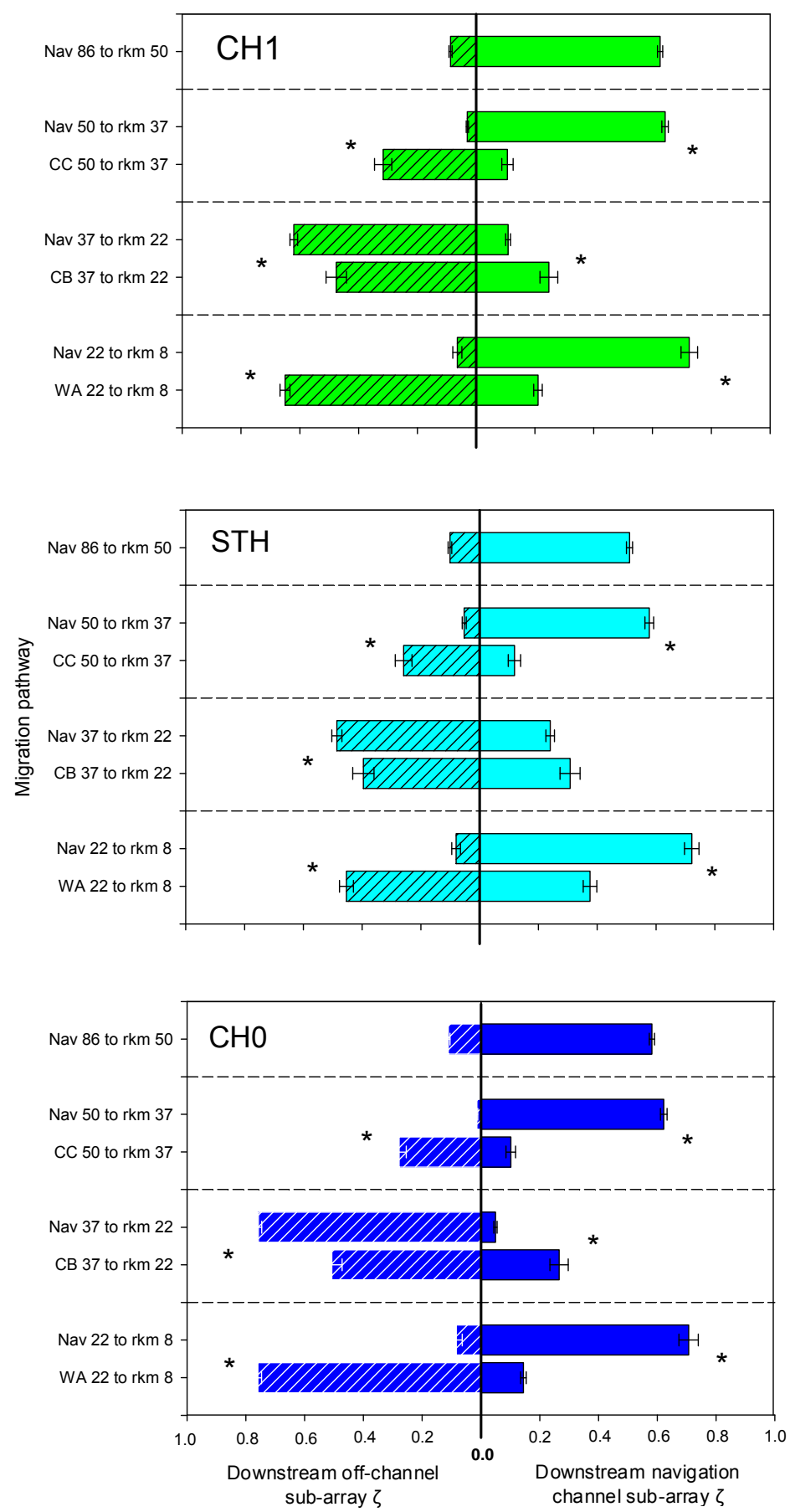

Figure 3.39. Joint probability of migrating to and being detected $(\zeta)$ at sub-arrays in off-channel areas (CC 50, CB 37, WA 22, and WA 8; hatched bars) and in the navigation channel (Nav 50, Nav 37, Nav 22, and Nav 8; solid bars) at the downstream boundary of each river reach for yearling Chinook salmon (CH1), steelhead (STH), and subyearling Chinook salmon (CH0) previously detected at sub-arrays in the navigation channel or off-channel areas at the upstream boundary of each reach. Asterisks indicate significant differences in $\zeta$ values between fish that migrated from different upstream sub-arrays to the same downstream subarray. 
The migration pathway used by yearling and subyearling Chinook salmon and steelhead to migrate from CR049.6 to CR037.3 differed depending on the sub-array at which they were detected at CR049.6. Fish that migrated from Nav 50 had significantly higher $\zeta$ values $(P<0.001)$ at the Nav 37 sub-array $(\zeta=0.58-0.64)$ than fish that migrated from CC $50(\zeta=0.10-0.12$; Figure 3.39). Conversely, fish that migrated from CC 50 had significantly higher $\zeta$ values $(P<0.001)$ at the off-channel CB 37 sub-array $(\zeta=0.26-0.32)$ than fish that migrated from Nav $50(\zeta=0.01-0.05$; Figure 3.39). These results suggest that yearling and subyearling Chinook salmon and steelhead that migrated in the navigation channel at rkm 50 remained primarily in the navigation channel to rkm 37, whereas fish that migrated through the side channel at rkm 50 mostly stayed off-channel, migrating within Cathlamet Bay to CR037.3.

The length of time taken to migrate from Nav 50 and CC 50 to CR037.3 differed significantly $(P<0.001)$ for all three species/run types. Yearling Chinook salmon, steelhead, and subyearling Chinook salmon that migrated from Nav 50 had median travel times of $4.5 \mathrm{~h}, 4.8 \mathrm{~h}$, and $5.1 \mathrm{~h}$, respectively, to CR037.3, whereas those that migrated from CC 50 had median travel times of $12.1 \mathrm{~h}, 12.6 \mathrm{~h}$, and $11.9 \mathrm{~h}$, respectively (Figure 3.40). These results indicate that juvenile Chinook salmon and steelhead that migrated through the off-channel area of Cathlamet Bay spent two to three times longer in this reach than fish that migrated in the navigation channel between CR049.6 and CR037.3.

Although yearling Chinook salmon and steelhead that migrated from CC 50 had higher probabilities of survival to CR037.3 than those fish that migrated from Nav 50 (Figure 3.41), the differences were not significant $(P>0.054)$. Yearling Chinook that migrated from CC 50 had an estimated probability of survival of $1.01(\mathrm{SE}=0.02)$, and those that migrated from Nav 50 had a survival probability of 0.98 (SE $=0.01$; Figure 3.41). Survival estimates $>1.0$ were the result of tag-life corrections, which were applied to both groups. Thus the focus should be on the relative survival probabilities, rather than the absolute estimates. Steelhead that migrated from CC 50 had a survival probability of 0.99 (SE $=0.04)$ compared to $0.92(\mathrm{SE}=0.01)$ for those that migrated from Nav 50 (Figure 3.41). Conversely, subyearling Chinook salmon that migrated from Nav 50 had a higher probability of survival to CR037.3 $(S=0.99 ; \mathrm{SE}=0.00)$ than subyearling Chinook that migrated from the CC 50 sub-array $(S=0.95 ; \mathrm{SE}=0.02$; Figure 3.41); again, the difference was not significant $(P=0.059)$.

In the CR037.3-CR022.0 reach, yearling and subyearling Chinook salmon and steelhead that migrated from either Nav 37 or CB 37 had higher $\zeta$ values at WA $22(\zeta=0.40-0.76)$ than at Nav 22 $(\zeta=0.05-0.31$; Figure 3.39). These results suggest juvenile Chinook salmon and steelhead that migrated from either sub-array at rkm 37 were more likely to migrate outside the navigation channel, across the broad tidal flat of Taylor Sands, and be detected at WA 22 than they were to migrate in the navigation channel and be detected at Nav 22. Furthermore, a comparison of groups of fish that migrated from Nav 37 and CB 37 revealed that all three tagged species/run types migrating from Nav 37 had significantly higher $\zeta$ values $(P<0.027)$ at WA $22(\zeta=0.49-0.76)$ than those fish that migrated from CB $37(\zeta=0.40$ 0.51 ; Figure 3.39), thereby indicating fish that migrated from Nav 37 were more likely to migrate outside the navigation channel to WA 22 than fish that migrated from CB 37. Conversely, for yearling and subyearling Chinook salmon, fish that migrated from CB 37 had significantly higher $\zeta$ values $(P<0.001)$ at Nav $22(\zeta=0.25-0.27)$ than those fish that migrated from Nav $37(\zeta=0.05-0.11$; Figure 3.39). Steelhead had similar $(P=0.061)$ and relatively high (compared to yearling and subyearling Chinook) $\zeta$ values $(\zeta=0.24-0.31)$ at Nav 22, regardless of whether they migrated from Nav 37 or CB 37 (Figure 3.39). These results indicate that steelhead may be more likely than yearling and subyearling Chinook salmon to migrate in the navigation channel at rkm 22. 

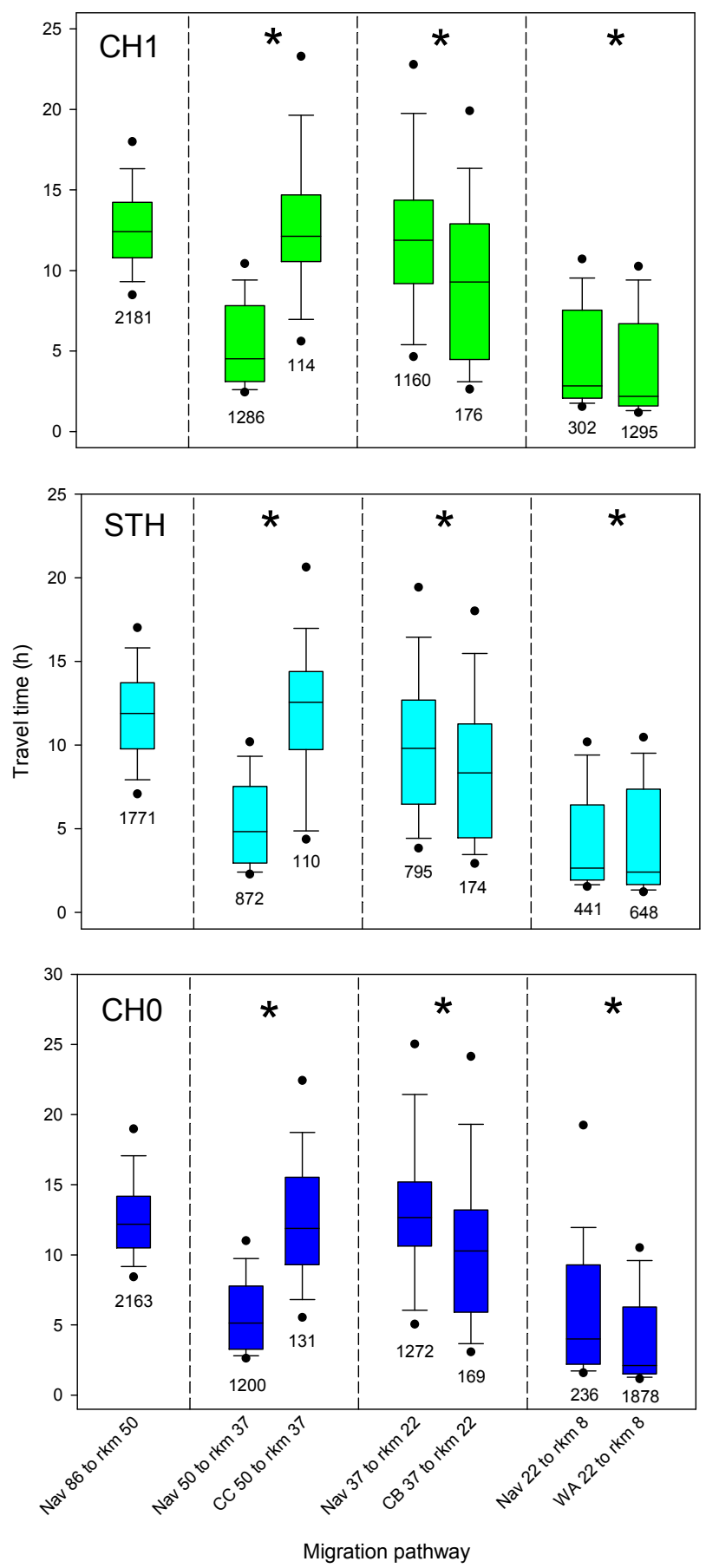

Figure 3.40. Travel time (in hours) through each reach for yearling Chinook salmon (CH1), steelhead $(\mathrm{STH})$, and subyearling Chinook salmon $(\mathrm{CH} 0)$ that migrated from each upstream subarray. Median travel time is represented by the solid horizontal line within boxes, the box represents the 25th and 75th percentiles, whiskers represent the 10th and 90th percentiles, and dots indicate the 5th and 95th percentiles. Sample sizes are shown below each box. Asterisks indicate significant differences between fish that migrated through the same reach from different upstream sub-arrays. 

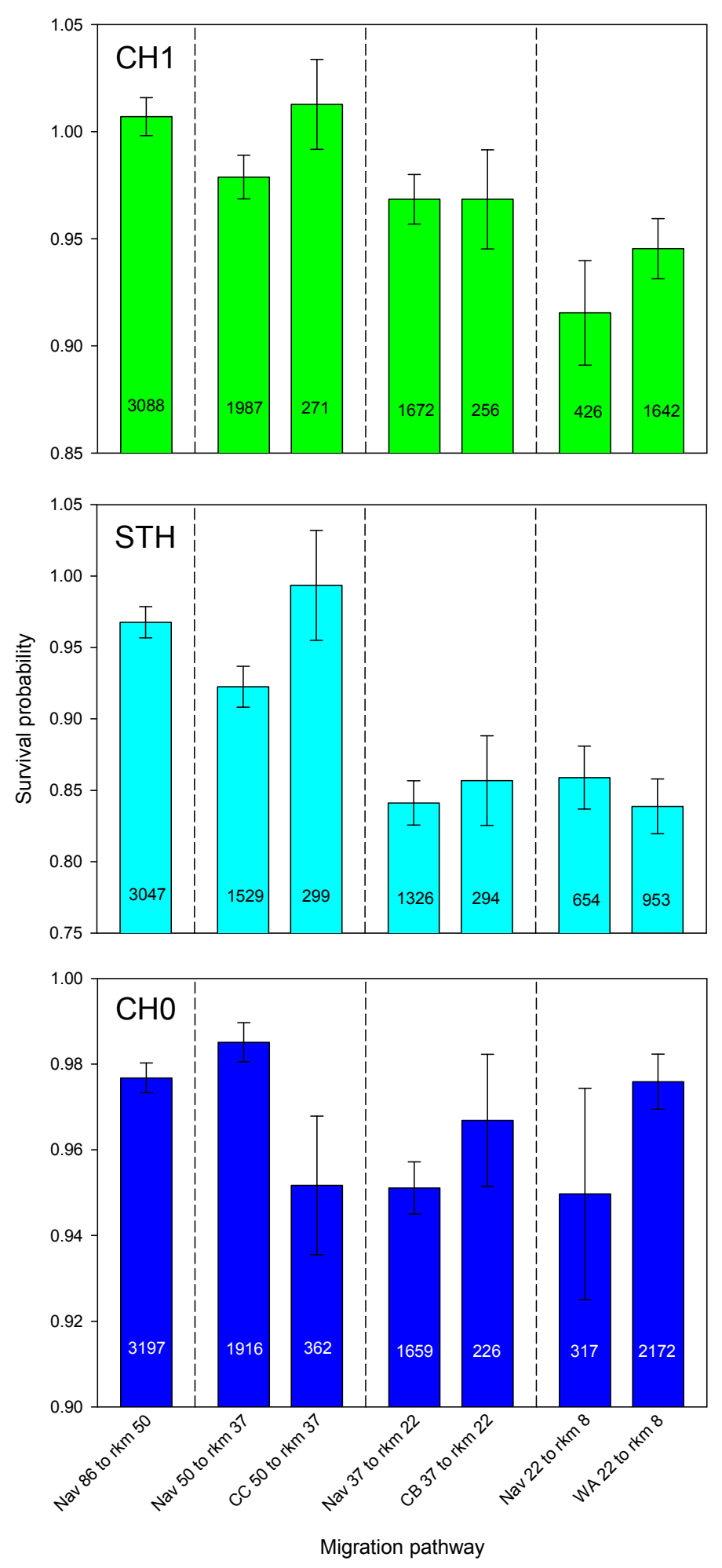

Figure 3.41. Probability of survival through each reach for yearling Chinook salmon (CH1), steelhead $(\mathrm{STH})$, and subyearling Chinook salmon $(\mathrm{CHO})$ that migrated from each upstream subarray. Sample sizes are shown within each bar. 
The length of time taken by yearling and subyearling Chinook salmon and steelhead to migrate from CR037.3 to CR022.0 differed, depending on the sub-array at which fish were detected at CR037.3. Steelhead generally migrated through the reach in the least amount of time; those that migrated from CB 37 took significantly less time (median $=8.3$ hours) than those that migrated from Nav 37 (median $=9.8$ hours; $P<0.001$; Figure 3.40). Yearling Chinook salmon that migrated from CB 37 also took significantly less time (median $=9.3$ hours) than those that migrated from Nav 37 (median $=11.9$ hours; $P<0.001$; Figure 3.40). Subyearling Chinook salmon took the most time to migrate from CR037.3 to CR022.0; again, those that migrated from CB 37 took significantly less time (median $=10.3$ hours) than those that migrated from Nav 37 (median $=12.7$ hours; $P<0.001$; Figure 3.40). Similar to the trend observed in upstream reaches, these results suggest juvenile Chinook salmon and steelhead that migrated outside the navigation channel took significantly more time to travel through the reach than those that migrated in the navigation channel.

Survival probabilities for yearling and subyearling Chinook salmon between CR037.3 and CR022.0 were high $(\geq 0.95)$ and similar, regardless of whether they migrated from Nav 37 or CB $37(P>0.362$; Figure 3.41). The probability of steelhead surviving from CR037.3 to CR022.0 was substantially lower, ranging from 0.84 to 0.86 , but similar whether they migrated from Nav 37 or $\mathrm{CB} 37$ ( $P=0.639$; Figure 3.41).

Once at CR022.0, yearling and subyearling Chinook salmon and steelhead remained primarily within their respective channels to CR008.3. Fish that migrated from Nav 22 had significantly higher $\zeta$ values $(P<0.001)$ at the Nav 8 sub-array $(\zeta=0.71-0.73)$ than those that migrated from WA $22(\zeta=0.14-0.38$; Figure 3.39). Conversely, fish that migrated from WA 22 had significantly higher $\zeta$ values $(P<0.001)$ at the WA 8 sub-array $(\zeta=0.45-0.76)$ than those that migrated from Nav $22(\zeta=0.06-0.08$; Figure 3.39). These results indicate juvenile Chinook and steelhead that migrated from the Washington shoreline channel at CR022.0 were more likely to migrate in the Washington channel to CR008.3, and those that migrated from the navigation channel at CR022.0 were more likely to remain in the navigation channel to CR008.3. However, steelhead that migrated from WA 22 had a $\zeta$ of $0.38(\mathrm{SE}=0.02)$ at the Nav 8 subarray compared to $\zeta$ values of $0.14(\mathrm{SE}=0.01)$ for subyearling Chinook and $0.21(\mathrm{SE}=0.01)$ for yearling Chinook (Figure 3.39), suggesting that steelhead had a greater tendency than yearling and subyearling Chinook to migrate from the Washington channel to the navigation channel between CR022.0 and CR008.3.

The length of time taken to migrate from Nav 22 to CR008.3 and from WA 22 to CR008.3 differed significantly for all three species/run types. Yearling Chinook salmon that migrated from Nav 22 took significantly more time (median $=2.8$ hours) to migrate to CR008.3 than those that migrated from WA 22 (median $=2.2$ hours; $P<0.001$; Figure 3.40). Steelhead that migrated from Nav 22 had a median travel time of 2.6 hours compared to 2.4 hours for those that migrated from WA 22 (Figure 3.40). Although this was a difference of only about 15 minutes, it was significant $(P=0.005)$. The median travel time of subyearling Chinook salmon that migrated from Nav 22 was 4.0 hours, which was almost twice that of subyearling Chinook that migrated from WA 22 (median $=2.1$ hours; $P<0.001$; Figure 3.40).

Survival from CR022.0 to CR008.3 was similar among pathways for yearling and subyearling Chinook salmon and steelhead. Yearling and subyearling Chinook salmon that migrated from WA 22 had higher probabilities of survival to CR008.3, ranging from 0.95 to 0.98 , than those that migrated from Nav 22, which had survival probabilities that ranged from 0.92 to 0.95 (Figure 3.41). However, the differences were not significant $\left(\chi^{2}<1.40 ; P>0.240\right)$. Steelhead had a substantially lower survival probability than juvenile Chinook, regardless of the pathway. Steelhead that migrated from Nav 22 had a 
survival probability of $0.86(\mathrm{SE}=0.02)$ to $\mathrm{CR} 008.3$, and those that migrated from WA 22 had a survival probability of $0.84(\mathrm{SE}=0.02$; Figure 3.41$)$; however, the difference between pathways was not significant $\left(\chi^{2}=0.54 ; P=0.462\right)$.

\subsubsection{Migratory Behavior in the Plume}

A total of 1,680 JSATS-tagged juvenile salmonids were detected on the array of 20 autonomous receivers in the Columbia River plume in 2010. A total of 638 tagged yearling Chinook salmon, 202 steelhead, and 840 subyearling Chinook salmon were detected in the plume between 5 May and 7 August 2010.

The median travel rate $(\mathrm{km} / \mathrm{d})$ decreased upon ocean entry for yearling and subyearling Chinook salmon and increased for steelhead (Figure 3.42). The variability in juvenile salmonid travel rate was substantially greater between rkm 8.3 and the plume than it was between $\mathrm{rkm} 153$ and 8.3 . About $14 \%$ of the yearling Chinook salmon took more than 3 days to travel from the mouth of the Columbia River to their last detection on the plume array (Figure 3.43).

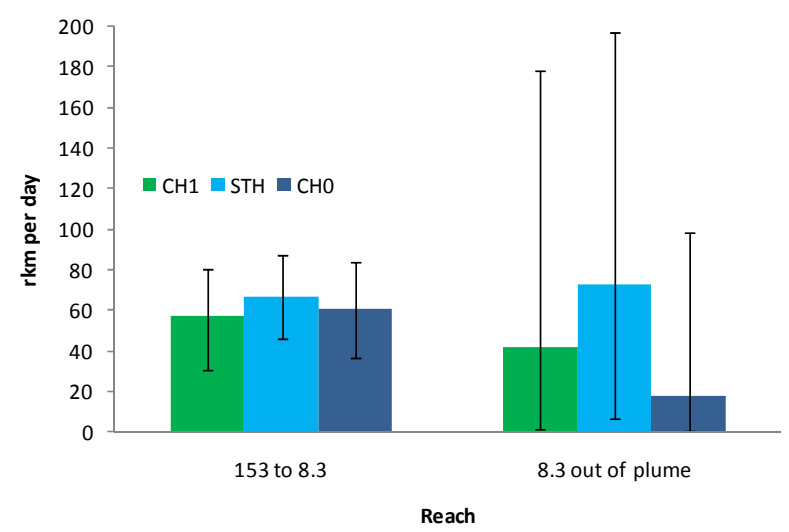

Figure 3.42. Median travel rate ( $\mathrm{rkm} / \mathrm{d}$ ) of acoustic-tagged yearling Chinook salmon $(\mathrm{CH} 1)$, steelhead (STH), and subyearling Chinook salmon (CH0) in the lower Columbia River (rkm 153 to 8.3 ) and between the mouth of the river and the JSATS plume array (rkm 8.3 to final detection in plume) in 2010. Error bars denote one standard error.

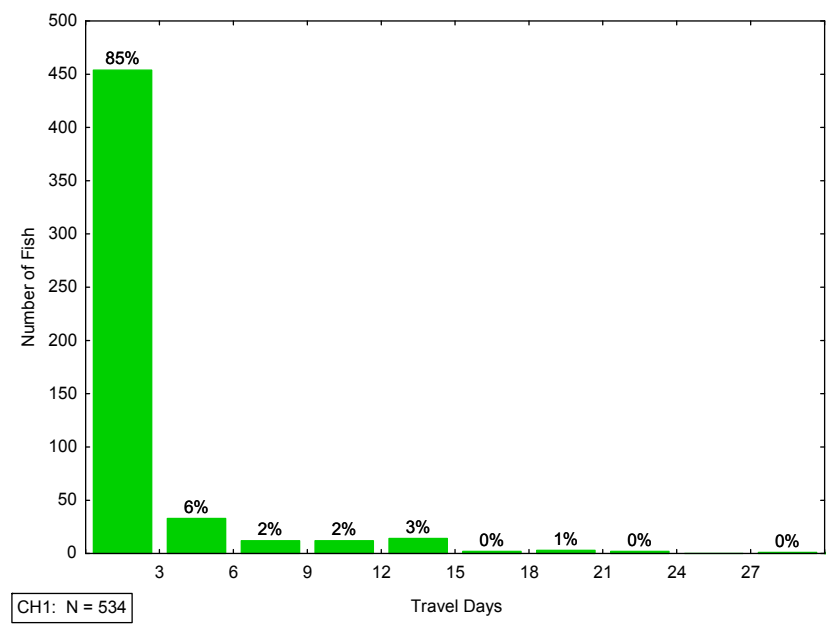

Figure 3.43. Travel time (days) of acoustic-tagged yearling Chinook salmon between the mouth of the Columbia River and last detection on the JSATS plume array in 2010. 
Tagged steelhead exited the mouth of the Columbia River and passed the array in the plume very quickly. Only 5\% of the steelhead took more than 3 days between their last detection at the mouth of the river and their final detection on the plume array (Figure 3.44). In contrast, subyearling Chinook salmon took more time in the transition from the river to the ocean, with $28 \%$ taking more than 3 days between the mouth of the river and the plume array (Figure 3.45).

Acoustic-tagged yearling Chinook salmon were more often detected migrating straight out over the terminus sub-array or passing the sub-array to the south off of Oregon during the early portion of their emigration in 2010. Only $6 \%$ of the tagged yearling Chinook salmon were last detected on the plume sub-array to the north of the mouth of the Columbia River between 5 May and 17 May 2010 (Figure 3.46). Steelhead also were rarely (5\%) detected moving north during this early portion of the emigration period, with nearly half (47\%) being last detected on the sub-array to the south of the mouth of the Columbia River. Movements of yearling Chinook salmon and steelhead shifted more northward after 17 May 2010. However, over the entire spring season, the majority of each species was last detected on the terminus and southern sub-arrays (Figure 3.47).

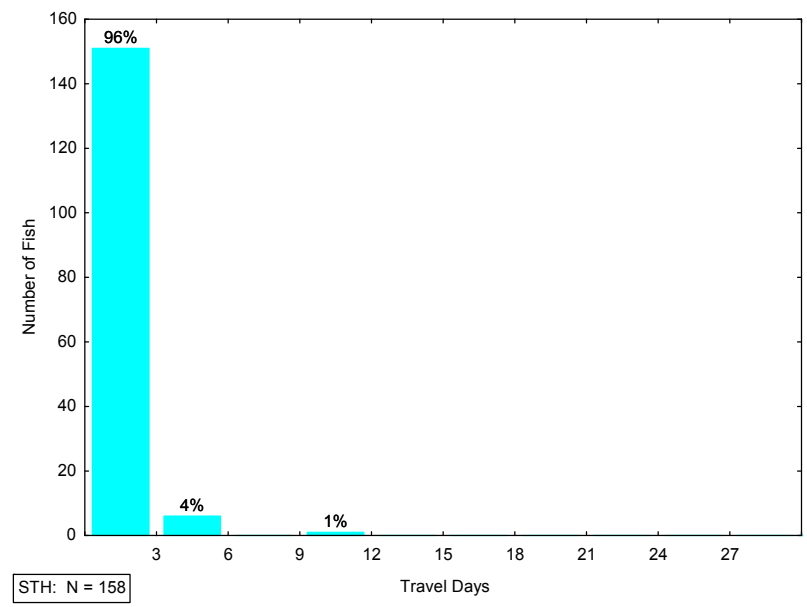

Figure 3.44. Travel time (days) of acoustic-tagged steelhead between the mouth of the Columbia River and last detection on the JSATS plume array in 2010.

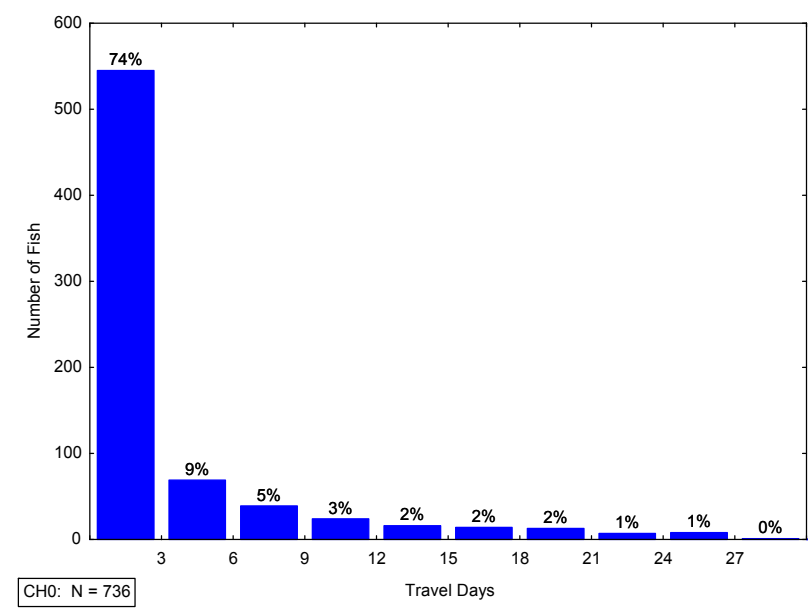

Figure 3.45. Travel time (days) of acoustic-tagged subyearling Chinook salmon between the mouth of the Columbia River and last detection on the JSATS plume array in 2010 
Over half (55\%) of the acoustic-tagged subyearling Chinook salmon were detected on the northern sub-array in the Columbia River plume in 2010 (Figure 3.48). Nearly equal portions were last detected on the terminus and southern sub-arrays.

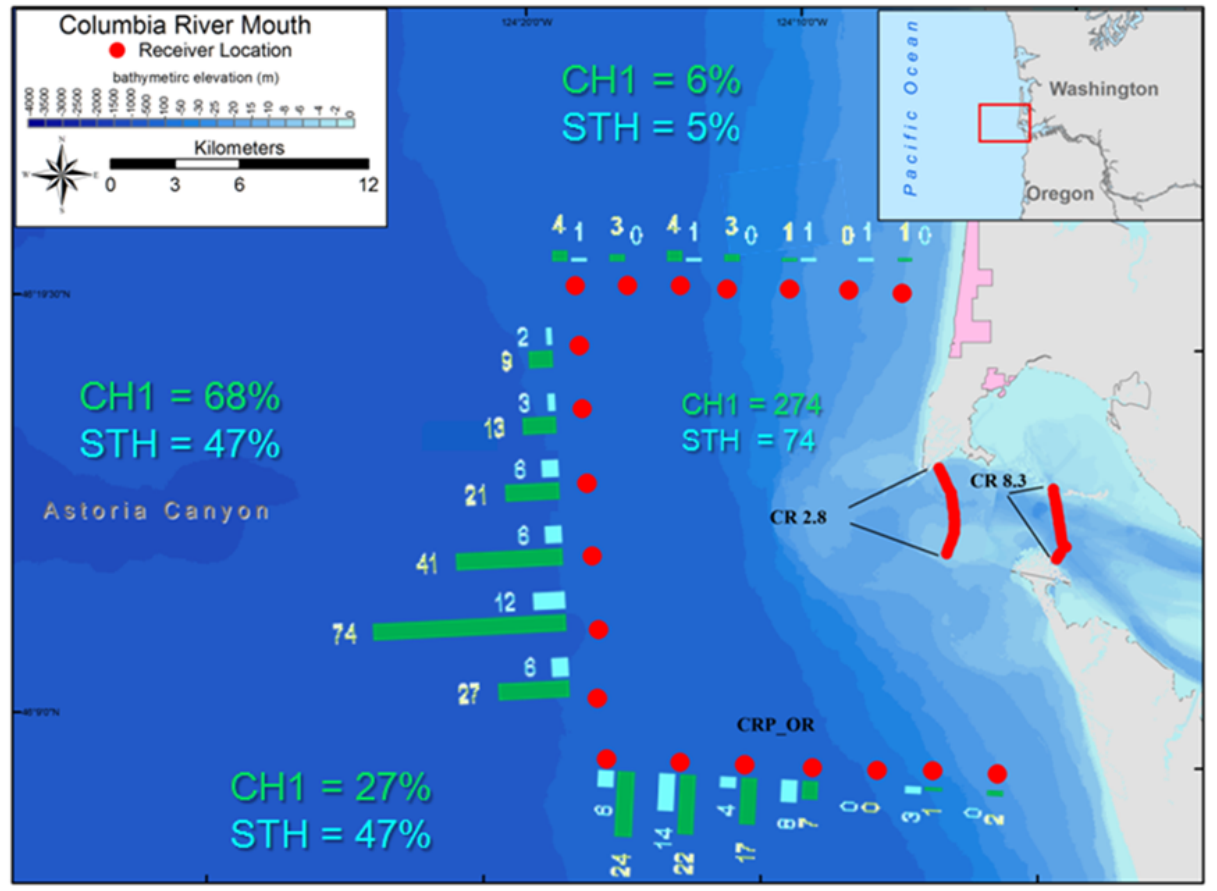

Figure 3.46. Last detection locations of acoustic-tagged yearling Chinook salmon (CH1) and steelhead (STH) on the Columbia River JSATS plume sub-arrays between 5 May and 17 May 2010.

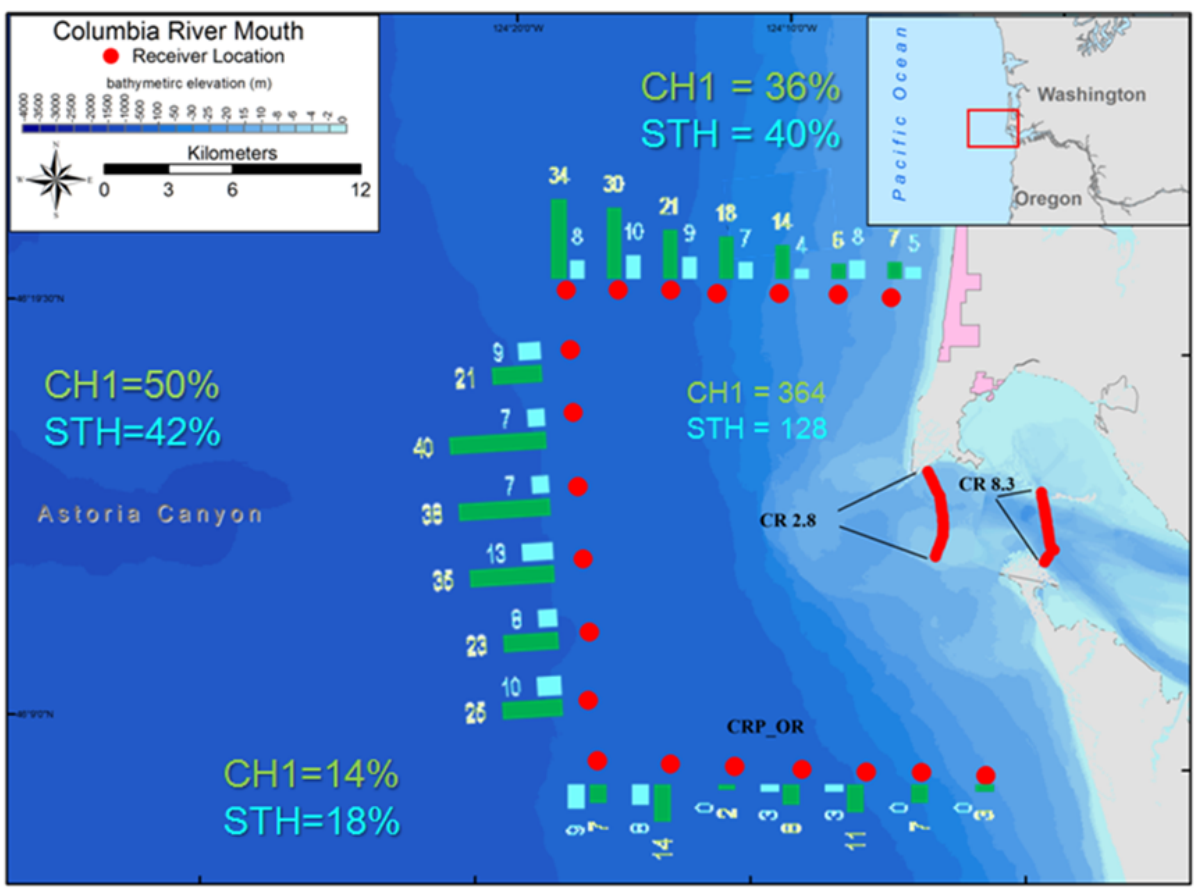

Figure 3.47. Last detection locations of acoustic-tagged yearling Chinook salmon (CH1) and steelhead (STH) on the Columbia River JSATS plume sub-arrays between 18 May and 18 June 2010. 


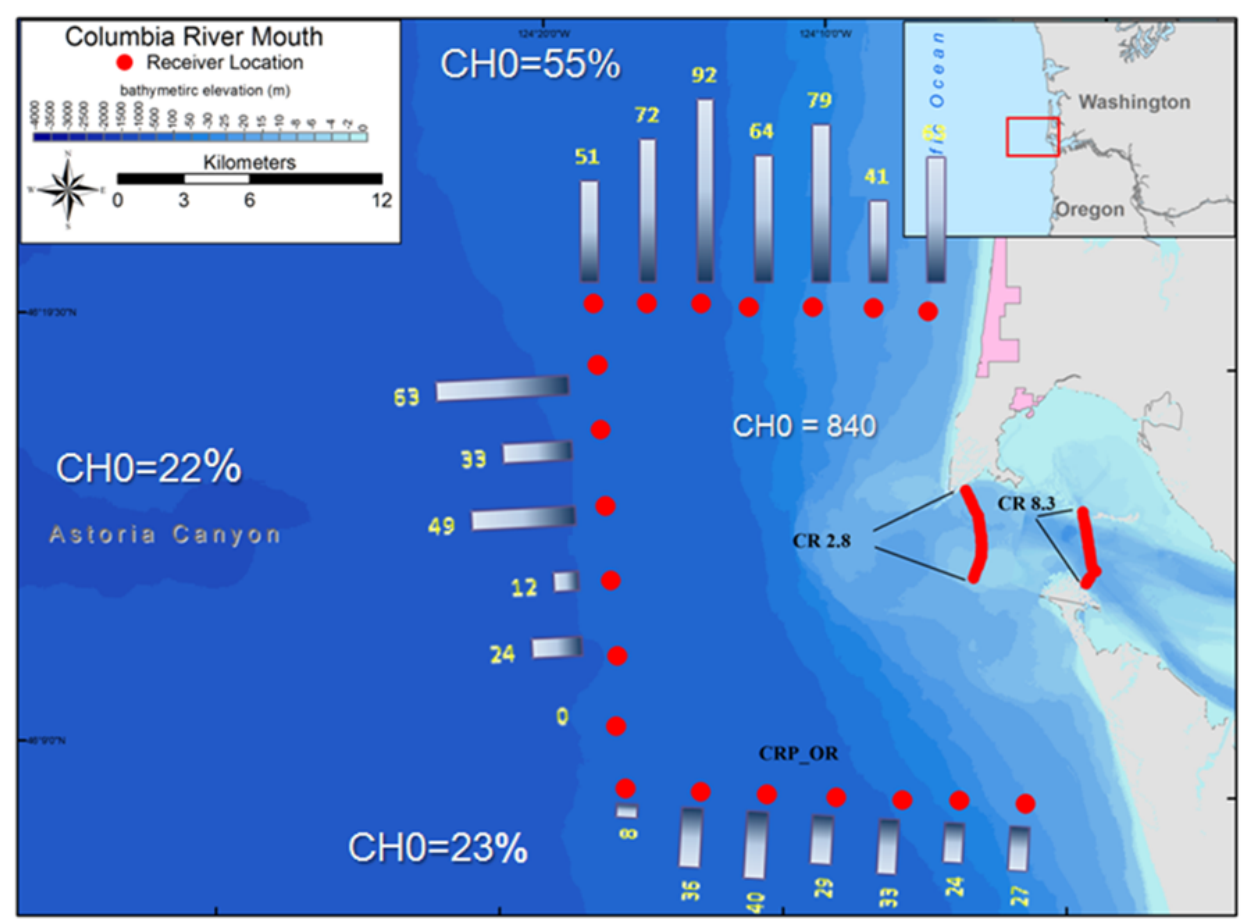

Figure 3.48. Last detection locations of acoustic-tagged subyearling Chinook salmon (CH0) on the Columbia River JSATS plume sub-arrays between 19 June and 7 August 2010.

\subsubsection{Cross-Channel Distribution}

The majority of yearling Chinook salmon were first detected in the Washington shoreline channel at the Astoria Bridge array (CR022.0; Figure 3.49). At the East Sand Island array (CR008.3), they were most frequently first detected between 1.5 and $2.5 \mathrm{~km}$ north of Clatsop Spit, halfway between the middle of the channel and the tip of West Sand Island (Figure 3.49). Very few yearling Chinook salmon were detected on the receivers located closest to East Sand Island. This area is in line with the end of a pile dike that extends out from East Sand Island (Figure 3.50). At the Columbia River bar array (CR002.8), the largest percentages of yearling Chinook salmon were first detected south of the navigation channel (Figure 3.50).

The distribution of steelhead at the Astoria Bridge array (CR022.0) was similar to yearling Chinook salmon with the greatest percentage of steelhead first detected in the Washington shoreline channel (Figure 3.51). However, a greater percentage of steelhead was detected in the middle of the river and in the Oregon shoreline channel than was observed for yearling Chinook salmon. At the East Sand Island array (CR008.3), steelhead were more often detected closer to Clatsop Spit (Oregon shoreline) than either yearling or subyearling Chinook salmon (Figure 3.51). At the Columbia River bar array (CR002.8), the greatest percentage of steelhead was first detected on the Oregon side of the navigation channel (Figure 3.50). 

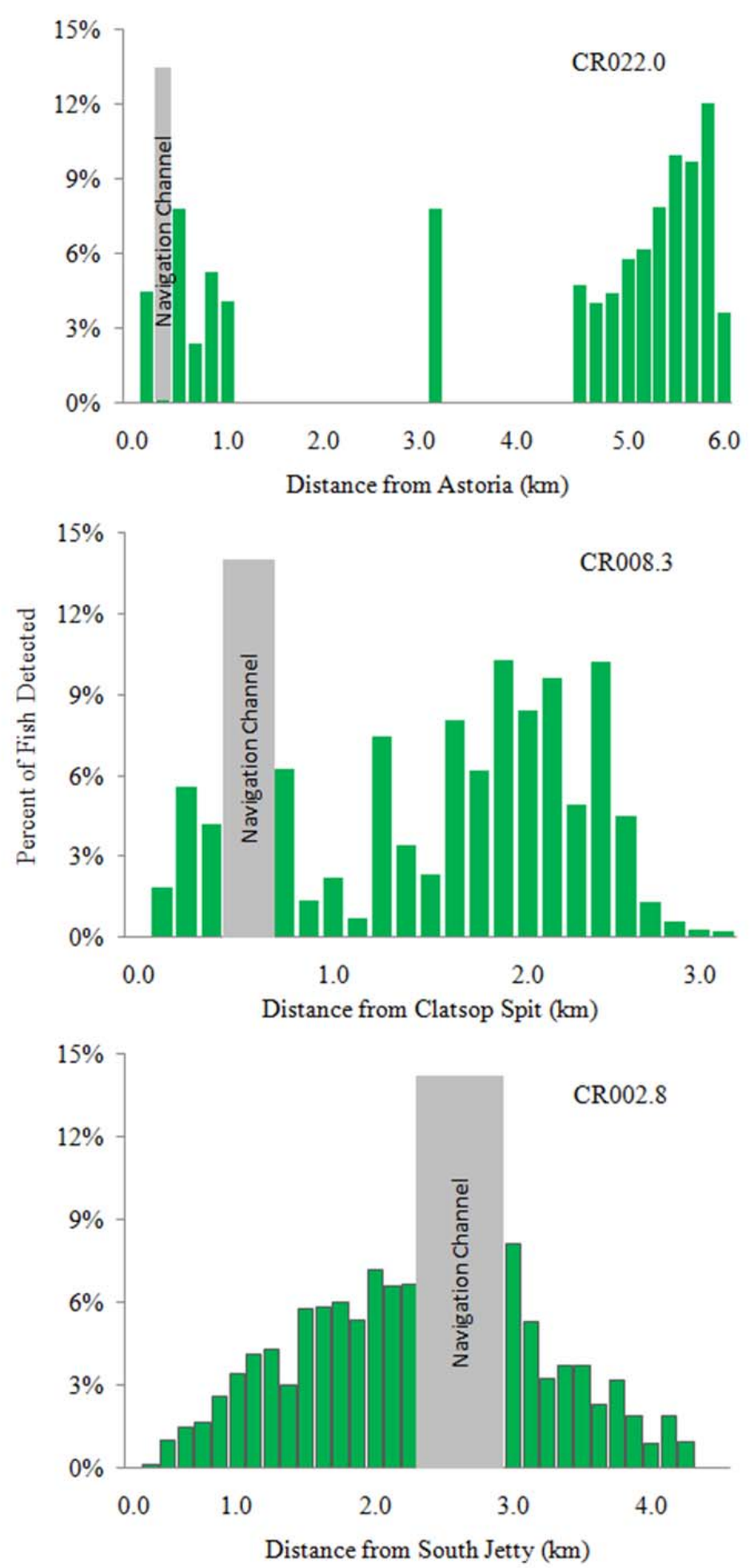

Figure 3.49. Cross-channel distribution of the first detections of acoustic-tagged yearling Chinook salmon at the Astoria Bridge (CR022.0), East Sand Island (CR008.3), and Columbia River bar (CR002.8) arrays. 


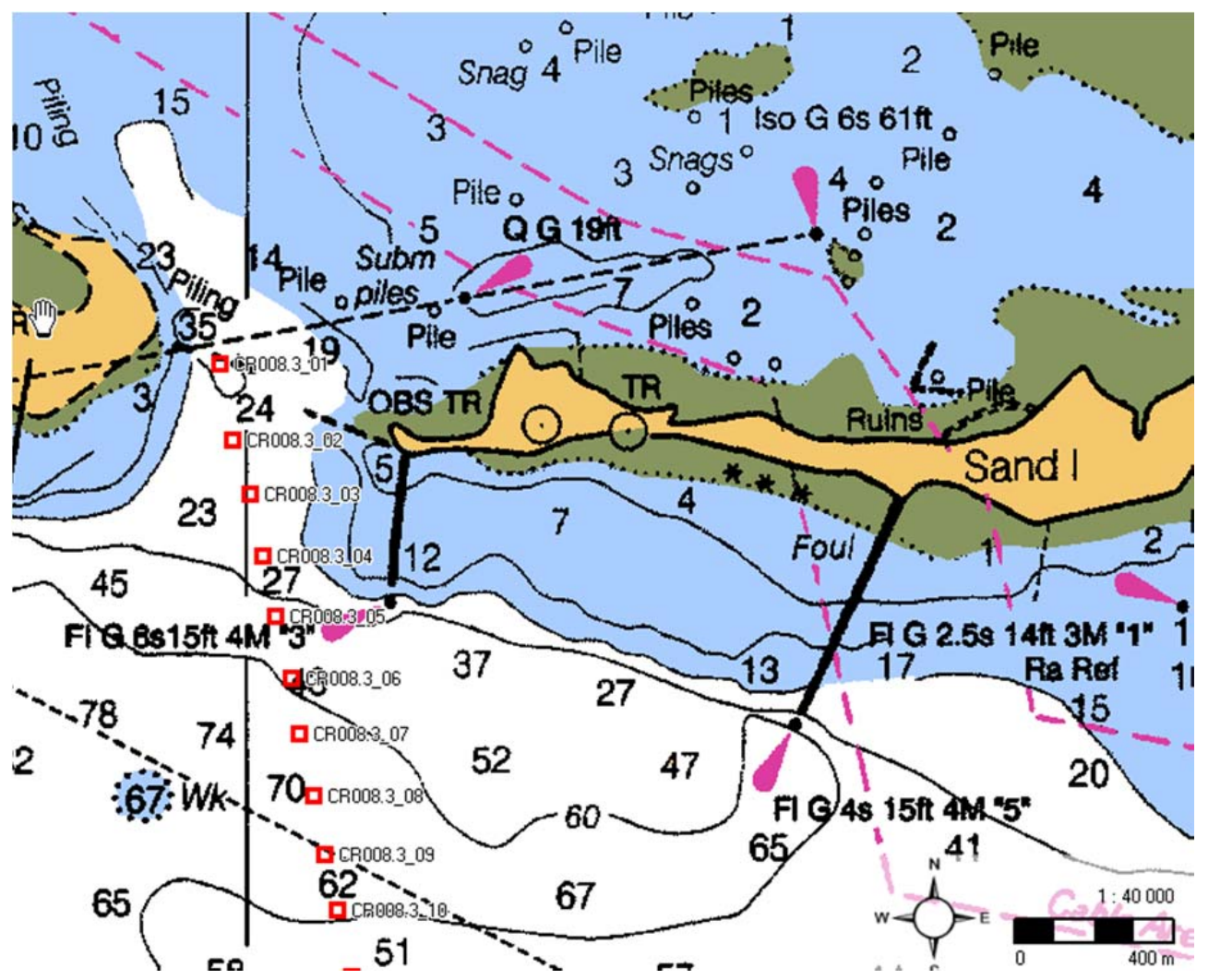

Figure 3.50. Detail of the CR008.3 array near East Sand Island showing the proximity of receiver positions to the pile dike that extends southward from the western tip of East Sand Island. For reference to cross-channel distribution figures, position CR008.3_05 is about $2.5 \mathrm{~km}$ from Clatsop Spit.

The distribution of steelhead at the Astoria Bridge array (CR022.0) was similar to that of yearling Chinook salmon, with the greatest percentage of steelhead first detected in the Washington shoreline channel (Figure 3.51). However, a greater percentage of steelhead was detected in the middle of the river and in the Oregon shoreline channel than was observed for yearling Chinook salmon. At the East Sand Island array (CR008.3), steelhead were more often detected closer to Clatsop Spit (Oregon shoreline) than either yearling or subyearling Chinook salmon (Figure 3.51. At the Columbia River bar array (CR002.8), the greatest percentage of steelhead was first detected on the Oregon side of the navigation channel (Figure 3.51).

The cross-channel distribution of subyearling Chinook salmon at the Astoria Bridge array (CR022.0) was highly skewed towards the Washington shoreline, with the greatest percentage of first detections being in the Washington shoreline channel (Figure 3.52). The distribution of subyearling Chinook salmon at the East Sand Island array (CR008.3) was similar to that of yearling Chinook salmon with the greatest percentage of first detections occurring around 2.0 to $2.5 \mathrm{~km}$ north of Clatsop Spit (Figure 3.52). In contrast to the distributions of yearling Chinook salmon and steelhead, the majority of the subyearling Chinook salmon were first detected at the Columbia River bar array (CR002.8) on the Washington side of the navigation channel (Figure 3.52). 

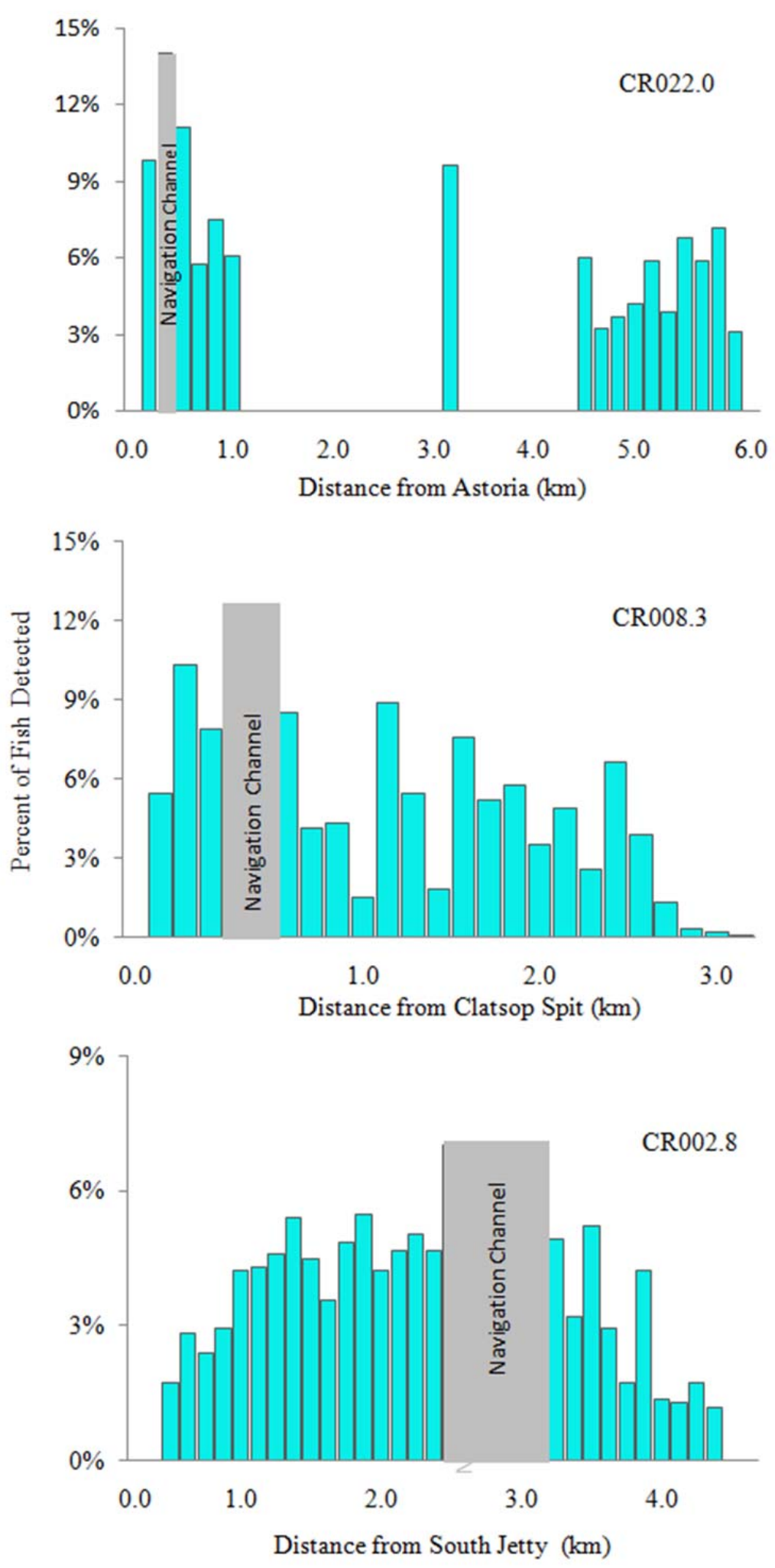

Figure 3.51. Cross-channel distribution of the first detections of acoustic-tagged steelhead at the Astoria Bridge (CR022.0), East Sand Island (CR008.3), and Columbia River bar (CR002.8) arrays. 

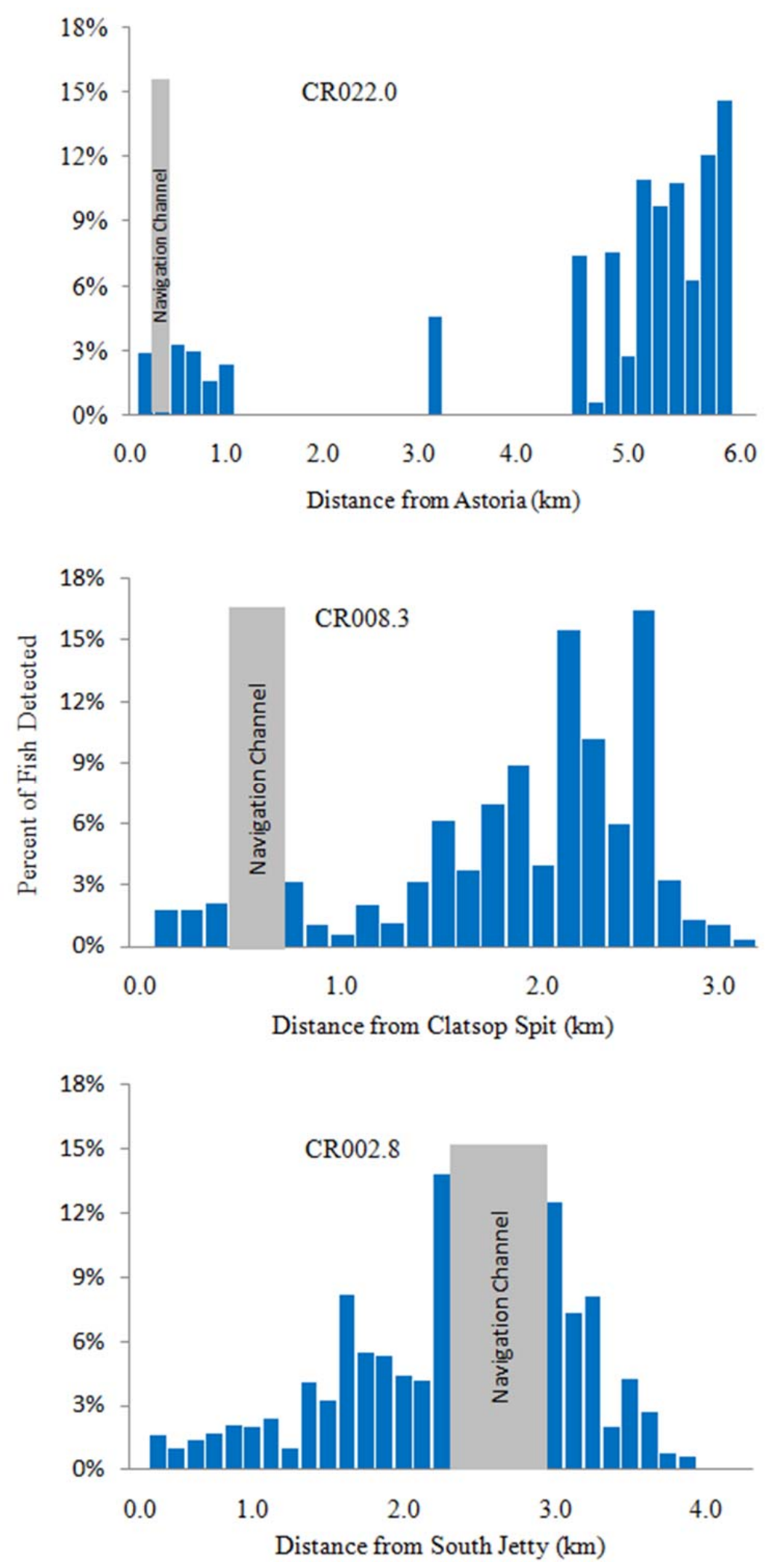

Figure 3.52. Cross-channel distribution of the first detections of acoustic-tagged subyearling Chinook salmon at the Astoria Bridge (CR022.0), East Sand Island (CR008.3), and Columbia River bar (CR002.8) arrays. 


\subsubsection{Diel Distribution}

Yearling Chinook salmon were detected nearly equally throughout the day at Harrington Point (CR037.3). However, at the Three Tree Point (CR049.6), Astoria Bridge (CR022.0), East Sand Island (CR008.3), and Columbia River bar (CR002.8) arrays yearling Chinook salmon were more likely to be detected in the morning, with detections declining throughout the daylight period and stabilizing around 3.0 to $3.5 \%$ during each hour of darkness (Figure 3.53).
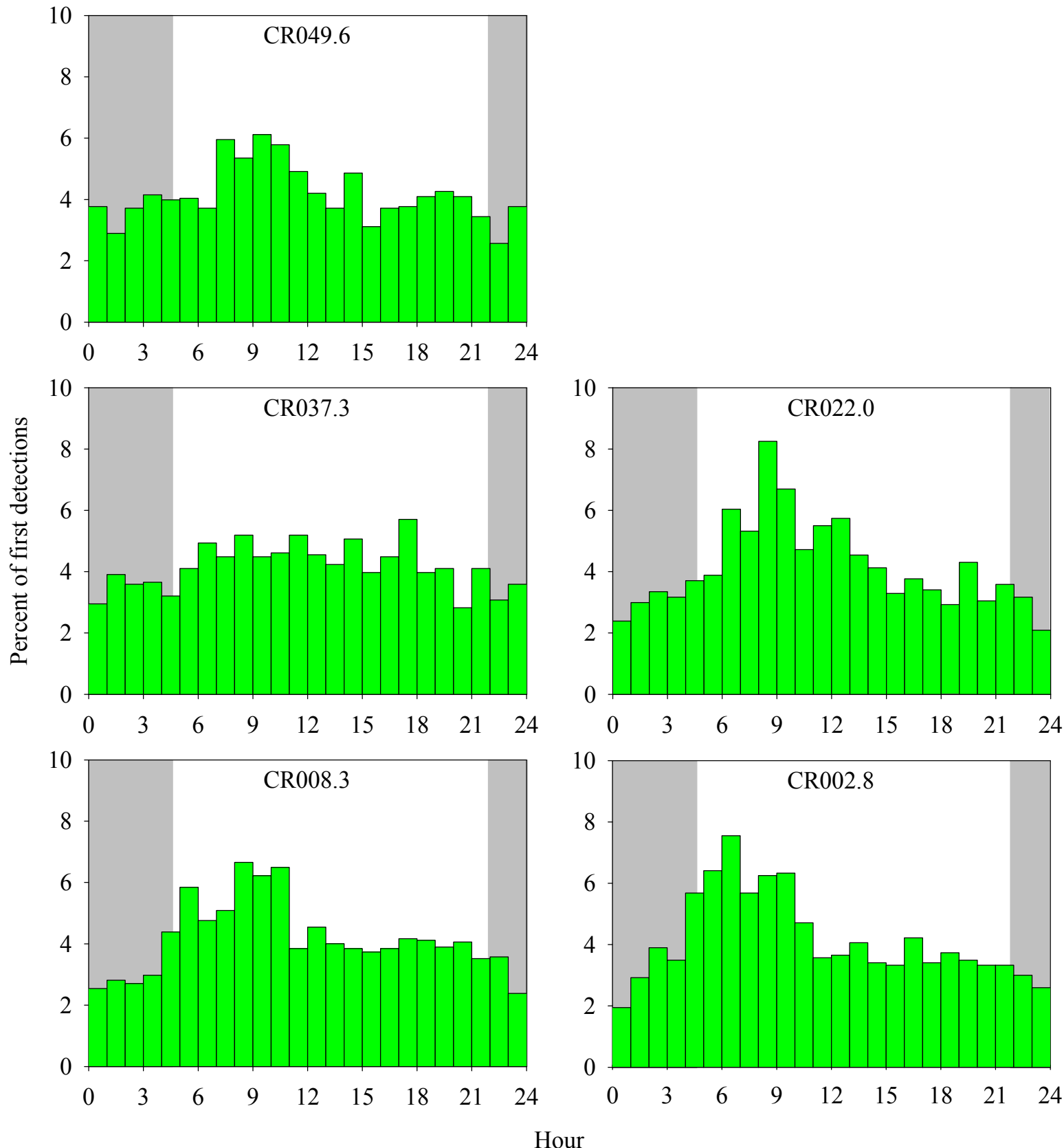

Figure 3.53. Hourly distributions of the first detections of yearling Chinook salmon at the Three Tree Point (CR049.6), Harrington Point (CR037.3), Astoria Bridge (CR022.0), East Sand Island (CR008.3), and Columbia River bar (CR002.8) arrays. Grey bars represent approximate hours of darkness. 
The highest percentage of steelhead first detections occurred in the early morning ( 7 to 10 a.m.) at all arrays (Figure 3.54). The lowest numbers of first detections of steelhead occurred during hours of darkness except for Three Tree Point array (CR049.6; Figure 3.54), where lower numbers were detected in the early afternoon. At the Columbia River bar (CR002.8) array the greatest percentage of detections occurred in the early morning and evening (Figure 3.54). At the Astoria Bridge (CR022.0) and Harrington Point (CR037.3) arrays, the percentage of steelhead detected gradually increased from early morning through 10 and 11 a.m., respectively, and declined throughout the afternoon and evening (Figure 3.54).
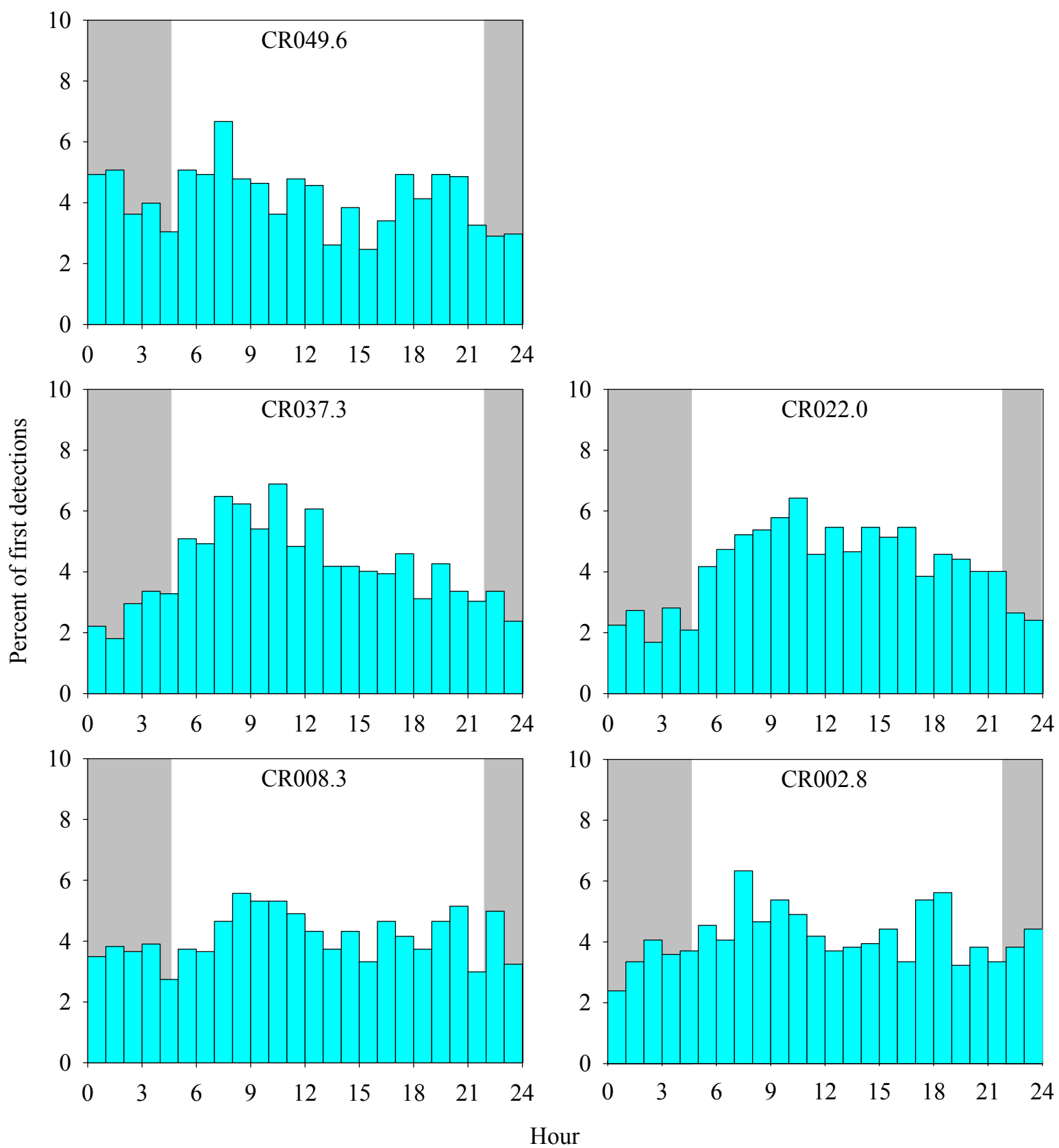

Figure 3.54. Hourly distributions of the first detections of steelhead at the Three Tree Point (CR049.6), Harrington Point (CR037.3), Astoria Bridge (CR022.0), East Sand Island (CR008.3), and Columbia River bar (CR002.8) arrays. Grey bars represent approximate hours of darkness. 
At all arrays but Harrington Point (CR037.3), the highest percentage of subyearling Chinook salmon first detections occurred in early morning (Figure 3.55). The lowest percentage of first detections of subyearling Chinook salmon was during early afternoon at the Astoria Bridge (CR022.0) and Columbia River bar (CR002.8) arrays and around 11 p.m. at all other arrays (Figure 3.55). Arrivals (first detections) of subyearling Chinook salmon at the three lower arrays (CR022.0, CR008.3, and CR002.8) appeared to follow a crepuscular pattern, with peaks in arrivals early and late in the daylight periods.
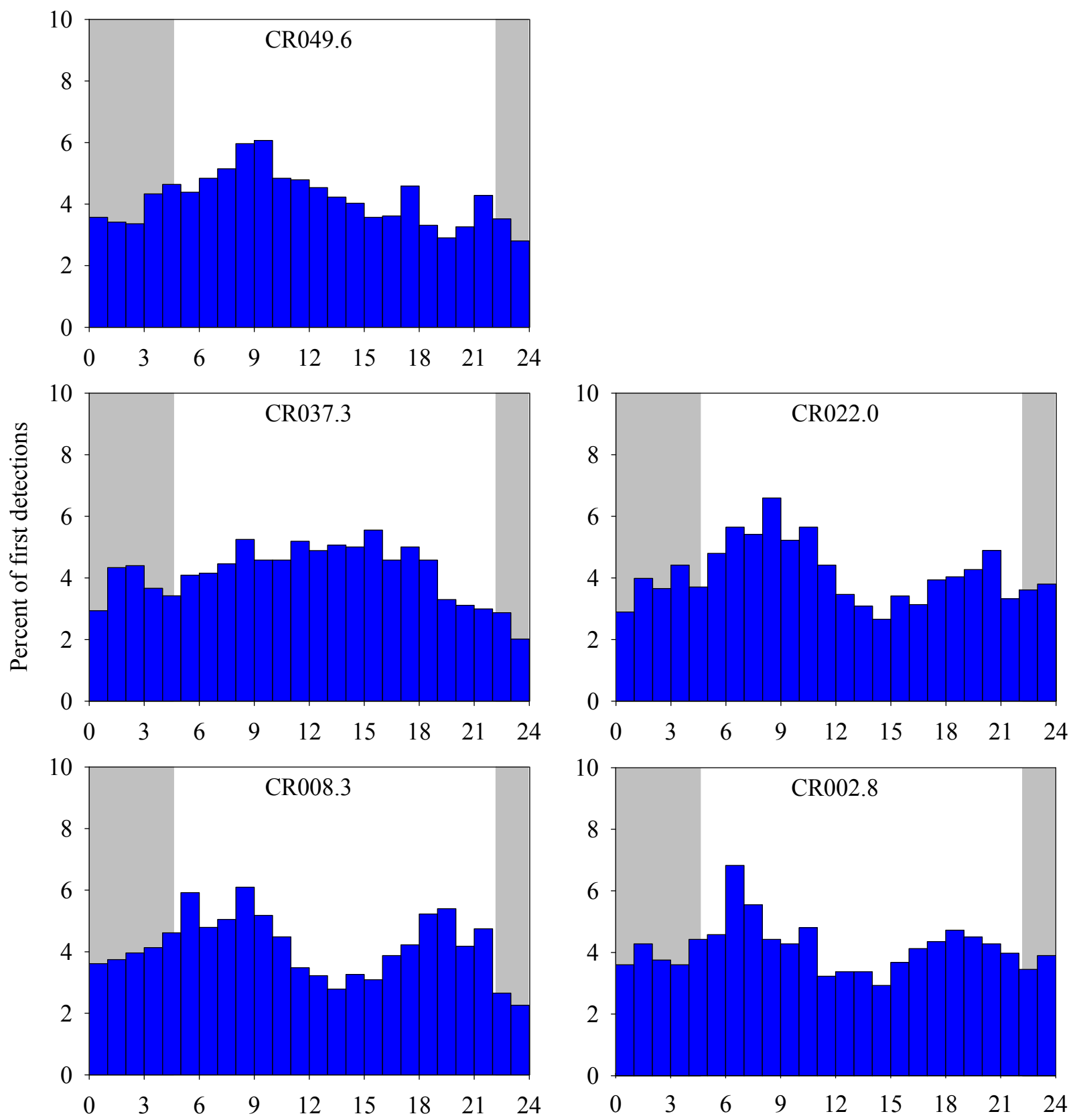

Hour

Figure 3.55. Hourly distributions of the first detections of subyearling Chinook salmon at the Three Tree Point (CR049.6), Harrington Point (CR037.3), Astoria Bridge (CR022.0), East Sand Island (CR008.3), and Columbia River bar (CR002.8) arrays. Grey bars represent approximate hours of darkness. 


\subsubsection{Tidal Influence}

Most first detections of acoustic-tagged juvenile salmonids occurred during ebbing tides in the lower $50 \mathrm{~km}$ of the Columbia River estuary. Analysis of the percentage of first detections against change in tide height at the time of detection indicated that all species or run types were most frequently first detected at all arrays downstream of rkm 50 during ebb tides (Figure 3.56, Figure 3.57, and Figure 3.58). The influence of tidal exchange on the movement of tagged fish was especially pronounced at the Astoria Bridge (CR022.0) and East Sand Island (CR008.3) arrays. Relatively few juvenile salmonids were first detected between rkm 22 and 8 during slack or flood tide conditions.

\subsubsection{Avian Predation}

A total of 592 JSATS-tagged fish released at Roosevelt, The Dalles, and Hood River in 2010 were detected at the Caspian tern or double-crested cormorant colony on East Sand Island. Of those, 132 were yearling Chinook salmon, 381 were steelhead, and 79 were subyearling Chinook salmon. Of the 2,607 yearling Chinook salmon detected at CR153.0, 4.1\% were detected at the colonies (Table 3.44). The percent of yearling Chinook detected at CR153.0 that were later detected at the bird colonies was highest for the first three virtual-release weeks (early-mid May; 4.5-4.6\%) before declining to below 4\% for the final two virtual-release weeks in late May. The percentage of steelhead detected at CR153.0 that were later detected at the bird colonies was substantially higher. Of the 2,455 steelhead detected at CR153.0, $11.7 \%$ were detected at the colonies (Table 3.44). The known predation rate generally increased for steelhead as the migration season progressed, from $7.1 \%$ in early May to $14.5 \%$ in late May/early June. Subyearling Chinook salmon experienced the lowest known predation rate; $2.3 \%$ of the 3,022 subyearling Chinook detected at CR153.0 were later detected at the colonies (Table 3.44). The known predation rate increased as the season progressed for subyearling Chinook salmon, from $0.7 \%$ in mid-June to $4.1 \%$ in mid-July.

A greater percentage of the yearling Chinook salmon and steelhead tags detected at the colonies were detected at the tern colony than at the cormorant colony, with $58 \%$ and $78 \%$ of the yearling Chinook and steelhead tags, respectively, detected at the tern colony. In contrast, the percentage of subyearling Chinook salmon tags detected at the colonies was higher at the cormorant colony (53\%) than at the tern colony $(47 \%)$. 

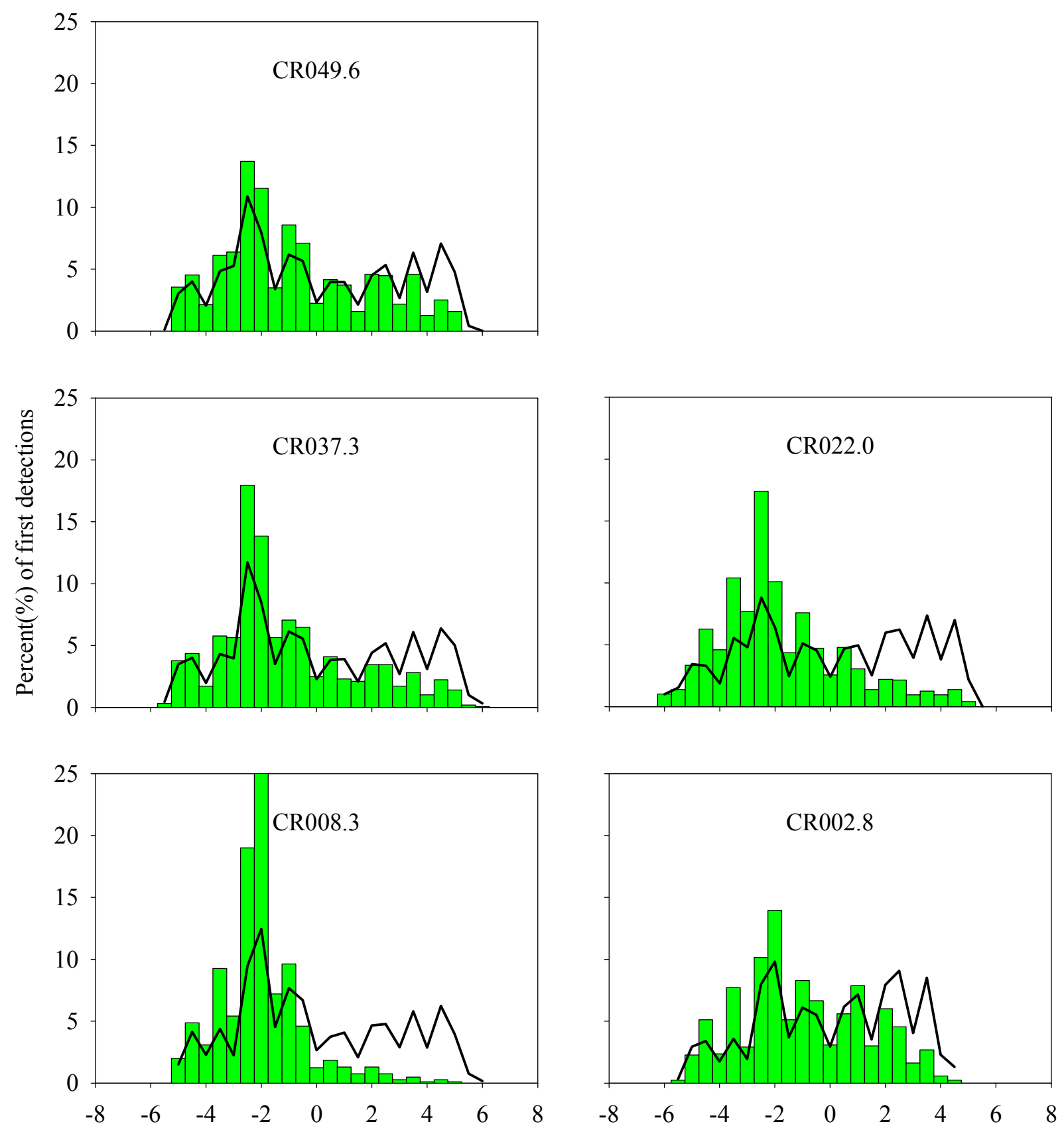

Tide change ( $\mathrm{cm} / 5-\mathrm{min})$

Figure 3.56. Percentage of the first detections of yearling Chinook salmon on arrays at Three Tree Point (CR049.6), Harrington Point (CR037.3), the Astoria Bridge (CR022.0), East Sand Island (CR008.3), and the Columbia River bar (CR002.8) versus change in tide elevation. The percent occurrence of each tide change is displayed as the solid line. 

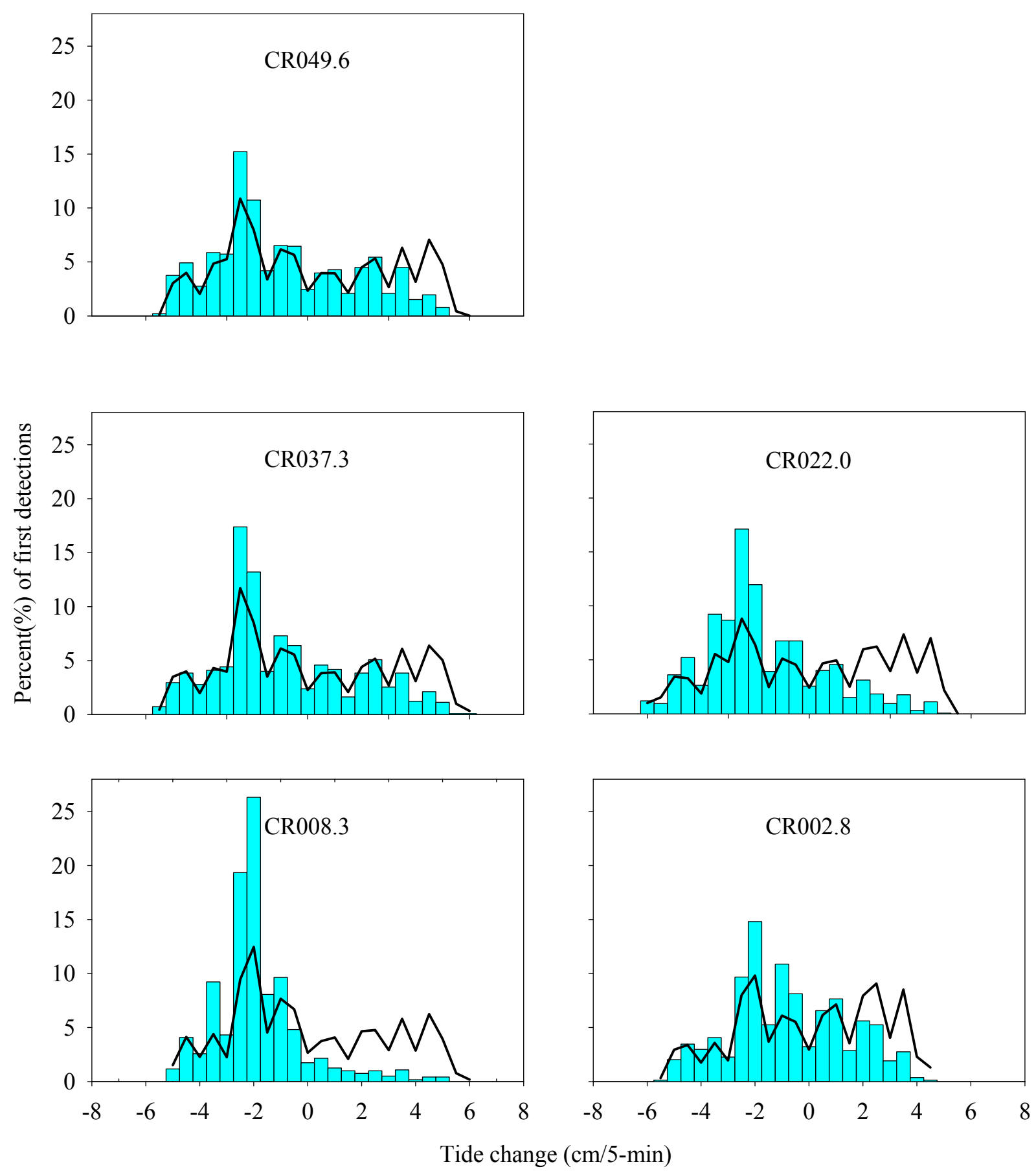

Figure 3.57. Percentage of the first detections of steelhead on arrays at Three Tree Point (CR049.6), Harrington Point (CR037.3), the Astoria Bridge (CR022.0), East Sand Island (CR008.3), and the Columbia River bar (CR002.8) versus change in tide elevation. The percent occurrence of each tide change is displayed as the solid line. 

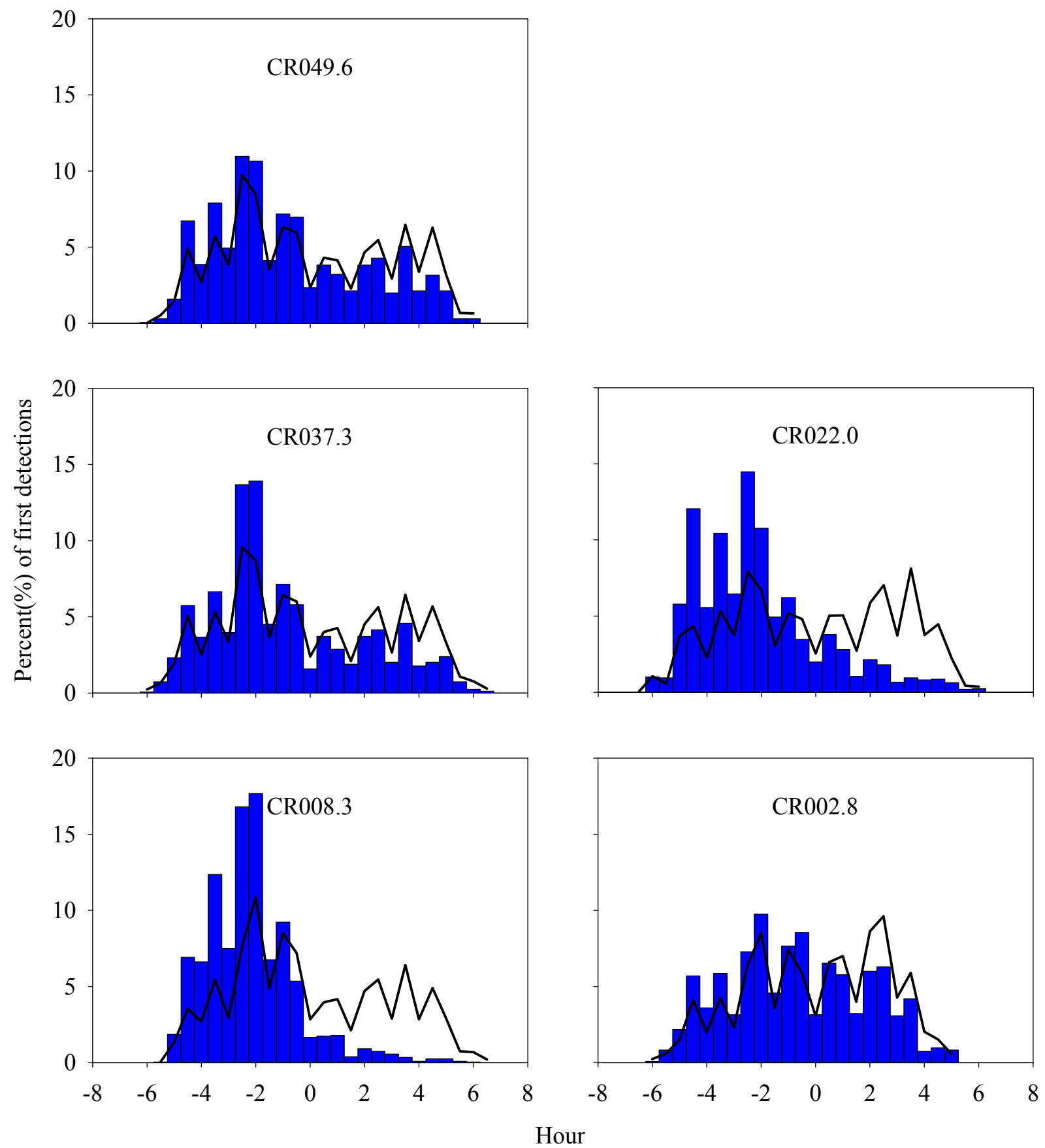

Figure 3.58. Percentage of the first detections of subyearling Chinook salmon on arrays at Three Tree Point (CR049.6), Harrington Point (CR037.3), the Astoria Bridge (CR022.0), East Sand Island (CR008.3), and the Columbia River bar (CR002.8) versus change in tide elevation. The percent occurrence of each tide change is displayed as the solid line. 
Table 3.44. Avian predator (Caspian tern and double-crested cormorant) colony recoveries of PIT tags from JSATS+PIT-tagged juvenile salmonids in the lower Columbia River estuary in 2010. The number of yearling Chinook salmon (CH1), steelhead (STH), and subyearling Chinook salmon (CH0) detected by the JSATS array at rkm 153 (CR153.0) and at the avian colonies are shown for each virtual-release week at rkm 153.

\begin{tabular}{|c|c|c|c|c|c|c|c|c|c|c|c|}
\hline & $\mathrm{CH} 1$ & & & & STH & & & & $\mathrm{CH} 0$ & & \\
\hline $\begin{array}{c}\text { CR153 } \\
\text { week }\end{array}$ & CR153 N & Colonies N & $\%$ & $\begin{array}{c}\text { CR153.0 } \\
\text { week }\end{array}$ & CR153.0 N & Colonies N & $\%$ & $\begin{array}{c}\text { CR153.0 } \\
\text { week }\end{array}$ & CR153.0 N & Colonies N & $\%$ \\
\hline May 2 & 584 & 26 & 4.5 & May 2 & 537 & 38 & 7.1 & Jun 14 & 302 & 2 & 0.7 \\
\hline May 9 & 611 & 28 & 4.6 & May 9 & 520 & 64 & 12.3 & Jun 21 & 647 & 6 & 0.9 \\
\hline May 16 & 485 & 22 & 4.5 & May 16 & 470 & 52 & 11.1 & Jun 28 & 680 & 17 & 2.5 \\
\hline May 23 & 500 & 14 & 2.8 & May 23 & 472 & 67 & 14.2 & Jul 5 & 737 & 19 & 2.6 \\
\hline May 30 & 427 & 16 & 3.7 & May 30 & 456 & 66 & 14.5 & Jul 12 & 656 & 27 & 4.1 \\
\hline Total & 2607 & 106 & 4.1 & Total & 2455 & 287 & 11.7 & Total & 3022 & 71 & 2.3 \\
\hline
\end{tabular}





\subsection{Discussion}

The annual estimated pooled survival probability of yearling Chinook salmon smolts from Bonneville Dam to the mouth of the Columbia River (rkm 8.3) has ranged from 0.665 to 0.799 between 2005 and 2009. In 2010 we grouped fish into virtual releases at rkm 153 instead of at Bonneville Dam, to avoid including any direct mortality from dam passage in our post-FCRPS survival estimates. The pooled survival probability estimate in 2010 for yearling Chinook salmon from rkm 153 to 8.3 was 0.844 ( $\mathrm{SE}=$ 0.021). By adding JSATS arrays between Bonneville Dam and East Sand Island (rkm 8.3) in 2007 and 2008, we determined that most of the losses of yearling Chinook salmon occurred between Three Tree Point (rkm 50) and rkm 8 (McMichael et al. 2010b). Based on information from our efforts in 2007 and 2008 , we increased the number of autonomous receivers in the lower $50 \mathrm{~km}$ of the estuary in 2009 and 2010 to more clearly determine where the greatest losses were occurring. Survival probability of yearling Chinook salmon from virtual release at rkm $153(10 \mathrm{~km}$ downstream of the mouth of the Willamette River) was high in the lower Columbia River and estuary (above rkm 50) in both 2009 and 2010 before declining sharply downstream of rkm 50 .

Steelhead smolt estimated survival probability was similar in 2010 to 2009 . In 2010, the pooled survival probability for steelhead from rkm 153 to the mouth of the Columbia River (rkm 8.3) was 0.603 $(\mathrm{SE}=0.023)$. Steelhead survival probability from rkm 153 to the mouth of the Columbia River was lowest in the lower portion of the estuary. Survival probability of steelhead smolts from virtual release at rkm 153 was much lower than that of either Chinook salmon stocks, but was generally high in the lower Columbia River down to about Oak Point (rkm 86) before declining very sharply between rkm 37.3 and East Sand Island (rkm 8.3). Reach survival probability estimates also indicated that survival probability of steelhead was lowest downstream of rkm 37. It is possible that steelhead behavior influences mortality in the Columbia River estuary with the steelhead tendency to migrate closer to the surface, which may relate to why PIT tags from the steelhead in our study were more likely to be recovered from the Caspian tern colony than from the double-crested cormorant colony.

Subyearling Chinook salmon estimated survival probability was relatively high in 2010 . In 2010 , the pooled survival probability for subyearling Chinook salmon from rkm 153 to the mouth of the Columbia River ( $\mathrm{rkm} 8.3$ ) was $0.861(\mathrm{SE}=0.055)$. The estimated probability of survival of subyearling Chinook salmon from Bonneville Dam to rkm 8.3 has ranged from 0.620 to 0.836 between 2005 and 2009 (McMichael et al. 2010b). By adding new JSATS arrays between Bonneville Dam and East Sand Island (rkm 8.3) in 2007 and 2008, we determined that most of the losses of subyearling Chinook salmon that occurred during the early portion of their emigration seasons in 2007 and 2008 (before $\sim 10$ July) took place between rkm 50 and $\mathrm{rkm} 8$ (McMichael et al. 2010b). In 2010, the apparent mortality of subyearling Chinook salmon was greatest in the final $37 \mathrm{~km}$ of the estuary; however, the last virtualrelease group for the week beginning 12 July had relatively low apparent survival probability throughout all reaches from rkm 153 to 8.3. Low apparent survival probability could result if some individuals remain alive, but cease migration. It remains to be determined whether a portion of the subyearling Chinook salmon that fail to emigrate from the Columbia River downstream of Bonneville in the same year they pass the dam elect to remain in the lower river or estuary to extend their rearing period prior to emigrating to sea (Connor et al. 2002, 2005; Buchanan et al. 2009).

This study provided the first comprehensive analysis of how juvenile salmonid passage experiences through the lower three dams in the FCRPS may influence subsequent salmonid survival probability after 
passing Bonneville Dam. It appears that most mortality related to dam passage occurred prior to the time when fish reached rkm 153 (82 km downstream of Bonneville Dam). Because of the large number of possible combinations and because passage is not evenly distributed among routes, only the most common route history combinations had sample sizes large enough to evaluate the effects of passage histories in the lower Columbia River and estuary. Future monitoring of JSATS-tagged fish in the lower Columbia River, estuary, and plume could add to this new understanding of the effects of passage route history on survival probability. If specific combinations of routes are more common for run-of-the-river fish, it may be worth focusing effort on determining the within- and post-FCRPS survival of those fish compared to the population at large to determine whether additional modifications to dam configurations or operations may be warranted.

In 2010, acoustic-tagged juvenile salmonids travelled relatively rapidly to the mouth of the Columbia River (rkm 8.3). All groups of juvenile salmonids detected at rkm 153 and 8.3 had a median travel time of less than 3 days. The spring freshet occurred somewhat in between the time period when acoustictagged juvenile salmonids were released in the spring and summer. Peak discharge in 2010 at the Beaver Army Terminal gauge site ( $\mathrm{rkm} \mathrm{86}$ ) occurred on 12 June, while $>90 \%$ of the spring emigrating fish had passed through the study area prior to 4 June and the summer migrants passed through the study area on the declining limb of the hydrograph.

The travel rate of yearling Chinook salmon followed the same trend observed in previous years; declining from about 75 to $100 \mathrm{~km} / \mathrm{d}$ in the upper estuary (upstream of Oak Point [rkm 86.2]) to about 40 $\mathrm{km} / \mathrm{d}$ in the lower estuary (between Three Tree Point [rkm 49.6] and the Astoria Bridge [rkm 22.0]), followed by an increase in median travel rate to about $100 \mathrm{~km} / \mathrm{d}$ and an increase in the variability about the median downstream of rkm 22.0 .

The influence of migratory pathway on travel time and survival probability observed in 2010 differed from results obtained in our previous research. In 2010, tagged fish that used off-channel migration pathways had significantly longer travel times than their cohorts migrating in or near the navigation channel. In contrast, results obtained in 2006, 2007, 2008, and 2009 indicated that the migration pathway had relatively little effect on the travel times of acoustic-tagged smolts (McMichael et al. 2010b). Although off-channel migrants almost always took longer (sometimes two to three times longer) than navigation channel migrants to migrate a reach in 2010, estimated survival probabilities were often similar between the two groups. In fact, the estimated survivals of yearling Chinook salmon and steelhead were higher for fish migrating through the off-channel areas than for their cohorts detected in or near the navigation channel between rkm 49.6 and 37.3.

Although most acoustic-tagged yearling and subyearling Chinook salmon and steelhead migrated from Harrington Point (rkm 37.3) in or near the main navigation channel, most of these fish were then detected at the Astoria Bridge ( $\mathrm{rkm} 22$ ) in the North Channel along the Washington shoreline. To get to the North Channel near the Astoria Bridge from the navigation channel near Astoria, Oregon, fish must cross an area of expansive shallow water known as the Taylor Sands. Crossing this area, especially during daylight, may increase the vulnerability of smolts to avian predation. This area is in the reach where we have measured the lowest survival probabilities of emigrating juvenile salmonids.

The JSATS array deployed in the Columbia River plume in 2010 confirms that the system works well in saltwater. The pilot effort in 2010 in the Columbia River plume produced the information necessary to enable the design of a robust estimate of survival probability of juvenile salmonids from the Columbia 
River into the near-shore ocean. The assumption that emigrating juvenile salmonids appear to remain on the Continental Shelf and migrate primarily northward upon entering the ocean from the Columbia River appears to be unjustified. Thus, to estimate survival probability of emigrating fish, it would be necessary to deploy receivers in a "box" pattern similar to the array we deployed in 2010. Based on the travel time and apparent emigration pattern, it appears that the best deployment design would include a sparse secondary array around the "box" centered on the mouth of the Columbia River in the plume. The addition of these arrays would provide additional time and distance over which survival and behavior of smolts could be monitored, thereby adding to the ability to evaluate the influence of the FCRPS passage history and any mitigative management actions, such as avian predator management.

Movements of yearling and subyearling Chinook salmon and steelhead in the lower Columbia River estuary appear to be heavily influenced by tide. In each of the last 5 years (2006-2010) the majority of first detections of acoustic-tagged smolts at the East Sand Island array (CR008.3) occurred during ebb, or outgoing, tides. These detection data indicate that flow has an important influence on emigrating smolts near the mouth of the river. Schreck et al. (2005) observed a similar relationship between water velocity and behavior of smolts in the lower Columbia River estuary. During periods of high water velocities, which occur during large tidal changes, the movement of smolts corresponded closely with the movements of simulated water particles (Schreck et al. 2005). This passive behavior may explain the large variability observed in the travel rate of acoustic-tagged smolts in the downstream-most reaches of the estuary. Some fish may be carried to the ocean on a single tide change, resulting in very high travel rates, whereas others may require multiple tide changes until a large enough ebb tide occurs to carry them all the way to the ocean. Fish that require multiple tide changes to migrate through the final reach of the estuary would appear to be moving slowly, have low travel rates, and may be more susceptible to avian predation due to their prolonged residence near the East Sand Island avian predator nesting colonies. This prolonged exposure to predation may help to explain the relatively low survival probabilities observed for yearling and subyearling Chinook salmon and steelhead between the Astoria Bridge (rkm 22.0) and East Sand Island (rkm 8.3) arrays.

Avian predation has been shown to account for a substantial amount of juvenile salmonid mortality in the Columbia River estuary (Collis et al. 2001; Roby et al. 2003; Ryan et al. 2003; Anderson et al. 2005, 2007). During the previous 5 years (2006 through 2010), 2.1\% to 5.5\% of yearling Chinook salmon implanted with acoustic transmitters were detected at the Caspian tern and double-crested cormorant nesting colonies on East Sand Island. The percentage (4.1\%) of acoustic-tagged yearling Chinook salmon detected at the colonies in 2010 was within the range observed during the previous 4 years. However, a larger proportion of the PIT tags from spring migrants (yearling Chinook salmon and steelhead) were recovered from the Caspian tern colony in 2010 than in 2009. In contrast, more of the PIT tags from subyearling Chinook salmon were detected at the double-crested cormorant colonies than at the tern colonies. Weekly survival probability estimates for yearling Chinook salmon and steelhead from rkm 153 to 8.3 were not significantly correlated with weekly known mortality rates due to avian predation (based on PIT-tag recoveries from the bird colonies). However, the estimated weekly survival probability of yearling Chinook salmon between rkm 49.6 and 37.3 as well as the reach between rkm 37.3 and 22 were correlated with known avian predation rates. Weekly estimated survival probabilities of subyearling Chinook salmon from rkm 153 to 8.3 were correlated with known avian predation rates. Additional analyses of existing JSATS data and PIT-tag recovery data would increase the understanding relative to the spatial and temporal aspects of avian predation losses in the Columbia River estuary, but those analyses are beyond the scope of this project. 
The addition of autonomous receiver arrays to partition the lower Columbia River and estuary into reaches, beginning in 2007, has vastly increased our understanding of the migratory behavior and survival of juvenile salmonids emigrating through this area. However, because we implanted hatchery- and natural-origin run-of-the-river fish that were captured upstream of Bonneville Dam and measured $95 \mathrm{~mm}$ or greater, the behavior and survival of the fish used in this study may differ from those of smaller juvenile fish, many of which enter the Columbia River from tributaries downstream of Bonneville Dam. These fish, particularly smaller subyearling Chinook salmon, may spend considerable amounts of time rearing in the estuary prior to emigrating to the ocean. A recent study conducted to investigate the possibility of decreasing the size of JSATS acoustic transmitters determined that significant reductions in the volume and weight of JSATS transmitters are possible by using an application-specific integrated circuit to replace most of the components required for current designs (Carlson and Myjak 2010). Reduction in JSATS transmitter weight to $0.2 \mathrm{~g}$ would permit tagging fish much smaller than the current threshold of a 95-mm fork length (down to about a 70-mm fork length; Carlson and Myjak 2010), which would allow for studies of smaller subyearling Chinook salmon in the Columbia River estuary. Pilot studies with prototype transmitters in the $0.2 \mathrm{~g}$ range or smaller and receiving systems designed to perform in shallow, tidally influenced, waters would be a worthwhile undertaking to increase the utility of the JSATS for addressing many unanswered questions regarding juvenile salmonid habitat use in the Columbia River estuary.

Several years of study have shown that a significant proportion of juvenile Chinook salmon and steelhead mortality occurs in the lower Columbia River and estuary. Travel time, migration pathway, and migration timing all appear to influence survival rates, but avian predation is an obvious mechanism of mortality in the lower $50 \mathrm{~km}$ where survival rate are lowest. In 2010, route histories of juvenile salmonids passing the lower three dams in the FCRPS were generally not found to influence survival significantly in the post-FCRPS portion of the river and estuary, in spite of obvious differences related to the direct effects of passage route. 


\subsection{References}

Anderson, S. K., D. D. Roby, D. E. Lyons, and K. Collis. 2005. Factors affecting chick provisioning by Caspian terns nesting in the Columbia River estuary. Estuarine, Coastal and Shelf Science 73:447-456.

Anderson, S. K., D. D. Roby, D. E. Lyons, and K. Collis. 2007. Relationship of Caspian tern foraging ecology to nesting success in the Columbia River estuary, Oregon, USA. Estuarine, Coastal and Shelf Science 73:447-456.

Buchanan, R. A., J. R. Skalski, and G. A. McMichael. 2009. Differentiating mortality from delayed migration in subyearling fall Chinook salmon (Oncorhynchus tshawytscha). Canadian Journal of Fisheries and Aquatic Sciences 66:2243-2255.

Budy, P., G. P. Thiede, N. Bouwes, C. E. Petrosky and H. Schaller. 2002. Evidence linking delayed mortality of Snake River salmon to their earlier hydrosystem experience. North American Journal of Fisheries Management 22:35-51.

Carlson, T. J., and M. J. Myjak. 2010. Juvenile Salmon Acoustic Telemetry System transmitter downsize assessment. PNNL-19366, prepared for the U.S. Army Corps of Engineers, Portland District, by the Pacific Northwest National Laboratory, Richland, Washington.

Collis, K., D. D. Roby, D. P. Craig, B. A. Ryan, and R. D. Ledgerwood. 2001. Colonial waterbird predation on juvenile salmonids tagged with passive integrated transponders in the Columbia River estuary: vulnerability of different species, stocks, and rearing types. Transactions of the American Fisheries Society 130:385-396.

Collis, K., D. D. Roby, D. P. Craig, S. Adamany, J. Adkins, and D. E. Lyons. 2002. Colony size and diet composition of piscivorous water birds on the lower Columbia River: implications for losses of juvenile salmonids to avian predation. Transactions of the American Fisheries Society 131:537-550.

Connor, W. P., H. L. Burge, R. Waitt, and T. C. Bjornn. 2002. Juvenile life history of wild fall Chinook salmon in the Snake and Clearwater rivers. North American Journal of Fisheries Management 22:702712.

Connor, W. P., J. G. Sneva, K. F. Tiffan, R. K. Steinhorst, and D. Ross. 2005. Two alternative juvenile life history types for fall Chinook salmon in the Snake River Basin. Transactions of the American Fisheries Society 134:291-304.

Cormack, R. M. 1964. Estimates of survival from the sightings of marked animals. Biometrika 51:429438.

Deters, K. A., J. W. Boyd, R. S. Brown, and A. G. Seaburg. In Press. Optimal suturing technique and number of sutures for surgical implantation of acoustic transmitters in juvenile salmonids. Transactions of the American Fisheries Society.

Efron, B., and R. J. Tibshirani. 1993. An introduction to the bootstrap. Chapman \& Hall, New York, NY, USA. 
Fox, D. S., S. Bell, W. Nehlsen, and J. Damron. 1984. The Columbia River Estuary - atlas of physical and biological characteristics. Columbia River Estuary Data Development Program, Columbia River Estuary Study Task Force, Astoria, Oregon.

Ferguson, J. W., R. F. Absolon, T. J. Carlson, and B. P. Sandford. 2006. Evidence of delayed mortality on juvenile Pacific salmon passing through turbines at Columbia River dams. Transactions of the American Fisheries Society 135: 139-150.

Hickey, B. M., S. Geier, N. Kachel, and A. MacFadyen. 2005. A bi-directional river plume: The Columbia in summer. Continental Shelf Research 25:1631-1656.

Jolly, G. M. 1965. Explicit estimates from capture-recapture data with both death and immigrationstochastic model. Biometrika 52:225-247.

Li, T., and J. J. Anderson. 2009. The vitality model: A way to understand population survival and demographic heterogeneity. Theoretical Population Biology 76: 118-131.

McComas, R. L., L. Gilbreath, S. G. Smith, G. Matthews, J. W. Ferguson, G. A. McMichael, J. A. Vucelick, and T. Carlson. 2007. A study to estimate salmonids survival through the Columbia River estuary using acoustic tags, 2005. Report prepared for the U.S. Army Corps of Engineers, Portland District, by National Marine Fisheries Service, Seattle, Washington. Available at: www.nwfsc.noaa.gov/research/ divisions/fed/ acoustictag.cfm (May 2009).

McComas, R. L., G. A. McMichael, J. A. Vucelick, L. Gilbreath, J. P. Everett, S. G. Smith, T. Carlson, G. Matthews, and J. W. Ferguson. 2008. A Study to Estimate Salmonid Survival through the Columbia River Estuary using Acoustic Tags, 2006. National Marine Fisheries Service, Seattle, Washington. Available at: https://www.nwp.usace.army.mil/pm/e/afep_estuary.asp.

McMichael, G. A., J. R. Skalski, K. A. Deters, M. S. Hughes, K. D. Ham, J. Kim, R. A. Harnish, and D. M. Trott. 2011. Survival of Juvenile Chinook Salmon During Barge Transport. PNNL-20253, Pacific Northwest National Laboratory, Richland, Washington.

McMichael, G. A., M. B. Eppard, T. J. Carlson, J. A. Carter, B. D. Ebberts, R. S. Brown, M. A. Weiland, G. R. Ploskey, R. A. Harnish, and Z. D. Deng. 2010a. The Juvenile Salmon Acoustic Telemetry System: a new tool. Fisheries 35(1):9-22.

McMichael, G. A., R. A. Harnish, B. J. Bellgraph, J. A. Carter, K. D. Ham, P. S. Titzler, and M. S. Hughes. 2010b. Survival and Migratory Behavior of Juvenile Salmonids in the Lower Columbia River Estuary in 2009. PNNL-19545, Pacific Northwest National Laboratory, Richland, Washington.

Ploskey, G. R., D. M. Faber, M. A. Weiland, and T. J. Carlson. 2011. Monitoring of Juvenile Yearling Chinook Salmon and Steelhead Survival and Passage at Bonneville Dam, Spring 2010, Summary Report. PNNL-19898, Pacific Northwest National Laboratory, Richland, Washington.

Ryan, B. A., A. S. Cameron, E. P. Nunnallee, and J. W. Ferguson. 2005. Detection of passive integrated transponder (PIT) tags on piscivorous bird colonies in the Columbia River basin, 2002. Report prepared for the U.S. Army Corps of Engineers, Walla Walla District, by the National Marine Fisheries Service, Seattle, Washington. Available at http://www.nwfsc.noaa.gov/publications/index.cfm (June 2009). 
Roby, D. D., K. Collis, and D. E. Lyons. 2005. Conservation and management for fish eating birds and endangered salmon. Pp. 161-165 in C. J. Ralph and T. D. Rich (eds.). Bird conservation implementation and integration in the Americas: Proceedings of the Third International Partners in Flight Conference. Gen. Tech. Rep. PSW-GTR-191, USDA Forest Service,Albany, California..

Schaller, H. A., and C. E. Petrosky. 2007. Assessing hydrosystem influence on delayed mortality of Snake River stream-type Chinook salmon. North American Journal of Fisheries Management 27:810824.

Schreck C. B., M. D. Karnowski, and B. J. Clemens. 2005. Evaluation of Post Release Losses and Barging Strategies that Minimize Post Release Mortality. Oregon Cooperative Fishery Unit, Department of Fisheries and Wildlife, Oregon State University, Corvallis, Oregon.

Schreck, C. B., T. P. Stahl, L. E. Davis, D. D. Roby, and B. J. Clemens. 2006. Mortality estimates of juvenile spring-summer Chinook salmon in the lower Columbia River and estuary, 1992-1998: Evidence for delayed mortality? Transactions of the American Fisheries Society 135:457-485.

Seber, G.A.F. 1965. A note on the multiple recapture census. Biometrika 52:249-259.

Sherwood, C. R., and J. S. Greagar. 1990. Sedimentary geology of the Columbia River estuary. Progress in Oceanography 25:15-79.

Sherwood, C. R., D. A. Jay, R. B. Harvey, P. Hamilton, and C. A. Simenstad. 1990. Historical changes in the Columbia River estuary. Progress in Oceanography 25:299-357.

Skalski, J.R., Smith, S.G., Iwamoto, R.N., Williams, J.G., and Hoffmann, A. 1998. Use of PIT-tags to estimate survival of migrating juvenile salmonids in the Snake and Columbia Rivers. Canadian Journal of Fisheries and Aquatic Sciences 55: 1484-1493.Titzler, P. S., G. A. McMichael, and J. A. Carter. 2010. Autonomous acoustic receiver deployment and mooring techniques for use in large rivers and estuaries. North American Journal of Fisheries Management 30:853-859.

Townsend, R. L., J. R. Skalski, P. Dillingham, and T. W. Steig. 2006. Correcting bias in survival estimation resulting from tag failure in acoustic and radiotelemetry studies. Journal of Agricultural Biology and Environmental Statistics 11(2):183-196.

U.S. Army Corps of Engineers (USACE). 2011. Surgical Protocols for Implanting JSATS Transmitters into Juvenile Salmonids for Studies Conducted for the U. S. Army Corps of Engineers. Version 1.0. USACE, Portland District, Portland, Oregon.

Weiland, M. A., G. R. Ploskey, J. S. Hughes, and 16 coauthors. 2010. Acoustic Telemetry Evaluation of Juvenile Salmonid Passage and Survival Proportions at John Day Dam, 2009. PNNL-19422 DRAFT, Pacific Northwest National Laboratory, Richland, Washington.

White, S. M. 1970. Mineralogy and geochemistry of continental shelf sediments off the WashingtonOregon coast. Journal of Sedimentary Petrology 40(1):38-54.

Woxell, L. K. 1998. Prehistoric beach accretion rates and long-term response to sediment depletion in the Columbia River Littoral System. Portland State University, Portland, Oregon. 

Appendix A

Acoustic-Tagged Fish Releases 



\section{Appendix A}

\section{Acoustic-Tagged Fish Releases}

Table A.1. Number, size, and tag burden of acoustic-tagged yearling Chinook salmon (including only alive-release fish) released in 2010. Standard errors are in parentheses.

\begin{tabular}{|c|c|c|c|c|c|c|c|c|c|c|}
\hline $\begin{array}{l}\text { Release } \\
\text { Date }\end{array}$ & $\mathrm{N}$ & $\begin{array}{l}\text { Mean FL } \\
(\mathrm{mm})\end{array}$ & $\begin{array}{l}\text { Min } \\
\text { FL } \\
(\mathrm{mm})\end{array}$ & $\begin{array}{l}\text { Max } \\
\text { FL } \\
(\mathrm{mm})\end{array}$ & $\begin{array}{c}\text { Mean } \\
\text { Weight }(\mathrm{g})\end{array}$ & $\begin{array}{l}\text { Min } \\
\text { Weight } \\
\text { (g) }\end{array}$ & $\begin{array}{l}\text { Max } \\
\text { Weight } \\
\text { (g) }\end{array}$ & $\begin{array}{l}\text { Tag } \\
\text { Burden } \\
(\%)\end{array}$ & $\begin{array}{c}\text { Min Tag } \\
\text { Burden } \\
(\%)\end{array}$ & $\begin{array}{c}\text { Max Tag } \\
\text { Burden } \\
(\%)\end{array}$ \\
\hline April 27 & 72 & $150.7(3.3)$ & 103 & 200 & $36.3(2.1)$ & 11.1 & 76.1 & $1.9(0.1)$ & 0.7 & 4.8 \\
\hline April 28 & 72 & $168.4(2.3)$ & 115 & 199 & $48.0(1.8)$ & 16.3 & 77.0 & $1.3(0.1)$ & 0.7 & 3.3 \\
\hline April 29 & 97 & $173.8(1.7)$ & 115 & 206 & $49.9(1.4)$ & 14.4 & 81.0 & $1.2(0.0)$ & 0.7 & 3.7 \\
\hline April 30 & 97 & $165.6(1.9)$ & 114 & 207 & $44.6(1.5)$ & 15.6 & 76.5 & $1.3(0.1)$ & 0.7 & 3.4 \\
\hline May 1 & 147 & $168.2(1.5)$ & 114 & 208 & $44.4(1.2)$ & 13.4 & 88.8 & $1.3(0.0)$ & 0.6 & 4.0 \\
\hline May 2 & 96 & $166.8(1.7)$ & 116 & 203 & $41.4(1.4)$ & 13.4 & 77.5 & $1.4(0.1)$ & 0.7 & 4.0 \\
\hline May 3 & 146 & 165.7 (1.6) & 113 & 216 & $43.7(1.3)$ & 15.7 & 92.4 & $1.4(0.0)$ & 0.6 & 3.4 \\
\hline May 4 & 98 & $165.2(1.9)$ & 119 & 208 & $45.4(1.6)$ & 16.5 & 94.5 & $1.3(0.0)$ & 0.6 & 3.2 \\
\hline May 5 & 146 & $158.4(1.5)$ & 109 & 202 & $38.0(1.1)$ & 12.3 & 77.6 & $1.6(0.0)$ & 0.7 & 4.3 \\
\hline May 6 & 97 & $159.5(1.7)$ & 120 & 200 & $38.4(1.3)$ & 17.0 & 77.2 & $1.5(0.1)$ & 0.7 & 3.1 \\
\hline May 7 & 145 & $155.2(1.6)$ & 107 & 203 & $36.8(1.2)$ & 12.3 & 85.3 & $1.7(0.1)$ & 0.6 & 4.3 \\
\hline May 8 & 97 & $156.6(1.8)$ & 118 & 211 & $34.2(1.3)$ & 12.8 & 85.2 & $1.8(0.1)$ & 0.6 & 4.1 \\
\hline May 9 & 147 & $149.9(1.4)$ & 99 & 208 & $30.8(1.0)$ & 9.2 & 87.9 & $1.9(0.1)$ & 0.6 & 5.8 \\
\hline May 10 & 0 & & & & & & & & & \\
\hline May 11 & 147 & $148.0(1.6)$ & 114 & 220 & $30.7(1.2)$ & 10.2 & 110.3 & $2.0(0.1)$ & 0.5 & 5.2 \\
\hline May 12 & 194 & $149.0(1.7)$ & 104 & 223 & $33.4(1.4)$ & 10.6 & 116.6 & $2.0(0.1)$ & 0.5 & 5.0 \\
\hline May 13 & 146 & $151.2(2.0)$ & 108 & 214 & $33.6(1.5)$ & 12.4 & 93.6 & $2.0(0.1)$ & 0.6 & 4.3 \\
\hline May 14 & 97 & $149.1(2.2)$ & 111 & 212 & $32.7(1.7)$ & 11.4 & 95.7 & $2.0(0.1)$ & 0.6 & 4.6 \\
\hline May 15 & 147 & $156.1(2.0)$ & 110 & 221 & $37.1(1.6)$ & 10.2 & 110.3 & $1.8(0.1)$ & 0.5 & 5.2 \\
\hline May 16 & 97 & $162.5(2.4)$ & 110 & 224 & $41.8(2.0)$ & 12.8 & 113.1 & $1.6(0.1)$ & 0.5 & 4.1 \\
\hline May 17 & 146 & $163.6(2.2)$ & 112 & 227 & $42.2(1.9)$ & 13.9 & 128.0 & $1.6(0.1)$ & 0.4 & 3.8 \\
\hline May 18 & 96 & $158.1(2.4)$ & 112 & 218 & $37.6(1.9)$ & 11.7 & 102.8 & $1.7(0.1)$ & 0.5 & 4.5 \\
\hline May 19 & 147 & $146.7(1.5)$ & 111 & 206 & $30.0(1.0)$ & 11.8 & 83.7 & $2.0(0.1)$ & 0.6 & 4.5 \\
\hline May 20 & 97 & $154.6(2.0)$ & 115 & 212 & $35.2(1.6)$ & 13.4 & 92.5 & $1.8(0.1)$ & 0.6 & 4.0 \\
\hline May 21 & 147 & $154.3(1.6)$ & 106 & 207 & $35.6(1.2)$ & 12.1 & 83.0 & $1.7(0.1)$ & 0.6 & 4.4 \\
\hline May 22 & 97 & $147.9(1.7)$ & 117 & 198 & $30.1(1.3)$ & 13.3 & 75.4 & $2.0(0.1)$ & 0.7 & 4.0 \\
\hline May 23 & 147 & $146.8(1.3)$ & 99 & 197 & $28.5(0.8)$ & 8.0 & 67.5 & $2.1(0.1)$ & 0.8 & 6.6 \\
\hline May 24 & 97 & $143.3(2.0)$ & 104 & 205 & $28.8(1.5)$ & 11.0 & 101.1 & $2.2(0.1)$ & 0.5 & 4.8 \\
\hline May 25 & 146 & $148.4(1.5)$ & 106 & 216 & $30.6(1.1)$ & 10.4 & 97.0 & $2.0(0.1)$ & 0.5 & 5.1 \\
\hline May 26 & 97 & $146.7(1.7)$ & 118 & 203 & $28.9(1.2)$ & 14.7 & 75.6 & $2.1(0.1)$ & 0.7 & 3.6 \\
\hline May 27 & 147 & $148.2(1.5)$ & 109 & 218 & $30.8(1.2)$ & 11.2 & 107.1 & $2.0(0.1)$ & 0.5 & 4.7 \\
\hline May 28 & 83 & $148.9(2.1)$ & 115 & 216 & 30.7 (1.5) & 12.5 & 88.7 & $2.0(0.1)$ & 0.6 & 4.2 \\
\hline May 29 & 75 & $151.7(2.7)$ & 117 & 221 & $34.9(2.2)$ & 14.1 & 100.3 & $1.9(0.1)$ & 0.5 & 3.8 \\
\hline May 30 & 25 & $152.8(4.4)$ & 111 & 221 & 34.7 (3.3) & 13.7 & 91.3 & $1.8(0.1)$ & 0.6 & 3.9 \\
\hline May 31 & 48 & $153.2(3.4)$ & 111 & 207 & $35.9(2.6)$ & 12.1 & 84.6 & $1.8(0.1)$ & 0.6 & 4.4 \\
\hline
\end{tabular}


Table A.2. Number, size, and tag burden of acoustic-tagged steelhead (including only alive -release fish) released in 2010. Standard errors are in parentheses.

\begin{tabular}{|c|c|c|c|c|c|c|c|c|c|c|}
\hline $\begin{array}{l}\text { Release } \\
\text { Date }\end{array}$ & $\mathrm{N}$ & $\begin{array}{c}\text { Mean FL } \\
(\mathrm{mm})\end{array}$ & $\begin{array}{l}\text { Min } \\
\text { FL } \\
(\mathrm{mm})\end{array}$ & $\begin{array}{c}\text { Max } \\
\text { FL } \\
(\mathrm{mm})\end{array}$ & $\begin{array}{c}\text { Mean } \\
\text { Weight }(\mathrm{g})\end{array}$ & $\begin{array}{l}\text { Min } \\
\text { Weight } \\
(\mathrm{g})\end{array}$ & $\begin{array}{l}\text { Max } \\
\text { Weight } \\
(\mathrm{g})\end{array}$ & $\begin{array}{c}\text { Tag } \\
\text { Burden } \\
(\%)\end{array}$ & $\begin{array}{c}\text { Min Tag } \\
\text { Burden } \\
(\%)\end{array}$ & $\begin{array}{c}\text { Max Tag } \\
\text { Burden } \\
(\%)\end{array}$ \\
\hline April 27 & 71 & $213.2(2.8)$ & 156 & 260 & $86.8(3.2)$ & 32.1 & 143.3 & $0.7(0.0)$ & 0.4 & 1.7 \\
\hline April 28 & 72 & $212.9(3.2)$ & 154 & 251 & $87.4(3.5)$ & 30.6 & 151.9 & $0.7(0.0)$ & 0.3 & 1.7 \\
\hline April 29 & 97 & $212.2(2.7)$ & 152 & 255 & $65.6(1.9)$ & 30.1 & 99.1 & $0.9(0.0)$ & 0.5 & 1.8 \\
\hline April 30 & 97 & $213.2(2.6)$ & 144 & 254 & $86.4(2.9)$ & 26.7 & 141.6 & $0.7(0.0)$ & 0.4 & 2.0 \\
\hline May 1 & 147 & 222.7 (1.9) & 161 & 260 & $92.8(2.2)$ & 35.2 & 150.2 & $0.6(0.0)$ & 0.4 & 1.5 \\
\hline May 2 & 96 & $220.4(2.2)$ & 163 & 257 & $90.4(2.4)$ & 35.4 & 135.2 & $0.6(0.0)$ & 0.4 & 1.5 \\
\hline May 3 & 149 & $220.3(1.8)$ & 161 & 259 & $91.2(2.2)$ & 30.6 & 153.1 & $0.6(0.0)$ & 0.3 & 1.7 \\
\hline May 4 & 97 & $220.5(2.1)$ & 177 & 258 & $93.1(2.6)$ & 46.9 & 150.9 & $0.6(0.0)$ & 0.4 & 1.1 \\
\hline May 5 & 147 & $216.5(1.6)$ & 158 & 260 & 84.3 (1.9) & 29.3 & 155.9 & $0.7(0.0)$ & 0.3 & 1.8 \\
\hline May 6 & 97 & $214.8(1.8)$ & 162 & 256 & $81.7(2.2)$ & 33.7 & 151.7 & $0.7(0.0)$ & 0.3 & 1.6 \\
\hline May 7 & 147 & $210.1(1.7)$ & 169 & 259 & $78.4(2.0)$ & 36.7 & 162.5 & $0.7(0.0)$ & 0.3 & 1.4 \\
\hline May 8 & 97 & $216.5(1.9)$ & 172 & 260 & $80.3(2.2)$ & 34.9 & 143.8 & $0.7(0.0)$ & 0.4 & 1.5 \\
\hline May 9 & 147 & $212.9(1.5)$ & 159 & 260 & $77.1(1.7)$ & 33.9 & 146.8 & $0.7(0.0)$ & 0.4 & 1.6 \\
\hline May 10 & 0 & & & & & & & & & \\
\hline May 11 & 147 & $209.2(1.8)$ & 150 & 254 & $75.3(2.0)$ & 26.9 & 140.1 & $0.8(0.0)$ & 0.4 & 2.0 \\
\hline May 12 & 192 & $209.9(1.6)$ & 156 & 259 & $78.0(1.8)$ & 25.5 & 157.6 & $0.8(0.0)$ & 0.3 & 2.1 \\
\hline May 13 & 146 & $211.0(1.8)$ & 151 & 260 & $78.9(2.1)$ & 34.1 & 171.2 & $0.7(0.0)$ & 0.3 & 1.6 \\
\hline May 14 & 97 & $207.6(2.3)$ & 155 & 256 & $73.9(2.5)$ & 31.0 & 146.4 & $0.8(0.0)$ & 0.4 & 1.7 \\
\hline May 15 & 146 & $207.9(1.8)$ & 157 & 258 & $74.0(2.0)$ & 34.3 & 147.9 & $0.8(0.0)$ & 0.4 & 1.5 \\
\hline May 16 & 97 & $211.1(2.6)$ & 142 & 260 & $76.9(2.8)$ & 22.0 & 135.0 & $0.8(0.0)$ & 0.4 & 2.4 \\
\hline May 17 & 147 & $206.5(2.1)$ & 140 & 258 & $73.2(2.1)$ & 22.5 & 142.1 & $0.8(0.0)$ & 0.4 & 2.4 \\
\hline May 18 & 97 & $208.8(2.5)$ & 169 & 257 & $78.3(2.8)$ & 37.6 & 168.5 & $0.8(0.0)$ & 0.3 & 1.4 \\
\hline May 19 & 147 & $207.9(2.2)$ & 154 & 260 & $75.2(2.3)$ & 29.3 & 146.8 & $0.8(0.0)$ & 0.4 & 1.8 \\
\hline May 20 & 97 & $213.0(2.5)$ & 157 & 257 & $80.4(2.8)$ & 34.2 & 145.4 & $0.7(0.0)$ & 0.4 & 1.5 \\
\hline May 21 & 147 & $211.4(2.1)$ & 148 & 257 & $79.4(2.1)$ & 28.0 & 143.0 & $0.8(0.0)$ & 0.4 & 1.9 \\
\hline May 22 & 97 & $203.6(2.7)$ & 148 & 258 & $70.0(2.5)$ & 29.4 & 131.2 & $0.9(0.0)$ & 0.4 & 1.8 \\
\hline May 23 & 147 & $212.8(2.1)$ & 152 & 255 & $79.0(2.1)$ & 26.4 & 141.0 & $0.8(0.0)$ & 0.4 & 2.0 \\
\hline May 24 & 97 & $212.0(2.9)$ & 158 & 260 & $82.4(3.0)$ & 33.1 & 145.0 & $0.7(0.0)$ & 0.4 & 1.6 \\
\hline May 25 & 147 & $210.0(2.3)$ & 149 & 255 & $79.7(2.3)$ & 25.7 & 143.0 & $0.8(0.0)$ & 0.4 & 2.1 \\
\hline May 26 & 97 & $206.6(3.0)$ & 146 & 260 & $75.4(3.1)$ & 25.2 & 145.9 & $0.8(0.0)$ & 0.4 & 2.1 \\
\hline May 27 & 147 & $207.1(2.2)$ & 154 & 260 & $74.7(2.3)$ & 28.0 & 149.1 & $0.8(0.0)$ & 0.4 & 1.9 \\
\hline May 28 & 83 & $213.3(2.9)$ & 156 & 259 & $79.1(3.0)$ & 30.5 & 141.8 & $0.8(0.0)$ & 0.4 & 1.7 \\
\hline May 29 & 75 & $214.2(3.4)$ & 150 & 260 & $81.9(3.5)$ & 25.8 & 148.4 & $0.8(0.0)$ & 0.4 & 2.1 \\
\hline May 30 & 25 & $214.5(5.0)$ & 162 & 254 & $83.0(6.0)$ & 36.8 & 164.8 & $0.7(0.1)$ & 0.3 & 1.4 \\
\hline May 31 & 49 & $214.8(3.9)$ & 156 & 256 & $83.1(4.7)$ & 29.8 & 152.1 & $0.8(0.0)$ & 0.3 & 1.8 \\
\hline
\end{tabular}


Table A.3. Number, size, and tag burden of acoustic-tagged subyearling Chinook salmon (including only alive-release fish) released in 2010. Standard errors are in parentheses.

\begin{tabular}{|c|c|c|c|c|c|c|c|c|c|c|}
\hline $\begin{array}{l}\text { Release } \\
\text { Date }\end{array}$ & $\mathrm{N}$ & $\begin{array}{c}\text { Mean FL } \\
(\mathrm{mm})\end{array}$ & $\begin{array}{l}\text { Min } \\
\text { FL } \\
(\mathrm{mm})\end{array}$ & $\begin{array}{c}\text { Max } \\
\text { FL } \\
(\mathrm{mm})\end{array}$ & $\begin{array}{c}\text { Mean } \\
\text { Weight }(\mathrm{g})\end{array}$ & $\begin{array}{l}\text { Min } \\
\text { Weight } \\
\text { (g) }\end{array}$ & $\begin{array}{c}\text { Max } \\
\text { Weight } \\
\text { (g) }\end{array}$ & $\begin{array}{c}\text { Tag } \\
\text { Burden } \\
(\%)\end{array}$ & $\begin{array}{c}\text { Min Tag } \\
\text { Burden } \\
(\%)\end{array}$ & $\begin{array}{c}\text { Max Tag } \\
\text { Burden } \\
(\%)\end{array}$ \\
\hline June 12 & 89 & $113.9(0.8)$ & 98 & 133 & $14.6(0.3)$ & 9.0 & 23.6 & $3.8(0.1)$ & 2.2 & 5.9 \\
\hline June 13 & 88 & $112.9(0.8)$ & 97 & 143 & $13.6(0.3)$ & 8.4 & 28.1 & $4.1(0.1)$ & 1.9 & 6.3 \\
\hline June 14 & 114 & $112.4(0.7)$ & 95 & 133 & $13.6(0.3)$ & 7.8 & 23.1 & $4.1(0.1)$ & 2.3 & 6.8 \\
\hline June 15 & 114 & $112.6(0.8)$ & 100 & 145 & $14.0(0.3)$ & 8.7 & 32.1 & $4.0(0.1)$ & 1.7 & 6.1 \\
\hline June 16 & 164 & $112.5(0.5)$ & 95 & 133 & $13.5(0.2)$ & 7.7 & 24.5 & $4.1(0.1)$ & 2.2 & 6.9 \\
\hline June 17 & 113 & $112.0(0.6)$ & 100 & 131 & $13.3(0.2)$ & 9.0 & 21.1 & $4.1(0.1)$ & 2.5 & 5.9 \\
\hline June 18 & 163 & $109.6(0.5)$ & 96 & 128 & $12.4(0.2)$ & 7.8 & 20.0 & $4.4(0.1)$ & 2.7 & 6.8 \\
\hline June 19 & 114 & $112.9(0.7)$ & 100 & 130 & $13.0(0.3)$ & 8.8 & 24.4 & $4.2(0.1)$ & 2.2 & 6.0 \\
\hline June 20 & 164 & $110.5(0.5)$ & 95 & 127 & $12.5(0.2)$ & 7.7 & 20.0 & $4.4(0.1)$ & 2.7 & 6.9 \\
\hline June 21 & 113 & $110.5(0.5)$ & 98 & 125 & $12.7(0.2)$ & 8.9 & 19.3 & $4.3(0.1)$ & 2.7 & 6.0 \\
\hline June 22 & 164 & $110.1(0.4)$ & 95 & 132 & $12.2(0.2)$ & 8.1 & 22.3 & $4.5(0.1)$ & 2.4 & 6.5 \\
\hline June 23 & 115 & $109.7(0.5)$ & 97 & 128 & $12.4(0.2)$ & 8.6 & 21.7 & $4.4(0.1)$ & 2.4 & 6.2 \\
\hline June 24 & 135 & $110.4(0.5)$ & 102 & 126 & $12.3(0.2)$ & 8.7 & 19.7 & $4.4(0.1)$ & 2.7 & 6.1 \\
\hline June 25 & 114 & $111.1(0.6)$ & 96 & 133 & $13.0(0.3)$ & 7.6 & 24.9 & $4.2(0.1)$ & 2.1 & 7.0 \\
\hline June 26 & 162 & $113.0(0.5)$ & 99 & 128 & $12.9(0.2)$ & 9.3 & 19.3 & $4.2(0.1)$ & 2.7 & 5.7 \\
\hline June 27 & 115 & $108.9(0.5)$ & 98 & 124 & $12.2(0.2)$ & 7.8 & 18.3 & $4.5(0.1)$ & 2.9 & 6.8 \\
\hline June 28 & 163 & $108.8(0.4)$ & 95 & 130 & $12.1(0.2)$ & 7.8 & 23.6 & $4.5(0.1)$ & 2.2 & 6.8 \\
\hline June 29 & 114 & $108.2(0.5)$ & 96 & 118 & $11.6(0.2)$ & 7.6 & 15.8 & $4.7(0.1)$ & 3.4 & 7.0 \\
\hline June 30 & 193 & $108.6(0.4)$ & 95 & 133 & $12.2(0.2)$ & 7.4 & 23.2 & $4.5(0.1)$ & 2.3 & 7.2 \\
\hline July 1 & 112 & $108.7(0.6)$ & 99 & 127 & $12.2(0.2)$ & 9.0 & 22.3 & $4.5(0.1)$ & 2.4 & 5.9 \\
\hline July 2 & 164 & $110.3(0.5)$ & 95 & 126 & $12.2(0.2)$ & 7.7 & 21.7 & $4.5(0.1)$ & 2.4 & 6.9 \\
\hline July 3 & 114 & $108.8(0.5)$ & 98 & 124 & $11.8(0.2)$ & 8.4 & 19.0 & $4.6(0.1)$ & 2.8 & 6.3 \\
\hline July 4 & 164 & $108.9(0.4)$ & 99 & 124 & $12.4(0.2)$ & 7.6 & 21.1 & $4.4(0.1)$ & 2.5 & 7.0 \\
\hline July 5 & 113 & $107.6(0.6)$ & 97 & 129 & $11.7(0.3)$ & 7.7 & 23.7 & $4.7(0.1)$ & 2.2 & 6.9 \\
\hline July 6 & 164 & $110.0(0.5)$ & 98 & 131 & $12.8(0.2)$ & 8.4 & 22.6 & $4.3(0.1)$ & 2.3 & 6.3 \\
\hline July 7 & 114 & $110.4(0.7)$ & 96 & 133 & $12.7(0.3)$ & 8.1 & 22.1 & $4.4(0.1)$ & 2.4 & 6.5 \\
\hline July 8 & 162 & $109.2(0.6)$ & 98 & 140 & $12.8(0.3)$ & 8.7 & 33.6 & $4.4(0.1)$ & 1.6 & 6.1 \\
\hline July 9 & 114 & $112.6(0.7)$ & 97 & 136 & $14.0(0.3)$ & 8.4 & 29.0 & $4.0(0.1)$ & 2.0 & 6.3 \\
\hline July 10 & 162 & $113.7(0.6)$ & 97 & 140 & $13.9(0.2)$ & 9.0 & 28.6 & $4.0(0.1)$ & 1.9 & 5.9 \\
\hline July 11 & 114 & $113.3(0.9)$ & 99 & 152 & $14.5(0.4)$ & 9.2 & 37.9 & $3.9(0.1)$ & 1.4 & 5.8 \\
\hline July 12 & 165 & $112.8(0.7)$ & 99 & 145 & $13.9(0.3)$ & 8.7 & 29.4 & $4.1(0.1)$ & 1.8 & 6.1 \\
\hline July 13 & 115 & $109.9(0.6)$ & 96 & 134 & $13.1(0.3)$ & 9.0 & 22.9 & $4.2(0.1)$ & 2.3 & 5.9 \\
\hline July 14 & 82 & $110.8(0.9)$ & 96 & 138 & $13.8(0.4)$ & 8.5 & 27.0 & $4.1(0.1)$ & 2.0 & 6.2 \\
\hline July 15 & 29 & $109.2(1.3)$ & 95 & 124 & $12.5(0.5)$ & 8.5 & 18.8 & $4.4(0.2)$ & 2.8 & 6.2 \\
\hline July 16 & 50 & $111.3(1.0)$ & 97 & 137 & $13.6(0.4)$ & 8.9 & 27.5 & $4.1(0.1)$ & 1.9 & 6.0 \\
\hline
\end{tabular}



Appendix B

Autonomous Receiver Locations 



\section{Appendix B}

\section{Autonomous Receiver Locations}

Table B.1. Physical site descriptions and sampling durations of single acoustic telemetry receivers and receiver arrays used to monitor survival and behavior of acoustic-tagged yearling and subyearling Chinook salmon and steelhead migrating from Knapp Point (rkm 153) to the Columbia River plume in 2010.

\begin{tabular}{lllrcc}
\hline \multicolumn{1}{c}{ rkm } & \multicolumn{1}{c}{ Physical site description } & Array ID & $\begin{array}{c}\text { Number of } \\
\text { receivers }\end{array}$ & $\begin{array}{c}\text { Date } \\
\text { deployed }\end{array}$ & $\begin{array}{c}\text { Date } \\
\text { retrieved }\end{array}$ \\
\hline 153.0 & Knapp Point (Knapp & CR153.0 & 5 & 28-Apr & 03-Aug \\
113.0 & Kalama, Cottonwood Island & CR113.0 & 10 & 27-Apr & 03-Aug \\
86.2 & Oak Point & CR086.2 & 6 & 27-Apr & 03-Aug \\
49.6 & Three Tree Point & CR049.6 & 4 & 27-Apr & 04-Aug \\
45.0 & Woody Island Channel & CR045.0 & 1 & 27-Apr & 04-Aug \\
37.3 & Harrington Point & CR037.3 & 7 & 27-Apr & 04-Aug \\
34.0 & Grays Bay, Rocky Point & CR034.0 & 2 & 27-Apr & 05-Aug \\
29.3 & Grays Bay, incl. Taylor Sands & CR029.3 & 5 & 27-Apr & 04-Aug \\
22.0 & Astoria Bridge & CR022.0 & 16 & 27-Apr & 03-Aug \\
8.3 & Estuary primary, East Sand Island & CR008.3 & 22 & 27-Apr & 05-Aug \\
2.8 & Estuary secondary, between north and south Jetties & CR002.8 & 27 & 27-Apr & 05-Aug \\
Ocean & CR Plume - Washington sub-array & CRP_WA & 7 & 27-Apr & 07-Aug \\
Ocean & CR Plume - Terminus sub-array & CRP_T & 6 & 27-Apr & 07-Aug \\
Ocean & CR Plume - Oregon sub-array & CRP_OR & 7 & 27-Apr & 07-Aug \\
\hline
\end{tabular}



Appendix C

Locations of CR022.0, CR008.3, and CR002.8 Receivers from Reference Points for Cross-Channel Distribution Analyses 



\section{Appendix C}

\section{Locations of CR022.0, CR008.3, and CR002.8 Receivers from Reference Points for Cross-Channel Distribution Analyses}

Table C.1. Location of the South Jetty reference point and location and distance $(\mathrm{km})$ of each Columbia River bar (CR002.8) receiver from the South Jetty reference point.

\begin{tabular}{|c|c|c|c|}
\hline & \multicolumn{3}{|c|}{ Receiver Location } \\
\hline & Latitude & Longitude & Distance from South Jetty $(\mathrm{km})$ \\
\hline South Jetty Reference Point & 46.2333 & -124.0616 & -- \\
\hline CR002.8_01 & 46.2711 & -124.0706 & 4.25 \\
\hline CR002.8_02 & 46.2701 & -124.0698 & 4.13 \\
\hline CR002.8 03 & 46.2690 & -124.0690 & 4.01 \\
\hline CR002.8_04 & 46.2681 & -124.0682 & 3.89 \\
\hline CR002.8_05 & 46.2670 & -124.0674 & 3.77 \\
\hline CR002.8_06 & 46.2660 & -124.0667 & 3.65 \\
\hline CR002.8_07 & 46.2649 & -124.0658 & 3.52 \\
\hline CR002.8_08 & 46.2639 & -124.0650 & 3.41 \\
\hline CR002.8_09 & 46.2629 & -124.0642 & 3.29 \\
\hline CR002.8_10 & 46.2620 & -124.0634 & 3.18 \\
\hline CR002.8_11 & 46.2609 & -124.0627 & 3.07 \\
\hline CR002.8_12 & 46.2595 & -124.0622 & 2.90 \\
\hline CR002.8_13 & 46.2579 & -124.0618 & 2.73 \\
\hline CR002.8_14 & 46.2564 & -124.0614 & 2.56 \\
\hline CR002.8_15 & 46.2549 & -124.0610 & 2.40 \\
\hline CR002.8_16 & 46.2534 & -124.0605 & 2.23 \\
\hline CR002.8_17 & 46.2524 & -124.0603 & 2.12 \\
\hline CR002.8_18 & 46.2513 & -124.0601 & 2.00 \\
\hline CR002.8_19 & 46.2504 & -124.0600 & 1.90 \\
\hline CR002.8_20 & 46.2494 & -124.0598 & 1.79 \\
\hline CR002.8_21 & 46.2484 & -124.0598 & 1.68 \\
\hline CR002.8_22 & 46.2474 & -124.0597 & 1.57 \\
\hline CR002.8_23 & 46.2464 & -124.0597 & 1.46 \\
\hline CR002.8_24 & 46.2454 & -124.0597 & 1.35 \\
\hline CR002.8_25 & 46.2444 & -124.0596 & 1.24 \\
\hline CR002.8_26 & 46.2429 & -124.0602 & 1.07 \\
\hline CR002.8_27 & 46.2415 & -124.0609 & 0.90 \\
\hline CR002.8_28 & 46.2400 & -124.0615 & 0.74 \\
\hline CR002.8_29 & 46.2385 & -124.0623 & 0.58 \\
\hline CR002.8_30 & 46.2371 & -124.0629 & 0.42 \\
\hline CR002.8_31 & 46.2356 & -124.0636 & 0.29 \\
\hline
\end{tabular}


Table C.2. Location of the Clatsop Spit reference point and location and distance $(\mathrm{km})$ of each East Sand Island (CR008.3) receiver from the Clatsop Spit reference point.

\begin{tabular}{cccc}
\hline & \multicolumn{3}{c}{ Receiver Location } \\
\cline { 2 - 4 } Receiver & Latitude & Longitude & $\begin{array}{c}\text { Distance from Clatsop Spit } \\
(\mathrm{km})\end{array}$ \\
\hline Clatsop Spit Reference Point & 46.2354 & -123.9993 & -- \\
CR008.3_24 & 46.2352 & -123.9972 & 0.16 \\
\hline CR008.3_23 & 46.2364 & -123.9962 & 0.27 \\
\hline CR008.3_22 & 46.2376 & -123.9951 & 0.41 \\
\hline CR008.3_19 & 46.2404 & -123.9920 & 0.79 \\
CR008.3_18 & 46.2412 & -123.9937 & 0.79 \\
\hline CR008.3_17 & 46.2426 & -123.9941 & 0.90 \\
\hline CR008.3_16 & 46.2439 & -123.9946 & 1.01 \\
\hline CR008.3_15 & 46.2452 & -123.9949 & 1.15 \\
\hline CR008.3_14 & 46.2466 & -123.9953 & 1.28 \\
\hline CR008.3_13 & 46.2479 & -123.9957 & 1.43 \\
\hline CR008.3_12 & 46.2492 & -123.9962 & 1.56 \\
CR008.3_11 & 46.2505 & -123.9966 & 1.70 \\
\hline CR008.3_10 & 46.2520 & -123.9971 & 1.86 \\
CR008.3_09 & 46.2532 & -123.9975 & 1.99 \\
\hline CR008.3_08 & 46.2546 & -123.9978 & 2.14 \\
CR008.3_07 & 46.2560 & -123.9983 & 2.29 \\
\hline CR008.3_06 & 46.2572 & -123.9986 & 2.43 \\
\hline CR008.3_05 & 46.2586 & -123.9991 & 2.59 \\
CR008.3_04 & 46.2600 & -123.9995 & 2.74 \\
\hline CR008.3_03 & 46.2614 & -123.9999 & 2.89 \\
CR008.3_02 & 46.2626 & -124.0005 & 3.03 \\
CR008.3_01 & 46.2643 & -124.0009 & 3.22 \\
\hline & & & \\
\hline & & & \\
\hline
\end{tabular}


Table C.3. Location of the Astoria reference point and location and distance $(\mathrm{km})$ of each Astoria Bridge (CR022.0) receiver from the Astoria reference point.

\begin{tabular}{cccc}
\hline & \multicolumn{3}{c}{ Receiver Location } \\
\cline { 2 - 4 } Receiver & Latitude & Longitude & $\begin{array}{c}\text { Distance from Clatsop Spit } \\
(\mathrm{km})\end{array}$ \\
\hline Astoria Reference Point & 46.1904 & -123.84930 & -- \\
CR022.0_01 & 46.24012 & -123.87228 & 5.80 \\
CR022.0_02 & 46.23879 & -123.87162 & 5.64 \\
CR022.0_03 & 46.23755 & -123.87145 & 5.51 \\
CR022.0_04 & 46.23651 & -123.87073 & 5.38 \\
CR022.0_05 & 46.23533 & -123.87034 & 5.25 \\
CR022.0_06 & 46.23433 & -123.86976 & 5.13 \\
CR022.0_07 & 46.23313 & -123.86905 & 4.98 \\
CR022.0_08 & 46.23187 & -123.86879 & 4.85 \\
CR022.0_09 & 46.23087 & -123.86838 & 4.73 \\
CR022.0_10 & 46.22988 & -123.86777 & 4.61 \\
CR022.0_11 & 46.21728 & -123.86141 & 3.13 \\
CR022.0_12 & 46.19805 & -123.85169 & 0.87 \\
CR022.0_13 & 46.19706 & -123.85100 & 0.75 \\
CR022.0_14 & 46.19613 & -123.85049 & 0.64 \\
CR022.0_15 & 46.19542 & -123.85004 & 0.56 \\
CR022.0_16 & 46.19249 & -123.84847 & 0.24 \\
CR022.0_17 & 46.19175 & -123.85214 & 0.26 \\
\hline
\end{tabular}



Appendix D

Autonomous Receiver Data Gap Chart 

Table D.1. Data Collection in the middle and lower Columbia River from 27 April to 10 August 2010. Green indicates receivers deployed and collecting data, red indicates receivers not deployed, pink indicates problems with data such as lost receivers or corrupted data files, light blue indicates receiver recovered too late to include in parts of the 2010 analysis.
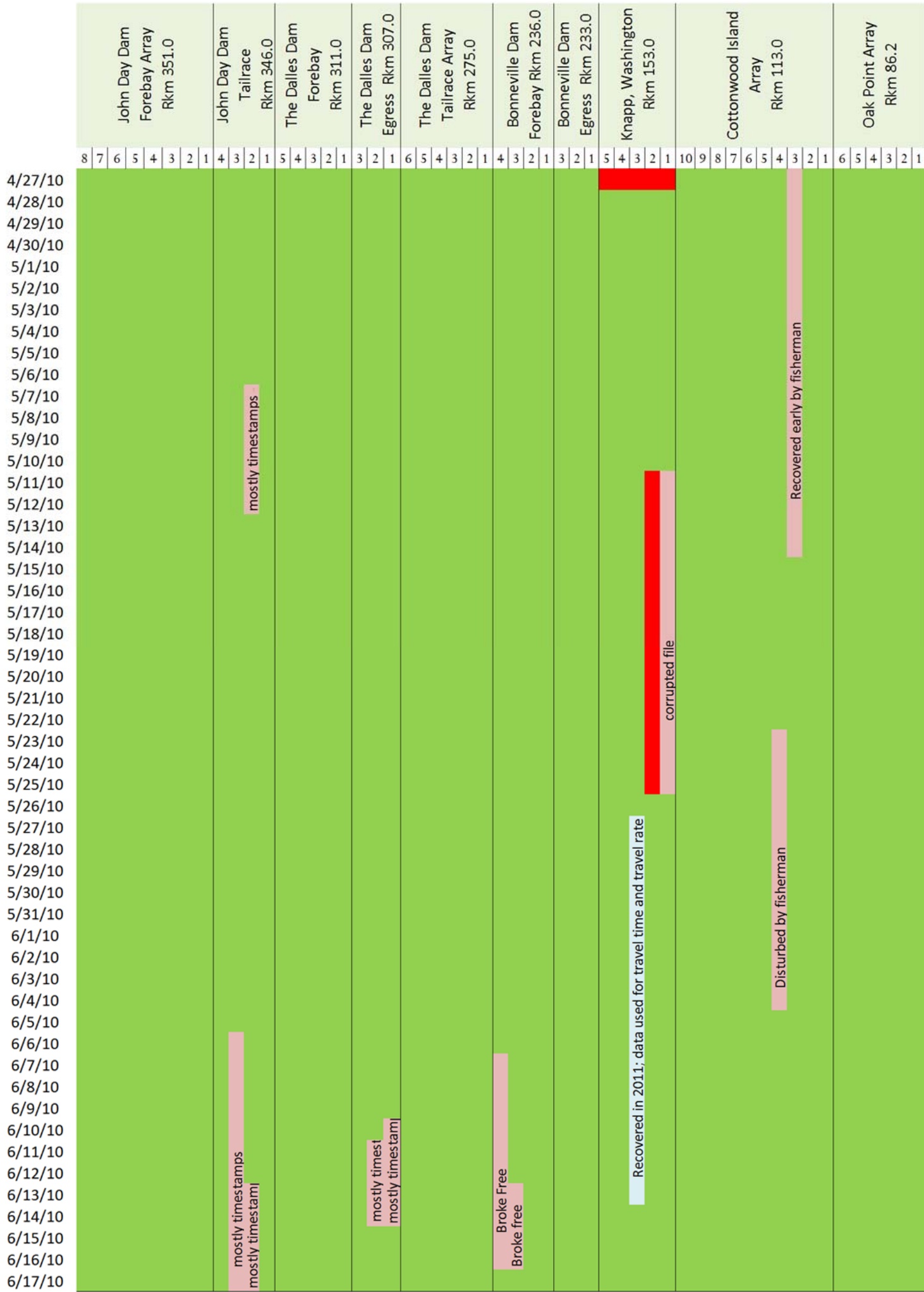
Table D.1. (contd)

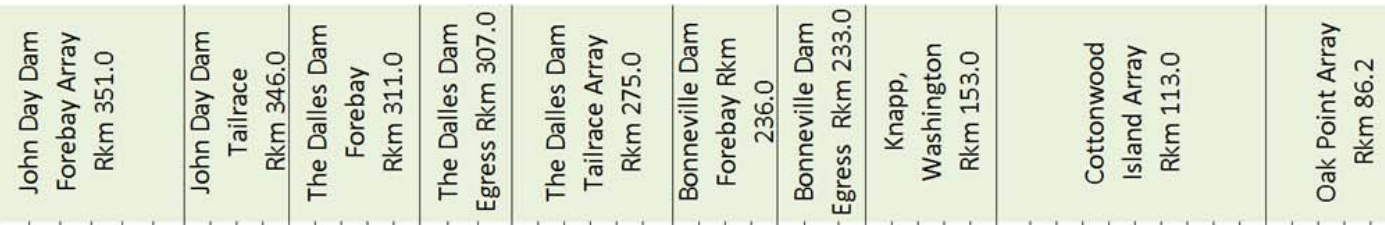

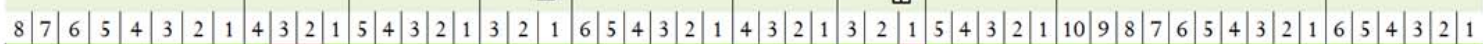
$6 / 18 / 10$

$6 / 19 / 10$

$6 / 20 / 10$

$6 / 21 / 10$

$6 / 22 / 10$

$6 / 23 / 10$

$6 / 24 / 10$

$6 / 25 / 10$

$6 / 26 / 10$

$6 / 27 / 10$

$6 / 28 / 10$

$6 / 29 / 10$

$6 / 30 / 10$

$7 / 1 / 10$

$7 / 2 / 10$

$7 / 3 / 10$

$7 / 4 / 10$

$7 / 5 / 10$

$7 / 6 / 10$

$7 / 7 / 10$

$7 / 8 / 10$

$7 / 9 / 10$

$7 / 10 / 10$

$7 / 11 / 10$

$7 / 12 / 10$

$7 / 13 / 10$

$7 / 14 / 10$

$7 / 15 / 10$

$7 / 16 / 10$

$7 / 17 / 10$

$7 / 18 / 10$

$7 / 19 / 10$

$7 / 20 / 10$

$7 / 21 / 10$

$7 / 22 / 10$

$7 / 23 / 10$

$7 / 24 / 10$

$7 / 25 / 10$

$7 / 26 / 10$

$7 / 27 / 10$

$7 / 28 / 10$

$7 / 29 / 10$

$7 / 30 / 10$

$7 / 31 / 10$

$8 / 1 / 10$

$8 / 2 / 10$

$8 / 3 / 10$

$8 / 4 / 10$

$8 / 5 / 10$

$8 / 6 / 10$

$8 / 7 / 10$

$8 / 8 / 10$

$8 / 9 / 10$

$8 / 10 / 10$ 
Table D.2. Data collection in the Lower Reach of the Estuary from 27 April to 10 August 2010. Green indicates receivers deployed and collecting data, red indicates receivers not deployed, and pink indicates problems with the data such as lost receivers or corrupted data files.
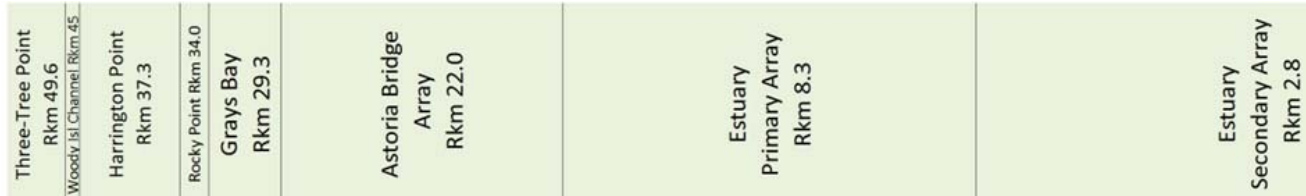

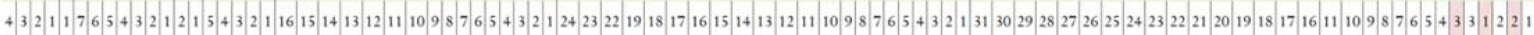

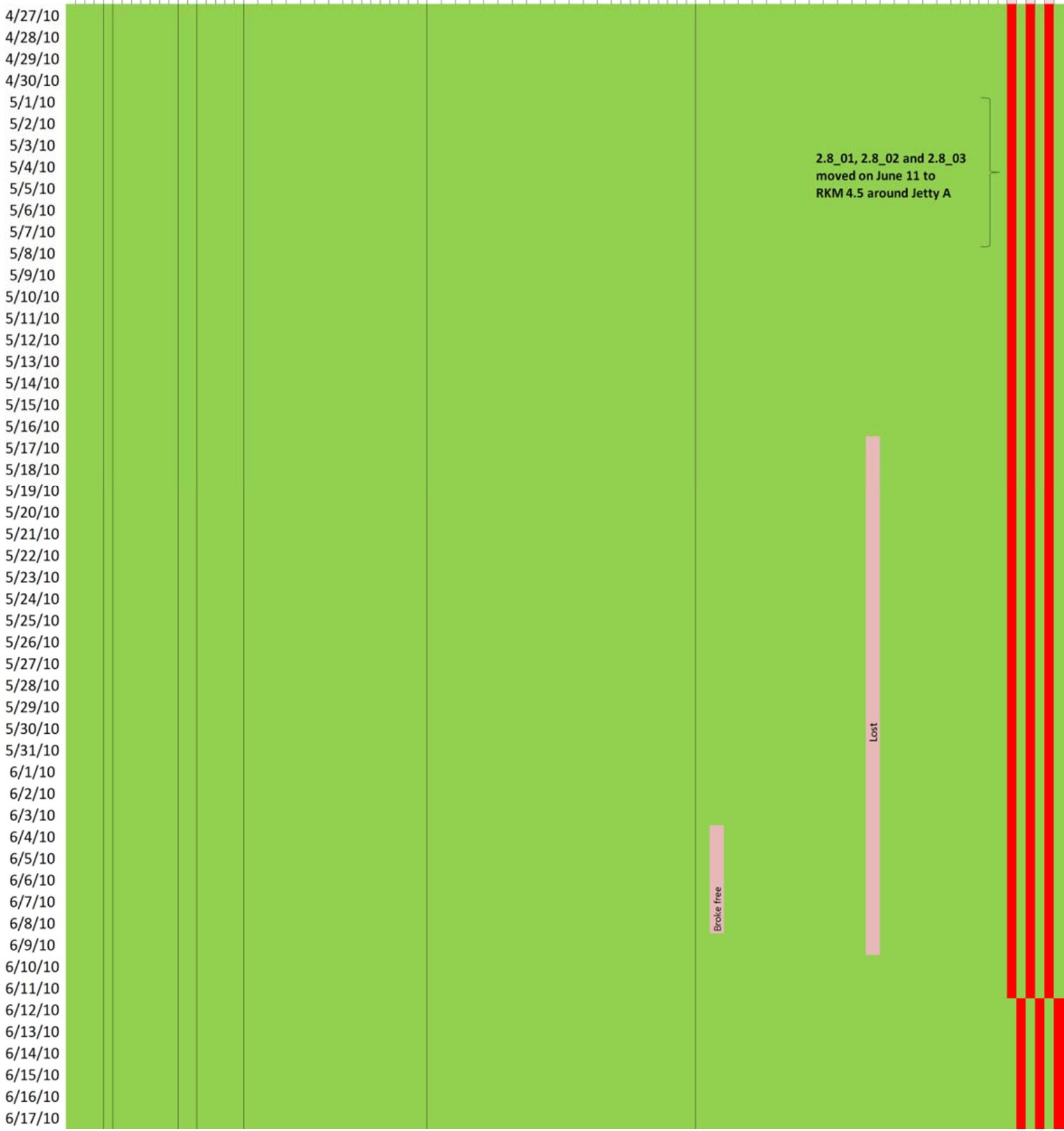


Table D.2. (contd)

\begin{tabular}{|c|c|c|c|c|c|c|}
\hline 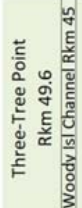 & 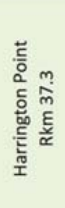 & 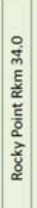 & 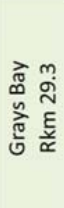 & 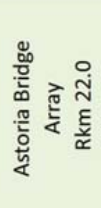 & 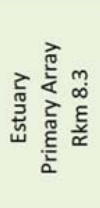 & 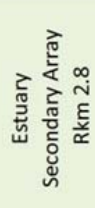 \\
\hline
\end{tabular}

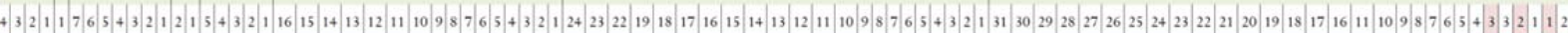

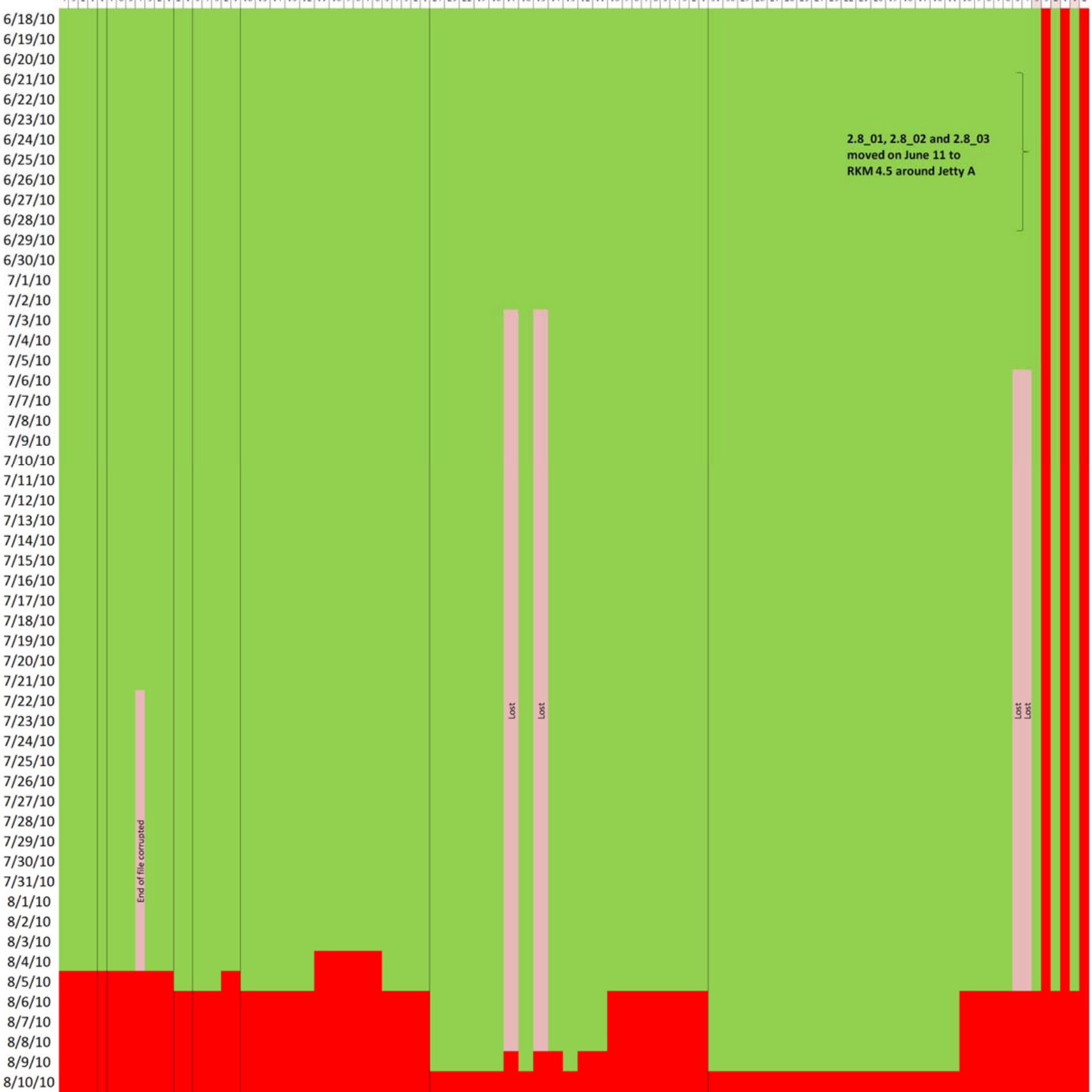


Table D.3. Autonomous receiver deployment in the plume of the Columbia River from 27 April to 8 August 2010. Green indicates receivers deployed and collecting data, red indicates receivers not deployed, and pink indicates problems with the data such as a lost receiver or corrupt data.
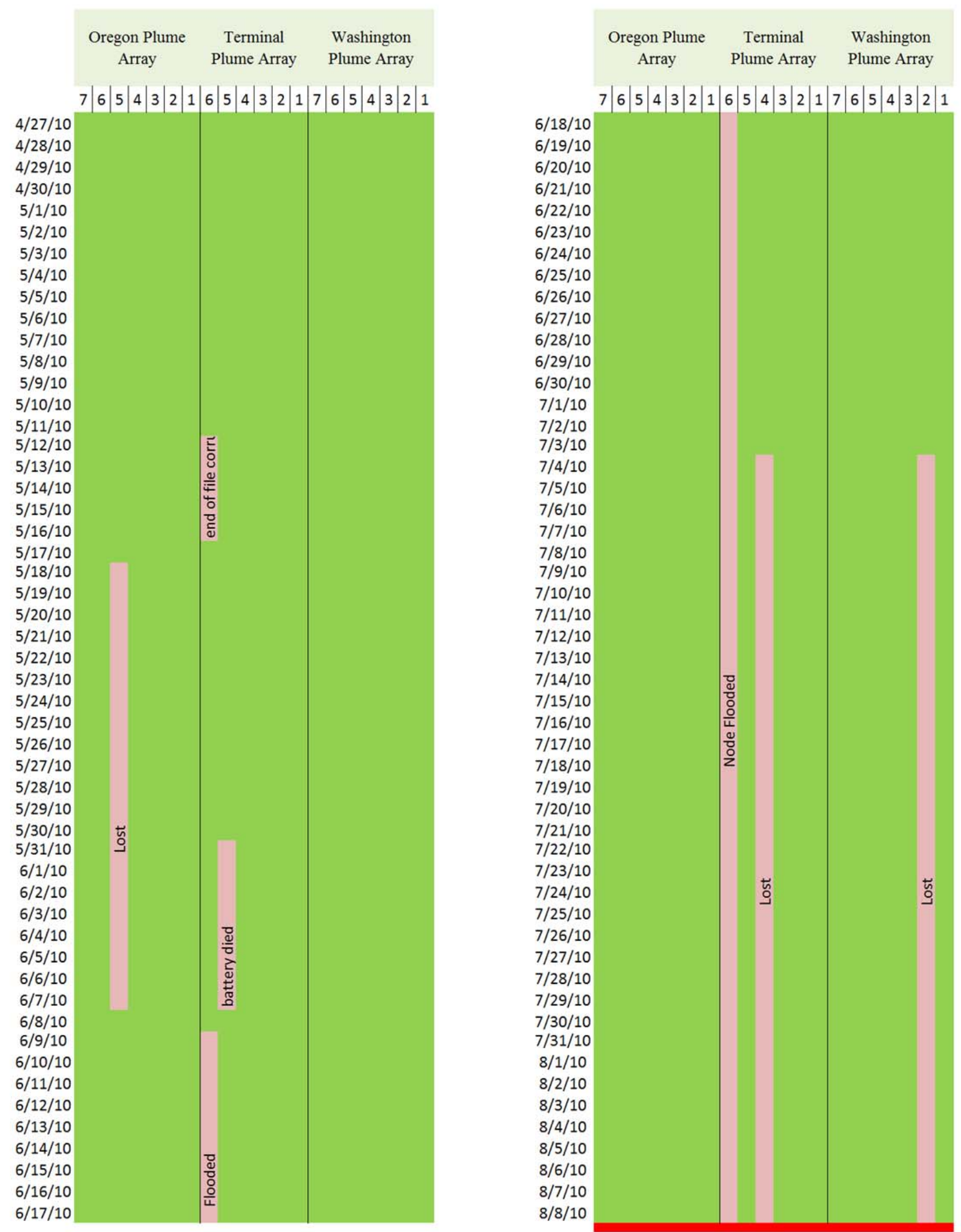




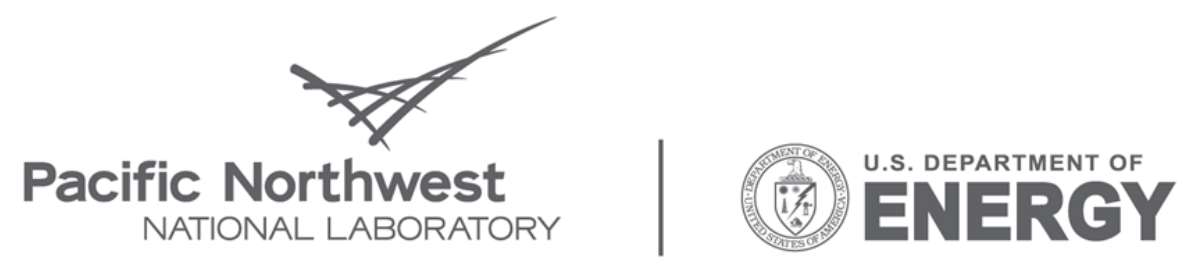

Proudly Operated by Battelle Since 1965

902 Battelle Boulevard

P.O. Box 999

Richland, WA 99352

1-888-375-PNNL (7665)

www.pnl.gov 